\title{
Semiannual Report to
}

THE ATOMIC ENERGY COMMISSION

SEPTEMBER 1964

LEON O. JACOBSON, M.D. Editor

MARGOT DOYLE, Ph.D.

Associate Edifor

PATENT CLEAR

THE PUBLIC IS APPROVIAINED. RELEASE TO

WGS ON FHA IN THE APRED. PROGEDURES

SECTUND

\author{
OPERATED BY THE UNIVERSITY OF CHICAGO \\ UNDER \\ CONTRACT AT-(11-1)-69
}




\section{DISCLAIMER}

This report was prepared as an account of work sponsored by an agency of the United States Government. Neither the United States Government nor any agency Thereof, nor any of their employees, makes any warranty, express or implied, or assumes any legal liability or responsibility for the accuracy, completeness, or usefulness of any information, apparatus, product, or process disclosed, or represents that its use would not infringe privately owned rights. Reference herein to any specific commercial product, process, or service by trade name, trademark, manufacturer, or otherwise does not necessarily constitute or imply its endorsement, recommendation, or favoring by the United States Government or any agency thereof. The views and opinions of authors expressed herein do not necessarily state or reflect those of the United States Government or any agency thereof. 


\section{DISCLAIMER}

Portions of this document may be illegible in electronic image products. Images are produced from the best available original document. 


\section{LEGAL NOTICE}

This report was prepared as an account of Government sponsored work. Neither the United States, nor the Commission, nor any person acting on behalf of the Commission:

A. Makes any warranty or representation, express or implied, with respect to the accuracy, completeness, or usefulness of the information contained in this report, or that the use of any information, apparatus, method, or process disclosed in this report may not infringe privately owned rights; or

B. Assumes any liabilities with respect to the use of, or for damages resulting from the use of any information, apparatus, method, or process disclosed in this report.

As used in the above, "person acting on behalf of the Commission" includes any employee or contractor of the Commission to the extent that such employee or contractor prepares, handles or distributes, or provides access to, any information pursuant to his employment or contract with the Commission.

Price $\$ 5.00$. Available from the Office of

Technical Services, Department of Commerce

Washington 25, D.C. 
ARGONNE CANCER RESEARCH HOSPITAL 950 EAST FIFTY-NINTH STREET - CHICAGO * ILLINOIS 60637

\section{Semiannual Report to}

\section{THE ATOMIC ENERGY COMMISSION}

SEPTEMBER 1964

LEON O. JACOBSON, M.D.

Editor

MARGOT DOYLE, Ph.D.

Associate Editor

OPERATED BY THE UNIVERSITY OF CHICAGO

UNDER

CONTRACT AT-(11-1)-69 
The metabolism of magnesium in the normal rat

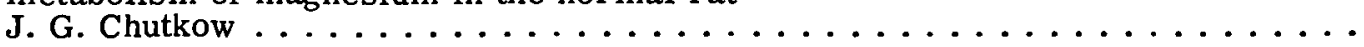

The sites of magnesium absorption and excretion in the intestinal tract of the rat

J. G. Chutkow . . . . . . . . . . . . . . . . . .

In vitro studies on the effect of erythropoietin on glucuse amint $1 \mathrm{C}^{14}$ incorporation into rat bone marrow cells

P. P. Dukes, F. Takaku and E. Goldwasser . . . . . . . . . . .

In vitro studies of cell types responsive to erythropoietin

F. Takaku, P. P. Dukes and E. Goldwasser ..............

Hemoglobin synthesis in marrow cell cultures: the effect of rat plasma on rat cells

0 . Gallien-Lartigue and E. Goldwasser . . . . . . . . . . . . .

The erythopoietic effect of testosterone in the polycythemic mouse

W. Fried, R. De Gowin and C. W. Gurney ................

$\mathrm{H}^{3}$-thymidine uptake by a ring- $\mathrm{X}$ chromosome in a human female

J. Rowley, S. Muldal, J. Lindsten and C. W. Gilbert . . . . . . . . . . . .

Hemolytic effects of steroids

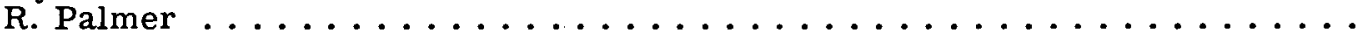

Metabolites of lithocolic acid-24- $\mathrm{C}^{14}$ in human bile and feces

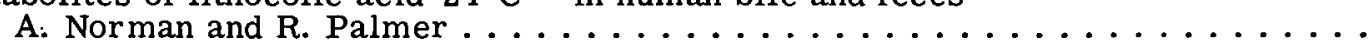

Biologic properties of polynucleotides. II. The anticoagulant properties of polynucleotides

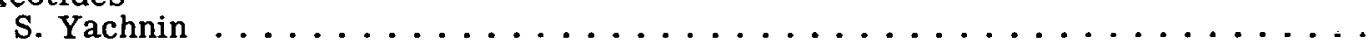

Biologic properties of polynucleotides. III. The anticomplementary properties of polyriboguanylic acid

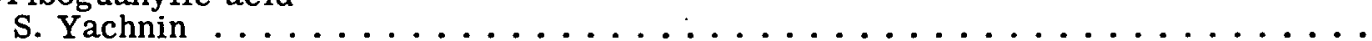

Biologic properties of polynucleotides. IV. The mechanism of complement inhibition by polyinosinic acid with observations on the in vivo effect of polyinosinic acid on complement activity

S. Yachnin and D. Rosenblum . . . . . . . . . . . . . . .

The synthesis of $4^{\prime}, 5^{\prime}$-amino fluorescin iodine-131

A. J. Verbiscar . . . . . . . . . . . . . . . . . . .

The use of $\mathrm{Tc}^{99 \mathrm{~m}}$ as pertechnetate for thyroid, liver and brain scanning

P. V. Harper, Jr., K. A. Lathrop, R. J. McCardle and G. Andros . . . . . . . . .

Collimators for radioisotope scanning systems

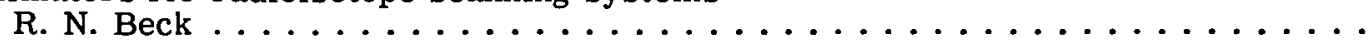

Techniques that aid in quantitative interpretation of scan data

D. B. Charleston, R. N. Beck, P. Eidelberg and M. W. Schuh . . . . . . .

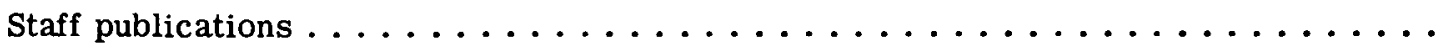




\title{
THE METABOLISM OF MAGNESIUM IN THE NORMAL $\underbrace{\text { RAT }}{ }^{*}$
}

By

\author{
J. G. Chutkow
}

Considerable evidence indicating the biologic importance of magnesium has accumulated uver lle lasst 60 years. Ito rolo in animal nutrition was firmly established 3 decades ago after the successful experimental production of a distinctive deficiency state in rats by the dietary deprivation of magnesium. ${ }^{1-4}$ As the number of reports has multiplied, the significance of severe acute and chronic alterations in magnesium balance in man has become increasingly apparent, although surprisingly little is yet definitively known about its normal metabolism. This is partly due to the inadequacies of the quantitative chemical methods used, which in general, lack sensitivity or accuracy, and therefore are poorly suited for tracing pathways in which small changes in relatively large quantities may be meaningful.

A more useful tool became available with the introduction of $\mathrm{Mg}^{28}$, an artificially produced radioactive isotope. Initially, its value in long-term studies was restricted by the concomitant physiologic disturbance produced by large quantities of carrier. Recently however, the specific activity of $\mathrm{Mg}^{28}$ has been substantially increased. This advance coupled with very low background level gamma-ray spectrometric techniques has made it possible to follow the excretion of magnesium in normal rats for as long as 120 hours with good counting statistics. In addition, some of the effects of varying amounts of magnesium on magnesium metabolism have been investigated.

\section{MATERIALS AND METHODS}

The recently described whole-body counting facility at the Argonne Cancer Research Hospi$\operatorname{tal}^{5}$ was used to count both the relatively large and very small amounts of radioactivity involved. A companion 3 by 3 inch NaI well crystal mounted in a heavy lead shield and connected to an identical analyzer-display system was also used.

$\mathrm{Mg}^{28}$ decays to $\mathrm{Al}^{28}$ by emitting one beta particle and four gamma-rays of $1.35 \mathrm{MeV}$ (70 per cent), $0.95 \mathrm{MeV}$ (30 per cent), $0.40 \mathrm{MeV}$ (30 per cent), and $0.032 \mathrm{MeV}$ (100 per cent). $\mathrm{Al}^{28}\left(\mathrm{~T}_{1 / 2}=\right.$ 2.3 minutes) decays to stable $\mathrm{Si}^{28}$ by the emission of one beta particle and one gamma-ray of 1.78 $\mathrm{MeV}{ }^{6}$ In all experiments and with all counting equipment, the counts per minute in a sample were obtained by summing the counts in all $12 \mathrm{keV}$-width channels from the beginning of the $1.35 \mathrm{MeV}$ to the end of the $1.78 \mathrm{MeV}$ photopeaks.

Counting techniques and preparation of isotope. $\mathrm{Mg}^{28}$ as $\mathrm{Mg}^{28} \mathrm{Cl}_{2}$ in $\mathrm{HCl}$ with a specific activity of 16 to $20 \mu \mathrm{c}$ of $\mathrm{Mg}^{28}-\mathrm{Al}^{28}$ per $\mathrm{mg}$ of stable magnesium at the time of administration to the animals was obtained from Brookhaven National Laboratory. The isotope was diluted with 10 per cent dextrose in water to a volume providing a 5 to 6 per cent dextrose concentration, a $\mathrm{pH}$ of 3.3 to 3.5 as measured on a Beckman pH meter, and an isotope concentration of 3 to $4 \mu \mathrm{c}$ per $\mathrm{ml}$. A one-ml aliquot was transferred to a lucite container with an internal diameter geometrically similar to a $120 \mathrm{~g}$ rat (in those experiments using 110 to $120 \mathrm{~g}$ rats) and was used as the

\footnotetext{
*This report is taken from a paper appearing in J. Lab. and Clin. Med. 63:80, 1964.
} 
reference standard (RS). The number of microcuries it contained was based on the assay made by Brookhaven at the time of shipment corrected for physical decay. A second aliquot was diluted 25 -fold. One- and 2-ml samples of the latter were placed in $150 \mathrm{ml}$ Erlenmeyer flasks and served as urine (US) and fecal (FS) standards. Linearity of the counting equipment well beyond the limits of activity used in these experiments made additional standards unnecessary. Unless otherwise indicated, each animal was anesthetized with ether and received $1 \mathrm{ml}$ of the remaining isotope intraperitoneally (ip), intravenously (iv) or by gastric intubation (po) as measured from a $1 \mathrm{ml}$ B-D Yale ${ }^{\circledR}$ tuberculin syringe. The amount of carrier magnesium ranged from 0.20 to $0.25 \mathrm{mg}$.

At the beginning of an experiment, the undiluted RS was placed on the floor of the iron cell 100 to $106 \mathrm{~cm}$ beneath the center of a square formed by the 4 crystals and counted in duplicate. The undiluted US and FS were then counted in the same position. The activity of these standards in microcuries was derived from the RS. The results rarely differed by more than 2 per cent from the calculated activity based on the known dilution. The RS was then diluted to $120 \mathrm{ml}$ (in the case of 110 to $120 \mathrm{~g} \mathrm{rat}$ ), firmly held on a wooden holder (Figure 1A) taped to the floor of the cell and counted before and after total body counts were obtained on the experimental animals. Immediately following the administration of isotope, the rats were placed in special adjustable lucite containers (Figure 1B) and placed in the same position as the RS for counting. The amount

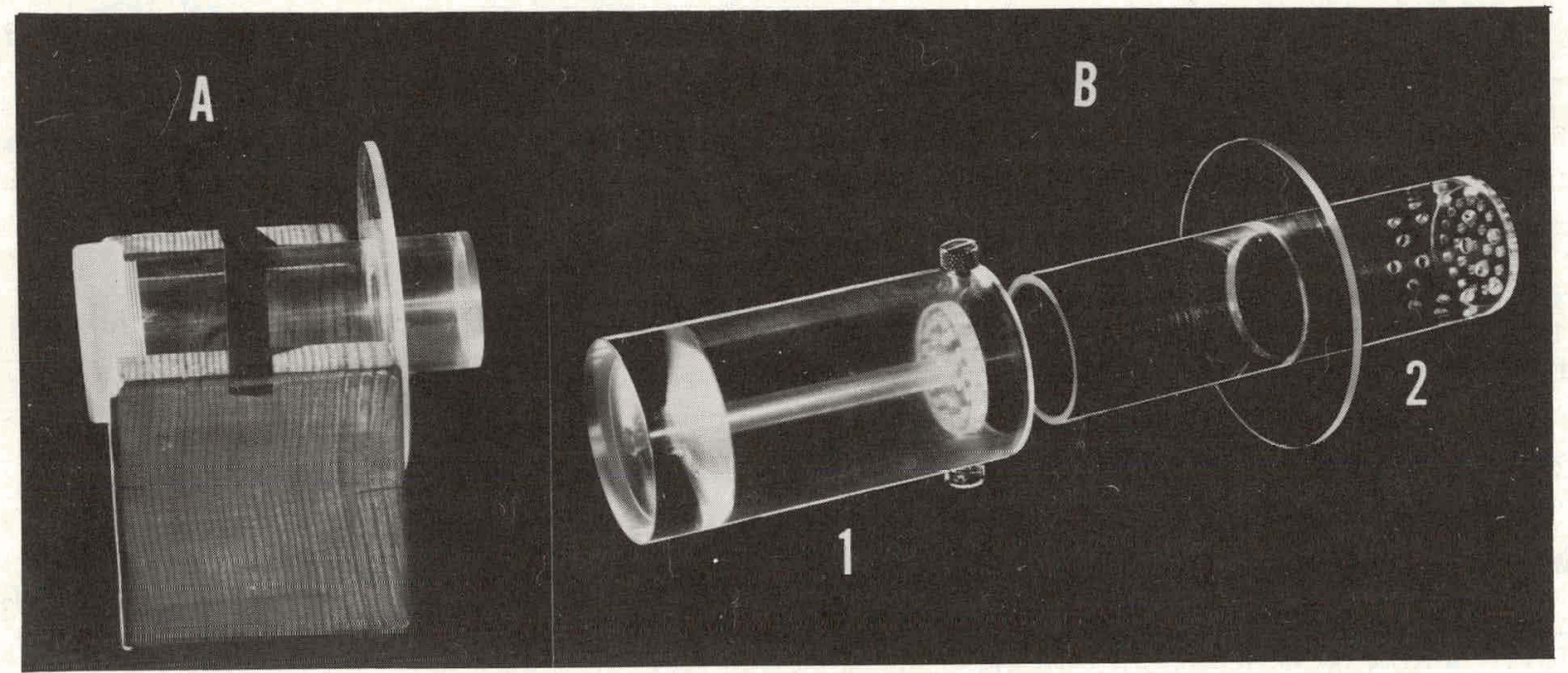

Figure 1. A. Lucite reference standard container fastened to the wooden holder in position for whole-body counting of the rats; B. The adjustable rat holder. The holder is made from 2 lucite tubes each sealed at one end. The larger (1) contains a fenestrated plunger and 2 locking screws. The smaller (2), with a thin lucite ring attached to the outside, fits within the outer tube around the plunger. As the tubes are pushed together, the plunger forces the animal in (2) toward the sealed end of the inner tube until further movement is prevented by the lucite ring. The rat then occupies approximately the same volume as the reference standard. The ring is also a guide for positioning the rat holder on the wooden block.

of isotope given each rat was therefore derived from the RS. The natural background of the rats was identical with that of the empty cell. When an undiluted "point source" of isotope (i.e. in the stomach) was evenly distributed through $120 \mathrm{ml}$ at this distance from the crystals, the total count increased 1.0 to 1.5 per cent. This crystal arrangement provided a counting efficiency of 0.14 per 
cent, and with the amount of isotope used a counting error of less than one per cent was easily obtained.

In all studies on magnesium excretion and absorption the US was diluted to $50 \mathrm{ml}$ and the FS to approximately $15 \mathrm{ml}$. The urine and feces were diluted to the same volume as their respective standards as described below, and all were counted in one of 2 ways. With the first method, the flasks were rigidly held by a flat lucite cup attached to a stand which was taped to the floor of the iron room in the center of a small square formed by the four crystals. This arrangement provided a counting efficiency of 5.0 to 6.0 per cent depending on the slight variation in crystal position from day to day. With the second method, the samples were positioned by the same lype of cup onto the face of the 3 inch well crystal and here the counting efficiency was 4.0 per cent. The 72 to 96 hour feces and 96 to 120 hour urine samples (see below) were counted to a period which yielded a 3 per cent sample counting error. All other samples were counted to give a counting error of 2.0 per cent or less.

In the plasma clearance studies, total body counts were not taken. Instead, $1 \mathrm{ml}$ of the solution containing the $\mathrm{Mg}^{28}$ was accurately measured in a tuberculin syringe and injected intravenously. At 4 different times during isotope administration, a $1 \mathrm{ml}$ sample was measured from the same syringe into an Erlenmeyer flask and counted on the floor of the iron cell as described previously. The mean activity of these four samples (coefficient of variation $= \pm 0.92$ per cent) represented the amount of isotope received by each rat, and was used as the RS from which the number of microcuries in the plasma standard was calculated. The plasma samples and standards were counted in the well of the 3 inch crystal at a counting efficiency of 5.8 per cent and a sample counting error of 2 per cent or less.

To minimize those errors introduced by the combination of possible day-to-day variation in counting efficiency of the equipment and in positioning of crystals which would have been magnified by large corrections for physical decay of the isotope, the number of microcuries in each sample of excreta or plasma was calculated from the standard counted at the same time. Because of the extremely short $\mathrm{T}_{1 / 2}$ of $\mathrm{Al}^{28}$ and the time elapsing between collection and counting (usually 2 hours or more), any $\mathrm{Al}^{28}$ present in a specimen as the result of the metabolism of aluminum would not have been detectable.

Plasma magnesium levels were determined in duplicate by a modification of the method of Orange and Rhein. ${ }^{7}$

\section{EXPERIMENTS}

Unless otherwise specified, non-fasting male albino rats (Sprague-Dawley strain) weighing 100 to $120 \mathrm{~g}$ were housed in individual metabolism cages to prevent coprophagy and provide separation of urine and feces. ${ }^{\dagger}$ All animals were fed powdered Rockland Complete Rat Diet containing 1.68 per cent calcium, 0.330 per cent magnesium and 0.800 per cent phosphorus (manufacturer's analysis) and tap water ad libitum. Food consumption was measured for 3 consecutive days prior to administration of radioisotope. The animals were randomized for placement into cages and for distribution into experimental groups by using tables of random numbers.

Studies on magnesium absorption and excretion in the young rat (mean weight of $110 \mathrm{~g}$ ). Four separate experiments were performed on a total of 58 animals. In the first three, 12 to 14 animals

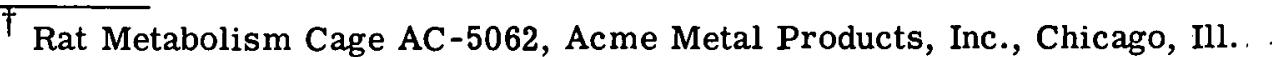


were divided into 2 equal groups. The first group received $\mathrm{Mg}^{28}$ ip; the second, po. In the fourth experiment, a third group of 6 animals receiving the isotope iv was added. Twelve of the 26 rats given $\mathrm{Mg}^{28}$ po also received carmine red dye orally at the same time. Urine and feces were quantitatively collected for the approximate periods: 0 to 22 hours, 22 to 48 hours, 48 to 72 hours, and 72 to 96 hours. In addition, a 96 to 120 hour urine sample was collected and a 6 hour count was taken on the first period urine from 16 animals in each group. The urines were collected directly into the Erlenmeyer flasks used for counting. At the end of each period, the urine baffle and funnel were rinsed with warm dilute hydrochloric acid and the washings added to the flask until the volume was equal to that of the diluted US. A check of the funnels after rinsing showed no detectable residual $\mathrm{Mg}^{28}$. Feces were transferred to an Erlenmeyer flask at the end of each period, diluted to the volume of the standard with dilute $\mathrm{HCl}$ and counted. After the assay for $\mathrm{Mg}^{28}$, the samples were discarded. At the conclusion of an experiment, randomly selected animals were slaughtered by aortic exsanguination and plasma magnesium levels determincd.

Studies on magnesium absorption and excretion in the older rat (mean weight of $300 \mathrm{~g}$ ). Twelve animals from the previous experiment were kept for 8 weeks until they reached a mean weight of $300 \mathrm{~g}$. The first experiment was then repeated after rerandomization of the animals. A reference standard holder and adjustable rat container the size of a $320 \mathrm{~g}$ rat were used.

The plasma clearance of $\mathrm{Mg}^{28}$ in the young rat. Thirty-two rats with a mean weight of $110 \mathrm{~g}$ ${ }_{ \pm} 3.2 \mathrm{~g}$ received the $\mathrm{Mg}^{28}$ in $1.0 \mathrm{ml}$ of 5 per cent dextrose in water intravenously. At intervals of from 3 minutes to 37 hours after administration, individual animals were slaughtered by aortic exsanguination and the heparinized blood immediately centrifuged. If obtained during the first 12 hours $1.0 \mathrm{ml}$ of plasma was counted with a $1.0 \mathrm{ml}$ standard. Because of low activity, subsequent plasma samples were increased to $2.0 \mathrm{ml}$ with a comparable dilution of the standard. Two correction factors were applied to the data. First, since it was assumed that the plasma volume of a rat was a constant of $3.13 \mathrm{ml}$ per $100 \mathrm{~g}$ body weight, ${ }^{8}$ comparable dilutions of the isotope by the total plasma volume were obtained by dividing the radioactivity per $\mathrm{ml}$ of plasma by the ratio of the 6-hour fasting weight of the rat to the 6-hour mean fasting weight of the group. Second, until extravascular distribution occurred, $1 \mathrm{ml}$ would have produced a significant increase in the total plasma volume of animals this size. Therefore, to determine the magnitude and duration of this dilution, 4 groups of animals (mean weight $110 \mathrm{~g}$ ) were given $1.0 \mathrm{ml}$ of 5 per cent dextrose in water iv. The animals of one group were slaughtered at $3,15,30$, and 60 minutes by aortic puncture. Seven uninjected animals were used as controls. Total plasma protein concentration was determined in duplicate by the biuret method for each rat. ${ }^{9}$ At 3 minutes, the mean plasma protein concentration was 9.20 per cent lower than the mean control value of $5.69 \mathrm{~g}$ per $100 \mathrm{ml}$ $(\mathrm{T}=3.34, \mathrm{p}<0.01>0.005)$; at 15 minutes, the 1.96 per cent difference was not significant; at 30 minutes and again at 60 minutes, the results were identical with the control. The 3 -minute sample, therefore, was corrected for the effects of the injected volume. Subsequently, a second experiment identical in design was run with 17 rats. Animals were slaughtered at 8 common and 9 different points in time. As the points in common were in good agreement, the results were combined. Magnesium levels were determined on plasma samples from 10 of the animals.

The effect of a large quantity of parenterally administered magnesium on the excretion of endogenous magnesium. Ten rats were divided into 2 groups. All received $\mathrm{Mg}^{28}$ ip. In addition, at the time of isotope administration, the test group was given $5 \mathrm{mg}$ of $\mathrm{Mg}$ as $\mathrm{MgCl}_{2} \cdot 6 \mathrm{H}_{2} 0$ in 0.5 $\mathrm{ml}$ of 5.0 per cent dextrose in water; and the control group, $0.5 \mathrm{ml}$ of 5 per cent dextrose in nor- 
mal saline. Urine and feces were collected for the periods: 0 to 20,20 to 43,43 to 67 , and 67 to 91 hours.

The effect of sustained acute hypermagnesemia on the absorption of magnesium: Twentytwo animals were divided into 2 groups. The experimental group received $5 \mathrm{mg}$ of $\mathrm{Mg}$ as $\mathrm{MgCl}_{2}$. $6 \mathrm{H}_{2} \mathrm{O}$ ip at the time of po administration of $\mathrm{Mg}^{28}$, and again 4 and 8 hours later. The controls received the same volume of 5 per cent dextrose in normal saline. Urine and feces were collected for 30 hours and assayed as before. Spot checks of the feces passed 2 to 3 hours after the end of the collection period showed no more activity than would have been expected from the endogenous fecal excretion of the absorbed isotope. After completion of the radioisotope study, the above animals plus extra rats from the same shipment were given $5.0 \mathrm{mg}$ of $\mathrm{Mg}$ ip. Varying numbers of animals were sacrificed by aortic puncture at 15 and 30 minutes, 1, 2, 3, and 4 hours. Plasma magnesium levels were determined in each animal and compared to 7 uninjected controls.

Effect of increasing amounts of orally administered magnesium on magnesium absorption and excretion. Thirty-nine rats fasted for 6 hours prior to the experiment were divided into 6 groups. In addition to $\mathrm{Mg}^{28}$ po, each group received $1.0 \mathrm{ml}$ of 5 per cent dextrose in water containing one of the following amounts of $\mathrm{Mg}$ as $\mathrm{MgCl}_{2} \cdot 6 \mathrm{H}_{2} \mathrm{O}: 5 \mathrm{mg}, 10 \mathrm{mg}, 15 \mathrm{mg}, 20 \mathrm{mg}$, or $25 \mathrm{mg}$. The control group was given an equal volume of 5 per cent dextrose in normal saline. To decrease the effect of other dietary factors on magnesium absorption, food was withheld for an additional 4 hours after injection of the isotope. Feces and urines were collected for 28 hours. Spot checks of feces at 30 hours and 32 hours gave the same results as in the preceding experiment. In a subsequent experiment, 14 animals were divided into 2 groups and fasted for 6 hours. The control group received $1.0 \mathrm{ml}$ of 5 per cent dextrose in normal saline; and the experimental group, 1.0 $\mathrm{ml}$ of 5 per cent dextrose in water containing $72.2 \mathrm{mg}$ of $\mathrm{NaCl}$ or $44 \mathrm{mg}$ of chloride (the equivalent chloride concentration to that produced by $15 \mathrm{mg}$ of $\mathrm{Mg}$ as $\mathrm{MgCl}_{2} \cdot 6 \mathrm{H}_{2} \mathrm{O}$ per ml). The remainder of the study was as above.

The effect of a large quantity of magnesium on the subsequent absorption of magnesium. Twenty-one animals were divided into 2 groups. The animals were fasted as in the previous experiment. Six hours before they were given the $\mathrm{Mg}^{28}$, the experimental group received $15 \mathrm{mg}$ of magnesium in $1.0 \mathrm{ml}$ of 5 per cent dextrose in water po, while the control group received an equal volume of 5 per cent dextrose in normal saline. Three hours prior to po injection of $\mathrm{Mg}^{28}$, the animals were allowed food ad libitum. Feces and urine were collected for 24 hours after the isotope was given and assayed as above. In a second experiment, 15 animals were divided into 2 groups and treated as above, except that the $\mathrm{Mg}^{28}$ was administered po 24 hours after the $15 \mathrm{mg}$ of magnesium or 5 per cent dextrose in normal saline.

Except for the Dunnett $T$ test ${ }^{55}$, all statistical methods were taken from Snedecor. ${ }^{10}$

\section{RESULTS}

Studies on the excretion and absorption of magnesium in the young rat. As the means and standard deviations of the corresponding ip and po groups in each experiment did not differ signigicantly, the results were combined into 2 groups each containing 26 animals.

Table 1 summarizes the major findings in the parenteral studies. Interestingly, excretion through the gastrointestinal tract accounted for a significant proportion of the daily loss of endogenous magnesium. The magnitude of this loss was most apparient in Periods III and IV when the effects of the small acute carrier load and the initial delay in recovery of the isotope from the 
Table 1

EXCRETION OF INTRAPERITONEALLY ADMINISTERED $\mathrm{Mg}^{28}$ IN 26 YOUNG MALE ALBINO RATS

\begin{tabular}{|c|c|c|c|c|c|c|c|}
\hline Period & & $\quad I$ & II & III & IV & V & \multirow{2}{*}{$\begin{array}{l}\text { Total } \\
\text { recovery } \\
\text { at } 120 \\
\text { hours }\end{array}$} \\
\hline $\begin{array}{l}\text { Hours after injection } \\
\text { of } \mathrm{Mg}^{28}\end{array}$ & $0-6^{a}$ & $0-22$ & $22-48$ & $48-7.2$ & $72-96$ & $96-120^{a}$ & \\
\hline $\begin{array}{l}\text { Cumulative total exçre- } \\
\text { tion at end of period } b\end{array}$ & $25.8 \pm 1.14$ & $46.3 \pm 0.77$ & $62.3 \pm 0.71$ & $69.8 \pm 0.78$ & $75.02 \pm 0.76$ & $78.03 \pm 0.68$ & $(78.82)^{d}$ \\
\hline $\begin{array}{l}\text { Urinary excretion during } \\
\text { periodb } \\
\text { A }\end{array}$ & $25.8 \pm 1.14$ & $40.7 \pm 0.85$ & $12.0 \pm 0.29$ & $5.9 \pm 0.21$ & $4.10 \pm 0.12$ & $3.01 \pm 0.11$ & $65.75 \pm 0.84$ \\
\hline $\begin{array}{l}\text { Fecal excretion during } \\
\text { period }^{\text {b }} \\
\text { B }\end{array}$ & & $5.6 \pm 0.26$ & $4.0 \pm 0.15$ & $1.6 \pm 0.08$ & $1.1 \pm 0.04$ & $(0.8)^{d}$ & $\frac{12.3}{(13.1)^{\mathrm{d}}}{ }^{0.34}$ \\
\hline$\frac{B}{A+B} \times 100^{c}$ & - & $12.8 \pm 0.62$ & $25.1 \pm 0.83$ & $20.8 \pm 0.51$ & $20.9 \pm 0.89$ & & \\
\hline $\begin{array}{l}\text { Mean } \frac{B}{A+B} \times 100 \\
\text { over indicated periods } c\end{array}$ & \multicolumn{3}{|c|}{$\begin{array}{l}\text { Periods I }+ \text { II }=18.7 \pm 0.55 \\
\text { Periods III }+ \text { IV }=20.8 \pm 0.60 \\
\text { Periods I - IV }=19.8 \pm 0.41\end{array}$} & \multicolumn{4}{|c|}{$\begin{aligned} & \text { Plasma Magnesium }= 1.64 \pm 0.33 \mathrm{Meq} / \text { liter } \\
&(\text { mean } \pm \text { S.D. })\end{aligned}$} \\
\hline
\end{tabular}

a Based on 16 rats

$\mathrm{b}_{\text {Mean }} \%$ of initial dose \pm standard error of the mean

$\because \quad \mathrm{c}_{\text {Mean }} \% \pm$ standard error of the mean

$\mathrm{d}_{\text {Assuming }}$ Period V fecal excretion $=\frac{0.198 \text { (Period V urine excretion) }}{0.802}$

? Mean weight $110 \mathrm{~g}$ 
feces were over. After iv injection, the 96-hour fecal loss was slightly but not significantly greater than in the control group ( $T=0.86, p=0.400$ ). The mean percentage of the total daily excretion recovered in the feces was the same. Figure 2 contains a graphic analysis of the curve which was fitted visually to the mean per cent of the initial dose retained at the end of each period. The

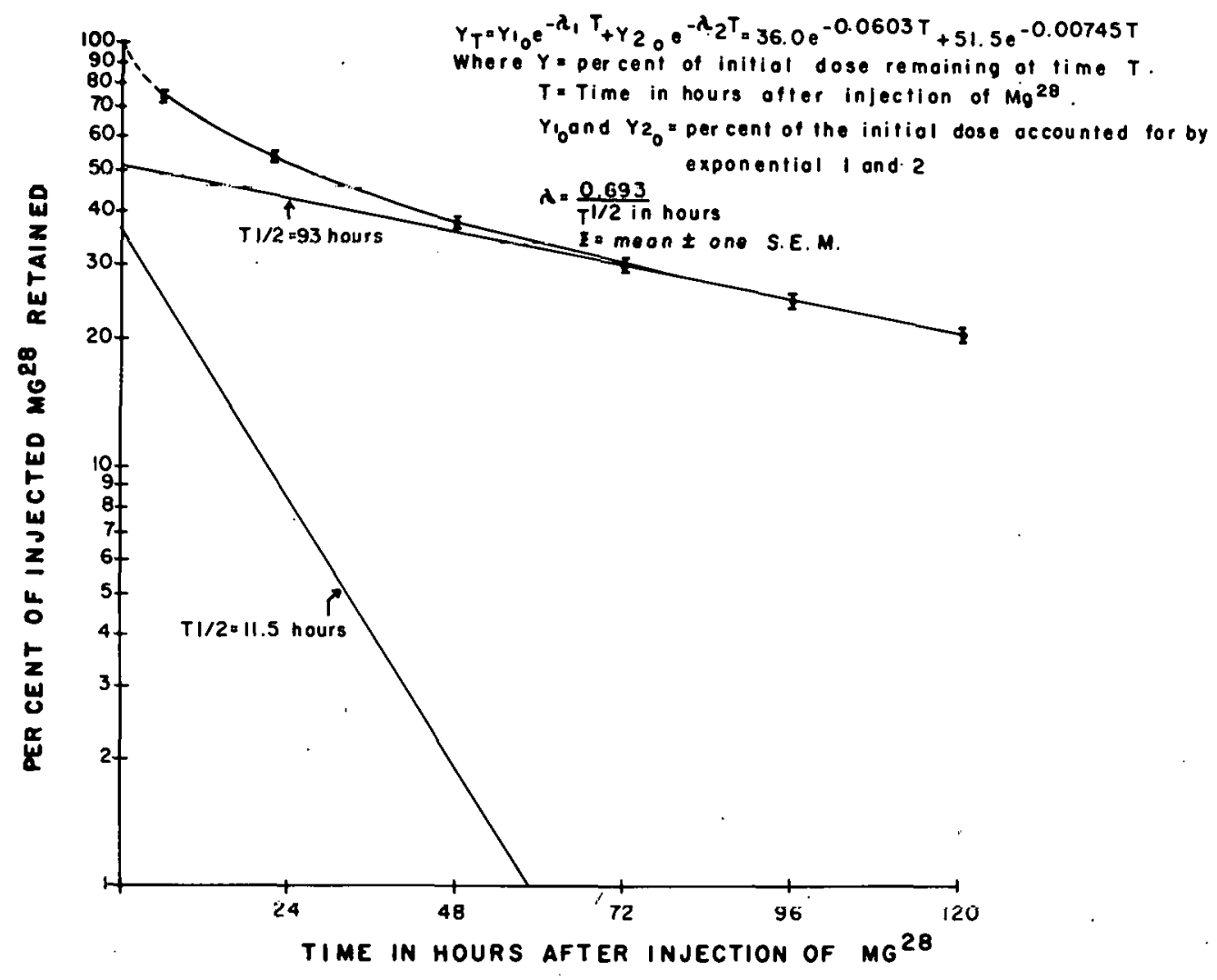

Figure 2. Graphic analysis of the mean retention of intraperitoneally administered $\mathrm{Mg} 28$ in young rats.

96 to 120 hour fecal loss was derived from the urinary excretion over the same period assuming that the fecal activity equaled $0.198 / 0.802 \times$ the urine activity. Three components are undoubtedly present; however, the most rapidly diminishing exponential which represents very early renal clearance of the carrier cannot be defined with any precision because of insufficient data. The slope of the slower of the 2 separable exponentials was fitted by eye. After extrapolation to the $y$-axis the differences between it and the experimental values were replotted semilogarithmically to determine the slope of the more rapidly turning-over component. The latter, with an 11.5 hour half-life, accounted for 36.0 per cent of the isotope; and the slower compartment, with a 93 hour half life, for $\mathbf{5 1 . 5}$ per cent. The values predicted by the derived equation agree well with the observed results. The mean biological half-retention time for $\mathrm{Mg}^{28}$ in the young animal was about 25 hours.

Ninety-five percent of the total fecal loss after po administration of the isotope occurred during the first period (Table 2). The concomitantly administered carmine red appeared in the stool by 4 to 8 hours and was completely passed by 10 to 14 hours. It was assumed therefore that 
Table 2

ABSORPTION AND EXCRETION OF $\mathrm{Mg}^{28}$ ADMINISTERED BY GASTRIC INTUBATION IN 26 YOUNG MALE ALBINO RATS ${ }^{\text {ef }}$

\begin{tabular}{|c|c|c|c|c|c|c|c|}
\hline Period & & I & II & III & IV & $\mathrm{V}$ & \multirow{2}{*}{$\begin{array}{l}\text { Total } \\
\text { recovery } \\
\text { at } 120 \\
\text { hours }\end{array}$} \\
\hline $\begin{array}{c}\text { Hours after injection } \\
\text { of } \mathrm{Mg} 28\end{array}$ & $0-6^{\mathrm{a}}$ & $0-22$ & $22-48$ & $48-72$ & $72-96$ & $96-120^{\mathrm{a}}$ & \\
\hline $\begin{array}{l}\text { Cumulative total excre- } \\
\text { tion at end of period } \\
\% \text { initial dosed } \\
\% \text { absorbed dose } \\
\text { o,d }\end{array}$ & $\begin{array}{r}7.3 \pm 0.37 \\
13.7 \pm 1.77\end{array}$ & $\begin{array}{l}70.0 \pm 1.21 \\
44.2 \pm 1.17\end{array}$ & $\begin{array}{l}80.4 \pm 1.04 \\
63.9 \pm 1.32\end{array}$ & $\begin{array}{l}84.8 \pm 1.08 \\
72.2 \pm 1.64\end{array}$ & $\begin{array}{l}88.3 \pm 1.08 \\
78.7 \pm 1.79\end{array}$ & $\begin{array}{l}89.9 \pm 1.06 \\
81.8 \pm 1.80\end{array}$ & \multirow[b]{3}{*}{$\begin{array}{l}34.0 \pm 0.99 \\
64.0 \pm 1.44\end{array}$} \\
\hline $\begin{array}{l}\text { Urinary excretion during } \\
\text { period }\end{array}$ & \multirow[b]{2}{*}{$\begin{array}{r}7.3 \pm 0.37 \\
13.7 \pm 1.77\end{array}$} & & & & & & \\
\hline $\begin{array}{l}\text { A } \\
\% \text { initial dose } \\
\% \text { absorbed dose }\end{array}$ & & $\begin{array}{l}18.8 \pm 0.65 \\
35.5 \pm 0.94\end{array}$ & $\begin{array}{r}7.4 \pm 0.25 \\
13.9 \pm 0.44\end{array}$ & $\begin{array}{l}3.4 \pm 0.15 \\
6.4 \pm 0.28\end{array}$ & $\begin{array}{l}2.7 \pm 0.16 \\
5.1 \pm 0.28\end{array}$ & $\begin{array}{l}1.7 \pm 0.65 \\
3.1 \pm 0.11\end{array}$ & \\
\hline $\begin{array}{l}\text { Fecal excretion during } \\
\text { period }\end{array}$ & & & & & & & \\
\hline $\begin{array}{l}\mathrm{B} \\
\% \text { initial dose } \\
\% \text { absorbed dose }\end{array}$ & & $\begin{array}{r}51.1 \pm 1.49 \\
8.7 \pm 0.23\end{array}$ & $\begin{array}{l}3.0 \pm 0.16 \\
5.7 \pm 0.28\end{array}$ & $\begin{array}{l}1.0 \pm 0.07 \\
1.9 \pm 0.16\end{array}$ & $\begin{array}{l}0.7 \pm 0.05 \\
1.4 \pm 0.09\end{array}$ & & $\begin{array}{l}55.9 \pm 1.43 \\
17.9 \pm 0.54\end{array}$ \\
\hline $\begin{array}{l}\frac{\mathrm{B}}{\mathrm{A}+\mathrm{B}} \times 100 \\
\text { Mean } \% \pm \text { S.E.M. }\end{array}$ & & $19.8^{c}$ & $29.0 \pm 1.09$ & $22.8 \pm 0.83$ & $22.1 \pm 1.41$ & & \\
\hline Net $\%$ absorption $=100$ & $\frac{98}{302}\left\{\begin{array}{l}\% \text { of ini } \\
\text { ered in }\end{array}\right.$ & $\begin{array}{l}1 \text { dose recov- } \\
\text { riod I urine }\end{array}$ & $-\left\{\begin{array}{l}\% \text { of initi } \\
\text { ered in } P\end{array}\right.$ & $\begin{array}{l}\text { lose recov-) } \\
\text { od I feces }\end{array}$ & $53.5 \pm 1.59 \mathrm{~d}$ & & \\
\hline
\end{tabular}

${ }^{\mathrm{a}}$ Based on 16 rats

$\mathrm{b}_{\%}$ of initial dose

Net \% absorption $\times 100$

$\mathrm{c}_{\text {Based on mean }} \frac{\mathrm{B}}{\mathrm{A}+\mathrm{B}} \times 100$ Periods I - IV from parenteral studies (see Table 1)

$\mathrm{d}_{\text {Mean }} \pm$ S.E.M.

Mean weight $=110 \mathrm{~g}$

${ }^{\mathrm{f}}$ Mean daily food consumption $=17.6 \mathrm{~g}$ 
most of the activity recovered by 22 hours represented all the unabsorbed $\mathrm{Mg}^{28}$, and that the remainder of the radioisotope found in the stool in that and all subsequent periods came from endogenous intestinal excretion. As calculated in Table 2, the net mean absorption was 53.5 per cent. Based on the amount of isotope absorbed, the total excretion in the po group exceeded that in the ip group by 3.77 per cent at the end of 120 hours $(T=1.99, p<0.100>0.050)$. This resulted from a highly significant 5.50 per cent greater fecal loss $(T=8.58, p<0.001)$. This figure is probably low due to the ratio used to calculate the endogenous fecal excretion during the first period. No significant variation in either the total urinary recovery $(T=1.03, p>0.200)$ or the mean per cent of the total daily loss found in the stool over periods III and IV ( $T=1.25, p=0.200$ ) was demonstrated. While it is possible that the greater intestinal excretion is an artifact representing the continued passage of unabsorbed $\mathrm{Mg}^{28}$ or that it reflects the absence of the normal renal. excretory shift in response to an acute parenteral load of carrier magnesium (see below), the most likely explanation is that the isotope is quantitatively more accessible to the cells of the gastrointestinal tract when given po. Consequently, it is present in greater amounts in the intestinal secretions and/or the desquamated mucosal cells. Unfortunately, the size of the "compartments" (39.5 and 52.5 per cent of the absorbed dose) and their half-lives (10.5 and 73.0 hours respectively) obtained from the graphic analysis of the retention of the absorbed isotope (Figure 3 ) cannot be compared statistically with the corresponding figures from the ip experiment. The error inherent in this method of analysis is very large, despite the excellent agreement between

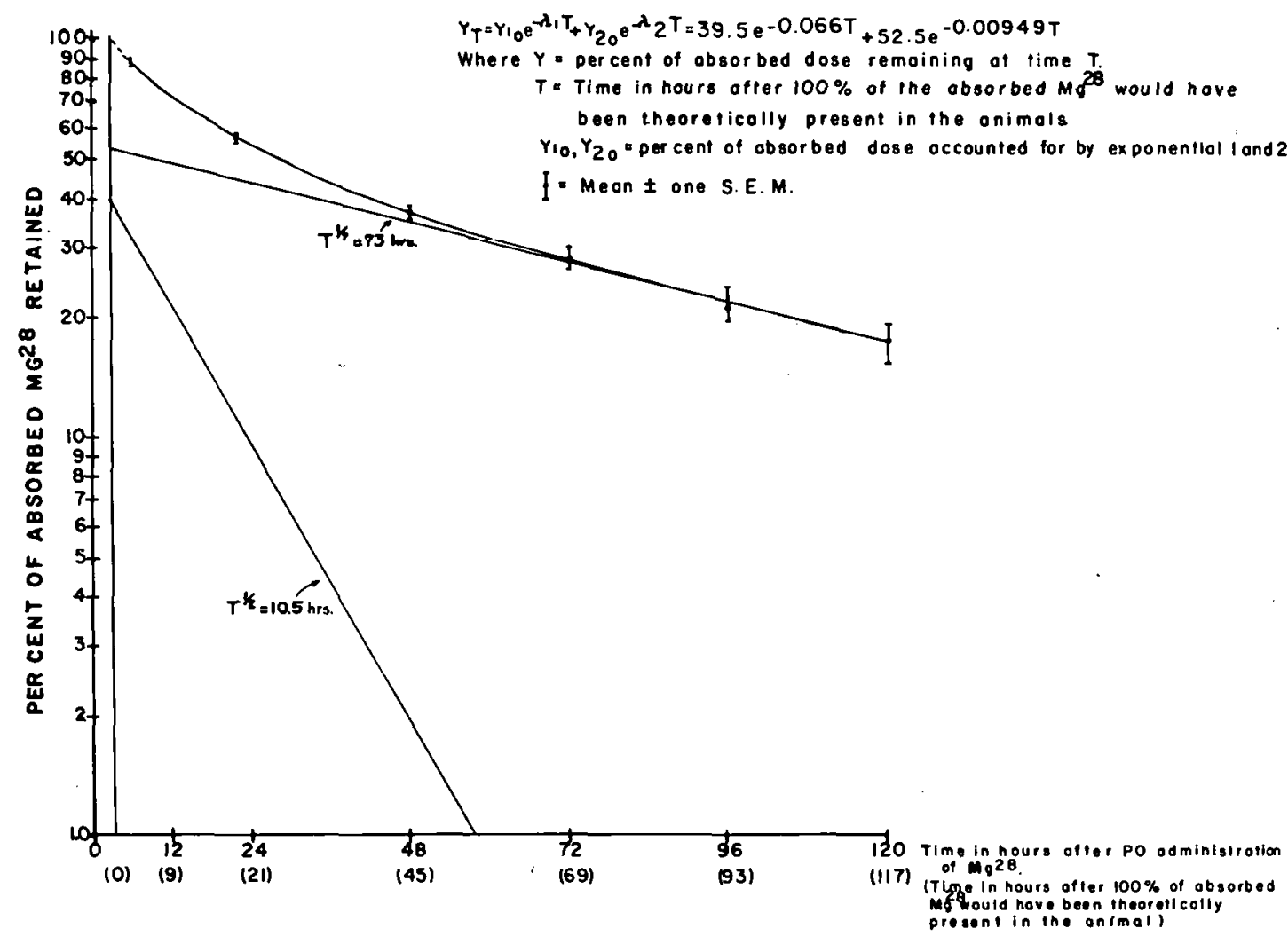

Figure 3. Graphic analysis of the mean retention of absorbed $\mathrm{Mg}^{28}$ in young rats. 
predicted and observed results; the data obtained at the end of any given period depend on the preceding period's values; and no definite time can be assigned either to the onset or to the completion of absorption. For the purpose of calculation, however, an extrapolated time at which 100 Fer cent of the absorbed isotope would theoretically have been present in the animals was determined. This proved to be approximately 3 hours after the administration of the $\mathrm{Mg}^{28}$.

Based on a mean daily food consumption of $17.6 \mathrm{~g}$, the young rat ingests $58 \mathrm{mg}$ of magnesium per day. The oral studies would predict that about $31.0 \mathrm{mg}$ of magnesium are absorbed daily, 25.4 $\mathrm{mg}$ of which are excreted over the next 5 days $(19.8 \mathrm{mg}$ in the urine and $5.6 \mathrm{mg}$ in the feces).

Studies on the excretion and absorption of magnesium in the older rat (Table 3). While rats varying in age are neither physiologically nor statistically comparable, several points are worth noting. First, the adult rat fully saturated with magnesium retained $\mathrm{Mg}^{28}$ very much as the younger animal did (discounting the greater initial delay in fecal recovery during the first 2 periods because of slower intestinal motility). Second, a significant amount of endogenous magnesium was excreted through the gastrointestinal tract. Third, the quantity of po $\mathrm{Mg}^{28}$ absorbed (49.58 \pm 3.86 per cent basing the calculation on the 48 rather than 24 hour urine and fecal loss) was very close to that absorbed in the young rat. Finally, the mean biological half-retention time of $\mathrm{Mg}^{28}$ in the older animals was about 30 hours.

The plasma clearance of intravenously administered $\mathrm{Mg}^{28}$ in the young rat. A graphic analysis of the visually fitted curve in Figure 4 was performed as previously described. While 4 slopes are shown, the curve basically consists of 3 components. The first, which includes the slopes with 8 and 45 minute half-lives represents the continuation of the extremely rapid disap-

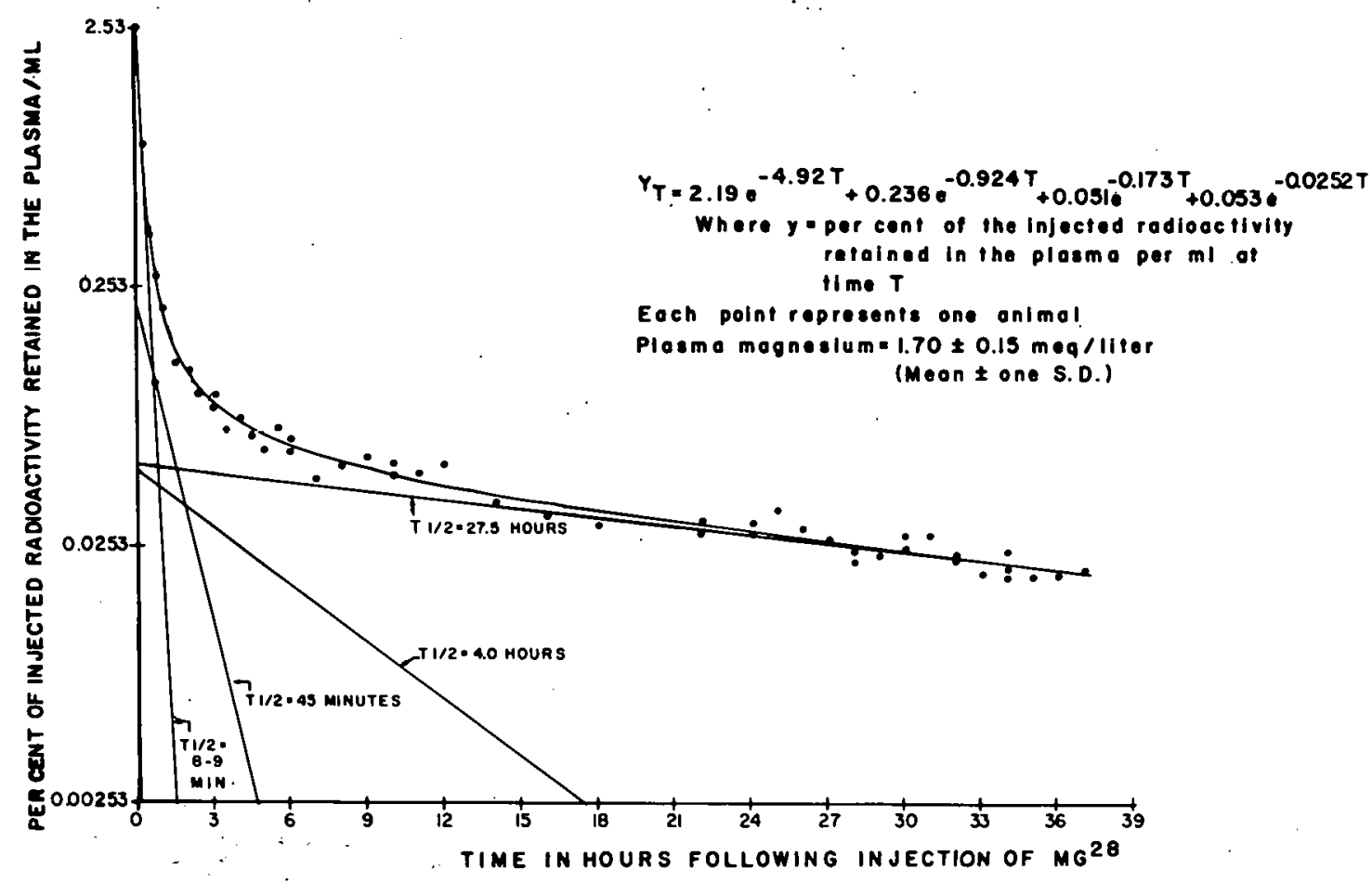

Figure 4. Graphic analysis of the plasma clearance of intravenously administer ed $\mathrm{Mg} 28$ in young rats. 
Table 3

EXCRETION OF INTRAPERITONEALLY ADMINISTERED $\mathrm{Mg}^{28}$ IN $6300 \mathrm{~g}$ MALE ALBINO RATS

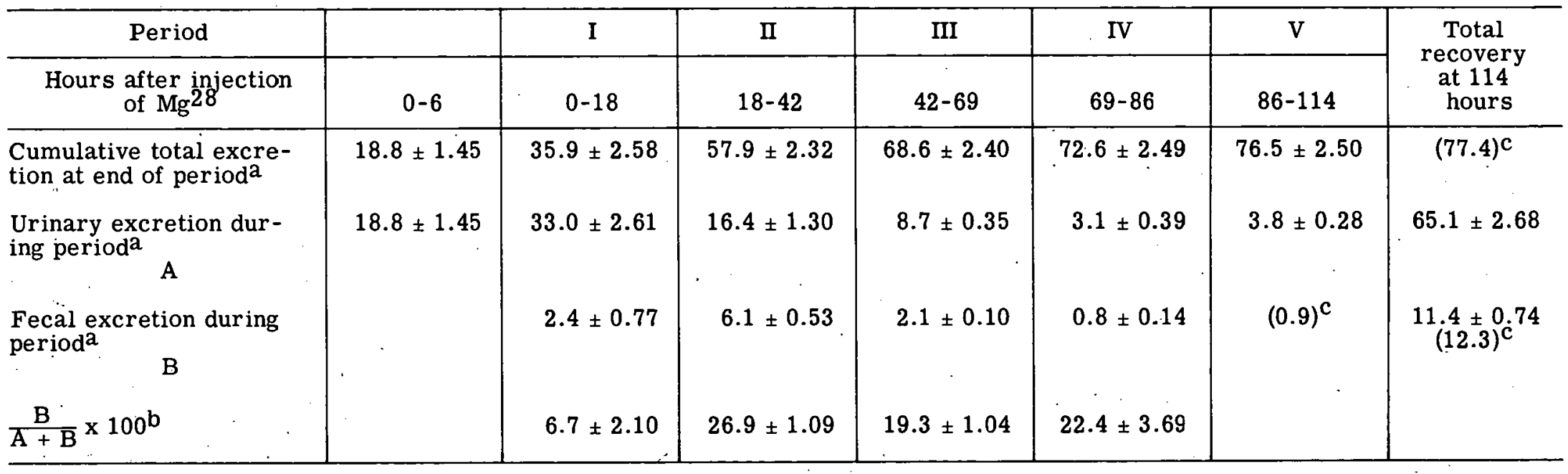

Mean $\frac{B}{A+B} \times 100$

Periods $\mathrm{I}+\mathrm{II}=16.8 \pm 1.21$

Periods I - IV $=18.7 \pm 1.21$

over indicated periods

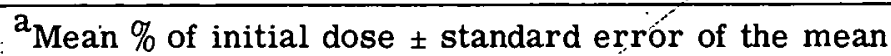

${ }^{b}$ Mean $\% \pm$ standard error of the mean

${ }^{c}$ Based on Period V fecal excretion $=\frac{0.187 \text { (Period V urine excretion) }}{0.813}$ 
pearance of $\mathrm{Mg}^{28}$ from the plasma, which was largely complete even before the first animals were slaughtered. In another experiment, 10 rats in the same weight range were given $\mathrm{Mg}^{28}$ iv and hourly uncatheterized urines were assayed for radioactivity. By 1 hour, a mean of 14 per cent of the initial dose had been excreted; and during the subsequent 6 hours, an additional 9 per cent was lost. Assuming the extremely unlikely possibility that all of the loss during the first hour occurred immediately after injection and making no corrections for the volume of plasma solids or the binding of isotope to plasma proteins, the $\mathrm{Mg}^{28}$ would have had to distribute itself through an extravascular volume equivalent to $30 \mathrm{ml}$ within 3 minutes. Accepting an interstitial fluid compartment equal to 15 per cent of the mean body weight of the group, the radioisotope must have entered a third physiological compartment which is considered for the purposes of this paper to consist of the intracellular space and exchangeable bone magnesium. This rapid movement continued at a decreasing rate over the next hour, and probably reflected a combination of normal compartmental exchange of magnesium plus a net tissue uptake of carrier. The second major component of the curve is represented by the intermediate slope with a 4-hour half-life; and, within the limits of the experiment, the final segment, by a slope with a half-life of 27.5 hours. Whether the $\mathrm{Mg}^{28}$ had mixed completely with the total body pool of exchangeable magnesium by 37 hours cannot be determined directly without knowing the total excretory loss at the end of each period.

The effects of large amounts of parenterally administered magnesium on the endogenous excretion and on the absorption of magnesium. Table 4 summarizes the effects of a 20 -fold increase in carrier on the excretion of ip injected $\mathrm{Mg}^{28}$. Expressed in terms of $\mathrm{mg}$ of carrier, the mean total urinary recovery rose 29 times (from 0.15 to $4.32 \mathrm{mg}$ ); and the fecal excretion, 12 times (from 0.03 to $0.37 \mathrm{mg}$ ). In the test group, 51.6 per cent of the entire 91 hour loss was recovered in the urine by 6 hours; and 76.6 per cent, by 20 hours. The figures for the control group were 29.0 and $\mathbf{5 2 . 6}$ per cent respectively. Clearly, then, the larger the quantity of acutely administered parenteral magnesium the greater will be the proportion recovered in the urine. While increased renal excretion of magnesium after ammonium chloride ingestion has been reported, ${ }^{51}$ the effects of the excess chloride and mild acidification from the $\mathrm{MgCl}_{2}$ were probably minor. Following the initial renal excretory shift over the first 20 hours, the mean per cent of the total daily magnesium loss found in the feces over Periods II to IV returned to a level that did not differ significantly from the control value $(T=0.73 ; p=0.500)$.

Approximately 28 per cent or $1.5 \mathrm{mg}$ of the injected magnesium was retained at the end of 20 hours despite magnesium absorption presumably in excess of the animals' needs. This was not the result of a temporary depression of absorption secondary to acute hypermagnesemia. The 11 animals which received $5 \mathrm{mg}$ of magnesium intraperitoneally at the time of, and 4 and 8 hours after the oral administration of $\mathrm{Mg}^{28}$ retained $50.61 \pm 1.80$ per cent of the radioisotope at 30 hours compared to $50.01 \pm 2.45$ per cent in the control groups. Even assuming no endogenous fecal excretion in the test group and a 4.28 per cent excretion (based on urinary loss) in the control group, the resulting 3.68 per cent difference in absorption would not be significant $(T=1.22$, p > 0.20). Since $5 \mathrm{mg}$ of magnesium produced elevated plasma levels for at least 3 hours after injection (Table 5), hypermagnesemia was maintained in these animals for approximately 11 hours after the $\mathrm{Mg}^{28}$ was given. As the transit time from the stomach to the caecum in the nonfasting young rat is 1 to 3 hours, and the largest proportion of magnesium absorption probably takes place in the proximal colon, ${ }^{54}$ any major effects on absorption produced by this large 
Table 4

EFFECT OF $5 \mathrm{Mg}$ OF CARRIER MAGNESIUM ON THE EXCRETION

OF INTRAPERITONEALLY ADMINISTERED Mg28 ${ }^{\mathrm{a}}$

\begin{tabular}{|c|c|c|c|c|c|c|}
\hline & & I & II & III & IV & Total re- \\
\hline Hours a & r injection & $0-20$ & $20-43$ & $43-67$ & $67-91$ & 91 hours \\
\hline $\begin{array}{l}\text { Cumulative total ex- } \\
\text { cretion at end of } \\
\text { period }\end{array}$ & $\begin{array}{l}0.25 \mathrm{mg} \\
\text { magnesium } \\
5.25 \mathrm{mg} \\
\text { magnesium }\end{array}$ & $\begin{array}{l}42.5 \pm 2.88 \\
71.6 \pm 2.45\end{array}$ & $\begin{array}{l}57.5 \pm 2.33 \\
81.1 \pm 2.20\end{array}$ & $\begin{array}{l}65.8 \pm 1.91 \\
86.3 \pm 2.41\end{array}$ & $\begin{array}{l}71.0 \pm 1.63 \\
89.3 \pm 2.37\end{array}$ & \\
\hline $\begin{array}{l}\text { Urinary excretion } \\
\text { during period } \\
\qquad A\end{array}$ & $\begin{array}{l}0.25 \mathrm{mg} \\
\text { magnesium } \\
5.25 \mathrm{mg} \\
\text { magnesium }\end{array}$ & $\begin{array}{l}37.3 \pm 2.76 \\
68.4 \pm 2.42\end{array}$ & $\begin{array}{r}11.4 \pm 0.53 \\
7.4 \pm 0.49\end{array}$ & $\begin{array}{l}6.1 \pm 0.67 \\
4.1 \pm 0.29\end{array}$ & $\begin{array}{l}4.1 \pm 0.43 \\
2.3 \pm 0.11\end{array}$ & $\begin{array}{l}59.0 \pm 1.59 \\
82.2 \pm 2.38\end{array}$ \\
\hline $\begin{array}{l}\text { Fécal excretion } \\
\text { during periodb } \\
\text { B }\end{array}$ & $\begin{array}{l}0.25 \mathrm{mg} \\
\text { magnesium } \\
5.25 \mathrm{mg} \\
\text { magnesium }\end{array}$ & $\begin{array}{l}5.2 \pm 0.44 \\
3.2 \pm 0.45\end{array}$ & $\begin{array}{l}3.6 \pm 0.24 \\
2.1 \pm 0.13\end{array}$ & $\begin{array}{l}2.1 \pm 0.16 \\
1.1 \pm 0.14\end{array}$ & $\begin{array}{l}1.1 \pm 0.09 \\
0.7 \pm 0.09\end{array}$ & $\begin{array}{r}12.0 \pm 0.28 \\
7.1 \pm 0.69\end{array}$ \\
\hline$\frac{B}{A+B} \times 100^{c}$ & $\begin{array}{l}0.25 \mathrm{mg} \\
\text { magnesium } \\
5.25 \mathrm{mg} \\
\text { magnesium }\end{array}$ & $\begin{array}{r}12.2 \pm 1.13 \\
6.5 \pm 0.61\end{array}$ & $\begin{array}{l}24.2 \pm 0.66 \\
22.1 \pm 1.91\end{array}$ & $\begin{array}{l}25.8 \pm 2.32 \\
21.6 \pm 2.00\end{array}$ & $\begin{array}{l}21.7 \pm 2.25 \\
22.4 \pm 2.52\end{array}$ & \\
\hline $\begin{array}{l}\text { Mean } \frac{B}{A+B} \times 100 \\
\text { over indicated } \\
\text { periods } C\end{array}$ & $\begin{array}{l}0.25 \mathrm{mg} \\
\text { magnesium } \\
5.25 \mathrm{mg} \\
\text { magnesium }\end{array}$ & $\begin{array}{l}I+I=18.2 \\
I+I=13.3\end{array}$ & $\begin{array}{l}\text { II - I } \\
\text { II - I }\end{array}$ & $\begin{array}{l}.9 \pm 1.56 \\
.1 \pm 1.95\end{array}$ & & \\
\hline
\end{tabular}

\footnotetext{
${ }^{\mathrm{a}}$ Each group consists of 5 rats

${ }^{b}$ Mean $\%$ of initial dose \pm S.E.M.

$\mathrm{c}_{\text {Mean } \% \pm \text { S.E.M. }}$
} 
Table 5

\section{EFFECT OF $5 \mathrm{Mg}$ OF INTRAPERITONEALLY INJECTED MAGNESIUM ${ }^{2}$ ON PLASMA MAGNESIUM LEVELS IN THE RAT}

\begin{tabular}{c|c|c|c|c}
\hline $\begin{array}{c}\text { Time after injection } \\
\text { in minutes }\end{array}$ & $\begin{array}{c}\text { No. of } \\
\text { animals }\end{array}$ & $\begin{array}{c}\text { Mean plasma magne- } \\
\text { sium meq/liter }\end{array}$ & \pm 1 S.D. & $\mathrm{P}^{\mathrm{b}}$ \\
\hline Controls & 6 & 1.70 & \pm 0.17 & \\
15 & 2 & 6.11 & & \\
30 & 2 & $(6.27,5.95)$ & 5.58 & \\
60 & 3 & 3.14 & \pm 0.09 & $<0.01$ \\
120 & 7 & 2.29 & \pm 0.15 & $<0.01$ \\
180 & 5 & 2.26 & \pm 0.12 & $<0.01$ \\
240 & 5 & 1.81 & \pm 0.06 & $>0.01$ \\
\hline
\end{tabular}

amount of parenteral magnesium should have been demonstrated in this period of time.

The effect of increasing amount of orally administered magnesium on magnesium absorption and excretion. The figures for absorption are based on the 36-hour fecal recovery and are presumably low because no factor for calculating the amount of endogenous fecal excretion of $\mathrm{Mg}^{28}$ under similar experimental conditions has been determined. As shown in Table 6, following an initial decline from the $0.23 \mathrm{mg}$ level, the percentage of $\mathrm{Mg}^{28}$ absorbed did not change significantly as the carrier was increased from 5 to $15 \mathrm{mg}$. While there was a difference between 20 and $25 \mathrm{mg}(\mathrm{T}=2.52, \mathrm{p}<0.050>0.025)$, neither varied significantly from the 5 to 15 $\mathrm{mg}$ levels. Expressed quantitatively, for every additional $5 \mathrm{mg}$ given orally, the amount of magnesium absorbed rose approximately $2.1 \mathrm{mg}$. Within the concentration range tested in this experiment, therefore, no upper limit to the absorption of magnesium was demonstrated. In addition, the quantity remaining unabsorbed rose until 3 of the 6 animals receiving $25 \mathrm{mg}$ developed transient diarrhea. The difference between the mean absorption found in control animals given 5 per cent dextrose in normal saline and those receiving chloride (as $\mathrm{NaCl}$ ) in a concentration equal to that produced by $15 \mathrm{mg}$ of $\mathrm{Mg}$ as $\mathrm{MgCl}_{2}$ per $\mathrm{ml}$ was not statistically significant.

From the data presented, it would appear that a quantitative increase in magnesium absorption was associated not only with a larger urinary loss but also a greater retention of the mineral. A similar finding has been reported in calves fed varying amounts of dietary magnesium over long periods of time. ${ }^{39}$ The magnitude of this retention, however, may be smaller than shown. When $\mathrm{Mg}^{28}$ was administered orally 6 hours after $15 \mathrm{mg}$ of magnesium po, the mean absorption in the test group decreased a significant 6.35 per cent $(T=3.75, p<0.005>0.001)$; however, by 24 hours, there was no difference between the control and experimental groups. 
Table 6

EFFECT OF INCREASING AMOUNTS OF ORALLY ADMINISTERED CARRIER MAGNESIUM ON $\mathrm{Mg}^{28}$ ABSORPTION AND URINARY EXCRETION IN FASTING YOUNG MALE RATS ${ }^{\mathrm{a}}$

\begin{tabular}{|c|c|c|c|c|c|c|}
\hline $\begin{array}{c}\mathrm{Mg} \text { of } \\
\text { magnesium } \\
\text { administered }\end{array}$ & $\begin{array}{l}\text { No. of } \\
\text { animals }\end{array}$ & $\begin{array}{l}\% \text { of injtial dose }{ }^{b} \text { of } \\
\mathrm{Mg}^{28} \text { absorbed } \\
\text { (Mean } \pm \text { S.E.M.) }\end{array}$ & $\begin{array}{l}\text { Mg of carrier } \\
\text { magnesium } \\
\text { absorbed } \\
\text { (Mean) }\end{array}$ & $\begin{array}{l}\text { \% of initial dose of } \\
\mathrm{Mg}^{28} \text { excreted } \\
\text { in urinec } \\
\text { (Mean } \pm \text { S.E.M.) }\end{array}$ & $\begin{array}{l}\text { Mg of carrier } \\
\text { magnesium } \\
\text { excreted in } \\
\text { the urinec } \\
\text { (Mean) }\end{array}$ & $\begin{array}{c}\text { Mg of absorbed } \\
\text { carrier magne- } \\
\text { sium retained } \\
\text { (Mean) }\end{array}$ \\
\hline 0.2 & 7 & $54.5 \pm 1.17$ & 0.1 & $19.0 \pm 0.76$ & 0.04 & 0.08 \\
\hline 5.2 & 7 & $42.9 \pm 2.69$ & 2.2 & $18.1 \pm 1.81$ & 0.9 & 1.3 \\
\hline 10.2 & 6 & $41.6 \pm 2.60$ & 4.3 & $19.2 \pm 1.33$ & 2.0 & 2.3 \\
\hline 15.2 & 7 & $40.6 \pm 2.22$ & 6.2 & $20.9 \pm 1.11$ & 3.2 & 3.0 \\
\hline 20.2 & 6 & $37.6 \pm 1.37$ & 7.6 & $21.4 \pm 0.69$ & 4.3 & 3.3 \\
\hline 25.2 & 6 & $44.2 \pm 2.25$ & 11.1 & $23.9 \pm 1.44$ & 6.0 & 5.1 \\
\hline
\end{tabular}

${ }^{\mathrm{a}}$ Animals fasted 6 hours before and 4 hours after receiving $\mathrm{Mg}^{28}$ and carrier magnesium

${ }^{b}$ Based on 36-hour fecal loss of $\mathrm{Mg}^{28}$ uncorrected for endogenous fecal excretion

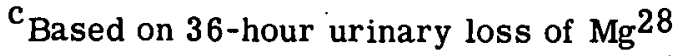




\section{DISC USSION}

Little information is available on the metabolism of magnesium in normal rats despite their extensive use in studies on the effects of magnesium deficiency. It will therefore be necessary to refer to work on other animals, realizing that many of the observed differences may be the result of significant species variation.

Assuming that magnesium enters the intestinal mucosal cells as $\mathrm{Mg}^{++}$, interpretation or comparison of results is complicated by the numerous in vivo intraluminal factors which are potentially capable of altering the chemical state of magnesium and consequently its absorption. Excluding the last 2 experiments, the $\mathrm{Mg}^{28}$ was given to non-fasting animals to insure the presence of these variables. $\mathrm{MgCl}_{2}$ was selected rather than $\mathrm{MgSO}_{4}$ because chloride is the most likely associated anion once the dietary magnesium has entered the duodenum. Furthermore, not only are there differences in the degree of dissociation between the two salts but sulfate has a well known cathartic effect.

All other factors being equal, our data show that magnesium absorption in the normal rat gr eatly exceeds apparent requirements; is mainly dependent on the amount or, more likely, the concentration of magnesium in the bowel lumen; has no demonstrable upper limit within the concentration range used in these experiments (up to 8 times the dietary content per $\mathrm{g}$ ); is depressed for at least 7 to 8 hours after the passage of a large amount of intraluminal magnesium; and is not affected by an acute elevation in the plasma magnesium level. Some of these conclusions have been suggested previously by others or may be inferred from data obtained in vivo in other mammals ${ }^{11-15}$ and from in vitro preparations of rat small intestine. ${ }^{16}$ The wide range reported for absorption ${ }^{13,14,17-25}$ reflects in part species, dietary and experimental differences. In contrast to Smith's work in the calf, ${ }^{13,26}$ we did not find any substantial depression in absorption with aging. Either by direct observation or by inference, the major site for magnesium absorption may be localized to the ileum in the rat, ${ }^{16}$ the caecum and small bowel in the young calf, ${ }^{26}$ somewhere proximal to the colon in the rabbit, ${ }^{21}$ and throughout the small intestine in the human; ${ }^{14,45}$ although, in the latter case, significant absorption through normal and diseased colon may occur. ${ }^{28,29}$ Recent work in our laboratory indicates that while absorption occurs throughout the small bowel, the largest percentage occurs in the caecum and ascending colon. 54

In both the young and older rat with normal intestinal and renal function, the kidney is the predominant, but far from the only, excretory pathway for magnesium administered parenterally or absorbed in excess of requirements. The role played by the kidneys has been firmly established. The chief point of variance is over the magnitude and adaptibility of the gastrointestinal excretion. While magnesium has been found in intestinal fluids in varying quantities, $8,30,31$ most of the evidence in other mammals is against any significant endogenous loss through the stool. $22,24,25,32-37$ One must view with reservations many of the studies using acute parenteral loads of magnesium, because fecal losses are inferred without actual measurement; this approach produces a marked enhancement of renal excretion; and, the chemical methods used for analysis of excreta are not sufficiently accurate to evaluate the significance of small daily increments in fecal magnesium in relation to the large and variable quantities remaining unabsorbed. The recent reports with $\mathrm{Mg}^{28}$ used as a tracer are more convincing; but most of these have been in man, where the combination of sluggish passage of intestinal contents and rapid radioisotope decay make quantitation difficult. On the other hand, using magnesium restriction ${ }^{13,38,39}$ and/or 
$\mathrm{Mg}^{28}, 14,17-19$ several investigators have unmasked quantitatively significant fecal excretion. It is interesting that with two exceptions ${ }^{14,38}$ these were herbivora and that our animals were fed a herbivorous diet. Langamann's results in rats ${ }^{40}$ are qualitatively similar but not comparable to ours. He added each animal's digestive tract to its 24-hour fecal collection prior to counting, and it is not clear whether the rats were fed or fasted during the experimental period.

As a mechanism for the rapid regulation of acute magnesium excess, gastrointestinal excretion is of little adaptive significance, especially in an animal with normal tissue accomodation for and renal clearance of magnesium. Its importance is more evident, however, in those conditions where excretory loss may be detrimental. The best example of this is in the young rat deprived of dietary magnesium. While quantitatively less than control values, fecal excretion continues despite severe, symptomatic hypomagnesemia. ${ }^{41}$ Furthermore, assuming that magnesium enters the bowel in a reabsorbable form, one would expect that any major disturbance in absorption would produce a significant drain on the animal's reserves. The upper gut appears to be the major location of this excretion. 54

The rapid disappearance of $\mathrm{Mg}^{28}$ from the plasma has been reported previously in rats ${ }^{42,43}$ and other mammals including man. ${ }^{24,44-46,53}$ This represents the initial renal and, to a much less extent, fecal excretion of a part of the original dose and of magnesium displaced from the more labile portion of the exchangeable body pool by the carrier $\mathrm{Mg}$. In addition, some transient net retention in the tissues, expecially the skeleton, may occur. In part, this retention might occur as the result of displacement of some of the animal's exchangeable calcium. ${ }^{47-49}$ By 72 hours in the young rat, the retained radioisotope acts as though it had entered a single large "compartment" which turns over slowly under normal conditions. From its size and from tissue distribution studies using $\mathrm{Mg}^{28}$, it probably consists largely of bone and muscle magnesium. $27,42,44,45 ; 52$

\section{ACKNOWLEDGMENT}

The author wishes to express his appreciation to Dr. R. J. Hasterlik of the Department of Medicine, the University of Chicago, for his valuable suggestions, criticisms and encouragment; to Mrs. Lucille Penas, Mr. James Illes and Mr. William Levi for their technical assistance; to Miss Linda Clark, Mr. David Kleinman and the other members of the Biological Sciences Computation Center, the University of Chicago, who were involved in the design of the digital computer program used to analyze the data from the balance studies; ${ }^{*}$ and to Miss M. Sandford Norbeck for help in preparing the manuscript.

\section{LITERATURE CITED}

1. Kruse, H. D., E. R. Orent, and E. V. McCollum. J. Biol. Chem., 96:519, 1932.

2. Orent, E. R., H. D. Kruse, and E. V. McCollum. Am. J. Physiol., 101:454, 1932.

3. Orent, E. R., H. D. Kruse, and E. V. McCollum. J. Biol. Chem., 106:573, 1934.

4. Tufts, E. V., and D. M. Greenberg. J. Biol. Chem., 122:693, 1937.

5. Charleston, D. B. In Proc. of a Symposium on Whole-Body Counting, Vienna, 1962, International Atomic Energy Agency, p. 189.

\footnotetext{
${ }^{*}$ Supported by United States Public Health Service Grant No. FR00013-01.
} 
6. Hine, G. J., and G. L. Brownell. Radiation Dosimetry, New York, 1956, Academic Press, Inc., p. 900 .

7. Orange, M., and H. C. Rhein. J. Biol. Chem., 189:379, 1951.

8. Altman, P. L., and D. S. Dittmer. Blood and Other Body Fluids, Washington, D. C., 1961, Federation of American Societies for Experimental Biology.

9. Annino, J. S. Clinical Chemistry, Principles and Procedures, Boston, 1956, Little, Brown and Co., p. 170 .

10. Snedecor, G. W. Statistical Methods Applied to Experiments in Agriculture and Biology, ed. 5, Ames, 1956, Iowa State College Press.

11. Watchhorn, E. J. Hyg., 32:156, 1932.

12. Hirschfelder, A. D. J. Biol. Chem., 104:647, 1934.

13. Smith, R. H. Biochem. J., 71:306, 1959.

14. Graham, L. A., J. J. Caesar, and A. S. V. Burgen. Metabolism, 9:646, 1960.

15. Heaton, F. W., and F. M. Parsons. Clin. Sc., 21:273, 1961.

16. Ross, D. B. J. Physiol., 106:417, 1962.

17. Field, A. C. Nature, $183: 983,1959$.

18. MacDonald, D. C. and A. D. Care. Nature, 184:736, 1959.

19. McAleese, D. M., M. C. Bell, and R. M. Forbes. J. Nutrition, 74:505, 1961.

20. Borbour, H. G., and J. E. Winter. J. Pharmacol. and Exptl. Therap., 43:607, 1931.

21. Aikawa, J. K. Proc. Soc. Exptl. Biol. and Med., 100:293, 1959.

22. Zumoff, B., E. H. Bernstein, J. J. Imarisio, and L. Hallman. Clin. Res., 6:260, 1958, (Abst.).

23. Aikawa, J. K., E. L. Rhoades, and G. S. Gordon. Proc. Soc. Exptl. Biol. and Med., 98:29, 1958.

24. Silver, L., J. S. Robertson, and L. S. Dahl. J. Clin. Invest., 39:420, 1960.

25. Fourman, P., and D. B. Morgan. Proc. Nutr. Soc., 21:34, 1962.

26. Smith, R. H. Nature, 184:821, 1959.

27. Chutkow, J. G. Unpublished data.

28. Fawcett, P. W., and J. P. Gens. J. A. M. A., 123:1028, 1943.

29. Collins, E. N., and P. W. Russell. Cleveland Clin. Quart., 16:162, 1949.

30. De Beer, E. J., G. G. Johnston, and D. W. Wilson. J. Biol. Chem., 108:113, 1935.

31. Levey, S., W. E. Abbott, H. Krieger, and J. H. Davis. J. Lab. and Clin. Med., 47:437, 1956.

32. Mendel, L. B., and S. R. Benedict. Am. J. Physiol., 25:1, 1909.

33. Courtney, A. M., and H. L. Fales. Am. J. Dis. Child., 9:318, 1915.

34. McCance, R. A., and E. H. Widdowson. Biochem. J., 33:523, 1939.

35. Smith, P. K., A. W. Winkler, and B. M. Schwartz. J. Biol. Chem., 129:51, 1939. 
36. Pritchord, J. A. Surg., Gynec. and Obst., 100:131, 1955.

37. Fitzgerald, M. C., and F. Fourman. Clin. Sc., 15:635, 1956.

38. Nicolaysen, R. Skand. Arch. Physiol., 73:75, 1936.

39. Blaxter, K. L., and J. A. F. Rook. J. Comp. Pathol., 64:176, 1954.

40. Langemann, F. W. Arch. Biochem. et Biophys., 84:278, 1959.

41. Chutkow, J. G. J. Lab. and Clin. Med., 60:867, 1962, (Abst.).

42. Rogers, T. A., and P. E. Mahan. Proc. Soc. Exptl. Biol. and Med., 100:235, 1959.

43. Breibert, S., J. S. Lee, A. McCoord, and G. B. Forbes. Proc. Soc. Exptl. Biol. and Med., $105: 361,1960$.

44. Aikawa, J. K., E. L. Rhoades, D. R. Harms, and J. Z. Reardon. Am. J. Physiol., 197:99, 1959.

45. Aikawa, J. K. Second United Nations International Conference on the Peaceful Uses of Atomic Energy, Vol. 24, Part 1, Isotopes in Biochemistry and Physiology, Geneva, 1958, United Nations, p. 148

46. Brandt, J. L., W. Glaser, and A. Jones. Metabolism, 7:355, 1958.

47. Womersley, R. A. Clin. Sc., 15:465, 1956.

48. Chesley, L. C., and I. Tepper. J. Clin. Invest., 37:1362, 1958.

49. Barker, E. S., J. R. Elkington, and J. K. Clark. J. Clin. Invest., 38:1733, 1959.

50. Greenberg, D. M., and E. V. Tufts. J. Biol. Chem., 114:135, 1936.

51. Martin, H. E., and R. Jones. Am. Heart J., 62:206, 1961.

52. MacIntyre, I., D. Davidsson, and P. C. Leong. Proc. of the Fourth International Conference of Biochemistry, Vol. XV, Oxford, 1960, Pergamon Press, p. 160, (Abst.).

53. Barnes, B. A., and G. L. Brownell. Proc. of the Second International Conference on the Peaceful Uses of Atomic Energy, Vol. 26, Isotopes in Medicine, Geneva, 1958, United Nations, p. 204.

54. Chutkow, J. G. J. Lab. and Clin. Med., 63:71, 1964.

55. Dunnett, C. W. J. Am. Stat. Assn., 50:1096, 1955. 


\section{THE SITES OF MAGNESIUM ABSORPTION AND EXCRETION \\ IN THE INTESTINAL TRACT OF THE RAT}

By

\section{J. G. Chutkow}

As noted in the previous report, ${ }^{1}$ very little information is available on the metabolism of magnesium within the alimentary tract. The present paper is concerned with the major intestinal sites of absorption and excretion of magnesium in the rat under experimental conditions designed to produce as few disturbances in the normal physiology of the bowel as possible.

\section{MATERIALS AND METHODS}

Non-fasting male albino rats (Sprague-Dawley strain) weighing 110 to $120 \mathrm{~g}$ were used in all experiments. The animals were housed in individual metabolism cages to prevent coprophagy and provide uncontaminated separation of urine and feces. They were fed powdered Rockland diet and tap water ad libitum.

$\mathrm{Mg}^{28}$ as $\mathrm{Mg}^{28} \mathrm{Cl}_{2}$ in $\mathrm{HCl}$ was obtained from Brookhaven National Laboratory. Its specific activity was 16 to $20 \mu \mathrm{c}$ of $\mathrm{Mg}^{28}-\mathrm{Al}^{28}$ at the time of administration to the animals. Detailed descriptions of the counting equipment and of the methods used have been presented elsewhere. ${ }^{1} \mathrm{~A}$ second heavily shielded 5 by 6 inch thallium-activated NaI well-crystal integrally mounted at each end to a photomultiplier tube was also used for counting small samples. The counting efficiency was approximately 15.6 per cent.

The volume of 5 per cent dextrose in water containing the $\mathrm{Mg}^{28}$ was carefully measured in a $1.0 \mathrm{ml} \mathrm{B}-\mathrm{D}$ Yale ${ }^{\circledR}$ tuberculin syringe and administered intravenously (iv), intraperitoneally (ip), or by orogastric intubation (po). Unless otherwise noted, a volume of radioactive solution equal to that received by each animal was measured into an Erlenmeyer flask from the injecting syringe at 4 separate times during the injection period. The mean activity of these 4 samples served as the reference standard from which, by comparison of activities, the number of microcuries contained in all other standards (urine, feces, and plasma) was calculated. 'The percentage of probable error of the net counting rate was two per cent or less.

Design of experiments. A table of random numbers was used whenever distribution of animals into experimental groups was necessary.

Experiment 1 . Two studies on a total of 50 animals were performed and the results combined.

In the first study, the rats were divided into 4 groups. While the animal was under ether anesthesia, its abdomen was opened; and $2.250 \mu \mathrm{c}$ of isotope in an $0.5 \mathrm{ml}$ volume was injected directly into the lumen of the bowel through a \#28 needle at one of the following sites: stomach, 2 to $3 \mathrm{~cm}$ distal to the pylorus, 20 to $24 \mathrm{~cm}$ proximal to the ileocecal junction, or the caecum. During injection, the bowel immediately proximal to the injection site was gently compressed to prevent an initial large retrograde flow of isotope. In preliminary studies where carmine red dye

*This report is taken from a paper appearing in J. Lab. and Clin. Med., 63:71, 1964. 
was used as an indicator, neither initial reflux of dye from the caecum into the terminal ileum, nor loss through the puncture site was observed. The abdominal incision was closed with sutures and metal clips and the excreta collected over the next 30 hours. Spot checks of feces passed at 32 to 34 hours showed no more activity than might be expected from the endogenous excretion of absorbed $\mathrm{Mg}^{28}$.

In the second study, a fifth group of operated animals which received $\mathrm{Mg}^{28}$ po before closure of the abdomen was added to the 4 groups already described.

Experiment 2. Aproximately $1 \mathrm{ml}$ of 5 per cent dextrose in water containing both the radioisotope and carmine red dye was administer ed po to each of 23 rats. Single animals were slaughtered by aortic exsanguination at 15 minute intervals for the first 5 hours and then from 6 to 6-1/2 hours after injection. The heparinized blood was immediately centrifuged and a $2.0 \mathrm{ml}$ aliquot of plasma was taken for counting. The entire bowel was removed and divided into 7 sections (stomach; first, second, third, and fourth $25 \mathrm{~cm}$ of small intestine; first 6 to $8 \mathrm{~cm}$ of the colon; and the remainder of the colon including all feces passed during the experimental period). The segments were transferred to and tightly packed down in individual test tubes. The contents of the urinary bladder were added to the previously voided urine. The remainder of the carcass was placed in a thin cellophane bag and saved for counting.

Because the carmine red dye obscured the end of the plunger so that accurage measurements of volume in the tuberculin syringe were not possible, an alternative method was used to calculate the amount of isotope received by each animal. Following initial assays of their activities, several $1.0 \mathrm{ml}$ aliquots of the radioactive solution were diluted to volumes equal to those of the different segments of bowel, the urines, or the carcasses, and served as "reference standards". The carcasses were counted as previously described. ${ }^{1}$ All other samples were counted in one of the two well-crystals concurrently with their respective standards. The counts per minute (cpm) in all samples were corrected for physical decay to a common time $\left(\mathrm{T}_{0}\right)$ and expressed in terms of a common reference activity $\left(\mathrm{RA}_{\mathrm{T}_{0}}=\right.$ the mean activity of the undiluted standards in net $\mathrm{cpm}$ at $\mathrm{T}_{0}$ ) as follows: net sample $\mathrm{cpm}_{\mathrm{T}_{0}}=$ (net sample $\mathrm{cpm}_{\mathrm{Tn}} \div$ net standard $\mathrm{cpm}_{\mathrm{Tn}}$ ) $\mathrm{x}$ net standard $\mathrm{cpm}_{\mathrm{T}_{0}} \times$ (net standard $\mathrm{cpm}_{\mathrm{T}_{0}} \div \mathrm{RA}_{\mathrm{T}_{0}}$ ). The total radioactivity initially administered to a rat was. assumed to equal the sum of the activities contained in all the specimens taken from the animal.

Experiment 3. Ten rats were given the $\mathrm{Mg}^{28}$ in $1.0 \mathrm{ml}$ of 5 per cent dextrose in water iv, and simultaneously, carmine red in $0.2 \mathrm{ml}$ of water po. Feces were collected hourly for the first 8 hours, and at 2 hour intervals for the next 4 hours. The number of pellets passed in each period was counted, and the presence or absence of dye noted. An additional 12 hour collection was made between 12 and 24 hours. Each sample was counted with a feces standard containing 4.00 per cent of the mean "reference standard" activity.

Experiment 4. Fourteen rats were given the radioisotope and carmine red as in experiment 3. Individual animals were slaughtered by aortic exsanguination at intervals of from 8 minutes to 7 hours after injection of the isotope. The heparinized blood was immediately centrifuged and a $1.0 \mathrm{ml}$ aliquot of plasma was saved for counting. The bowel from the stomach to the distal colon was removed and divided into 8 sections: stomach (to pylorus); first, second, third, fourth and fifth $20 \mathrm{~cm}$ segments of the small intestine; first 6 to $8 \mathrm{~cm}$ segment of the colon, and remaining colon. The luminal contents were gently expressed, weighed wet, and placed into a test tube for counting. Any specimen containing material which might be stripped mucosa was discarded. The location of the dye was noted and the intensity graded on an arbitrary 0 to $2+$ scale. All counts 
were corrected to a common time and expressed as cpm per $100 \mathrm{mg}$ of intraluminal content (feces) or per ml (plasma).

Except for the Dunnett $\mathrm{T}$ test, ${ }^{19}$ all statistical methods were taken from Snedecor. ${ }^{2}$

\section{RESULTS}

Experiment 1 (Table 1). No statistically significant difference in absorption was found between the sham operated rats and those injected through the stomach wall; between those injected

Table 1

THE ABSORPTION: OF $\mathrm{Mg}^{28}$ FOLLOWING DIRECT INJECTION INTO THE LUMEN OF THE BOWEL

\begin{tabular}{l|c|c|c}
\hline $\begin{array}{c}\text { Site of } \mathrm{Mg}^{28} \\
\text { injection }\end{array}$ & $\begin{array}{c}\text { No. of } \\
\text { animals }\end{array}$ & $\begin{array}{c}\text { Mean \% of initial } \\
\text { dose absorbed }\end{array}$ & S.E.M. \\
\hline Stomach $^{\mathrm{a}}$ & 6 & 67.4 & \pm 2.64 \\
Stomach $^{\mathrm{b}}$ & 11 & 63.3 & \pm 3.72 \\
Duodenum $_{\text {Distal ileum }} \mathrm{c}$ & 10 & 69.1 & \pm 3.19 \\
Caecum & 11 & 58.6 & \pm 3.91 \\
\hline
\end{tabular}

${ }^{a}$ Sham operated. (Injected through oro-gastric tube).

${ }^{b}$ Injected directly into gastric lumen.

${ }^{\mathrm{c}}$ Injected 20 to $24 \mathrm{~cm}$ from ileo-caecal valve.

${ }^{\dagger}$ Not corrected for the intestinal excretion of absorbed isotope.

in the lumen of the stomach and in the lumen of the duodenum; or between those given isotope in the distal ileum and in the caecum. All of the results are presumably low because no correction could be made for the intestinal excretion of previously absorbed $\mathrm{Mg}^{28}$ as the factor necessary for such calculations ${ }^{1}$ has not been determined under similar experimental conditions. The mean absorption for all animals receiving $\mathrm{Mg}^{28}$ in the upper gastrointestinal tract was $66.3 \pm 2.04$ per cent (mean \pm 1 S.E.M.) of the administered dose. Based on this figure, 7.7 per cent less isotope was absorbed after injection into the distal ileum $(\mathrm{p}>0.01){ }^{*}$ and 11.63 per cent less, after injection through the wall of the caecum $(p<0.01){ }^{*}$ These findings may be interpreted in two ways: either 83 per cent of the total absorption of magnesium occurs in the colon, or 55 per cent of the magnesium which is not absorbed in the small bowel is subsequently absorbed in the colon.

Based on a maximum mean absorption of 69 per cent (duodenal injection), these studies indicate that manipulation of the bowel enhances magnesium absorption. Although a group of unoperated controls was not included in the present experiment, it has been shown that normal rats in the same weight range as those used in these studies absorb a mean of 53 per cent of a po dose of $\mathrm{Mg}^{28}{ }^{1}$ Whether this change is the result of a primary alteration in mucosal permeability or

\footnotetext{
* Two compared values are considered significantly different if $\mathrm{p}<0.01$ by the Dunnett $\mathrm{T}$
} test. 
merely reflects prolonged contact between the absorptive surfaces of the bowel and the radiomagnesium due to lransient postoperative hypomotility is not clear.

Experiment 2. In this study, the amount of isotope absorbed by an animal was calculated to be equal to the total activity recovered in the carcass plus the urine. The results in Table 2 are arranged in order of increasing absorption. Assuming that a large bolus of isotope had just arrived in the terminal segment of small bowel in animal 6, the results from animals 1 through 7 would demonstrate a minimum absorption of 7.6 per cent in the first $75 \mathrm{~cm}$ of small intestine. In all probability, the isotope was about to enter the caecum in animal 12 and had recently passed into the colon in large quantities in animals 11 and 13 , indicating that an additional 5 per cent of the initial dose was absorbed prior to the colon, presumably through the distal ileum. The rapid increase in absorption after rat 13 suggests that most, if not all, of the remaining uptake of $\mathrm{Mg}^{28}$ took place in the proximal colon. If this is the case, the large intestine would account for a maximum of 71 per cent of the total absorption of $\mathrm{Mg}$, based on the data from rat 23 . Because the radioisotope is dispersed throughout the gut from rats 8 through 18 , a better approximation of the fractional absorption occurring in the colon may be derived from estimated maximum and minimum values. In the colon, the minimum absorption would be 17.3 per cent of the recovered activity (rat 23 minus rat 19); the maximum, 35 per cent; and the approximate mean, 26 per cent. Comparable figures for the entire remaining gut would be 12.7 per cent (rat 12), 25.3 per cent (rat 19), and a mean of 19 per cent. Based on the sum of the mean figures, about 58 per cent of the absorption of $\mathrm{Mg}$ occurred in the large intestine. Using plasma levels of radioactivity as the sole criterion, one would have had to conclude that the major site of $\mathrm{Mg}^{28}$ absorption was in the distal ileum.

Experiment 3 (Figure 1). The fecal pellets were used as crudely convenient units in comparing the results from one animal to another. On an average, 12 pellets containing a total of $4.5 \pm 0.81$ per cent (mean \pm S.E.M.) of the cumulative 12 hour fecal excretion of $\mathrm{Mg}^{28}$ were passed before the carmine red was first detected. Just prior to or concurrently with the appearance of the dye in the pellets, the fecal radioactivity rose abruptly in every animal; reached a maximum of 8 to 30 times the pre-dye activity per pellet; and then decreased to levels somewhat lower than the maximum for the remainder of the hourly collections. $3.3 \pm 0.17$ per cent of the administered isotope was recovered in the stool by 12 hours; and $5.0 \pm 0.28$ per cent, by 24 hours. In the young, non-fasting rat, the transit time from the stomach to the distal ileum is usually $1-1 / 2$ to 2 hours; and, from the distal ileum to the anus, an additional 3 to 4 hours. In 9 of the 10 animals studied, 5 to 6 hours elapsed before the orally administered dye first appeared in the feces. In animal 10, one of the pellets contained carmine red at 4 hours. It would appear, therefore, that all but a small fraction of the endogenous magnesium excretion occurs in the upper gastrointestinal tract. In order to postulate a major site of excretion in the lower bowel, one would have to assume either the combination of an abnormally rapid transit time from the stomach to the distal ileum and a marked depression of colonic motility, or, in view of the rapid decline in plasma radioactivity (see below), a large initial mucosal uptake of $\mathrm{Mg}^{28}$ followed by a 2 hour latent period before the sudden onset of excretion.

Experiment 4 (Figure 2). Eight minutes after the administration of the $\mathrm{Mg}^{28}$ iv, the radioactivity per $100 \mathrm{mg}$ in the specimen taken from the first $20 \mathrm{~cm}$ of the small bowel was equal to that in $100 \mathrm{mg}$ of plasma (even without correction for the binding of magnesium by plasma proteins). In animals slaughtered later, the activity of the contents in the lower intestinal segments 
Table 2

THE ABSORPTION OF ORALLY ADMINISTERED Mg28 IN THE YOUNG RAT

\begin{tabular}{|c|c|c|c|c|c|c|c|c|c|c|c|c|}
\hline \multirow{3}{*}{$\begin{array}{l}\text { Rat } \\
\text { no. }\end{array}$} & \multirow{3}{*}{$\begin{array}{l}\text { Time in } \\
\text { minutes } \\
\text { after } \\
\text { injection }\end{array}$} & \multirow{3}{*}{$\begin{array}{c}\% \text { of } \\
\text { recover ed } \\
\text { activity } \\
\text { absorbed }\end{array}$} & \multicolumn{9}{|c|}{$\%$ of recovered activity found in:b } & \multirow{3}{*}{$\begin{array}{l}\text { Plasma } \\
\text { activity } \\
\text { (net cpm } \\
\text { per } 2 \mathrm{ml} \text { ) }\end{array}$} \\
\hline & & & \multirow{2}{*}{ Carcass } & \multirow{2}{*}{ Urine } & \multirow{2}{*}{ Stomach } & \multicolumn{4}{|c|}{$25 \mathrm{~cm}$ segments of small bowel } & \multirow{2}{*}{$\begin{array}{l}\text { First } \\
6 \text { to } 8 \mathrm{~cm} \\
\text { of colon }\end{array}$} & \multirow{2}{*}{$\begin{array}{l}\text { Distal } \\
\text { colon }\end{array}$} & \\
\hline & & & & & & First & Second & Third & Fourth & & & \\
\hline $\begin{array}{r}1 \\
2 \\
3 \\
4 \\
5 \\
6 \\
7 \\
8 \\
9 \\
10 \\
11 \\
12 \\
13 \\
14 \\
15 \\
16 \\
17 \\
18 \\
19 \\
20 \\
21 \\
22 \\
23\end{array}$ & $\begin{array}{r}15 \\
30 \\
45 \\
105 \\
75 \\
60 \\
90 \\
135 \\
195 \\
150 \\
225 \\
165 \\
285 \\
240 \\
210 \\
180 \\
120 \\
255 \\
270 \\
300 \\
360 \\
390 \\
375\end{array}$ & $\begin{array}{r}0.8 \\
0.9 \\
2.8 \\
3.4 \\
6.4 \\
7.5 \\
7.6 \\
10.4 \\
11.2 \\
11.3 \\
12.5 \\
12.7 \\
12.7 \\
14.6 \\
16.9 \\
17.1 \\
18.0 \\
24.9 \\
25.3 \\
32.2 \\
36.5 \\
37.0 \\
42.6\end{array}$ & $\begin{array}{r}0.8 \\
0.9 \\
2.7 \\
3.3 \\
5.9 \\
6.9 \\
6.8 \\
8.8 \\
10.4 \\
9.8 \\
10.7 \\
10.7 \\
11.1 \\
14.1 \\
15.2 \\
14.3 \\
17.5 \\
22.2 \\
21.1 \\
29.1 \\
31.8 \\
34.9 \\
33.8\end{array}$ & $\begin{array}{l}0.0 \\
0.0 \\
0.1 \\
0.1 \\
0.5 \\
0.6 \\
0.8 \\
1.6 \\
0.8 \\
1.6 \\
1.8 \\
2.0 \\
1.6 \\
0.5 \\
1.6 \\
2.8 \\
0.5 \\
2.7 \\
4.2 \\
3.1 \\
4.7 \\
2.1 \\
9.8\end{array}$ & $\begin{array}{r}74.2 \\
65.1 \\
26.6 \\
49.6 \\
5.7 \\
2.2 \\
13.1 \\
2.0 \\
20.1 \\
12.5 \\
6.9 \\
5.7 \\
5.6 \\
6.3 \\
11.7 \\
18.3 \\
0.4 \\
1.1 \\
0.5 \\
0.6 \\
1.9 \\
0.6 \\
0.5\end{array}$ & $\begin{array}{r}9.5 \\
8.4 \\
12.1 \\
9.1 \\
5.7 \\
6.2 \\
4.8 \\
1.6 \\
1.7 \\
2.1 \\
1.1 \\
2.4 \\
1.5 \\
1.6 \\
1.9 \\
2.2 \\
1.5 \\
2.1 \\
1.3 \\
1.9 \\
1.2 \\
1.2 \\
1.2\end{array}$ & $\begin{array}{r}15.5 \\
18.0 \\
15.2 \\
2.2 \\
10.5 \\
7.5 \\
10.9 \\
2.3 \\
1.8 \\
2.2 \\
1.4 \\
4.5 \\
2.6 \\
1.9 \\
2.9 \\
2.9 \\
2.3 \\
2.3 \\
1.2 \\
1.5 \\
1.9 \\
1.2 \\
1.7\end{array}$ & $\begin{array}{r}0.0 \\
7.6 \\
43.2 \\
35.2 \\
71.7 \\
8.8 \\
63.9 \\
7.5 \\
9.4 \\
6.3 \\
7.5 \\
13.8 \\
5.2 \\
6.4 \\
9.1 \\
3.5 \\
5.4 \\
3.6 \\
1.9 \\
2.9 \\
2.6 \\
1.4 \\
2.4\end{array}$ & $\begin{array}{r}0.0 \\
0.0 \\
0.0 \\
0.4 \\
0.0 \\
67.8 \\
0.4 \\
37.2 \\
23.2 \\
34.8 \\
13.3 \\
60.4 \\
3.6 \\
10.4 \\
15.0 \\
16.5 \\
46.2 \\
7.7 \\
1.9 \\
4.1 \\
1.8 \\
1.8 \\
1.6\end{array}$ & $\begin{array}{r}0.0 \\
0.0 \\
0.0 \\
0.0 \\
0.0 \\
0.0 \\
0.0 \\
38.9 \\
32.6 \\
30.7 \\
55.8 \\
0.5 \\
63.5 \\
54.9 \\
42.4 \\
38.3 \\
26.0 \\
56.3 \\
61.2 \\
55.3 \\
10.8 \\
13.6 \\
9.9\end{array}$ & $\begin{array}{c}0.0 \\
0.0 \\
0.0 \\
0.0 \\
0.0 \\
0.0 \\
0.0 \\
0.0 \\
0.0 \\
0.0 \\
1.4 \\
0.0 \\
5.3 \\
3.8 \\
0.0 \\
1.0 \\
0.0 \\
1.9 \\
6.5 \\
1.2 \\
43.3 \mathrm{~d} \\
43.1 \mathrm{~d} \\
40.0 \mathrm{~d}\end{array}$ & $\begin{array}{r}326 \\
291 \\
1068 \\
627 \\
1128 \\
2239 \\
1080 \\
1075 \\
1106 \\
1347 \\
1197 \\
1341 \\
1344 \\
1520 \\
1190 \\
1331 \\
2317 \\
1783 \\
1503 \\
1843 \\
1107 \\
1433 \\
1398\end{array}$ \\
\hline
\end{tabular}

${ }^{a}$ Based on the amount of activity recovered in the carcass and the urine.

$\mathrm{b}_{0.0}$ indicates activity in the feces is not significantly greater than the background.

$\mathrm{c}_{\text {Including all feces passed per anum. }}$

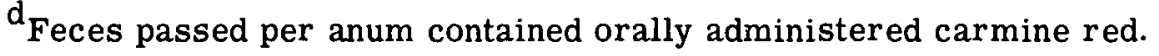




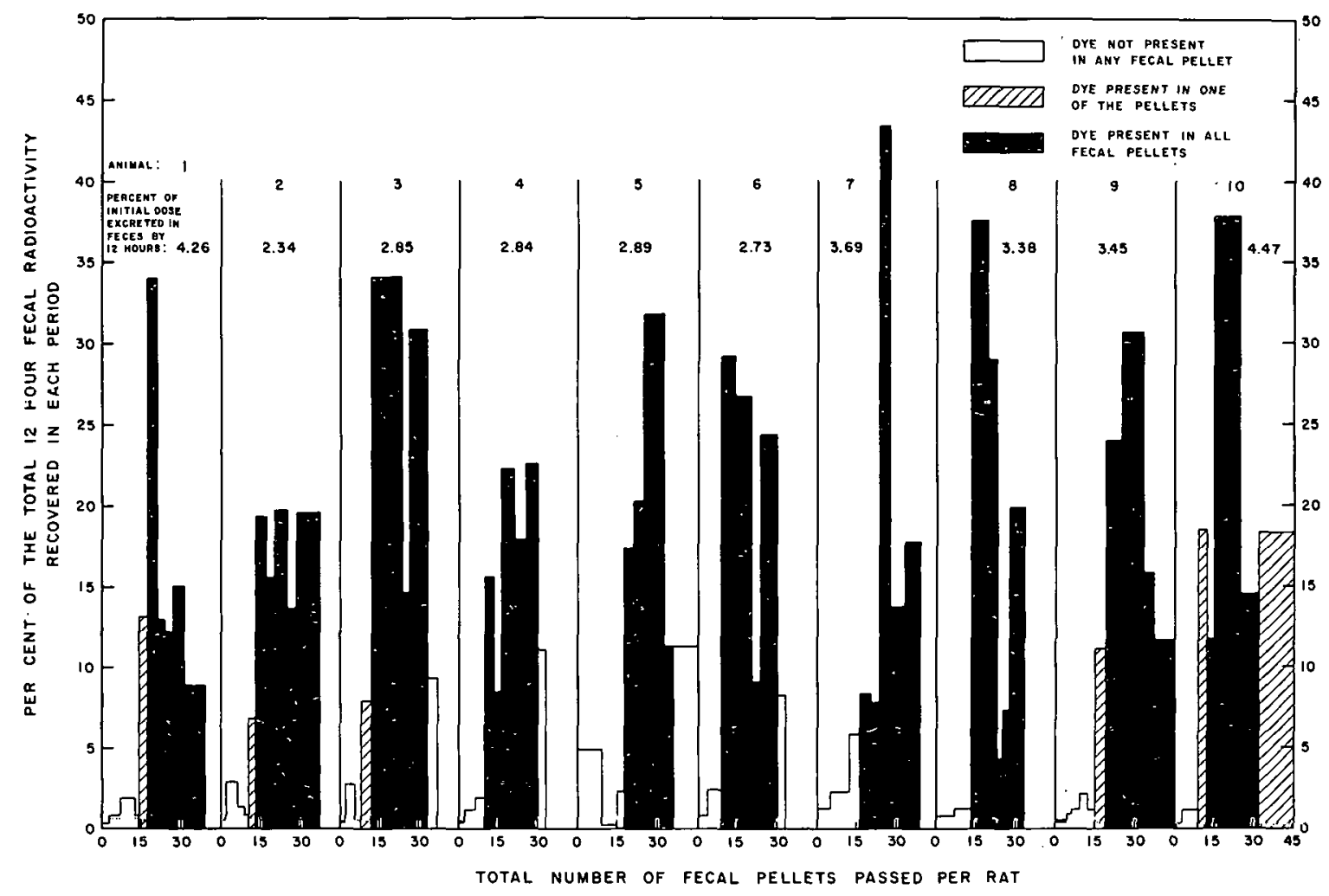

Figure 1. The initial 12 hour fecal excretion of intravenously injected $\mathrm{Mg}^{28}$ in 10 non-fasting rats. Each animal received carmine red po at the time of radioisotope injection. Each bar represents the radioactivity and number of pellets recovered in a 1 or 2 hour collection period. If only 1 pellet was passed, it was added to the next collection.

invariably (and usually abruptly) increased immediately before or with the appearance of the carmine red. Since the dye marked the location of food originally present in the stomach when the isotope was injected, most of the $\mathrm{Mg}^{28}$ recovered in the ileum and colon must have been excreted in the upper alimentary tract and distal to the stomach.

The concentrations of $\mathrm{Mg}^{28}$ in the material taken from the first $20 \mathrm{~cm}$ of the small intestine of animals slaughtered from 5 to 7 hours after injection must be viewed with reservation. Compared to the levels in the plasma and in the adjacent section of bowel, they would indicate that the magnesium content of the digestive fluids at that point was about 30 times greater than in the plasma and that a marked gradient of intraluminal activity was present which would not be anticipated from the previous absorption studies. The gradient may be partially explained by the dilution of relatively pure succus entericus from the proximal intestine in the lower segments of bowel by large amounts of gastric contents which tend to spurt in poorly mixed boli through the upper gut. As to the apparent high magnesium content of the intestinal fluids, $\mathrm{Mg}^{28}$ in the presence of small amounts of carrier magnesium rapidly penetrates the intracellular space when it is administered acutely in a single iv dose. ${ }^{1}$ Assuming that the isotope returns to the extracellular fluid at a slower rate than it originally entered the (mucosal) cells responsible for the enteric secretion of magnesium (reflecting preferential excretion into the bowel lumen), then these cells would act as temporary reservoirs of radiomagnesium of relatively high specific activity; and, until 


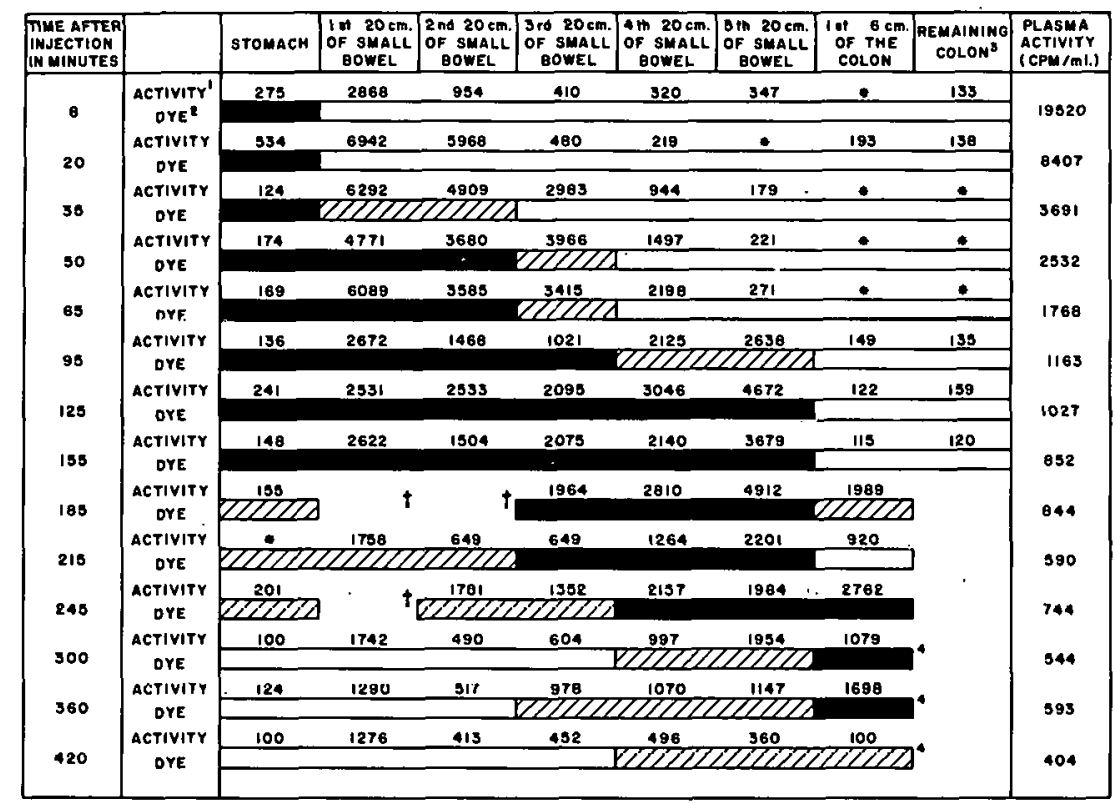

1. CPM PER 100 mgms. OF IntRaluminal CONTENT

2. LEQEND: "D NO CARMINE REO PRESENT IN CONTENTS OF INTESTINAL SEQMENT

एका $1^{+}$

3. COLLECTIONS DISCONTINUEO AFTER ISS MINUTES

4. FEces containino dYe passeo per anum

† contaminateo oy intestimal mucosa

* recovereo activity less than loo cpu pen loo mom intralunimal content

Figure 2. The site of the enteric excretion of intravenously administered $\mathrm{Mg}^{28}$ in the non-fasting rat. Each animal received carmine red po at the time of radioisotope injection.

equilibrium with the extracellular fluid was reestablished, their secretions would contain $\mathrm{Mg}^{28}$ in concentrations greatly exceeding the rapidly declining plasma levels.

\section{DISCUSSION}

The data from the first 2 experiments indicate that magnesium is absorbed throughout most of the intestinal tract of the non-fasting young rat and that the major site of absorption is probably in the first 6 to $8 \mathrm{~cm}$ of the colon. Part of these results are in agreement with a recent report ${ }^{3}$ that the transport of magnesium from the mucosal to the serosal surface of everted sacs of isolated rat intestine was quantitatively greater in segments taken from the ileum than from the jejunum. Among papers dealing with this aspect of magnesium absorption, ${ }^{4-10}$ only 2 provide evidence substantiating the importance of the large bowel. ${ }^{4,5}$ Symptoms of acute hypermagnesemia may occur in man after the rectal administration of hypertonic solutions of Epsom salts, 11-13 indicating that magnesium can be absorbed through the colon; however this absorption may be due to temporary alterations in the permeability of the colonic mucosa induced by intrinsic disease and/or massive amounts of $\mathrm{MgSO}_{4}$. While aging has been associated with quantitative changes in magnesium uptake, ${ }^{4,14}$ a significant alteration in the pattern of absorption in rats with maturation seems unlikely in view of the similarity in retention of orally administered $\mathrm{Mg}^{28}$ between young and older animals. 1 
On the other hand, the principal site of intestinal excretion of endogenous magnesium seems to be located in the upper gastrointestinal tract. The early appearance and rapid rise of radioactivity in the contents of the first 20 to $40 \mathrm{~cm}$ of the small bowel indicate the importance of the duodenal and jejunal mucosa in the excretion of magnesium. In this regard, Ross' observation ${ }^{3}$ that magnesium continued to be lost from the serosal solution of everted sacs of upper jejunum taken from the rat despite large concentrations of the cation in the mucosal solution is of interest. Due to the paucity of available information, the relative contributions made by the liver and the pancreas cannot be assessed with any degree of certainty. To our knowledge, there are no published data on the concentration of magnesium in the digestive fluids of the rat; and the limited data from other species ${ }^{15,17}$ are too variable to permit generalizations. In man, intravenously administered $\mathrm{Mg}^{28}$ has been recovered in the bile. ${ }^{15}$ While requiring further verification, preliminary experiments in rats suggest that the amount of magnesium lost through the biliary tract is not quantitatively significant. 18

\section{ACKNOWLEDGMENT}

The technical assistance of Mrs. Lucille Penas and the valuable suggestions and critical review of this work by Dr. R. J. Hasterlik, Professor of Medicine, the University of Chicago, are gratefully acknowledged. The Dunnett $T$ test analysis digital computer program was designed by Mr. Richard Blough of the Biological Sciences Computation Center of the University of Chicago supported by USPH Grant FR-00013-01.

\section{LITERATURE CITED}

1. Chutkow, J. G. J. Lab. and Clin. Med., 63:80, 1964.

2. Snedecor, G. W. Statistical Methods Applied to Experiments in Agriculture and Biology, ed. 5, Ames, 1956, Iowa State College Press.

3. Ross, D. B. J. Physiol., 106:417, 1962.

4. Smith, R. H. Nature, 184:821, 1959.

5. Watchorn, E. J. Hyg., 32:156, 1932.

6. Aikawa, J. K., E. L. Rhoades, and G. S. Gordon. Proc. Soc. Exptl. Biol. and Med., 98:29, 1958.

7. Aikawa, J. K. Proc. Soc. Exptl. Biol. and Med., 100:293, 1959.

8. Terkildsen, T. C. Acta Pharmacol. Toxicol., 8:374, 1952.

9. Graham, L. A., J. J. Caesar, and A. S. V. Burgen. Metabolism, 9:646, 1960.

10. Nicolaysen, R. Skand. Arch. Physiol., 73:75, 1936.

11. Fawcett, D. W., and J. P. Gens. J. A. M. A., 123:1028, 1943.

12. Collins, E. N., and P. W. Russell. Cleveland Clin. Quart., 16:162, 1949.

13. Stevens, A. R., Jr., and H. G. Wolff. Arch. Neurol. Psychiat., 63:749, 1950.

14. Ross, D. B. Nature, 189:840, 1961.

15. Altman, P. L., and D. S. Dittmer. Blood and Other Body Fluids, Washington, D.C., 1961, Federation of American Societies for Experimental Biology. 
16. Aikawa, J. K. Second United Nations International Conference on The Peaceful Uses of Atomic Energy, Vol. 24, Part 1, Isotopes in Biochemistry and Physiology, Geneva, 1958, United Nations, p. 148.

17. De Beer, E. J., G. G. Johnston, and P. W. Wilson. J. Biol. Chem., 108:113, 1935.

18. Chutkow, J. G. Unpublished data.

19. Dunnett, C. W. J. Am. Stat. Assn., 50:1096, 1955. 


\title{
IN VITRO STUDIES ON THE EFFECT OF ERYTHROPOIETIN \\ ON GLUCOSAMINE-1-C ${ }^{14}$ INCORPORATION INTO RAT BONE MARROW CELLS
}

By

\author{
P. P. Dukes, F. Takaku, ${ }^{\dagger}$ and E. Goldwasser
}

Whilc the action of the livinume, erythrupoietin, is known to result in an increased number of red cells in vivo, ${ }^{1}$ little is understood concerning the chemical mechanisms underlying this process. The difficulties of investigating, in vivo, the details of the chemical processes are obvious and several reports of attempts to study erythropoietin action in vitro have recently appeared. $^{2-7}$ In general either morphological criteria or the incorporation of hemoglobin precursors have been used as indices of hormone action. In this communication we have investigated the possiblility that an early effect of erythropoietin might be seen if the biogenesis of the substances composing the red cell stroma were studied. Our results show that erythropoietin stimulates the incorporation of glucosamine-1- $\mathrm{C}^{14}$ into the structural material of marrow cells maintained in culture. The chemical characterization of the labeled materials derived from such cells is, however, not yet complete. A preliminary report of some of these findings has been published. ${ }^{8}$

\section{MATERIALS AND METHODS}

Marrow was aspirated from the femora and tibiae of male Sprague-Dawley rats weighing approximately $200 \mathrm{~g}$. Fxcept where otherwise indicated, cells were suspended in a medium consisting of 50 per cent NCTC 199 (Microbiological Associates) ${ }^{\ddagger}$ and 50 per cent unfiltered calf serum (Colorado Serum Co.) previously incubated at $56^{\circ}$ for $30 \mathrm{~min}$, and containing in addition 40 units of penicillin G, $25 \mu \mathrm{g}$ of streptomycin and $0.02 \mu$ moles of D-glucosamine-1-C ${ }^{14}(5.1 \mathrm{mc}$ per mmole) (New England Nuclear Corp.) per ml. Where indicated, other materials than water were used to dilute the 10 -fold concentrated NCTC 199 medium to the normal concentration. The pH of the complete medium was adjusted to $7.3-7.4$ by addition of 10 per cent $\mathrm{NaHCO}_{3}$. Incubation of the cells was carried out in replicate at $37^{\circ}$ in stationary $12 \mathrm{ml}$ stoppered, Pyrex heavy-walled, centrifuge tubes containing $2 \mathrm{ml}$ of the cell suspension. A jet of a mixture of 95 per cent air and 5 per cent $\mathrm{CO}_{2}$ was directed over the surface of the cell suspension for $1 \mathrm{~min}$ before stoppering. In some experiments the tubes were covered with sterile gauze and incubated in a continuous flow of gas mixture.

After incubation the cells were centrifuged at $4^{\circ}$ for $5 \mathrm{~min}$ at $400 \mathrm{xg}$ and washed twice with cold, isotonic saline, the supernatant fluid being discarded. After resuspension of the pellet in 1 $\mathrm{ml}$ of saline, the acid insoluble fraction was precipitated by addition of $1 \mathrm{ml}$ of cold 10 per cent

\footnotetext{
This report is taken from a paper that appeared in Endocrinology, 74:960, 1964.

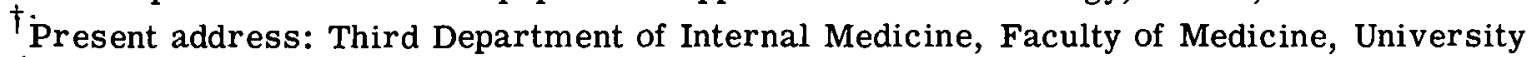
of Tokyo, Hongo, Tokyo, Japan.

$¥$ For detailed composition, see Reference 17.
} 
TCA. ${ }^{*}$ One hour later the precipitate was collected in an ice bath, washed twice with 5 per cent TCA, with ethanol, and with ethanol:ether (1:1). The washed precipitates were plated on weighed stainless steel planchets, either as suspensions in ethanol or dissolved in performic acid (formic acid: 30 per cent $\mathrm{H}_{2} \mathrm{O}_{2} 5: 1 \mathrm{v} / \mathrm{v}$ ). In both cases the results were the same and the latter procedure was therefore generally used since it was easier to get a homogeneous layer with it. Samples were counted in a thin-window, low background Tracerlab Omniguard counter, and results are expressed as counts per min per mg of dry weight of residue.

Erythropoietin was supplied by the Hematology Study Section of the United States Public Health Service and used either as the crude step III preparation (lot 137) or as the more highly purified fractions derived from similar preparations. ${ }^{9}$ All preparations were assayed in vivo as described earlier, ${ }^{10}$ using the unit previously defined. ${ }^{11}$

Sialic acid was determined by the Mauzerall and Granick modification of the direct Ehrlich reaction. ${ }^{12}$ Chromatography of sialic acids N-acetyl-neuraminic acid (NAN) and N-glycolyl-neuraminic acid (NGN) was done on Whatman No. 3 MM paper in Svennerholm's solvent system

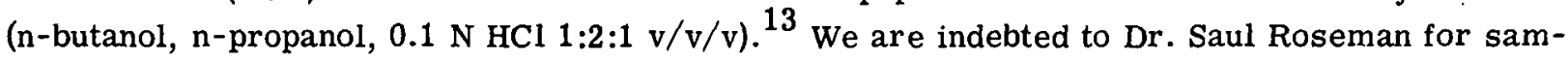
ples of NAN and NGN.

\section{RESULTS}

The effect of erythropoietin upon glucosamine uptake by marrow cells incubated in several media was tested under both conditions of gassing (see Methods). The greatest stimulation by erythropoietin (Table 1) was found when medium 199 and inactivated calf serum were present and this combination was used in subsequent experiments.

In vitro rat marrow cells incorporate glucosamine-1-C ${ }^{14}$ into the acid insoluble fraction continuously for at least $24 \mathrm{hr}$ at an increasing rate. ${ }^{8}$ When erythropoietin is added to the culture medium there is a significant stimulation of incorporation. The difference between the time courses of the stimulated and control samples is linear with time and can be extrapolated to zero effect of the hormone at about $2.5 \mathrm{hr}$. The results of a short incubation experiment are shown in Figure 1. Repeated experiments with varying times of incubation have always given the same result: stimulation of glucosamine incorporation begins between 2 and $3 \mathrm{hr}$ after the cells have been exposed to exogenous erythropoietin.

In studying the effect of 0.5 units of erythropoietin, pools of residues from control and stimulated cultures were prepared after $24 \mathrm{hr}$ of incubation with glucosamine. Each pool was divided into two, one half being used to determine the total radioactivity and weight. The control aliquot contained $2400 \mathrm{cpm}$ in $470 \mu \mathrm{g}$, and the stimulated aliquot was $4170 \mathrm{cpm}$ in $510 \mu \mathrm{g}$. The remaining half-samples were hydrolyzed for $2 \mathrm{hr}$ at $80^{\circ}$ in $3 \mathrm{ml}$ of $0.05 \mathrm{~N} \mathrm{H}_{2} \mathrm{SO}_{4}$ according to the procedure of Gottschalk. ${ }^{14}$ The control sample had 56.4 per cent of its radioactivity solubilized by this procedure, while for the stimulated sample the value was $\mathbf{5 5 . 2}$ per cent. The ratio of stimulated to control radioactivity was 1.74 in the unhydrolyzed sample and 1.71 in the solubilized hydrolyzate, reflecting similar effects of the hormone in both the solubilized and the insoluble fractions.

This acid-insoluble fraction contains about one-half of the total radioactivity of the cells. The washed residue of water-lysed marrow cells (stroma) similarly contains about one-half of the original counts. While the acid-insoluble fraction contains more of the cellular material than does the stroma preparation, it contains the stroma-material as well. We have used the acid precipitation technique in order to avoid using large volumes of liquid. 
Table 1 .

COMPARISON OF MEDIA AND CULTURE CONDITIONS

\begin{tabular}{l|c|c|c}
\hline \multicolumn{1}{c|}{$\begin{array}{l}\text { Medium and incubation } \\
\text { procedure }\end{array}$} & \multicolumn{2}{|c|}{$\begin{array}{c}\text { Specific activity, } \\
\text { cpm per mga }\end{array}$} & $\begin{array}{c}\% \\
\text { increase }\end{array}$ \\
\cline { 2 - 3 } & Control & Erythropoietin & \\
\hline $\begin{array}{l}50 \% 19950 \% \text { rat plasma, } \\
\text { continuous gassing }\end{array}$ & 2780 & 3710 & 33 \\
$\begin{array}{l}\text { 60\% 100 60\% fetal calf } \\
\text { serum, closed tubes }\end{array}$ & 1305. & $\cdots$ & 6 \\
$\begin{array}{l}50 \% 19950 \% \text { calf serum, } \\
\text { closed tubes }\end{array}$ & 1690 & 3230 & 91 \\
$\begin{array}{l}50 \% 19950 \% \text { calf serum, } \\
\text { continuous gassing }\end{array}$ & 4090 & 7125 & 74 \\
$\begin{array}{l}50 \% 10950 \% \text { calf serum, } \\
\text { closed tubes }\end{array}$ & 3380 & 6165 & 83 \\
$\begin{array}{l}\text { 60\% 109 40\% rat plasma, } \\
\text { continuous gassing }\end{array}$ & 2530 & 2865 & 13 \\
\hline
\end{tabular}

${ }^{\mathrm{a}}$ All values are means of at least. 2 determinations.

${ }^{b}$ Bottom row 0.4 units per $\mathrm{ml}$, all others 0.5 units per $\mathrm{ml}$.

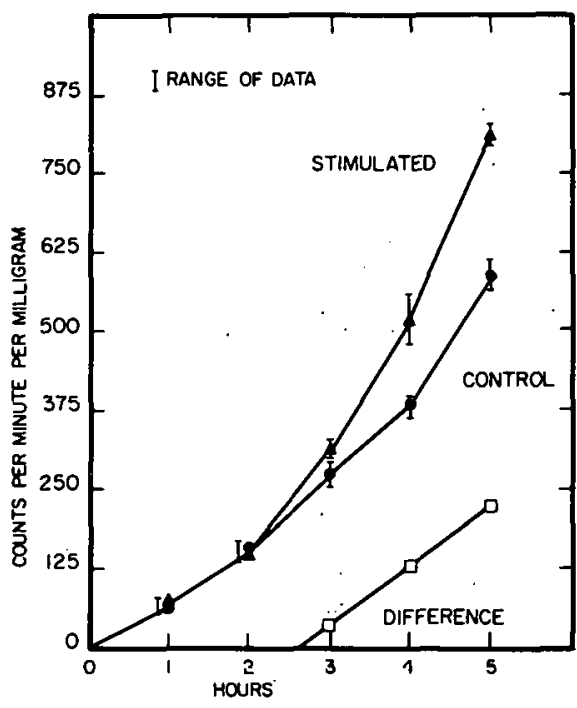

Figure 1. Effect of erythropoietin on the time course of glucosamine uptake into bone marrow cells in culture. The stimulated cultures had 0.25 units of erythropoietin per ml present.

The combined supernatant fractions were reduced to a small volume in a flash evaporator and the acid removed with the liquid cation exchanger Amberlite LA-2. No radioactivity was transferred to the LA-2 layer. Portions of the two hydrolyzates were chromatographed along 
with indicator spots of glucosamine, NAN, and NGN, with the results shown in Figure 2. The distribution of radioactivity was similar in the control and stimulated materials; NAN and NGN accounted for 45 - 50 per cent of the total radioactivity applied to the paper, and represented about 27 per cent of the total residue radioactivity, while the origin of the chromatogram accounted for 37 per cent of the applied radioactivity, or 21 per cent of the total residue counts.

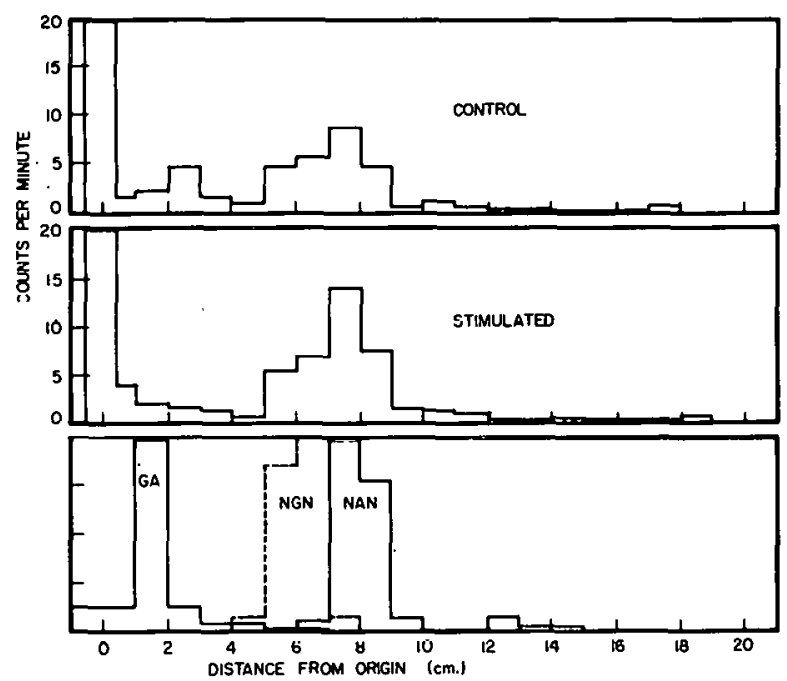

Figure 2. Paper chromatography of compounds solubilized from marrow cell residue (see Text) with $0.05 \mathrm{~N} \mathrm{H}_{2} \mathrm{SO}_{4}$ at $80^{\circ}$. Ref erence spots: $\mathrm{GA}=$ glucosamine, $\mathrm{NGN}=\mathrm{N}-\mathrm{glycolyl}$ neuraminic acid and NAN - N-acetyl neuraminic acid. The bottom chromatogram indicates the position of the indicator compounds based on colorimetric determinations. Amounts are expressed in arbitrary units on the ordinate.

The relationship between amount of erythropoietin and response of the cells, in terms of increase in specific activity of the residue over the control value, was an S-shaped curve typical of hormone effects when plotted on arithmetic coordinates. A plot of response against logarithm of the dose yielded the expected straight line over most of the range of response. At low doses, however, the response fell off markedly. When Step III erythropoietin was used, the response leveled off in the high dose region, actually showing a depression as dose was increased. This effect was probably due to the presence of an inhibitory material in the Step III preparation as will be shown below. To compensate for variations from experiment to experiment, we have expressed glucosamine incorporations as per cent change from the specific activity of the control samples done at the same time. The log dose-response curves shown in Figure 3 present the data so expressed from a large number of different experiments. When incubation was done in the closed tube system the response remained linear with $\log$ of dose up to about $0.75-1.0$ units of erythropoietin per ml.

While this type of incubation is useful because of the long linear region of the log-dose response curve it is definitely sub-optimal. When the incubations were done in loosely covered tubes with continuous gassing, the linear region of the curve extended only to about $0.3-0.4$ units per $\mathrm{ml}$, but the specific activities of both control and stimulated samples were considerably higher than with the closed system. This effect is probably due to better $\mathrm{pH}$ control. In spite 


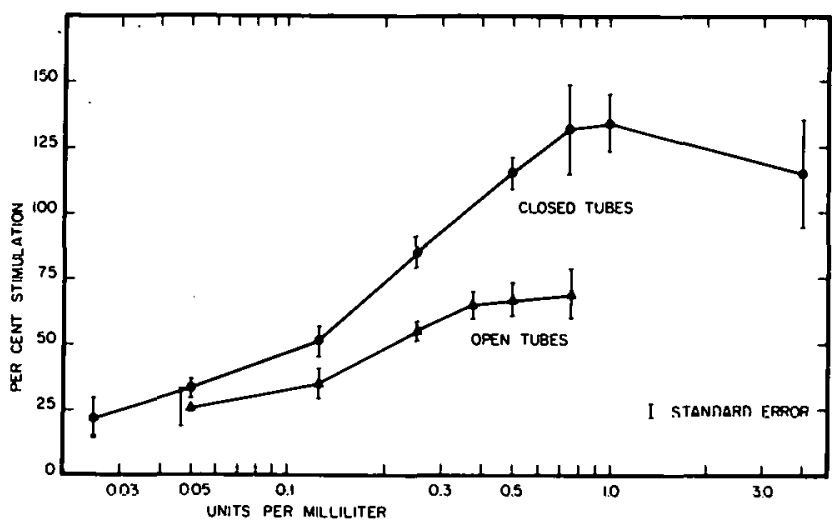

Figure 3. Relationship of amount of Step III erythropoietin to glucosamine uptake into residue fraction of rat marrow cells. Difference from control specific activity is expressed as per cent stimulation.

of this, the effect of erythropoietin, expressed as per cent increase in specific activity, was greater in the closed tube system.

In order to demonstrate that erythropoietin, and not some other material purified along with it, was responsible for the observed stimulation of glucosamine uptake, erythropoietin preparations of differing degrees of purity were compared in vitro. The relationship of these preparations, their potencies (units per $\mathrm{mg}$ ) when assayed in vivo, and abbreviations for them are shown in Table 2. Details of unitage and methods of preparation of these fractions have been published

Table 2

IN VIVO POTENCY OF ERYTHROPOIETIN PREPARATIONS USED IN VITRO

\begin{tabular}{|c|c|c|}
\hline Fraction & Description & $\begin{array}{c}\mathrm{u} / \mathrm{D} \mathrm{U} \text { protein } \\
\text { in vivo }\end{array}$ \\
\hline A & Step III (Lot 137) standard & 7.3 \\
\hline $\mathbf{B}$ & 0.53 saturated $\left(\mathrm{NH}_{4}\right)_{2} \mathrm{SO}_{4} \mathrm{pH} 6.3$ precipitate of Step III & 4.7 \\
\hline $\mathrm{C}$ & $\begin{array}{l}\text { Step IV }=0.67 \text { saturated }\left(\mathrm{NH}_{4}\right)_{2} \mathrm{SO}_{4} \mathrm{pH} 3.3 \text { precipitate } \\
\text { of Step III }\end{array}$ & 11.0 \\
\hline $\mathrm{D}$ & Supernatant of Step IV & 1.3 \\
\hline $\mathbf{E}$ & $\begin{array}{l}\text { Step } V=\text { third supernatant from calcium phosphate gel } \\
\text { fractionation of active peak material from Bio-Rex } 70 \\
\text { fractionation of "Supernatant of Step IV" }\end{array}$ & 216 \\
\hline $\mathbf{F}$ & Highest purified fraction derived from Step $\mathrm{V}$ & 910 \\
\hline
\end{tabular}

$\mathrm{a}_{1} \mathrm{D} U$ defined as $\mathrm{A}_{280}$ in $1 \mathrm{ml}$ with $1 \mathrm{~cm}$ lightpath is approximately equivalent to $1 \mathrm{mg}$ protein for the above samples.

previously. ${ }^{9}$ A dose-response curve for each of these fractions is shown in Figure 4: it is readily apparent that they differ greatly. Only fraction C (Step IV) shows an unbroken linear response 


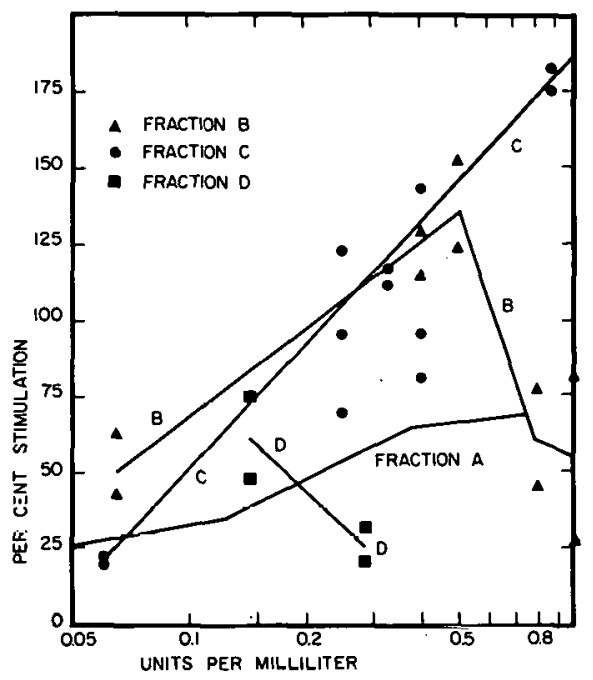

Figure 4. Comparison of dose response curves of various erythropoietin preparations. All incubations were done in open tubes. Fractions are defined in Table 2. For standard error of curve a (Step III) see Figure 3. The indicated points are actual experimental values.

up to 0.9 units per $\mathrm{ml}$. All the other preparations were inhibitory at amounts well below that level. The comparison of potencies of the fractions described in Table 2 should therefore be based only on the lower part of the dose range where little or no depression is apparent. These fractions, although most of them contained an inhibitor of some kind, had a potency about 40 per cent of that expected from their assay in vivo (see also Table 3 ). Since fraction $D$ contained the highest inhibitory activity it was not surprising that even highly purified erythropoietin fractions derived from it also showed diminished activity in vitro (Table 3 ).

The data in Table 3 illustrate our observation that both fractions $A$ and $F$ contain an inhibitory component. When fraction $A$ at a concentration of 0.12 units per $\mathrm{ml}$ is combined with fraction $F$ at a concentration of 0.25 units per $\mathrm{ml}$ (both activities being based on assay in vivo) the effect on the marrow cells is not quite additive. That is, the added 0.12 units of fraction $A$ is not completely expressed. When, however, the concentration of fraction $A$ was increased to 0.25 units per $\mathrm{ml}$, there was a very pronounced depression of the in vitro effect, resulting in essentially no stimulation of incorporation.

This inhibitory material is confined not only to fractions derived from anemic plasma. A preparation of Step $\mathrm{I}^{11}$ from normal sheep plasma also caused a depression of glucosamine incorporation when tested in the presence of fraction $F$, but when assayed alone was neither inhibitory nor stimulatory (Tables 4 and 5 ).

When unfractionated anemic plasma was tested (since anemic sheep plasma was no longer available, rat plasma was used), its activity in vitro was essentially as predicted from the in vivo assay. 
Table 3

ACTIVITY OF PARTIALLY PURIFIED PREPARATIONS IN VITRO

\begin{tabular}{|c|c|c|c|c|}
\hline Preparation & $\begin{array}{c}\text { Units per ml } \\
\text { based on } \\
\text { in vivo assay }\end{array}$ & $\begin{array}{l}\text { Mean difference of } \\
\text { specific activity } \\
\text { cpm per mg expressed } \\
\text { as \% of control }\end{array}$ & $\begin{array}{l}\text { Units per ml detected } \\
\text { in vitro based on } \\
\text { Step III dose } \\
\text { response curve }\end{array}$ & $\begin{array}{l}\% \text { of full } \\
\text { in vivo } \\
\text { activity }\end{array}$ \\
\hline $\begin{array}{l}\text { Fraction } \mathrm{E}^{\mathrm{a}} \\
\text { (Step V) }\end{array}$ & $\begin{array}{l}0.375 \\
0.75\end{array}$ & $\begin{array}{l}45 \\
79\end{array}$ & $\begin{array}{l}0.09 \\
0.23\end{array}$ & $\begin{array}{l}24 \\
31\end{array}$ \\
\hline Fraction $F$ & $\begin{array}{l}0.2 \\
0.35 \\
0.4 \\
0.7 \\
1.75\end{array}$ & $\begin{array}{l}13 \\
55 \\
56 \\
91 \\
86\end{array}$ & $\begin{array}{l}0.03 \\
0.14 \\
0.14 \\
0.3 \\
0.27\end{array}$ & $\begin{array}{l}-\mathrm{b} \\
40 \\
35 \\
43 \\
15^{b}\end{array}$ \\
\hline $\begin{array}{c}\text { Fraction F } \\
+0.125 \mathrm{u} \\
\text { Step III }\end{array}$ & $0.25(+0.125)$ & 89 & $0.24-0.125=0.115$ & 46 \\
\hline $\begin{array}{l}\text { Fraction F } \\
+0.25 \mathrm{u} \\
\text { Step III }\end{array}$ & $0.25(+0.25)$ & 26 & $0.03-0.25=0$ & $0^{c}$ \\
\hline
\end{tabular}

${ }^{\mathrm{a}}$ For nomenclature, see Table 2.

${ }^{\mathrm{b}}$ Probably outside of logarithmic response range.

${ }^{c}$ Eliminated $88 \%$ of added Step III activity.

Table 4

ASSAY IN VITRO OF PREPARATIONS DERIVED FROM NORMAL PLASMAS

\begin{tabular}{|c|c|c|}
\hline Preparation & Amount mg per ml & $\begin{array}{l}\text { Mean change of specific } \\
\text { activity cpm per mg as } \\
\text { expressed as } \% \\
\text { of control }\end{array}$ \\
\hline $\begin{array}{l}\text { Normal sheep Step Ia obtained } \\
\text { from normal sheep plasma by the } \\
\text { same procedure as erythropoietin } \\
\text { in Step I }\end{array}$ & $\begin{array}{l}0.1 \\
0.5 \\
1.0\end{array}$ & $\begin{array}{r}-12 \\
15 \\
-10\end{array}$ \\
\hline $\begin{array}{l}\text { Normal human plasma }{ }^{b} \text { fraction } \\
\text { VI according to Cohn }\end{array}$ & 0.5 & 1 \\
\hline
\end{tabular}

${ }^{\mathrm{a}} 0.006$ units erythropoietin per $\mathrm{mg}$ in the in vivo rat assay.

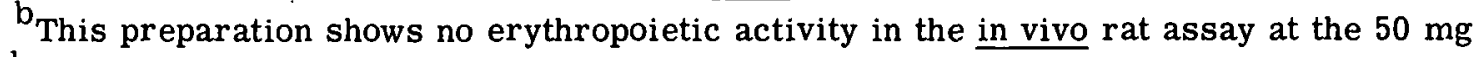
level. 
Table 5

\section{DEPRESSION OF GLUCOSAMINE UPTAKE BY THE COMBINED ACTION OF HIGHLY PURIFIED ERYTHROPOIETIN AND MATERIAL PREPARED FROM NORMAL SHEEP PLASMA}

\begin{tabular}{c|c|c}
\hline $\begin{array}{c}\text { Fraction F (see } \\
\text { Table 3) in vivo } \\
\text { units per mI }\end{array}$ & $\begin{array}{c}\text { Step I from normal } \\
\text { sheep (see Table 4) } \\
\text { mg per ml }\end{array}$ & $\begin{array}{c}\text { Mean change of } \\
\text { specific activity } \\
\text { cpm per mg } \\
\text { expressed as } \\
\text { \% control }\end{array}$ \\
\hline 0.25 & 0.1 & +4 \\
0.5 & 0.1 & -8 \\
0.25 & 1.0 & -33 \\
0.5 & 1.0 & -57 \\
\hline
\end{tabular}

\section{DISCUSSION}

The substance responsible for increased glucosamine incorporation into rat marrow cell stroma seems to be erythropoietin for the following reasons:

Preparations of erythropoietin with potencies ranging from 1 to 900 units per $\mathrm{mg}$ of protein, and crude anemic plasma ( 0.07 units per mg protein) are stimulatory. There is a rough correspondence between potency as determined by assay in vivo and activity in vitro. If erythropoietin and the glucosamine incorporating factor were different, they would have to be present in a relatively constant ratio in the fractions which represent a 10,000-fold range in potency. The absence of a stimulatory factor in the Step I fraction derived from normal plasma also supports this argument.

The dose response curve obtained for Step III erythropoietin seems to consist of 3 parts: the first shows a gradual increase; the second represents a logarithmic function of the dose up to a maximal dose, the magnitude of which is essentially dependent on the incubation conditions with other variables held constant; the third shows a depression. The first part of the curve seems to represent the range of erythropoietin concentrations in which the probability of successful encounters between hormone molecules and target cells is only slightly enhanced by an increase in erythropoietin concentration. This is followed by a region where a small change in erythropoietin concentration causes a large increase in response: after this middle region, the effect of increasing concentration falls off, probably due to the paucity of free target cells available for the extra number of hormone molecules. The last two regions constitute the logarithmic part of the curve.

The linear increase over control of the labeled product with time, which starts approximately $2.5 \mathrm{hr}$ after the introduction of erythropoietin allows the following conclusions: 1) Glucosamine uptake is a relatively fast indicator of erythropoietin action. 2) During the lag period (the first $2.5 \mathrm{hr}$ ) a fixed amount of synthetic capacity is formed which leads to increased glucosamine incorporation into the cell stroma. Otherwise, it would be necessary to postulate a complex equilibrium with some feedback inhibition in order to account for the fact that the labeled product is 
not formed at a rate which increases with time. 3) The erythropoietin exerts its effect for a limited period; since if some cells were stimulated much later than at zero time, the increment curve should again deviate from linearity. We have evidence that cells which are subjected to exogenous erythropoietin $8 \mathrm{hr}$ after the culture was started are still capable of being stimulated. The possibility remains, however, that the number of susceptible cells declines as a consequence of exposure to impure erythropoietin preparations. The disappearance of erythropoietin in the cultures due to either specific removal or nonspecific breakdown may also play a role in limiting the action of the hormone.

The marrow cell culture system compares favorably with the most sensitive in vivo assay for erythropoietin. Incorporation of radioiron into red cells of the polycythemic mouse ${ }^{15}$ and the incorporation of glucosamine by cells in vitro can both detect 0.05 units of hormone. The in vitro system described by Krantz et al. ${ }^{7,16}$ which measures the effect of erythropoietin on the rate of heme synthesis also has about the same order of sensitivity.

The existence of an inhibitory component in erythropoietin containing fractions of plasma makes it necessary to interpret in vitro experiments with great caution, especially when quantitative information is needed. Fractions derived from the same parent material (Step III erythropoietin), depressed incorporation at different dose levels. Fraction C (Step IV erythropoietin) showed no inhibition within the range tested, while fraction $D$ inhibited at the lowest level tested, and fraction $\mathrm{B}$ seemed to have less inhibitor than the starting material. These data suggest that the inhibitor has been concentrated in the supernatant fraction and that its effect becomes apparent only after a threshold value is exceeded. In the experiment cited in Table 4, fractions A and $F$ were at concentrations high enough to exceed any presumed threshold. The data clearly show; however, that the inhibitory materials do not increase proportionately with increase in erythropoietin activity, since Fraction $D$ with a low potency had the highest amount of inhibitor per unit. It is still possible that the effects are not restricted to those cells which respond to erythropoietin but might well represent a general type of inhibition of all the cells in the culture.

The data accumulated on the chemical identity of the labeled cellular materials are still far from a complete characterization. The complexities of the structures of the red cell stroma and: the difficulties inherent in working with mixed populations of cells make it clear that the complete analysis of the insoluble residue may be a very long process. About one-fourth of the glucosamine which has been incorporated into the structural material, however, has been accounted for as sialic acids of both the $\mathrm{N}$-acetyl and $\mathrm{N}$-glycolyl types, which are easily hydrolyzed off the insoluble stroma material.

The chief value of the system described here, seems to lie in its potential as a tool for studying the mode of action of erythropoietin on a cellular level. Other processes such as morphological changes resulting from erythropoietin action are without doubt much farther removed from the primary events by which erythropoietin may initiate the development of erythroid cells from their primitive precursors. We hope to use this system to study the appearance of those enzymes responsible for the conversion of free glucosamine to structural polysaccharide components under the initiating influence of erythropoietin. 


\section{LITERATURE CITED}

1. Gordon, A. S., S. J. Piliero, W. Kleinberg, and H. M. Freedman. Proc. Soc. Exptl. Biol. Med., 86:255, 1954.

2. Rosse, W. F., and C. W. Gurney. J. Lab. Clin. Med., 53:446, 1959.

3. Matoth, Y, and L. Kaufman. Blood, 20:165, 1962.

4. Erslev, A. J. Proc. Soc. Exptl. Biol. Med., 110:615, 1962.

5. Powsner, E. R., and L. Berman. In Jacobson, L. O., and M. Doyle (eds.). Erythropoietin, New York, Grune and Stratton, Inc., 1962, p. 286.

6. Korst, D. R., E. P. Frenkel, and J. E. Wilhelm. In Jacobson, L. O., and M. Doyle (eds.). Erythropoietin. New York, Grune and Stratton, Inc., 1962, p. 310.

7. Krantz, S. B., O. Gallien-Lartigue, and E. Goldwasser. Fed. Proc., 22:410, 1963 (Abstract).

8. Dukes, P. P., F. Takaku, and E. Goldwasser. Biochem. Biophys. Res. Commns., 13:223, 1063.

9. Goldwasser, E., W. F. White, and K. B. Taylor. Biochim. Biophys. Acta, 64:487, 1962.

10. Fried, W., L. F. Plzak, L. O. Jacobson, and E. Goldwasser. Proc. Soc. Exptl. Biol. Med., $94: 237,1957$.

11. White, W. F., C. W. Gurney, E. Goldwasser, and L. O. Jacobson. Recent Progr. Hormone Res., 16:219, 1960.

12. Mauzerall, D., and S. Granick. J. Biol. Chem., 219:435, 1956.

13. Svennerholm, E., and L. Svennerholm. Nature, 181:1154, 1958.

14. Gottschalk, A., and E. R. B. Graham. Biochim. Biophys. Acta, 34:380, 1959.

15. DeGowin, R. L., D. Hofstra, and C. W. Gurney. Proc. Soc. Exptl. Biol. Med., 110:48, 1962.

16. Krantz, S. B., O. Gallien-Lartigue, and E. Goldwasser. J. Biol. Chem., 238:4085, 1963.

17. Morgan, J. F., H. J. Morton, and R. C. Parker. Proc. Soc. Exptl. Biol. Med., 73:1, 1950 


\title{
IN VITRO STUDIES OF CELL TYPES RESPONSIVE TO ERYTHROPOIETIN ${ }^{*}$
}

By

\author{
F. Takaku, ${ }^{\dagger}$ P. P. Dukes and E. Goldwasser
}

In a previous paper ${ }^{1}$ we have demonstrated that sheep plasma erythropoietin preparations can cause significant increases in the incorporation of glucosamine-1- $\mathrm{C}^{14}$ into a fraction of rat marrow cells that resembles red cell stroma. Comparison of the effects of anemic plasma and of several partially purified fractions of erythropoietin suggested that this effect was most probably due to the hormone itself rather than to another factor. In this report we will present data accumulated in an attempt to identify those marrow cells that are responsive to erythropoietin.

\section{MATERIALS AND METHODS}

Bone marrow cells were collected from rats as already described. ${ }^{1}$ Rat white cells were obtained by washing out the peritoneal cavity with physiological saline according to the method of Gordon. ${ }^{2}$ Mice were made polycythemic by the intraperitoneal injection of washed homologous red cells, ${ }^{3}$ and their spleens were teased aseptically in the incubation medium to provide a cell suspension. Rats starved for 4 days were the source of marrow cells with a reduced percentage of normoblasts, while rats hemolyzed with phenylhydrazine were the source of hyperplastic marrow. The neutralized phenylhydrazine $(9.6 \mathrm{mg}$ per rat) was injected on the first and third days and the marrow was collected on the sixth day. Marrow from rats exposed to $600 \mathrm{r}$ total-body dose of $x$ rays (250 KVP, $0.5 \mathrm{~mm}$ Cu plus $1 \mathrm{~mm} \mathrm{Al,} 95 \mathrm{~cm}$ target distance) was collected 4 days after irradiation.

The cells, which were collected under sterile conditions, were incubated in the medium used previously at $37^{\circ}$ in horizontal gauze covered tubes (the open method described in Reference 1) exposed to a continuous gas flow. After incubation the cells were collected by centrifugation, washed free of unincorporated glucosamine and the residues prepared as already described.

Separation of cells by centrifugation in a density/viscosity gradient was modified from the method of Goodman. ${ }^{4}$ Normal rat marrow cells were washed once with sterile saline and resuspended in 14 times their volume of 5 per cent polyvinyl pyrollidone (PVP) ${ }^{\ddagger}$ in saline containing 0.2 per cent methylcellulose. This suspension was carefully layered over $32 \mathrm{ml}$ of a solution of PVP, which had a linear concentration gradient ranging from 25 per cent at the bottom to 5 per cent at the top, in a $40 \mathrm{ml}$ lusteroid tube. The concentration of methylcellulose was kept at 0.2 per cent throughout the PVP solution. The tube was then centrifuged in a swing-out rotor at room temperature $\left(25^{\circ}\right)$ allowing $2.5 \mathrm{~min}$ to accelerate to $800 \mathrm{rpm}(200 \mathrm{~g}), 2.5 \mathrm{~min}$ at this speed, and 4 min to decelerate without braking. Fractions of the contents were collected after puncturing the bottom of the tube. The cells were immediately freed of PVP with 2 saline washes and resuspended in the incubation medium. An aliquot of each fraction containing $7 \times 10^{6}$ cells was diluted

* This report is taken from a paper that appeared in Endocrinology 74:402, 1964.

${ }^{\dagger}$ Present address: Third Department of Internal Medicine, Faculty of Medicine, University of Tokyo, Hongo, Tokyo, Japan.

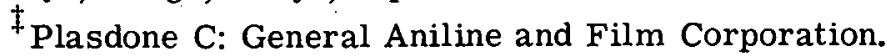


with medium and incubated both with and without added erythropoietin. Smears of all preparations, made for purposes of evaluating the cell types present, were stained with Wright's stain.

Erythropoietin (Step III, lot 137) was generously supplied by the Hematology Study Section of the United States Public Health Service. It had a potency of 7.3 units per mg of protein.

\section{RESULTS}

Cells from the different sources were tested for the effect of erythropoietin upon glucosamine incorporation in order to learn something about the nature of the cells responsive to the hormone. Peripheral red cells from normal rats incorporated glucosamine at an extremely low rate (Table 1). The very small amount of incorporation was probably due to the presence of white cells and was not increased by erythropoietin.

Table 1

INCORPORATION OF GLUCOSAMINE INTO RAT AND MOUSE CELLS OF VARIOUS TYPES

\begin{tabular}{l|c}
\hline \multicolumn{1}{c|}{ Population of cells } & $\begin{array}{c}\text { Specific activity of residue } \\
\text { after } 24 \mathrm{hr} \text { of incubation } \\
\text { cpm per mg }\end{array}$ \\
\hline Rat & $1000-5000$ \\
$\quad$ Bone marrow cells & $1000-2500$ \\
White cells & $20-70$ \\
Red cells & \\
Mouse & 480 \\
Normal spleen cells & 420 \\
$\quad$ Polycythemic spleen cells & \\
\hline
\end{tabular}

The peritoneal white cells incorporated glucosamine actively, but the activity was not significantly stimulated by erythropoietin (Figure 1).

Cells from the spleens of polycythemic mice, containing no demonstrable normoblasts, were significantly stimulated by erythropoietin as early as 6 hrs after the hormone was added (Figure 2).

Further data relating to the normoblast are presented in Table 2. The normoblast content of the marrow cell suspension from starved rats was 0.5 per cent, from normal rats was 15 per cent, and from phenylhydrazine-treated rats was 20 per cent. 0.25 units of erythropoietin per $\mathrm{ml}$ had essentially the same effect on each of these cell populations, indicating that under these conditions, erythropoietin does not act directly upon normoblasts.

The effect of $600 \mathrm{r}$ total-body irradiation on the responsiveness of marrow cells to erythropoietin confirms this conclusion. Of the cells that could be identified in the irradiated marrow, 93.9 per cent were red cells, 3.7 per cent were mature and immature white cells; 1.6 per cent were reticulum cells, and 0.8 per cent were normoblasts. The control level of glucosamine incorporation was affected to a small extent by irradiation, but the responsiveness to erythropoietin was completely abolished (Table 3 ). 


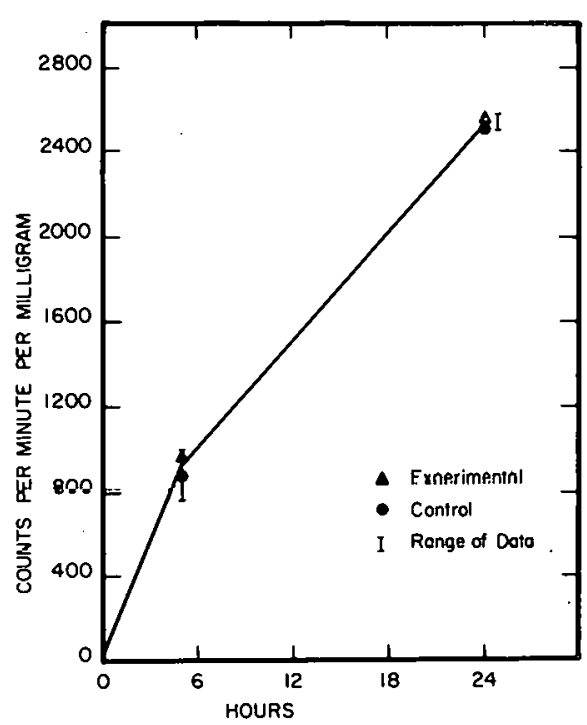

Figure 1. Time course of glucosamine incorporation into granulocytes from a peritoneal exudate. Experimental equals 3.3 units of erythropoietin per $\mathrm{ml}$.

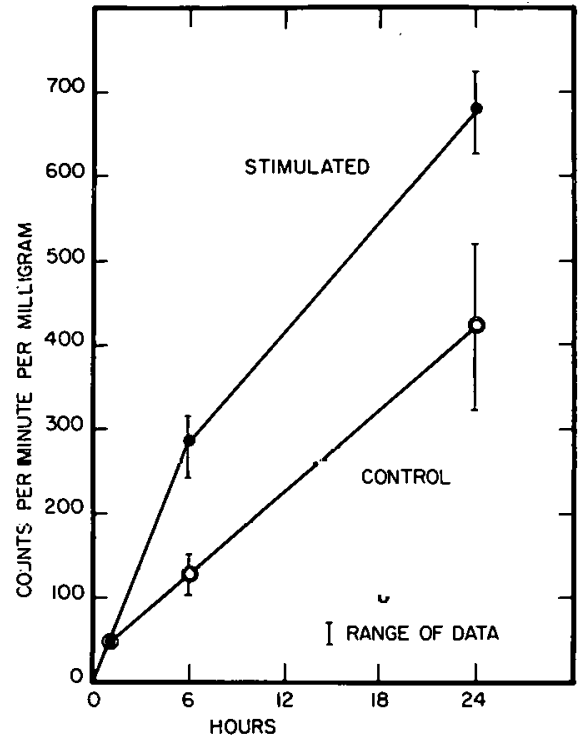

Figure 2. Time course of glucosamine incorporation into polycythemic mouse spleen cells. Stimulated equals 3.9 units erythropoietin per $\mathrm{ml}$.

Table 2

\section{EFFECT OF ERYTHROPOIETIN ON GLUCOSAMINE INCORPORATION BY BONE MARROW CULTURES}

\begin{tabular}{|c|c|c|c|}
\hline & Starved rat ${ }^{a}$ & Normal rat & $\begin{array}{c}\text { Phenylhydrazine- } \\
\text { treated rat }\end{array}$ \\
\hline Control cpm & $1421^{\mathrm{C}}(1312,1530)$ & $800(795,725,879)$ & $862(909,750,928)$ \\
\hline Erythropoietin ${ }^{\mathrm{b}} \mathrm{cpm}$ & $\begin{array}{l}2054 \underset{2065)}{(2009,2088} \text {, } \\
\text { 2065) }\end{array}$ & $\begin{array}{c}1389 \begin{array}{l}(1290,1549 \\
1327)\end{array} \\
\text {, }\end{array}$ & $1387 \underset{1304)}{(1564,1292}$ \\
\hline Difference & 633 & 589 & 525 \\
\hline Control cpm per mg & $8125(8200,8050)$ & $\begin{array}{c}5090(5480,4300 \\
5500)\end{array}$ & $\begin{array}{c}3830(4130,3570 \\
3780)\end{array}$ \\
\hline $\begin{array}{l}\text { Erythropoietin }{ }^{\mathrm{b}} \mathrm{cpm} \\
\text { per mg }\end{array}$ & $\begin{array}{c}12010 \begin{array}{c}(13400,9740, \\
12900)\end{array}\end{array}$ & $\begin{array}{c}8210(7820,9400 \\
7400)\end{array}$ & $\begin{array}{c}7250(8240,7000 \\
6520)\end{array}$ \\
\hline Difference & 3830 & 3120 & 3720 \\
\hline White cells \% of total & 59 & 43 & 36 \\
\hline Normoblasts $\%$ of total & 0.5 & 15.5 & 20 \\
\hline Red cells \% of total & 30 & 21 & 16.5 \\
\hline $\begin{array}{l}\text { Unidentified immature } \\
\text { cells \% of total }\end{array}$ & 11 & 19.5 & 27 \\
\hline
\end{tabular}
1

${ }^{a}$ In all cultures $10 \times 10^{6}$ cells per ml were incubated in 50\% NCTC $19950 \%$ calf serum.

$\mathrm{b}_{0.25}$ units per $\mathrm{ml}$.

c Mean and experimental values are indicated in parentheses. 
Table 3

\section{EFFECT OF X-RADIATION AND VARIATION OF CELL NUMBER ON THE STIMULATION OF GLUCOSAMINE INCORPORATION BY ERYTHROPOIETIN}

\begin{tabular}{|c|c|c|c|}
\hline$\cdot$ & $\begin{array}{c}\text { Normal rat } \\
10 \times 10^{6} \text { cells per ml }\end{array}$ & $\begin{array}{c}\text { Normal rat } \\
5 \times 10^{6} \text { cells per } \mathrm{ml}\end{array}$ & $\begin{array}{l}\text { X-rayed rat (on the } \\
\text { fourth day after } \\
\text { irradiation) } \\
10 \times 10^{6} \text { cells per } \mathrm{ml}\end{array}$ \\
\hline Control cpm & $\begin{array}{c}1441^{b}(1644,1325 \\
1353)\end{array}$ & $481(465,447,530)$ & $224(226,292,154)$ \\
\hline Erythropoietin ${ }^{\mathrm{a}} \mathrm{cpm}$ & $2136 \begin{array}{l}(2214,2245 \\
1955)\end{array}$ & $845(901,815,819)$ & $220(195,217,248)$ \\
\hline Difference: & 695 & 364 & -4 \\
\hline Control cpm per mg & $\begin{array}{c}5010(5870,4420 \\
4750)\end{array}$ & $\begin{array}{c}4060(4040,4060 \\
4070)\end{array}$ & $\begin{array}{c}3490(3230,4170 \\
3080)\end{array}$ \\
\hline $\begin{array}{l}\text { Erylhropoietin cpm } \\
\text { per mg }\end{array}$ & $\begin{array}{c}7700(7250,8020, \\
7830)\end{array}$ & $\begin{array}{c}6500(6670,6270 \\
6560)\end{array}$ & $\begin{array}{c}3540(3540,4340, \\
2750)\end{array}$ \\
\hline Difference & 2690 & 2440 & 50 \\
\hline
\end{tabular}

${ }^{\mathrm{a}} 0.25$ units per $\mathrm{ml}$.

${ }^{b}$ Mean and experimental values are indicated in parentheses.

Those cells that were separated in the PVP gradient were tested for response to erythropoietin, and a semiquantitative evaluation of the types present in each fraction was made. The positive identification of such cells is quite poor, however, due to changes in morphology caused either by the PVP or by processing of the smears. Although erythropoietin stimulated all the fractions, the greatest effect was seen in Fraction III, which contained the highest proportion of blast cells (Table 4).

\section{DISCUSSION}

Our observations rule out several types of cells as the target cells of erythropoietin action. While mature white cells (peritoneal granulocytes), take up glucosamine very well, they are unaffected by the hormone. Mature red cells show neither any appreciable glucosamine incorpor'dtion nor any effect of erythropoietin. Direct action of the hormone on normoblasts resulting in increased proliferation or enlarged cell size is excluded by several lines of evidence all of which, in the present paper, are based upon the assumption that we are in fact measuring erythropoietin by studying the stimulation of glucosamine incorporation. The evidence is as follows: There is no change in the magnitude of erythropoietin effect on marrow cell populations that contain widely varying percentages of normoblasts; there is a definite effect upon spleen cells from polycythemic mice containing no detectable normoblasts; cells separated by the PVP gradient show quite dissimilar effects of erythropoietin even when they contain similar proportions of normoblasts. These data, on the other hand, do not exclude the possibility that the effect of the hormone on normoblasts might be deferred and thus would not be reflected in the 24-hr glucosamine intake studies.

It is also possible that erythropoietin could cause a normoblast to skip divisions and develop 
Table 4

EFFECT OF ERYTHROPOIETIN UPON RAT MARROW CELL FRACTIONS SEPARATED BY DENSITY GRADIENT CENTRIFUGATION

\begin{tabular}{|c|c|c|c|}
\hline \multirow{2}{*}{$\begin{array}{l}\text { Layer } \\
\text { (volume } \mathrm{ml} \text { ) }\end{array}$} & \multirow[t]{2}{*}{ Population of cells ${ }^{\mathrm{a}}$} & \multicolumn{2}{|c|}{$\begin{array}{l}\text { Increase in erythropoietin } \\
\text { samples }(\text { cpm per mg) over } \\
\text { control }\end{array}$} \\
\hline & & Mean & (Individual value) \\
\hline $\begin{array}{l}I \\
(7)\end{array}$ & $\begin{array}{l}\text { Lymphocyte predominant, some normoblasts, } \\
\text { few white cells, few red cclls, fcw mcgalraryo } \\
\text { cytes, few blast cells }\end{array}$ & 605 & $(510,700)$ \\
\hline$\underset{(7)}{\pi}$ & $\begin{array}{l}\text { Red cell predominant, some lymphocytes, some } \\
\text { white cells, some normoblasts, few blast cells }\end{array}$ & 565 & $(397,732)$ \\
\hline$\underset{(6.5)}{\operatorname{III}}$ & $\begin{array}{l}\text { White cell predominant, highest per cent of } \\
\text { blast cells, some normoblasts, few red cells, } \\
\text { few lymphocytes }\end{array}$ & 932 & $(682,1182)$ \\
\hline$\underset{(5.5)}{\operatorname{IV}}$ & $\begin{array}{l}\text { White cell predominant, some normoblasts, few } \\
\text { blast cells, few red cells, few lymphocytes }\end{array}$ & 210 & $(105,315)$ \\
\hline$\underset{(6.5)}{V}$ & $\begin{array}{l}\text { Red cell predominant, some normoblasts, some } \\
\text { white cells, some lymphocytes, few blast cells }\end{array}$ & 680 & $(560,800)$ \\
\hline
\end{tabular}

${ }^{a}$ Aliquots were adjusted to $7 \times 10^{6}$ cells per $\mathrm{ml}$.

$\mathrm{b}_{0.5}$ units per $\mathrm{ml}$.

into a reticulocyte as suggested, among others, by Borsook et al. ${ }^{5}$ and by Stohlman. ${ }^{6}$ Such an effect could not be detected in our system because the cell wall-stroma may be fully formed at an early normoblast stage, as has been shown by Yunis and Yunis ${ }^{7}$ in the case of the cell isoantigens, and therefore glucosamine incorporation would probably not increase. If this type of response is disregarded, the data showing that the response to a nonsaturating dose of erythropoietin is proportional to cell number, and the absence of such a response 4 days after irradiation (Table 3) (when no response is apparent in plethoric mice ${ }^{9}$ ) suggests that the erythropoietin target cells constitute a small fraction of the bone marrow cell population. This fraction, by its $x$ ray sensitivity and by the elimination of the cell types found to be nonresponsive, may be restricted to the stem cells along with perhaps their differentiated daughter cells.

Three possible mechanisms may then be considered compatible with the data presented: Erythropoietin may act on stem cells alone; erythropoietin may act on differentiated daughter cells of stem cells alone, implying that stem cell differentiation is not directly regulated by erythropoietin; or erythropoietin may cause stem cell differentiation, but may also act on the first descendants of stem cells that have already been directed toward the red cell lineage.

\section{LITERATURE CITED}

1. Dukes, P. P., F. Takaku, and E. Goldwasser. Endocrinology, 74:960, 1964.

2. Gordon, A. S., R. O. Neri, C. D. Siegel, and B. S. Dornfest. Acta Haematol., 23:323, 1960.

3. Jacobson, L. O., E. Goldwasser, L. F. Plzak, and W. Fried. Proc. Soc. Exptl. Med., 94: $243,1957$. 
4. Goodman, J. W. Exptl. Cell Res., 21:88, 1960.

5. Borsook, H., J. B. Lingrel, J. L. Scaro, and R. L. Millette. Nature, 196:347, 1962.

6. Stohlman, F. Trans. N. Y. Acad. Sci., 24:312, 1962.

7. Yunis, J. J., and E. Yunis. Blood, 22:53, 1962.

8. Gurney, C. W., L. G. Lajtha, and R. Oliver. Brit. J. Haematol., 8:461, 1962. 


\title{
HEMOGLOBIN SYNTHESIS IN MARROW CELL CULTURE: \\ THE EFFECT OF RAT PLASMA ON RAT CELLS
}

\author{
By \\ O. Gallien-Lartigue ${ }^{\dagger}$ and E. Goldwasser
}

In a recent paper ${ }^{1}$ we showed that continued heme synthesis by cultures of bone marrow cells from the rat for periods over about 12 hours was dependent upon the presence of erythropoietin in the culture medium. The value of marrow cell cultures for the assay of erythropoietin, and for the investigation of the chemical mode of action of the hormone as a model for the study of differentiation, has been the subject of further experimentation.

Our earlier paper ${ }^{1}$ contained indirect evidence that a simple procedure in which the extraction of heme from an acidified lysate of marrow cells into butanone ${ }^{2}$ followed by the measurement of heme radioactivity is adequate for the determination of hemoglobin synthesis. Since one well-defined end product of stem-cell differentiation is hemoglobin, it was important to demonstrate directly that the assumption of equivalence between heme formation and hemoglobin synthesis was justified. The experiments described below indicate that essentially all of the heme found in the butanone extract is, in fact, derived from hemoglobin. We have also found a modification of the culture medium which can effect a substantial increase in the amount of hemoglobin synthesized.

The assumption that heme synthesis corresponds with hemoglobin formation by this system is -shown to be warranted by the experimental data described in Figure 1. Approximately 5 per cent of the total heme counts were lost in washing the hemoglobin crystals obtained from both cultures. The hemoglobin isolated after crystallization and chromatography on diethylaminoethyl cellulose represented about 93 per cent of the original $\mathrm{Fe}^{59}$ extractable by the acid-butanone method. The chromatograms shown in Figure 1 demonstrate that in both cases the hemoglobin had a constant specific activity and that there were no other components containing $\mathrm{Fe}^{59}$ present.

In our original method the marrow cells were incubated in 60 per cent 109 medium and 40 per cent rat plasma. The $\mathrm{Fe}^{59}$ was added to rat plasma and incubated at $37^{\circ}$ for 12 hours or more, before addition to the cells, to allow sufficient time for equilibration. To avoid collection of rat plasma we attempted to substitute commercially available fetal calf serum in the medium. This substitution resulted in a decrease of hemoglobin radioactivity by about 50 per cent. When the iron was bound to the fetal calf serum, while the remainder of the protein part of the medium was rat plasma, the amount of $\mathrm{Fe}^{59}$ in the hemoglobin was reduced to about one-sixth that found when the medium was all rat plasma. On the other hand, when the main part of the protein consisted of fetal calf serum and the iron was bound to rat plasma, the label in hemoglobin was increased somewhat more than threefold. (See Table 1.)

We interpret these data as indicating that the marrow cells in culture can synthesize hemo-

This report is taken from a paper that appeared in Science, 17:277, 1964.
${ }^{\dagger}$ Present address: College de France, Laboratoire d'Embryologie Experimentale, Paris. 


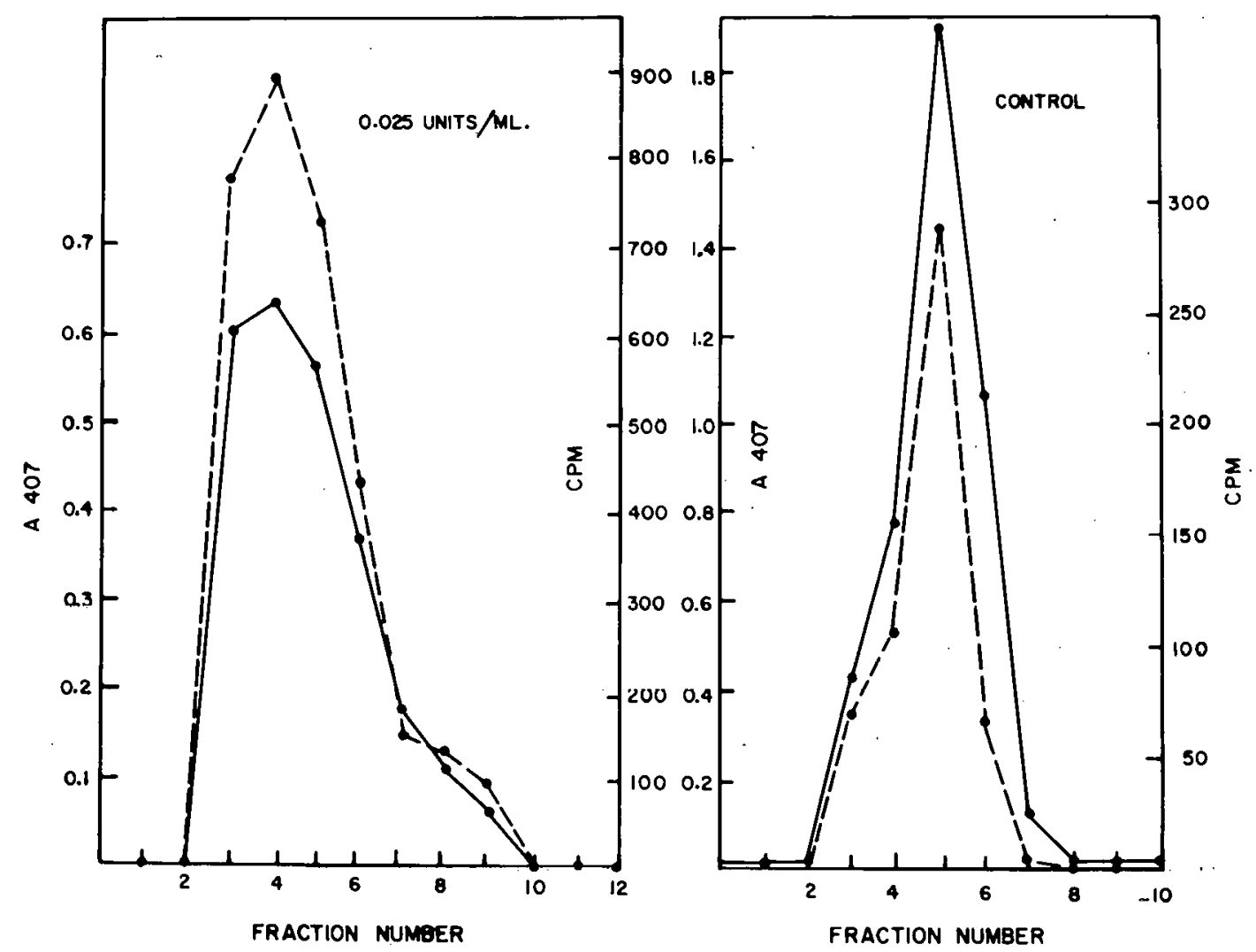

Figure 1. Left: Pool of cells $\left(7.5 \times 10^{6}\right)$ cultured in the presence of 0.025 units of erythropoietin per milliliter in a total volume of $2.4 \mathrm{ml}$. After cells were washed and lysed the stroma was removed and a solution containing $0.4 \mathrm{mg}$ of crystalline rat hemoglobin was added to the lysate. Right: Pool of cells $\left(8.4 \times 10^{6}\right)$ cultured in the absence of erythropoietin, treated in the same manner as above with $0.6 \mathrm{mg}$ of carrier crystalline hemoglobin added. To each lysate was added an equal volume of Drabkin's solution;* cyanmethemoglobin was crystallized by addition of ammonium sulfate to one-half saturation and allowing the solutions to stand at $4^{\circ}$ for 20 days. The crystals were collected, washed with saturated ammonium sulfate and dissolved in $2.0 \mathrm{ml}$ of water. Chromatography was done on a column $\left(3 \mathrm{~cm} \times 3 \mathrm{~cm}^{2}\right)$ of DEAEcellulose at $4^{\circ}$. The cyanmethemoglobin was eluted with $0.01 \mathrm{M}$ Tris buffer $\mathrm{pH} 7.4$ 10 per cent saturated with ammonium sulfate. All $\mathrm{Fe}^{59}$ determinations were done in a well-type scintillation counter. The solid lines refer to absorbancy at $407 \mathrm{m \mu}$ and the broken lines to net count rate.

globin at an accelerated rate when provided with some factor, possibly nutritional, in fetal calf serum. This factor would appear to be different from the "sticking factor" for which fetal calf serum is usually employed, since the marrow cells do not attach to the dish during the relatively short incubation. In addition, rat plasma must contain an iron-binding factor (probably transferrin) which is important for optional hemoglobin synthesis by rat marrow cells. The observation that the iron-binding material in fetal calf serum is much less effectual than that in the isologous plasma points to a type of specificity which enables cells to utilize only a limited range of iron-binding materials for maximal hemoglobin synthesis.

Although the total iron was not determined in these experiments, other independent measure-

\footnotetext{
${ }_{1 \mathrm{~g} \mathrm{NaHCO}}, 52 \mathrm{mg} \mathrm{KCN}, 198 \mathrm{mg} \mathrm{K} \mathrm{K}_{3} \mathrm{Fe}(\mathrm{CN})_{6}$ per liter.
} 
Table 1

EFFECT OF IRON-BINDING COMPONENT IN PLASMA UPON INCORPORATION OF $\mathrm{Fe}^{59}$ INTO HEMOGLOBIN ${ }^{*}$

\begin{tabular}{|c|c|c|c|c|c|c|}
\hline \multirow{2}{*}{ Exptl. } & \multicolumn{2}{|c|}{ Contents of medium (\%) } & \multicolumn{2}{|c|}{$\mathrm{Fe}^{59}$ content $(\%)$} & \multirow{2}{*}{$\begin{array}{c}F e^{59} \\
\text { incorporated }^{\mathrm{a}} \\
\text { (count/min) }\end{array}$} & \multirow{2}{*}{$\begin{array}{c}\% \text { standard } \\
\text { conditions } \\
\text { (Experiment } A)\end{array}$} \\
\hline & $\begin{array}{c}\text { Rat } \\
\text { plasma }\end{array}$ & $\begin{array}{l}\text { Fetal calf } \\
\text { serum }\end{array}$ & $\begin{array}{c}\text { Rat } \\
\text { plasma }\end{array}$ & $\begin{array}{c}\text { Fetal calf } \\
\text { serum }\end{array}$ & & \\
\hline A & 43.8 & 0 & 3.8 & 0 & 3689 & 100 \\
\hline B & 0 & 43.6 & 0 & 3.8 & 1745 & 47 \\
\hline $\mathrm{C}$ & 43.8 & 0 & 0 & 3.8 & 617 & 17 \\
\hline $\mathrm{D}$ & 0 & 43.8 & 3.8 & 0 & 12113 & 330 \\
\hline
\end{tabular}

${ }^{\mathrm{a}}$ Net counts per minute of $\mathrm{Fe}^{59}$ incorporated into hemoglobin in 24 hours.

* All culture media contained $52.4 \%$ of 109 medium supplemented with $0.024 \mathrm{mg}$ of glutamine and 80 units of penicillin per ml. Each plastic petri dish $(60 \times 15 \mathrm{~mm})$ contained $10 \times 10^{6}$ nucleated cells derived from marrow of tibias and fibulas of male Sprague-Dawley rats fasted for 72 hours, and $1.0 \mu \mathrm{C}$ of $\mathrm{Fe}^{59} \mathrm{Cl}_{3}$ bound to protein in a total volume of $2.16 \mathrm{ml}$. The cells were incubated for 24 hours at $37^{\circ}$ in an atmosphere of 95 per cent air: 5 per cent $\mathrm{CO}_{2}$.

ments indicate that fetal calf serum contains at most about 40 per cent more iron than rat plasma and that the transferrin contents of the two are approximately the same. These data and those in Table 1-clearly rule out any effect of iron concentration being responsible for the differences seen with the various mixtures.

These observations provide a basis for an increase in sensitivity of the marrow cell culture method for the study of hemoglobin synthesis, for the in vitro assay of erythropoietin, and for investigations into the mechanism of action of the hormone.

\section{LITERATURE CITED}

1. Krantz, S. B., O. Gallien-Lartigue, and E. Goldwasser: J. Biol. Chem., 238:4085, 1963.

2. Teale, F. W. J. Biochim. Biophys. Acta, 35:543, 1959. 
THE ERYTHROPOIETIC EFFECT OF TESTOSTERONE IN THE POLYCYTHEMIC $\rightarrow$ MOUSE ${ }^{*}$

By

W. Fried, R. De Gowin and C. W. Gurney

The treatment of various refractory anemias with testosterone $e^{1-3}$ has led us to investigate the mechanism by which this hormone affects erythropoiesis. Several investigators have demonstrated increased red blood cell counts in rats after long-term treatment with testosterone. These increases were more striking in animals with hormone levels altered by castration or hypophysectomy, ${ }^{4-6}$ and were very slight in normal animals. ${ }^{7}$ Most early studies failed to demonstrate significant increases in the hemoglobin levels or in the total red cell volumes. $4,5,8$

In this report, we shall describe the effects of testosterone on the rate of $\mathrm{Fe}^{59}$ uptake in the polycythemic mouse, an animal which has proved valuable for studies of the mechanism of erythropoietic stimulants. 9,10

\section{METHODS}

CF No. 1 female mice 6 to 8 weeks of age and weighing 25 to $30 \mathrm{~g}$ were used in all experiments.

Mice were made polycythemic by injecting $0.5 \mathrm{ml}$ of an 80 per cent suspension of washed mouse RBC's I.V. on 2 consecutive days. ${ }^{10}$ All polycythemic mice had hematocrits between 55 per cent and 65 per cent at the termination of the experiment.

The rate of $\mathrm{Fe}^{59}$ uptake into newly formed $\mathrm{RBC}^{\prime} \mathrm{S}$ was determined by injecting $0.5 \mu \mathrm{c}$ $\mathrm{Fe}^{59} \mathrm{Cl}^{\dagger}$ intravenously at the times specified. Three days later, $0.25 \mathrm{ml}$ of blood was removed by cardiac puncture and counted in a well-type scintillation counter. Radioactivity was calculated as the percentage of the injected dose of $\mathrm{Fe}^{59}$ in the peripheral red cells.

Testosterone was administered subcutaneously as testosterone proprionate in sesame oil ${ }^{\ddagger}$ in concentration of $25 \mathrm{mg}$ per $\mathrm{ml}$, or testosterone in isotonic aqueous suspension ${ }^{\S}$ in concentration of $25 \mathrm{mg}$ per $\mathrm{ml}$.

\section{RESULTS}

The effects of testosterone on polycythemic mice. The following experiment demonstrates that testosterone can prevent the usual maximal transfusion-induced suppression of erythropoiesis in the normal mouse, and can stimulate erythropoiesis in a maximally suppressed animal.

Group I received 10 (Ia) or 20 (Ib) daily $2.5 \mathrm{mg}$ injections of testosterone in oil. Controls (Ic) received 20 daily injections of sesame oil $(0.1 \mathrm{ml}) . \mathrm{Fe}^{59}$ was given on the final day of injection. Polycythemia was produced by transfusing $0.5 \mathrm{ml} \mathrm{RBC's}$ on days 5 and 6 prior to injection of $\mathrm{Fe}^{59}$.

This report is taken from a paper that will appear in Proc. Soc. Biol. Med.

${ }^{\dagger}$ Specific activity of the tracer was $36 \mathrm{mc}$ per $\mathrm{mg}$ Fe.

${ }^{\ddagger}$ Commercially prepared by Schering Co. under trademark Oreton.

$\S$ Commercially prepared by Otganon, Inc. under trademark Organon. 
Group II received 10 daily $2.5 \mathrm{mg}$ injections of testosterone in oil (IIa) or an equivalent volume of sesame oil ( $\mathrm{mb}) . \mathrm{Fe}^{59}$ was given on the final day of injection. Polycythemia was induced by hypertransfusion 10 days prior to the first testosterone injection and again on the day of the first injection.

Figure 1 indicates that testosterone given either before or after hypertransfusion produced a 20- to 30-fold increase in the rate of iron incorporation as compared to controls. Twenty daily testosterone injections did not produce a significantly higher rate of $\mathrm{Fe}^{59}$ uptake than did 10 injections.

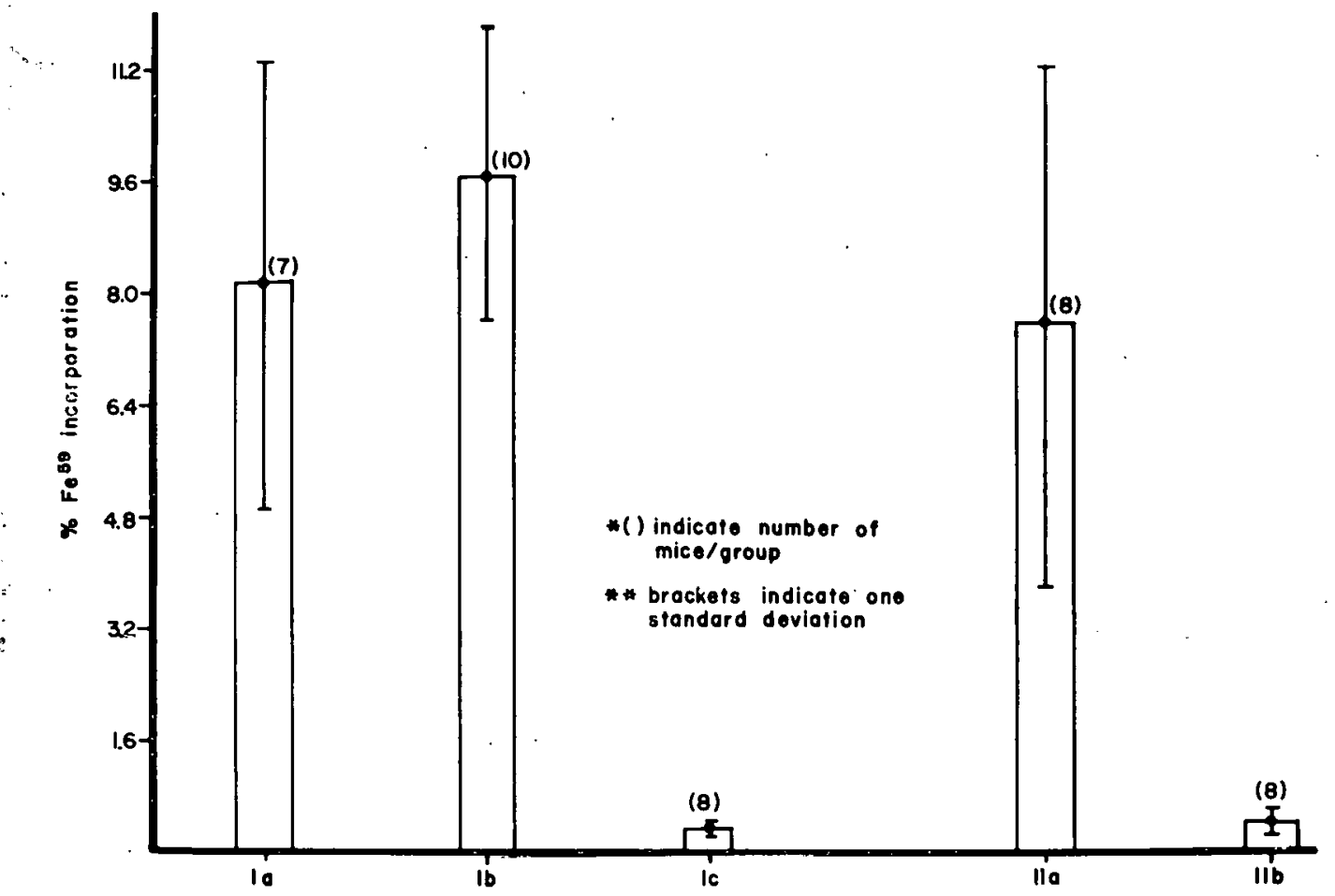

Figure 1. Effect of testosterone on polycythemic mouse.

Duration of action of a single dose of testosterone. In this experiment the magnitude of the erythropoietic response was considered as a function of time following a single dose of $2.5 \mathrm{mg}$ of testosterone. Aqueous and oil suspensions of testosterone were used to minimize any delay due to slow release from the injection site. All mice were injected with $0.5 \mathrm{ml}$ packed RBC's 5 and 6 days before injection with $\mathrm{Fe}^{59}$. A single $2.5 \mathrm{mg}$ dose of testosterone was given as indicated on the abscissa in Figure 2. The response in terms of $\mathrm{Fe}^{59}$ incorporation is recorded on the ordinate. The effect of testosterone is first detectable after 48 hours, and reaches its peak by 96 hours, after which maximum activity persists for at least 24 hours. The effect of aqueously suspended testosterone, indicated by the interrupted line in Figure 2, resembles that obtained with testosterone suspended in oil.

The optimum single dose of testosterone. Mice were transfused 5 and 6 days prior to injection of $\mathrm{Fe}^{59}$; a single injection of testosterone was given 4 days prior to $\mathrm{Fe}^{59}$. The dose of testosterone is indicated on the abscissa in Figure 3. The $\mathrm{Fe}^{59}$ incorporation is on the ordinate. It is 


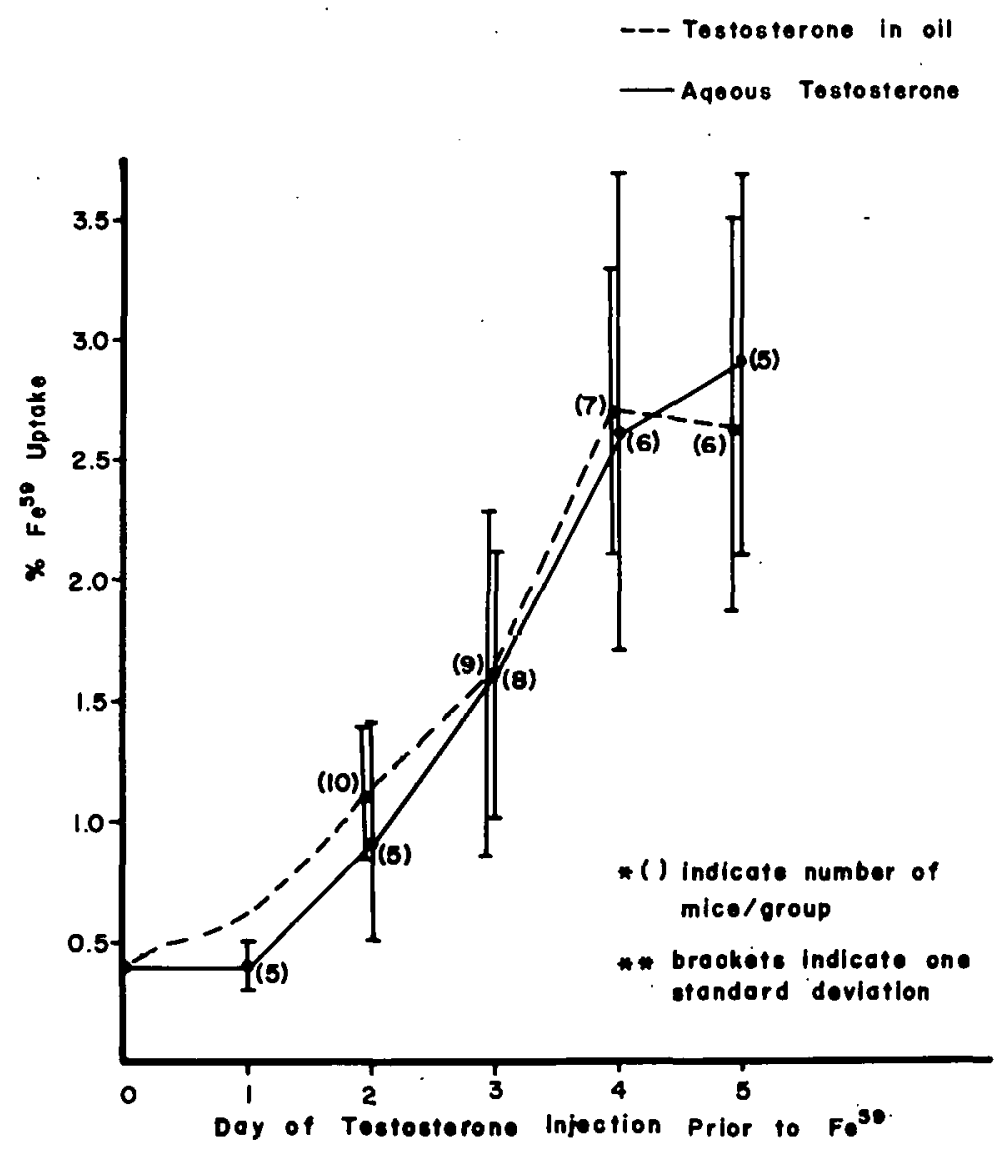

Figure 2. Time of appearance of erythropoetic response after single dose of testosterone.

apparent that 2.5 or $5 \mathrm{mg}$ injections of testosterone are not significantly more effective than 1 $\mathrm{mg}$. When less than $1 \mathrm{mg}$ is given, the erythropoietic effect diminishes.

The effect of numerous daily testosterone injections on normal mice. Mice were injected daily for 45 days with $2.5 \mathrm{mg}$ testosterone in $0.1 \mathrm{ml}$ sesame oil, or with $0.1 \mathrm{ml}$ sesame oil. Several of the peripheral blood parameters as well as the rate of $\mathrm{Fe}^{59}$ incorporation were determined. The results are given in Table 1. It is apparent that testosterone has no detectable effect on white blood cell level or hemoglobin production and does not alter the 16 hour incorporation of $\mathrm{Fe}^{59}$ by newly formed erythrocytes in the normal animal.

\section{DISCUSSION}

The experiments indicate that testosterone, when given in pharmacological doses, can quite significantly increase the rate of erythropoiesis in polycythemic mice. It should however, be emphasized that it was not possible to restore erythropoiesis to anything approaching the normal rate even by repeated massive doses of testosterone, and that testosterone did not affect significantly any of the parameters of erythropoietic activity in normal mice.

The ability to stimulate erythropoiesis in the polycythemic mouse suggests that testosterone is able to lead to differentiation of a stem cell into the erythroid series, either directly or indi- 


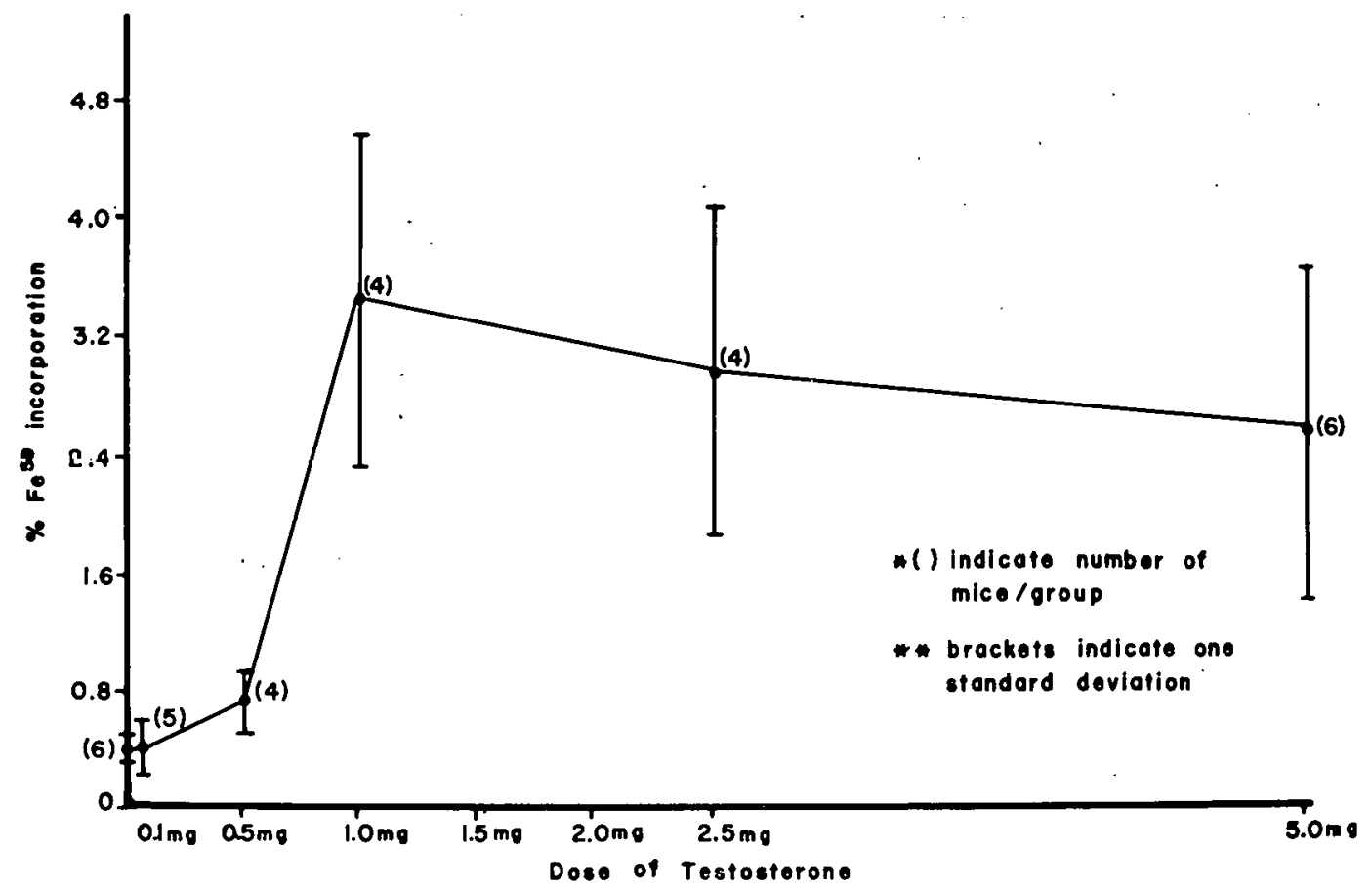

Figure 3. Relation of dose of testosterone to $\mathrm{Fe}^{59}$ uptake.

Table 1

EFFECT OF LONG RANGE TESTOSTERONE INJECTION ON NORMAL MICE

\begin{tabular}{l|c|c|c|c|c}
\hline & $\begin{array}{c}\text { Hgb } \\
(13)\end{array}$ & $\begin{array}{c}\text { Hct } \\
(13)\end{array}$ & $\begin{array}{c}\text { Retic } \\
(7)\end{array}$ & $\begin{array}{c}5 e^{59} \text { uptake } \\
(7)\end{array}$ & $\begin{array}{c}\text { WBC } \\
(7)\end{array}$ \\
\hline Testosterone & $16.7 \pm 0.9$ & $52.2 \pm 2.5$ & $3.5 \pm 0.5$ & $32.6 \pm 1.6$ & $9161 \pm 1900$ \\
Control & $15.9 \pm 0.3$ & $50.3 \pm 1.2$ & $3.5 \pm 0.3$ & $27.8 \pm 9.8$ & $9580 \pm 2400$ \\
\hline
\end{tabular}

( ) indicate number of mice/group.

rectly. There are a number of ways in which this might be effected: First, testosterone might increase the basal metabolic rate, thereby increasing the $\mathrm{O}_{2}$ demand to above the rate of delivery which, before testosterone administration, had been more than adequate to supply tissue oxygen needs. In such a case, endogenous production of erythropoietin would be expected. To date, significant increases in the BMR following testosterone have been demonstrated only in eunochoid humans treated with methyl testosterone. ${ }^{6}$ It is of interest that testosterone proprionate, the preparation used in our experiments, had no effect on the BMR of eunochoid males. ${ }^{6}$ It has also been demonstrated that testosterone increases mitotic activity in the female thyroid gland. ${ }^{11}$ The effects of androgens on the basal metabolic rate of polycythemic mice are currently being investigated.

Second, testosterone has been shown to increase the organ weights of several non-endocrine organs, most notably the kidney. ${ }^{12}$ The epithelial cell cytoplasm is most affected, but the mechanism responsible for this change is not known. Since much evidence points to the kidney as a 
site of erythropoietin production, ${ }^{13,14}$ it is conceivable that erythropoietin production by the kidney might also be increased by direct action upon the renal parenchymal cell.

Third, testosterone might potentiate the effect of small amounts of endogenous erythropoietin elaborated in the polycythemic mouse if the small amount of iron incorporation in the unstimulated polycythemic mouse is a consequence of the continued elaboration of very slight amounts of erythropoietin. Such an effect might be direct, or might be indirect, by antagonization of the already demonstrated inhibitory action of estrogens on erythropoiesis. 15

Finally, testosterone might act directly upon the stem cells, inducing differentiation into the erythrocytic compartment. These various possibilities are currently under study.

\section{LITERATURE CITED}

1. Kennedy, B. J., and A. S. Gilbertson. New Engl. J. Med., 256:719, 1957.

2. Gardner, F. H., and J. C. Pringle, Jr. New Engl. J. Med., 264:103, 1961.

3. Shahidi, U. T., and L. K. Diamond. New Engl. J. Med., 264:953, 1961.

4. Vollmer, E. P., A. S. Gordon, and H. A. Chaupper. Endocrinology, 31:619, 1942.

5. Crafts, R. C. Endocrinology, 39:407, 1946.

6. McCullough, E. P., and R. Jones. J. Clin. Endocrinol., 2:243, 1942.

7. Vollmer, E. P., and A. S. Gordon. Endocrinology, 29:828, 1941.

8. Van Dyke, D. C., A. N. Contopolous, B. S. Williams, M. E. Simpson, J. H. Lawrence, and H. M. Evans. Acta Haematol., 11:203, 1954.

9. Jacobson, L. O., E. Goldwasser, and C. W. Gurney. Ciba Symposium on Haemopoiesis, London, J. and E. Churchill Ltd., 1960, pp. $423-45$.

10. De Gowin, R. L., D. Hofstra, and C. W. Gurney., Proc. Soc. Exptl. Biol: Med., 11:48, 1962.

11. Nathanson, I. T., A. M. Brues, and R. W. Rawson. Proc: Soc. Exptl. Biol. Med., 43:737; 1940.

12. Selye, H. J. Urology, 42:637, 1939.

13. Jacobson, L. O., E. Goldwasser, W. Fried, and L. Plzak. Trans. Ass. Am. Physicians, 70: 305, 1957.

14. Naets, J. P. Nature, 181:1134, 1958.

15. Dukes, P. P., and E. Goldwasser. Endocrinology, 69:21, 1961. 


\section{$\mathrm{H}^{3}$ THYMIDINE UPTAKE_BY A RING X-CHROMOSOME IN A HUMAN FEMALE* ${ }^{*}$}

By

J. Rowley, s. Muldal, ${ }^{\dagger}$ J. Lindsten ${ }^{\ddagger}$ and C. W. Gilbert ${ }^{\dagger}$

The use of $\mathrm{H}^{3}$ thymidine to label cultures of peripheral leukocytes has revealed a marked asynchrony in the replication of one chromosome in the normal human female. ${ }^{1-4}$ The hypothesis that this chromosome, which labels late in the period of DNA synthesis, is one of the two Xchromosomes, is supported by the finding of three late labeling chromosomes in males with the karyotype XXXXY,${ }^{5,7}$ four late labelíng chromosomes in a female $\mathrm{XXXXX}^{8}$, and one large late labeling chromosome in patients with gonadal dysgenesis and the karyotype $\mathrm{XX}_{\mathrm{I}}{ }^{8-11}$ where the large $\mathrm{X}_{\mathrm{I}}$ chromosome is presumed to represent an isochromosome for the long arm of one $\mathrm{X}$ chromosome. 12

The present study on human cells having two X-chromosomes morphologically distinctly different was undertaken to determine whether the late labeling $\mathrm{X}$ is the same in all cells, and whether the abnormal $\mathrm{X}$ is always the late labeling chromosome. The abnormal $\mathrm{X}$-chromosome in this study is a ring $\mathrm{X}$-chromosome.

\section{MATERIALS AND METHODS}

Autoradiographic studies were carried out on metaphases of leukocytes from peripheral blood obtained from a 22-year-old woman with gonadal dysgenesis whose cells contain 45, 46 and 47 chromosomes with a karyotype $\mathrm{XO} / \mathrm{XX}_{\mathrm{R}} / \mathrm{XX}_{\mathrm{R}} \mathrm{X}_{\mathrm{R}}$ respectively ( $\mathrm{ring}=\mathrm{X}_{\mathrm{R}}$ ). ${ }^{13}$ The ring $\mathrm{X}$ chromosome is present in 30 per cent of the metaphases cultured from peripheral blood. Cells from long term cultures of skin and ovary show 45 chromosomes and are XO; in repeat short term cultures of skin and a lymph node, about 10 per cent of the cells contain 46 chromosomes and are $\mathrm{XX}_{\mathrm{R}^{\circ}}{ }^{14}$ Some cells from these short term cultures are sex chromatin positive. Buccal mucosa smears show no sex chromatin bodies. Normal appearing drumsticks are present in 9 of 500 neutrophil leukocytes.

The cultures obtained from peripheral blood were labeled with $\mathrm{H}^{3}$ thymidine (Amersham, specific activity $2.3 \mathrm{mc} \mu / \mathrm{M}$ ) using $0.2 \mu \mathrm{c} / \mathrm{ml}$ of medium, as previously described. ${ }^{3}$ Slides were prepared by the air-dry method from two cultures labeled for 3 and $4 \mathrm{hr}$, with Colcemid (Ciba) added for the last 1 or $1-1 / 2 \mathrm{hr}$. They were processed as follows:

Method 1. Slides were coated with Kodak AR10 stripping film, exposed for 6 to 7 days, and stained with Leishman-Giemsa. Labeled metaphases were karyotyped and grain counted.

Method 2. Slides were stained with 2 per cent acetic orcein and all $\mathrm{xx}_{\mathrm{R}}$ metaphases were photographed. The slides were coated with stripping film and exposed for 6 days. Only the labeled $\mathrm{XX}_{\mathrm{R}}$ metaphases were karyotyped and grain counted.

$$
\text { irec. Thalli had. Sci. U.S. }
$$

\footnotetext{
${ }^{*}$ This paper appeared in P.N.A.S. (U.S.), $51: 779,1964$.

†Paterson Research Laboratories, Christie Hospital and Holt Radium Institute, Manchester, England.

${ }_{\text {Endocrinology Clinic, Karolinska Sjukhuset, Stockholm, Sweden. }}$
} 


\section{RESULTS}

Fifty cells were analyzed from cultures labeled for $3 \mathrm{hr}$, and 38 cells were analyzed from cultures labeled for $4 \mathrm{hr}$. The grain counts over the metaphases and the ring chromosomes are listed in Table 1. About 50 per cent of the $\mathrm{XX}_{\mathrm{R}}$ metaphases are labeled when cultured with $\mathrm{H}^{3}$ thymidine for $3 \mathrm{hr}$. As would be expected, the 3-hr samples (Figure 1) are less intensely labeled than the 4-hr samples. There are 19 cells containing rings with 3 grains or less in the $3-\mathrm{hr}$ sample, and 2 such cells in the 4-hr sample. These cells do not contain a heavily labeled chromosome in the X-6-12 group. The XO metaphases do not contain a late labeling X-chromosome.

The length of the ring, as measured in 51 cells, was approximately 0.6 the length of the normal X-chromosome in 44 of them. In the other 7 cells, the ring appeared to be the same size as the normal X-chromosome. The variation.in size and shape of the ring can be seen in Figure 2. The largest chromosome from the 13-15 group, included for comparison, has a length approximately 0.6 that of the normal $X$, and thus is about equal in size to the majority of ring $\mathrm{X}$-chromosomes.

In Figure 3 the proportion of grains over the ring $\mathrm{X}$-chromosome is compared with the total number of grains over the remaining 45 chromosomes. The mean grain count for all metaphases (45 chromosomes) in the 3 - or 4 -hr sample equals 1.0. When the metaphases are grouped according to grain counts $0-99,100-199,200-299,300$ and over, the mean of each group can be compared with the mean of the total (1.0). The ratio of the mean grain count over the ring $\mathrm{X}$-chromosome to that over the remaining 45 chromosomes in all metaphases ( $\mathrm{X} / 45 \mathrm{ratio}$ ) is 0.06 in the $3-\mathrm{hr}$ sample and 0.07 in the $4-\mathrm{hr}$ sample. However when the $\mathrm{X} / 45$ ratio is computed for metaphases at the end of DNA synthesis (i.e., containing less than 100 grains), it is 0.14 for the $3-\mathrm{hr}$ sample and 0.25 for the 4-hr sample.

When the grain counts over the ring are compared to total grain counts over all 46 chromosomes, the mean grain count over the ring constitutes 5.5 per cent of the total grains in the 3-hr sample and 6.3 per cent in the 4-hr sample. Limiting the analysis to metaphases containing less than 100 grains, the ring constitutes 12 per cent of the total grains over all chromosomes in the 3-hr sample and 20 per cent in the 4-hr sample.

\section{DISCUSSION}

In all instances the late labeling $\mathrm{X}$-chromosome is the same in all cells, and is always the abnormal ring $\mathrm{X}$-chromosome. The degree of labeling of the ring is much more variable than that found in the other late $X^{\prime}$ 's studied. This is especially true in ring $X^{\prime}$ 's obtained from the 3-hr labeled cultures. Many metaphases have very low grain counts, indicating that only a few chromosomes were still synthesizing DNA at the time of addition of $\mathrm{H}^{3}$ thymidine. The ring is unlabeled in some of these metaphases, indicating that it had finished DNA synthesis before the last autosomes.

Since the method used to analyze the grain count data in the study of the ring is similar to that used in our previous studies of the normal female, XXXXY male and $\mathrm{XX}_{\mathrm{I}}$ female, we can compare the data from the ring with these other cases (Figure 3). Data for the isochromosome- $X$ (which is 20 per cent larger than the normal $\mathrm{X}$ ) has been adjusted by multiplying the grain counts by $5 / 6$. 


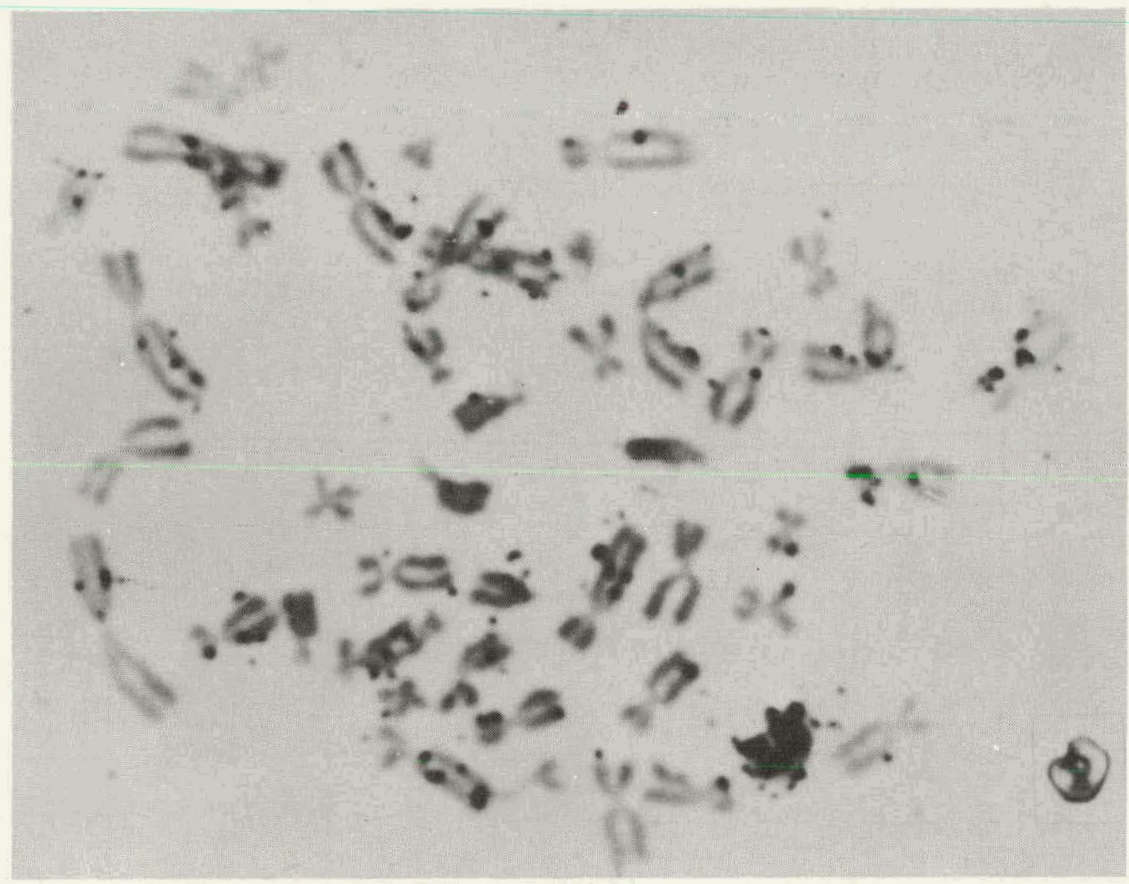

Figure 1. Photomicrographs of autoradiograms of metaphase chromosomes from $\mathrm{XX}_{\mathrm{R}}$ cells. The arrow indicates the heavily labeled ring $\mathrm{X}$-chromosome. The insert shows the ring $\mathrm{X}$-chromosome before coating with stripping film.

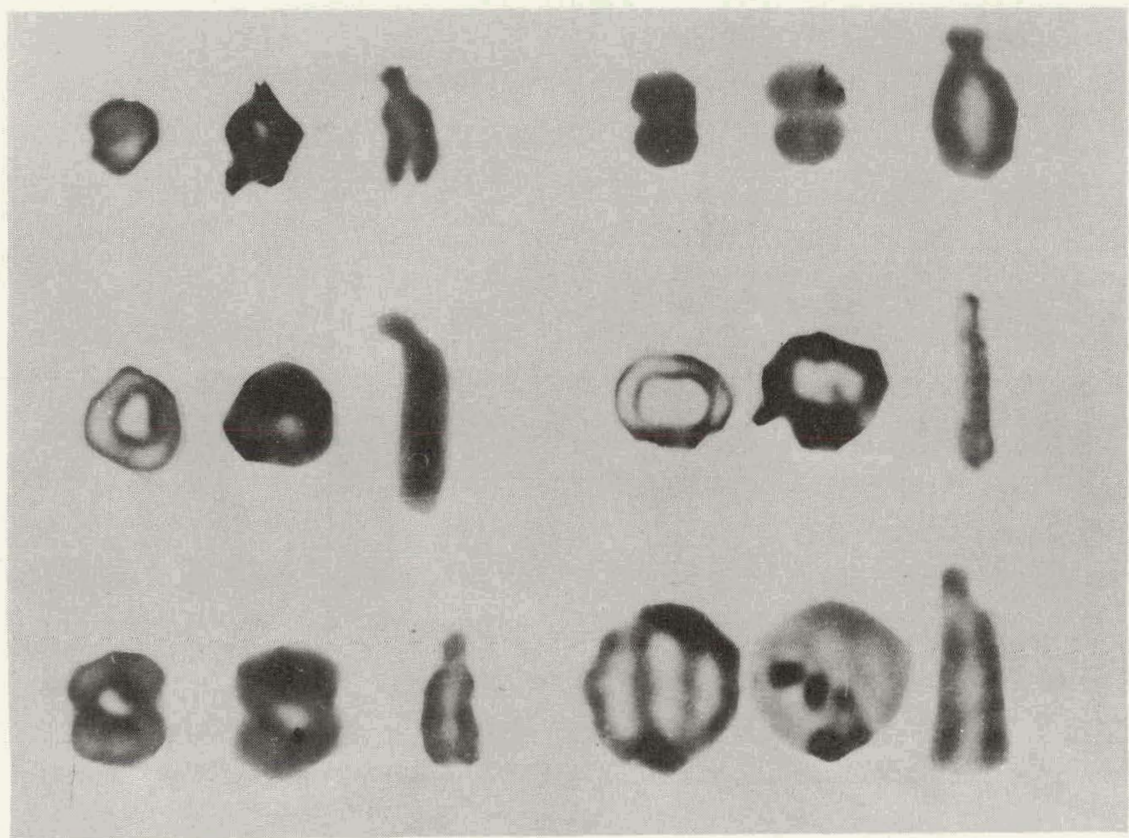

Figure 2. Ring $\mathrm{X}$-chromosomes from six metaphases showing variation in size and shape. Each group contains the pre- and post-coating ring $\mathrm{X}$-chromosome and the largest chromosome in the 13-15 group for comparison. 
Table 1

COMPARISON OF NUMBER OF AUTORADIOGRAPHIC GRAINS

FOR 3-HR AND 4-HR INCUBATION

A. Incubation with $\mathrm{H}^{3}$ Thymidine for $3 \mathrm{Hr}$

\begin{tabular}{|c|c|c|c|c|c|}
\hline $\begin{array}{c}\text { Grains } / \text { ring } \\
\text { (a) }\end{array}$ & $\begin{array}{c}\text { Grains/45 } \\
\text { chromosomes (b) }\end{array}$ & $\begin{array}{c}\text { Mean } \\
\text { grains/ring }\end{array}$ & $\begin{array}{l}\text { Mean grains/45 } \\
\text { chromosomes }\end{array}$ & $\begin{array}{l}\text { Proportion } \\
\text { of sample } \\
\text { to total }\end{array}$ & $\begin{array}{l}\text { Proportion of } \\
\text { ring to } 45 \\
\text { chromosomes }(\mathrm{a} / \mathrm{b})\end{array}$ \\
\hline $\begin{array}{c}0 \\
5 \\
7 \\
5 \\
0 \\
14 \\
0 \\
1 \\
4 \\
0 \\
9 \\
3 \\
1 \\
3 \\
8 \\
8 \\
2,1 \\
14 \\
3,4 \\
11 \\
3 \\
11 \\
13 \\
7 \\
0,0,0\end{array}$ & $\begin{array}{r}3 \\
6 \\
11 \\
12 \\
15 \\
16 \\
17 \\
19 \\
23 \\
27 \\
27 \\
28 \\
31 \\
42 \\
42 \\
43 \\
43 \\
52 \\
54 \\
58 \\
70 \\
71 \\
75 \\
93 \\
96\end{array}$ & 5.32 & 39 & 0.32 & 0.14 \\
\hline $\begin{array}{r}2 \\
10 \\
0 \\
8 \\
4 \\
1 \\
2 \\
14 \\
31 \\
5 \\
3 \\
6 \\
5 \\
0 \\
0 \\
7 \\
7\end{array}$ & $\begin{array}{l}111 \\
111 \\
115 \\
125 \\
126 \\
129 \\
136 \\
137 \\
143 \\
145 \\
150 \\
150 \\
155 \\
162 \\
173 \\
180 \\
195\end{array}$ & 6.18 & 144 & 1.21 & 0.04 \\
\hline $\begin{array}{r}12 \\
10 \\
4 \\
14 \\
28 \\
14 \\
22 \\
17\end{array}$ & $\begin{array}{l}250 \\
255 \\
259 \\
269 \\
336 \\
367 \\
437 \\
450\end{array}$ & 10 & $\begin{array}{l}258 \\
398\end{array}$ & $\begin{array}{l}2.13 \\
3.28\end{array}$ & $\begin{array}{l}0.04 \\
0.05\end{array}$ \\
\hline
\end{tabular}

* Mean grain count for 45 chromosomes $=121$ 
Table 1 (continued)

B. Incubation with $\mathrm{H}^{3}$ Thymidine for $4 \mathrm{Hr}$

\begin{tabular}{|c|c|c|c|c|c|}
\hline $\begin{array}{l}\text { Grains/ring } \\
\text { (a) }\end{array}$ & $\begin{array}{l}\text { Grains/45 (b) } \\
\text { chromosomes (b) }\end{array}$ & $\underset{\text { grains/ring }}{\text { Mean }}$ & $\begin{array}{c}\text { Mean grains } / 45 \\
\text { chromosomes }\end{array}$ & $\begin{array}{c}\text { Proportion } \\
\text { of sample } \\
\text { to total }\end{array}$ & $\begin{array}{l}\text { Proportion of } \\
\text { ring to } 45 \\
\text { chromosomes }(\mathrm{a} / \mathrm{b})\end{array}$ \\
\hline $\begin{array}{r}12 \\
7 \\
10 \\
4 \\
2 \\
13 \\
11 \\
21 \\
14\end{array}$ & $\begin{array}{l}16 \\
20 \\
32 \\
34 \\
40 \\
42 \\
47 \\
71 \\
74\end{array}$ & 10.4 & 41.8 & 0.17 & 0.25 \\
\hline $\begin{array}{l}10 \\
10 \\
13 \\
15 \\
22 \\
13 \\
12 \\
12 \\
16 \\
20 \\
15\end{array}$ & $\begin{array}{l}110 \\
111 \\
114 \\
120 \\
124 \\
146 \\
157 \\
161 \\
166 \\
176 \\
178\end{array}$ & 14.4 & 142 & 0.57 & 0.10 \\
\hline $\begin{array}{r}12 \\
20 \\
7 \\
18 \\
10 \\
18\end{array}$ & $\begin{array}{l}207 \\
228 \\
261 \\
262 \\
271 \\
276\end{array}$ & 14 & 251 & 1.00 & 0.06 \\
\hline $\begin{array}{r}9 \\
17 \\
20 \\
23 \\
25 \\
2 \\
25 \\
20 \\
62 \\
28 \\
27 \\
35\end{array}$ & $\begin{array}{l}304 \\
316 \\
353 \\
383 \\
383 \\
400 \\
488 \\
536 \\
582 \\
657 \\
768 \\
901\end{array}$ & 24.4 & 506 & 2.02 & 0.05 \\
\hline
\end{tabular}

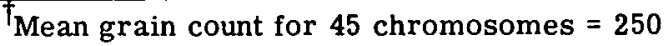

$\begin{array}{ll}\mathrm{X} / 45 \text { ratio for late } \mathrm{X} \text { in normal XX female: } & 0.17 \\ 3 \text { late } \mathrm{X}^{\prime} \mathrm{s} \text { in } \mathrm{XXXXY} \text { male: } & 0.18 \\ \mathrm{X}_{\mathrm{I}} \text { in } \mathrm{XX}_{\mathrm{I}} \text { female: } & 0.15 \\ \mathrm{X}_{\mathrm{R}} \text { in } \mathrm{XX}_{\mathrm{R}} \text { female } & 0.06-0.07\end{array}$

As can be seen from Figure 3, the pattern of DNA synthesis of the ring is similar to that of other $\mathrm{X}$-chromosomes in that the ring $\mathrm{X}$ contributes the greatest proportion of grains in metaphases with the lowest degree of labeling (0.1 to 0.3$)$. This is a logical finding since a late synthesizing chromosome will become most apparent in those metaphases in which almost all other chromosomes have finished synthesis.

The regression curve for the ring $\mathrm{X}$-chromosome falls below that of the other $\mathrm{X}$-chromosomes, 

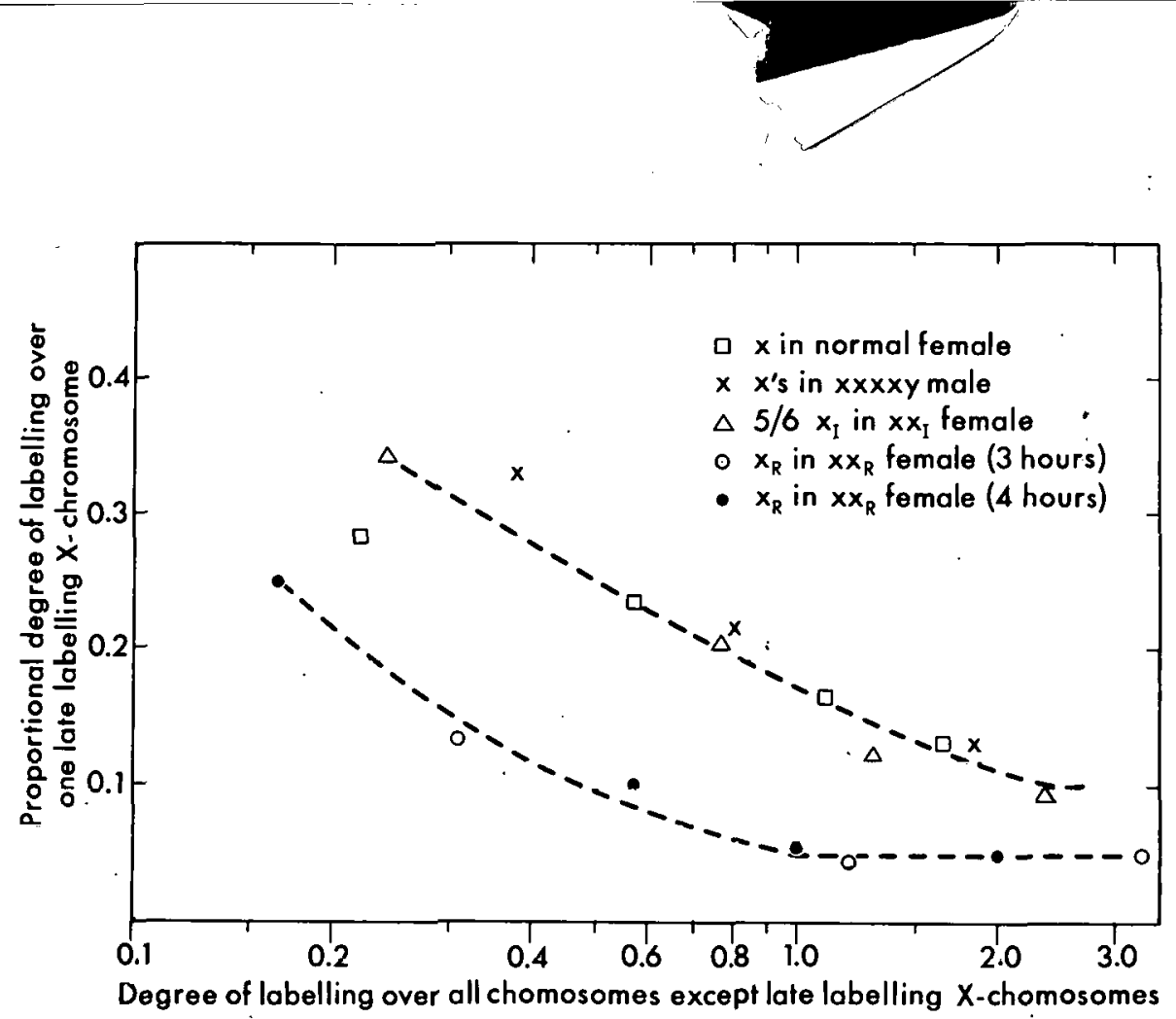

Figure 3. Comparison of late labeling X-chromosomes. Regression time relating the proportion of grains over the late labeling $\mathrm{X}$-chromosomes to the grains over the other chromosomes in cells with different total label.

although the differences in the slope of these regression curves is not significant. There are two obvious explanations for this. First, as can be seen in Table 1, 14 metaphases have been included which are heavily labeled, i.e., above 300 grains, whereas in the study of the late $\mathrm{X}$ of the XXXXY male, metaphases had a maximum of 305 grains. The inclusion of the heavily labeled metaphases has the effect of shifting the ring $X$ curve to the left of that for the other $X$-chromosomes. Second, the ring $\mathrm{X}$-chromosome is smaller that the normal $\mathrm{X}$-chromosome. The problem of correcting for variations in ring size is a difficult one. Ring chromosomes are structurally unstable with frequent deletions and duplications. ${ }^{15}$ We have not adjusted individual rings to a standard sizefor example, the normal $\mathrm{X}$ - in each metaphase, because of the difficulties involved in measuring ring chromosomes. Even at the lowest point of the regression curve the ring $\mathrm{X}$-chromosome is labeled more heavily than the average chromosome of equivalent size.

The hypothesis that the late synthesizing $\mathrm{X}$-chromosome forms the sex chromatin body is supported by the fact that the sex.chromatin bodies in 5 patients with presumptive isochromosomes for the long arm of the $X$ have a greater amount of DNA than do those of the normal female. ${ }^{14}$ The measurement of the DNA content of the sex chromatin bodies present in cells from the bone marrow and a lymph node obtained from the present patient has not been completed. Thus it is not possible at present to correlate their size with the estimated size of the ring $X$.

It has been proposed that the late synthesizing $\mathrm{X}$-chromosome is heteropycnotic and genetically "inactive" in the interphase nucleus. 3 The "Lyon Hypothesis" 16 was formulated to explain the variegated expression of $\mathrm{X}$-linked genes in female mice with two normal $\mathrm{X}$-chromosomes. The recent finding by Ohno and Cattanach ${ }^{17}$ that in the skin of mice with variegated phenotype, positive heteropycnosis is apparently associated with genetic "inactivity" strengthens the inactive-X hypothesis for this species. However, Russell's experiments ${ }^{18}$ in female mice using $\mathrm{X}$ - 
chromosomes containing an autosomal translocation show that there is a gradient of inactivation spreading over a limited distance. It has been suggested that the inactive- $\mathrm{X}$ hypothesis can apply to all female mammals. 19

Recently, Benirschke et al.$^{20}$ have studied $\mathrm{H}^{3}$ thymidine labeled tissue-culture cells of a female hybrid between a donkey (male) and a Grevy zebra (female). A late replicating chromosome was found which in some cells possessed the morphologic features of a donkey $\mathrm{X}$. In other cells it resembled a more metacentric chromosome tentatively identified as the Grevy zebra X. Although not enough cells could be studied to determine whether random or selective late replication of one or the other of the sex chromosomes took place, the evidence suggests the existence of two populations of late replicating $\mathrm{X}$ chromusumes.

Davidson et al. ${ }^{21}$ have demonstrated quite elegantly the existence of two populations of cells cloned from skin cell cultures obtained from Caucasian females heterozygous for G-6-PD deficiency and Negro females found to have two G-6-PD electrophoretic bands. Analysis of four clones from each of the Caucasian females showed that in each case one clone was clearly in the deficient range and three were in the normal range. Clones from single cells obtained from the Negro females yielded only single electrophoretic bands. This seems to favor the "Lyon Hypothesis"-in each single cell of the female only one G-6-PD locus is operative.

Additional evidence supporting this conclusion has just been published by Beutler et al. ${ }^{22}$

The $\mathrm{X}$-linked gene involved in gamma globulin production apparently also shows $\mathrm{X}$-inactivation. Bach et al. ${ }^{23}$ have shown that 65-75 per cent of lymphocytes obtained from females heterozygous for agammaglobulinemia stain with flourescein-conjugated anti-human gamma globulin as compared with 95 per cent of lymphocytes from normal controls. This appears to indicate two populations of cells, those with and those without gamma globulin production.

However, these findings do not imply that an entire $\mathrm{X}$ chromosome is inactivated in the human female. Sanger et al. ${ }^{24}$ Gorman et al.,${ }^{25}$ and Reed et al. ${ }^{26}$ failed to find mosaicism in females heterozygous for the sex-linked $\mathrm{Xg}^{\mathrm{a}}$ blood group. Thus it appears that each locus must be tested separately for evidence of $\mathrm{X}$-inactivation.

Two cases of presumptive isochromosome for the long arm of the $\mathrm{X}$ have recently been used as evidence that the $\mathrm{Xg}^{\mathrm{a}}$ blood group genes are on the short arm of the $\mathrm{x}^{27}$ Each patient is $\mathrm{Xg}(\mathrm{a}-)$ while both father and mother are $\mathrm{Xg}(\mathrm{a}+)$. The patient obtains her normal $\mathrm{X}$-chromosome from her mother and the isochromosome from her father. It is postulated that since she lacks her father's $\mathrm{Xg}^{\mathrm{a}}$ antigen, it must be located on the short arm of the $\mathrm{X}$-chromosome. The authors have recognized the possibility that the isochromosomes of both of the patients could reflect merely lack of gene action and would not afford evidence of the arm on which $\mathrm{Xg}^{2}$ is located. However, since there is, at present, no proof that $\mathrm{X}$ inactivation applies to the $\mathrm{Xg}^{\mathrm{a}}$ gene, the postulate appears valid.

The applicability of this type of genetic evidence must await further clarification of the relationship of the late labeling $\mathrm{X}$ and the sex chromatin body to genetic "activity".

Our studies indicate that in metaphases containing morphologically abnormal X-chromosomes, only the abnormal $\mathrm{X}$ is late labeling. The extension of the "Lyon Hypothesis" of random inactivation of one of two normal X-chromosomes, to apply to morphologically abnormal X-chromosomes, requires some modification of the hypothesis. It is possible that there is random "inactivation" of either the normal, or the structurally abnormal $X$; but the genetic deficiencies of the structurally abnormal $\mathrm{X}$ would be lethal, and the cell line with the genetically "active" ring $\mathrm{X}$ or iso- $\mathrm{X}$ would 
die. The only surviving cell lines would have the normal X "active". An alternative hypothesis can be formulated: if one $\mathrm{X}$-chromosome is deficient, the normal $\mathrm{X}$ always remains "active," whereas the abnormal $\mathrm{X}$ is genetically inactive and is the late synthesizing $\mathrm{X}$-chromosome which forms the sex chromatin body. It is not possible at present to determine which hypothesis is correct: either would result in the genetic "inactivation" of the abnormal X-chromosome in all cells.

Whatever the mechanism is that results in late-labeling in 1) morphologically normal $\mathrm{X}$ chromosomes in excess of one per cell and 2) morphologically abnormal $\mathrm{X}$ chromosomes (for example, presumptive isochromosomes for both the long and short arm, the ring $\mathrm{X}$, and an $\mathrm{X}$ chromosome with a deletion of the short arm), ${ }^{28}$ it must be able to operate in $\mathrm{X}$ chromosomes which are without either a long or a short arm. Therefore, the postulate of Grumbach et al. ${ }^{8}$ that selective induction of the isopycnotic or heteropycnotic state in the aberrant $\mathrm{X}$ chromosome might involve the incorporation of an episomal factor into an $\mathrm{X}$ chromosome at a specific receptive locus does not explain the late-replicating pattern of the many aberrant $\mathrm{X}$ chromosomes studied to date.

\section{ACKNOWLEDGMENTS}

The authors acknowledge the kindness of Dr. K. G. Tillinger for permission to study this patient. They thank Jessie Eastwood, Judith Mikuta and Anita Tillberg for their technical assistance. Dr. Lindsten wishes to thank Nordisk Insulinfond for a personal grant; Dr. Rowley acknowledges a personal grant from the Dr. Julian D. Levinson Research Foundation for Mentally Retarded Children.

\section{LITERATURE CITED}

1. German, J. L. Lancet 1:764, 1962, Trans. N.Y. Acad. Sci., 24;395, 1962.

2. Morishima, A., M. M. Grumbach, and J. H. Taylor. P.N.A.S. (U.S.), 48:756, 1962.

3. Gilbert, C. W., S. Muldal, L. G. Lajtha, and J. Rowley. Nature, 195:869, 1962.

4. Moorhead, P. S., and V. S. Defendi. J. Cell. Biol., 16:202, 1963.

5. Rowley, J., S. Muldal, C. W. Gilbert, L. G. Lajtha, J. Lindsten, M. Fraccaro, and K. Kaijser. Nature, 197:251, 1963.

6. Mukherjee, B. B., O. J. Miller, W. R. Breg, and S. Bader. In preparation.

7. Atkins, L., J. A. Böök, K.-H. Gustavson, O. Hansson, and M. Hjelm. Cytogenet. $2: 208,1963$.

8. Grumbach, M. M., A. Morishima, and J. H. Taylor. P.N.A.S. (U.S.), 49:581, 1963.

9. Muldal, S., C. W. Gilbert, L. G. Lajtha, J. Lindsten, J. Rowley, and M. Fraccaro. Lancet, $1: 861,1963$.

10. Gianelli, F. Lancet, $1: 863,1963$.

11. Miller, O. J., B. B. Mukherjee, S. Bader, and A. C. Christakos. Nature, 200:918, 1963.

12. Fraccaro, M., D. Ikkos, J. Lindsten, R. Luft, and K. Kaijser. Lancet, 2:1144,1960.

13. Lindsten, J., and K.-G. Tillinger. Lancet, 1:593, 1962.

14. Lindsten, J. The Nature and Origin of X Chromosome Abberations in Turner's Syndrome, Uppsaala, Sweden; Almquist and Wiksel, 1963. 
15. McClintock, B. Genetics, $23: 315,1938$

16. Lyon, M. F. Am. J. Human Genet., 14:135, 1962.

17. Ohno, S., and B. M. Cattanach. Cytogenet., 1:129, 1962.

18. Russell, L. B. Science, 140:976, 1963.

19. Lyon, M. F. Genetic Res., 4:93, 1963.

20. Benirschke, K., R. J. Low, L. E. Brownhill, L. B. Caday, and J. deVeneccia-Fernandez. Chromosoma, in press.

21. Davidson, R. G., H. M. Nitowsky, and B. Childs. P.N.A.S. (U.S.), 50:481, 1963.

22. Beutler, E., and M. Baluda. Lancet, 1:189, 1964.

23. Bach, F., and K. Hirschhorn. Proc. 11th Intern. Congr. Genet. p. 312, 1963.

24. Sanger, R., R. R. Race, P. Tippett, J. Hamper, J. Gavin, and T. E. Cleghorn. Vox Sang. $7: 571,1962$.

25. Gorman, J. G., A. M. Treacy, and A. Cahan. J. Lab. Clin. Med., 61:642, 1963.

26. Reed, T. E., N. E. Simpson, and B. Chown. Lancet, 2:467, 1963.

27. Lindsten, J., M. Fraccaro, P. E. Polani, J. L. Hamerton, R. Sanger, and R. R. Race. Nature, 197:648, 1963.

28. Muldal, S., L. Tiepolo, M. Fraccaro, and J. Lindsten. Unpublished data. 
By

R. H. Palmer

A number of neutral and acidic steroids produce fever and inflammation in man. ${ }^{1}$ Inflammation probably reflects the cytotoxicity of these compounds, and since hemolysis is one expression of cellular toxicity, several steroids were investigated for hemolytic properties in vitro, and their hemolytic and pyrogenic activities compared.

Steroids were dissolved in $0.5 \mathrm{ml}$ methanol and added to $2.0 \mathrm{ml} 0.02 \mathrm{M}$ phosphate buffered saline ( $\mathrm{pH} 6.6$ ); $0.05 \mathrm{ml}$ of a 50 per cent suspension of washed human erythrocytes were then added and gently mixed. After incubation at $37.0^{\circ} \mathrm{C}$, the suspensions were centrifuged and the hemoglobin in an aliquot of supernatant determined by conversion to cyanmethemoglobin with Drabkins reagent and measurement of the optical density at $540 \mathrm{~m} \mu$. Because the absolute rate of hemolysis varied widely with small $\left(0.5-1.0^{\circ} \mathrm{C}\right)$ changes in temperature, incubations were performed with several concentrations of each steroid for a given time and with one concentration of each steroid for different periods of time. The resulting hemolytic curves permitted accurate assessment of the relative hemolytic potency of these compounds when appropriate sections of the curves were compared.

Table 1 shows the relative hemolytic activity of several neutral and acidic steroids. The bile

Table 1

HEMOLYTIC ACTIVITY OF NEUTRAL AND ACIDIC STEROIDS*

\begin{tabular}{l|c}
\hline \multicolumn{1}{c|}{ Steroid } & $\Delta$ O.D. $540 \mathrm{~m} \mu$ \\
\hline Glycolithocholic acid & 0.590 \\
Taurolithocholic acid & 0.539 \\
Lithocholic acid & 0.533 \\
Deoxycholic acid & 0.517 \\
Chenodeoxycholic acid & 0.225 \\
Progesterone & 0.203 \\
11-ketopregnanolone & $0.174 \quad 0$ \\
Testosterone & 0.173 \\
Cholic acid & 0.139 \\
Control & 0.130 \\
\hline
\end{tabular}
minutes.

Steroid concentration: $0.04 \mu \mathrm{M} / \mathrm{ml}$. Incubation: $37.0^{\circ} \mathrm{C}$ for 120

$\Delta$ O.D. of 0.320 represents $50 \%$ hemolysis.

\footnotetext{
This paper appeared in Nature, 201:1134, 1964.
} 
acid results confirm and extend the earlier work of Berliner and Schoenheimer ${ }^{2}$ and Grodins, Berman and Ivy. ${ }^{3}$ Both lithocholic and deoxycholic acids are strongly hemolytic, while the primary bile acids, from which they are derived by $\mathrm{C} 7$ dehydroxylation (i.e., chenodeoxycholic and cholic acid respectively), are considerably less so. Lithocholic acid and its taurine and glycine conjugates all have equivalent hemolytic properties; in man, they also all produce intense inflammation, but taurolithocholic acid is unique in being non-pyrogenic.

Tateno and Kilbourne ${ }^{4}$ have reported that progesterone is more hemolytic than testosterone, and Segaloff ${ }^{5}$ has described hemolytic properties of some testosterone derivatives in vitro and in vivo. In this investigation, as shown in Table 1, these and other neutral steroids were found to be intermediate in activity, falling between chenodeoxycholic and cholic acids. Their relative potency is shown better in the first column of Table 2, with lithocholic acid for comparison.

Table 2

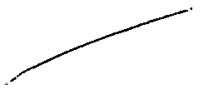

INHIBITION OF STEROID HEMOLYSIS BY SERUM ALBUMIN*

\begin{tabular}{l|c|c|c}
\hline \multirow{2}{*}{ Steroid } & \multicolumn{3}{c}{ Albumin concentration $\mathrm{mg} / \mathrm{ml}$} \\
& $\underline{0}$ & $\underline{7}$ & $\underline{14}$ \\
& $\Delta$ O.D. & $540 \mathrm{~m} \mu$ above controls \\
\hline Lithocholic acid & 0.536 & 0.300 & 0.148 \\
Progesterone & 0.326 & 0.223 & 0.157 \\
Etiocholanolone & 0.306 & 0.255 & 0.217 \\
Androsterone & 0.242 & 0.158 & 0.148 \\
11-ketopregnanolone & 0.226 & 0.188 & 0.104 \\
\hline
\end{tabular}
minutes.

Steroid concentration: $0.2 \mu \mathrm{M} / \mathrm{ml}$. Incubation: $37.0^{\circ} \mathrm{C}$ for 110

$\triangle$ O.D. of 0.320 represents $50 \%$ hemolysis.

Lithocholic acid, etiocholanolone and 11-ketopregnanolone are potent fever producing agents; the thermogenic properties of progesterone and androsterone are less consistent and less pronounced; and deoxycholic acid, chenodeoxycholic acid and testosterone are not pyrogenic. Clearly there appears to be no correlation between hemolytic and pyrogenic' activities.

Hemolysis produced by all of the steroids examined was inhibited by human serum, a finding in keeping with most studies on hemolysis. ${ }^{6}$ The inhibitory effects of two serum components, cholesterol and albumin, on steroid hemolysis were examined; although cholesterol caused some inhibition, particularly of bile acid hemolysis, albumin alone could account for most of the inhibitory effects of serum. 'Table 2 shows the results of incorporating small amounts of human serum albumin in the test system described.

Data in the literature indicate that the relative binding of steroids to human serum albumin is lithocholic acid > deoxycholic and chenodeoxycholic acids > cholic acid, ${ }^{7}$ and progesterone > testosterone. ${ }^{8}$ Red cells also bind more progesterone than testosterone, ${ }^{8}$ and adsorption of bile acids to red blood cells precedes their lysis. ${ }^{9}$ Thus the hemolytic potency of these steroids correlates with the extent of protein binding, and it is possible that both hemolysis and its inhibition may be related to the relative affinity of the steroids for erythrocytes and serum protein. The ex- 
act mechanism by which steroids effect hemolysis is not clear, but in this investigation no methemoglobin formation could be demonstrated. In addition, the extreme temperature sensitivity of the hemolytic test system further suggests that physical rather than enzymatic processes are involved.

These investigations extend the number of neutral and acidic steroids shown to have hemolytic properties, and, together with previous observations, ${ }^{1}$ indicate that the cytotoxic or inflammatory properties of steroids are independent of their pyrogenic activity.

\section{ACKNOWLEDGMENT}

The author wishes to express appreciation to Dr. Attallah Kappas for encouragement and support of these studies.

\section{LITERATURE CITED}

1. Kappas, A., and R. H. Palmer. Pharm. Rev., 15:123, 1963.

2. Berliner, F., and R. Schoenheimer. J. Biol. Chem., 124:525, 1938.

3. Grodins, F. S., A. L. Berman, and A. C. Ivy. J. Lab. Clin. Med., 27:181, 1941.

4. Tateno, I., and E. D. Kilbourne. Proc. Soc. Exptl. Biol., N;Y., 86:186, 1954.

5. Segaloff, A. J. Clin. Endocrinol. and Metabolism, 14:244, 1954.

6. Ponder, E. Hemolysis and Related Phenomena, New York, Grune and Stratton, Inc., 1948, p. 263.

7. Rudman, D., and F. E. Kendall. J. Clin. Invest., 36:538, 1957.

8. Sandberg, A. A., W. R. Slaunwhite, Jr., and H. N. Antoniades. Recent Progr. Hormone Research, 13:209, 1957 .

9. Croes, R., and R. Ruyssen. Nature, 171:846, 1953. 


\section{METABOLITES OF LITHOCHOLIC ACID-24- $\mathrm{C}^{14}$ IN HUMAN BILE AND FECES}

By

\section{A. Norman ${ }^{\dagger}$ and R. H. Palmer ${ }^{\ddagger}$}

Lithocholic acid ${ }^{\S}$ is an endogenous steroid which has recently been shown to have potent pyrogenic and inflammatory activity $\ln \operatorname{man}^{1}$ and to produce cirrhosis of the liver in several species. ${ }^{2,3}$ It is present in human bile $e^{4}$ and feces, 5 and, because of its extremely toxic properties, is a substance of potential pathogenic significance in various diseases of the gastrointestinal tract. Knowledge of its metabolism is therefore of importance, and in this report data are presented concerning the metabolites of orally-administered lithocholic acid-24- $\mathrm{C}^{14}$ in human bile and feces.

\section{METHODS}

Preparation of $\mathrm{C}^{14}$-labeled compounds. Labeled lithocholic acid (3a-monohydroxycholanic acid-24-C ${ }^{14}$ ), with a specific activity of $8 \mu \mathrm{c}$ per $\mathrm{mg}$, was synthesized according to the method of Bergström, Rottenberg, and Voltz. ${ }^{6}$ Methyl 3-ketocholanate-24- $\mathrm{C}^{14}$ was prepared by oxidation with aluminum tert-butoxide, ${ }^{7}$ and methyl isolithocholate- $24-\mathrm{C}^{14}$ by reduction of the 3-keto derivative with $\mathrm{H}_{2}-\mathrm{PtO}_{2} \cdot{ }^{8}$ Taurolithocholic acid-24- $\mathrm{C}^{14}$ and glycolithocholic acid-24- $\mathrm{C}^{14}$ were synthesized by the method of Bergström and Norman. 9,10

Clinical material. Lithocholic acid-24- $\mathrm{C}^{14}(11 \mu \mathrm{c})$, as the sodium salt was given orally in a dilute ethanol solution to 4 patients with radiologically functioning gallbladders 20 hours (2 patients) and 72 hours (2 patients) before elective cholecystectomy for cholelithiasis. The patients had no clinical or laboratory evidence of any other disease of the liver or gastrointestinal system. Feces from the latter 2 patients were collected in twenty-four hour fractions for analysis. Bile was obtained at operation, and neither the bile nor the gallbladder wall gave any gross indication of stasis or infection. Data on the patients are presented in Table 1.

Extraction methods. Fecal specimens were homogenized in 50 parts of acetone and refluxed for 12 hours. After filtration, the residue was further extracted by refluxing with chloroform : methanol 1:1 for 48 hours, ${ }^{11}$ for quantitative extraction of bile acids. The acetone and chloroform : methanol extracts were evaporated separately, dissolved in an alkaline water solution, acidified to $\mathrm{pH} 1$, and extracted with ether and then $\mathrm{n}$-butanol.

\footnotetext{
*Bile Acids and Steroids, 138. The work is part of investigations supported by Statens Medicinska Forskningarăd and Stockholms Läns Landsting. A preliminary report was presented to the International Conference on the Biochemistry of Lipids, Stockholm, Sweden, August 5-7, 1963. This paper appeared in J. Lab. and Clin. Med., 63:986, 1964.

$\dagger$ Department of Clinical Chemistry, iStockholm's,Lans Centralasarett, Danderyd, and Department of Chemistry, Karolinska Institute, Stockholm, Sweden.

Fellow of the National Foundation.

$\$_{\text {The following bile acid trivial names have been employed: lithocholic acid ( } 3 a-\text { monohy- }}$ droxycholanic acid), isolithocholic acid ( $3 \beta$-monohydroxycholanic acid), chenodeoxycholic acid ( $3 a, 7 a$-dihydroxycholanic acid), deoxycholic acid $(3 a, 12 a$-dihydroxycholanic acid), and cholic acid $(3 a, 7 a, 12 a-$ trihydroxycholanic acid).
} 
Table 1

ISOTOPE CONTENT OF GALLBLADDER BILE AFTER ORAL ADMINISTRATION OF $11 \mu \mathrm{c}$ LITHOCHOLIC ACID-24- $\mathrm{C}^{14}$

\begin{tabular}{c|c|c|c|c}
\hline Patient & Age & Sex & $\begin{array}{c}\text { Hours after } \\
\text { administration }\end{array}$ & $\begin{array}{c}\text { Gallbladder bile } \\
(\mathrm{cpm} / \mathrm{ml})\end{array}$ \\
\hline A.D. & 44 & M & 20 & 155,000 \\
M.K. & 54 & F & 20 & 174,000 \\
A.E. & 50 & F & 72 & 20,000 \\
A.L. & 49 & F & 72 & 0 \\
\hline
\end{tabular}

Methanol extracts of bile were prepared by adding $1 \mathrm{ml}$ of bile to $20 \mathrm{ml}$ methanol and refluxing for 4 hours. Bile was hydrolyzed in $5 \mathrm{~N} \mathrm{NaOH}$ for 48 hours at $135^{\circ} \mathrm{C}$ in steel bombs. The hydrolysate was acidified and extracted with ether.

Weak hydrolysis of the chromatographic fractions containing saponifiable derivatives was performed by refluxing for 2 hours in $1 \mathrm{~N} \mathrm{NaOH}$ in 90 per cent methanol. Water was added, the excess methanol evaporated, and the reaction mixture acidified and extracted with ether.

Chromatographic techniques. The phase systems used for chromatography are listed in $\mathrm{Ta}$ ble 2. Columns for reversed phase partition chromatography using phase systems F2, F3, G, and G1, consisted of $4 \mathrm{ml}$ stationary phase supported on $4.5 \mathrm{~g}$ hydrophobic Super Cel, as described previously. ${ }^{12,13}$ For phase system H.D., $3 \mathrm{ml}$ of stationary phase were supported on $4.5 \mathrm{~g}$ Hostalene. ${ }^{14,15}$ For phase systems G, G1, and H.D., up to $50 \mathrm{mg}$ of extract could be used for a $4.5 \mathrm{~g}$ column. For phase systems F2 and F3, however, great care had to be taken to prevent overloading of the column. For example, more than $2 \mathrm{mg}$ of lithocholic acid on a $4.5 \mathrm{~g}$ column was likely

Table 2

\section{CHROMATOGRAPHIC SYSTEMS}

\begin{tabular}{|c|c|c|c|c|c|}
\hline \multicolumn{6}{|c|}{ Partition chromatography } \\
\hline Phase system & Moving phase & $\mathrm{ml}$ & \multicolumn{2}{|c|}{ Stationary phase } & $\mathrm{ml}$ \\
\hline F2(15) & methanol : water & $180: 120$ & \multicolumn{2}{|c|}{ chloroform : heptane } & $45: 5$ \\
\hline F3(15) & methanol : water & $195: 105$ & \multicolumn{2}{|c|}{ chloroform : heptane } & $45: 5$ \\
\hline $\mathrm{G}(16)$ & methanol : water & $255: 45$ & \multicolumn{2}{|c|}{ heptane } & 50 \\
\hline G1(16) & methanol : water & $249: 51$ & \multicolumn{2}{|l|}{ heptane } & 50 \\
\hline H. D. (18) & isopropanol : water. & $165: 135$ & \multicolumn{2}{|c|}{ chloroform : heptane } & $10: 40$ \\
\hline $\mathrm{Td}(19)$ & iso-amyl acetate : heptane & $240: 60$ & \multicolumn{2}{|c|}{ formic acid : water } & $35: 15$ \\
\hline \multicolumn{6}{|c|}{ Thin-layer chromatography } \\
\hline Phase system & \multicolumn{3}{|c|}{ Moving phase } & \multicolumn{2}{|c|}{$\mathrm{ml}$} \\
\hline $\mathrm{I}(20)$ & \multicolumn{3}{|c|}{ trimethyl pentane : ethyl acetate : acetic acid } & \multicolumn{2}{|c|}{$40: 20: 0.5$} \\
\hline$\amalg(20)$ & \multicolumn{3}{|c|}{ trimethyl pentane : ethyl acetate : acetic acid } & \multicolumn{2}{|c|}{$50: 10: 0.2$} \\
\hline III(21) & \multicolumn{3}{|c|}{ n-butanol : water : acetic acid } & \multicolumn{2}{|c|}{$50: 5: 5$} \\
\hline $\operatorname{IV}(22)$ & \multicolumn{3}{|c|}{ propionic acid : iso-amyl acetate : water : n-propanol } & \multicolumn{2}{|c|}{$15: 20: 5: 10$} \\
\hline
\end{tabular}


to result in broad and irregular peaks. When results from larger columns have been shown, the effluent volumes have been corrected to correspond to a $4.5 \mathrm{~g}$ column for the sake of comparison. For $4.5 \mathrm{~g}$ columns, $2 \mathrm{ml}$ fractions were collected and titrated with $0.02 \mathrm{~N} \mathrm{NaOH}$ in methanol. Isotope in the fractions was determined as indicated below.

Ascending paper chromatography was performed using phase system $\mathrm{Td}$, as modified from Sjövall. ${ }^{16}$

Thin-layer chromatography of unconjugated bile acids was performed using systems I and II, ${ }^{17}$ and of conjugated bile acids using systems III and IV. ${ }^{18,19}$ With systems I and II, spots were detected by spraying with concentrated sulfuric acid and heating, while for systems III and IV, spraying the heated plates with 10 per cent phosphomolybdic acid in ethanol, as described by Hofmann, ${ }^{20}$ was found to be more satisfactory.

Alumina chromatography was carried out using the method of Danielsson, Eneroth, Hellström, Linstedt, and Sjövall, ${ }^{21}$ with aluminum oxide grade III (10 g) and eluting with increasing concentrations of benzene in hexane.

Isotope determinations. The isotope content in liquid samples was determined by plating aliquots and counting with a Frieseke-Hoepfner methane gas-flow counter. Isotope on paper strips following paper chromatography or electrophoresis was counted, either stepwise or continuously, in a paper scanner using a Frieseke-Hoepfner windowless counter with a $1 \mathrm{~cm}$ slit. After thin-layer chromatography, radioactive spots were located by autoradiography, using Kodirex roentgen film. For quantitation, the optical density of the film was measured with a Zeiss PMQ II spectrophotometer equipped with a Zeiss Chromatogram-Zusatzgerät, using a wave length of $550 \mathrm{m \mu} .{ }^{22}$ This procedure was found to be reliable and gave results entirely comparable to those obtained with paper chromatography and quantitation by direct scanning or elution of $1 \mathrm{~cm}$ strips.

Paper electrophoresis. Paper electrophoresis was performed in barbiturate buffer of ionic strength $0.1, \mathrm{pH} \mathrm{8.6}$, in an electrical field of 7.5 volts per $\mathrm{cm}$ for 3 hours. ${ }^{23}$ Fifty microliters of bile were used on $4.0 \mathrm{~cm}$ wide strips of Whatman No. 1 paper.

Gel-filtration. The columns measured $1.3 \times 40 \mathrm{~cm}$ and were prepared from Sephadex G-25 in saline. A dilution of $0.5 \mathrm{ml}$ bile in $1.5 \mathrm{ml}$ distilled water was applied and the columns eluted with distilled water at a rate of about $10 \mathrm{ml}$ per hour.

\section{RESULTS}

\section{A. Labeled Compounds in Feces.}

After the oral administration of lithocholic acid-24- $\mathrm{C}^{14}$ to human beings, a wide variety of labeled metabolites were excreted in the feces. A preliminary chromatography of an extract of feces with phase system H.D. revealed that while the free lithocholic acid appeared just after the front, most of the isotope was eluted later in two main regions: one, subsequently shown to consist of Fractions A and B, appeared just before, and one, Fraction C, just after cholesterol. The procedure used to separate the various fecal metabolites is outlined in Figure 1.

Chromatographic Fraction L. Chromatography of the fecal extract with phase system F2, is shown in Figure 2. No labeled metabolites were eluted before the main peak, Fraction $\mathrm{L}$, which contained the free 3 -monohydroxycholanic acids present in feces. ${ }^{21}$ These acids could be separated by thin-layer chromatography (Figure 3), and quantitation of the labeled isomers showed that the $3 \alpha$ form predominated. In all, Fraction L contained less than 4 per cent of the total iso- 


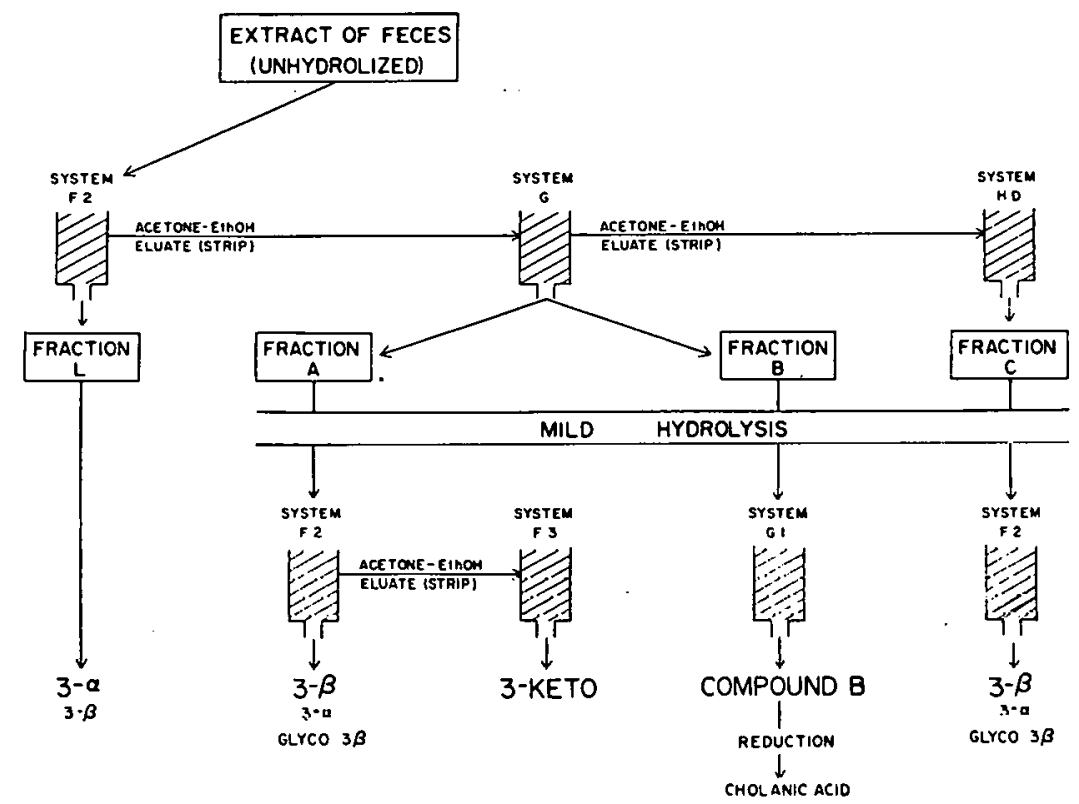

Figure 1. Outline for fractionation and separation of the metabolites of lithocholic acid-24-C14 in feces by reversed phase partition chromatography. $3 \alpha=$ lithocholic acid, $3 \beta$ $=$ isolithocholic acid, 3-Keto $=3$-ketocholanic acid, Glyco$3 \beta=$ glycoisolithocholic acid. For chromatographic systems see Table 2 .

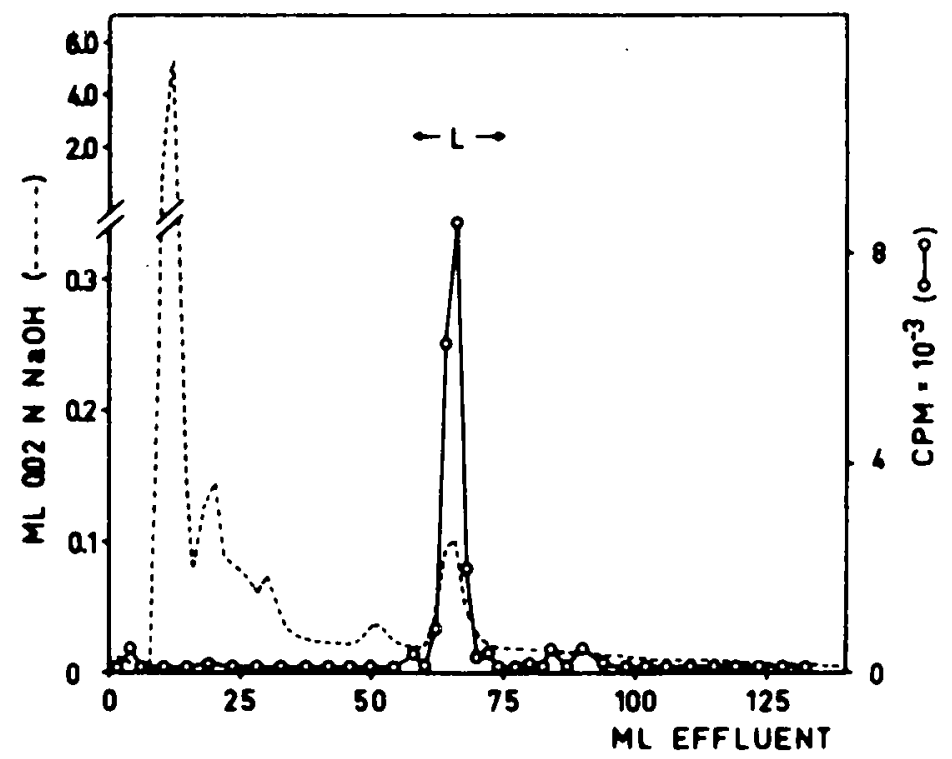

Figure 2. Isolation of the free 3-monohydroxycholanic acid fraction in feces with phase system F2. Feces collected 48 to 72 hours after the oral administration of $11 \mu \mathrm{c}$ lithocholic acid-24-C ${ }^{14}$ to patient $A . E$. were extracted and an aliquot chromatographed as shown. The titration peak corresponding to the isotope peak results from the unlabeled 3-monohydroxycholanic acids present in feces. 


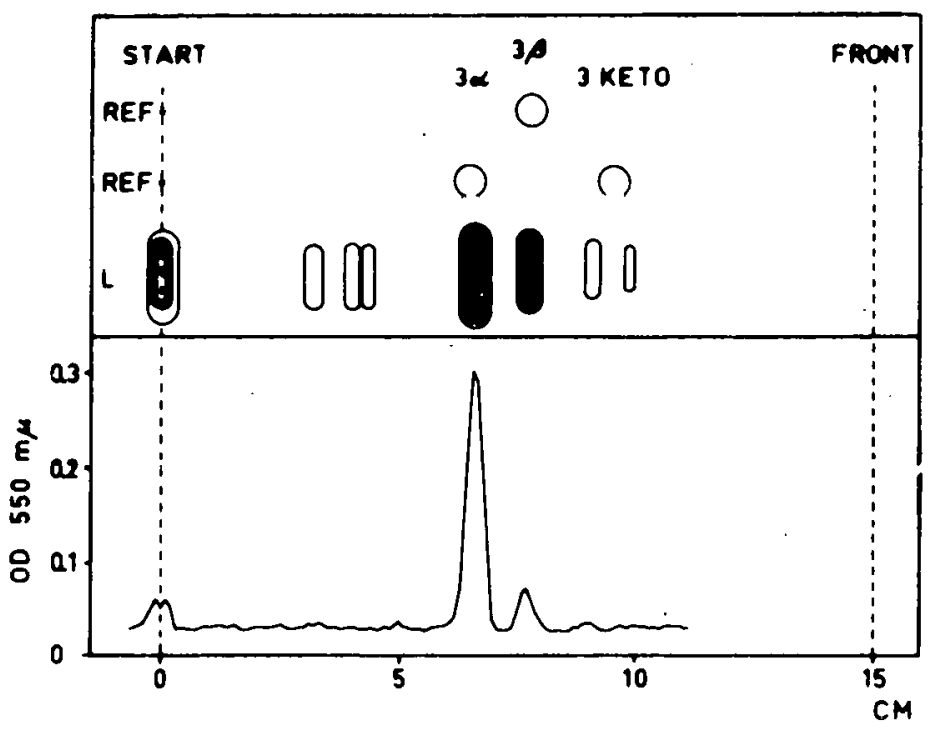

Figure 3. Separation of lithocholic and isolithocholic acids from fraction L, Figure 2, by thin-layer chromatography. System I. Reference substances: lithocholic acid ( $3 \alpha)$, isolithocholic acid ( $3 \beta)$, and 3 -ketocholanic acid (3-keto). In the upper part, open figures represent spots detected by spraying with sulphuric acid, and the cross hatching represents radioactive spots detected by autoradiography. A densiometric recording of the autoradiograph is shown in the lower part.

tope present in the fecal extract. Quantitative data on this and other chromatographic fractions for patients A.E. and A.L. are shown in Table 3.

Chromatographic Fraction A. When the isotope remaining in the stationary phase after chromatography with phase system F2 was eluted with acetone-alcohol and chromatographed with phase system G, two more fractions, designated A and B, could be separated. Weak hydrolysis of Fraction A followed by chromatography with phase system F2 gave a main 3 -monohydroxycholanic acid peak, and a small, more hydrophilic peak. This latter peak had the same mobility as glycolithocholic acid on thin-layer chromatography (system III). Hydrolysis of this conjugate gave a free acid with the mobility of isolithocholic acid (system I). The 3 -monohydroxycholanic acid peak from hydrolyzed Fraction A was found to consist mainly of isolithocholic acid, with only traces of lithocholic acid, when analyzed by thin-layer chromatography (system I). In one patient, A.L., a significant amount of radioactivity remained in the stationary phase following chromatography of hydrolyzed Fraction A with phase system F2. Most of this had the mobility of 3-ketocholanic acid on thin-layer chromatography (system I) and was eluted together with added 3-ketocholanic acid on column chromatography with phase system F3 (Figure 4). With repeated recrystallizations of the isotope together with unlabeled 3-ketocholanic acid, the specific activity remained constant, further confirming its identity. Thus Fraction A contains 3-ketocholanic acid and saponifiable derivatives of isolithocholic and, to a lesser extent, glycoisolithocholic acids.

Chromatographic Fraction B. The second large Fraction (B) obtained from chromatography with phase system $G$ consisted of two main compounds as shown by thin-layer chromatography 
Table 3

PERCENTAGE DISTRIBUTION OF FECAL ISOTOPE IN THE CHROMATOGRAPHIC FRACTIONS AND ITS COMPOSITION AFTER HYDROLYSIS

\begin{tabular}{|c|c|c|c|c|c|c|}
\hline & $\begin{array}{c}\% \\
\text { extracted* }\end{array}$ & $\mathbf{L}$ & A & B & $\mathrm{C}$ & Total \\
\hline Feces A.L. 24 to 48 hours & 94 & & & & & \\
\hline lithocholic acid & & 24.9 & 0.7 & 0 & 1.6 & 27.2 \\
\hline $\begin{array}{l}\text { isolithocholic acid } \\
\text { (glycine conjugated) }\end{array}$ & & $\begin{array}{l}4.5 \\
(0.8)\end{array}$ & $\begin{array}{c}8.0 \\
(0.8)\end{array}$ & 6.8 & 38.9 & 58.2 \\
\hline 3-ketocholanic acid & & 0 & 7.0 & 0 & 0 & 7.0 \\
\hline compound B & & 0 & 0 & 5.0 & 0 & 5.0 \\
\hline \multirow[t]{2}{*}{ unidentified } & & 0 & 2.6 & $\underline{0}$ & 0 & 2.6 \\
\hline & & 29.4 & 18.3 & 11.8 & 40.5 & 100.0 \\
\hline Feces A.E. 24 to 48 hours & 79 & & & & & \\
\hline lithocholic acid & & 8.1 & 0.4 & 0 & 0 & 8.5 \\
\hline $\begin{array}{l}\text { isolithocholic acid } \\
\quad \text { (glycine conjugated) }\end{array}$ & & 1.2 & $\begin{array}{r}13.2 \\
(5.0)\end{array}$ & 5.8 & $\begin{array}{r}62.6 \\
(5.8)\end{array}$ & 82.8 \\
\hline 3-ketocholanic acid & & 0 & 0 & 0 & 0 & 0 \\
\hline \multirow[t]{2}{*}{ compound B } & & $\underline{0}$ & 0 & 8.7 & $\underline{0}$ & 8.7 \\
\hline & & 9.3 & 13.6 & 14.5 & 62.6 & 100.0 \\
\hline Feces A.E. 48 to 72 hours & 95 & & & & & \\
\hline lithocholic acid & & 3.6 & $\dagger$ & 0 & 2.0 & $\dagger$ \\
\hline $\begin{array}{l}\text { isolithocholic acid } \\
\text { (glycine conjugated) }\end{array}$ & & 1.0 & $\dagger$ & $\begin{array}{l}10.4 \\
\text { (trace) }\end{array}$ & 37.6 & $\dagger$ \\
\hline 3-ketocholanic acid & & 0 & 0 & 0 & 0 & 0 \\
\hline \multirow[t]{2}{*}{ compound B } & & 0 & 0 & $\underline{12.8}$ & 0 & 12.8 \\
\hline & & 4.0 & 32.6 & 23.2 & 39.6 & 100.0 \\
\hline
\end{tabular}

${ }^{*} \%$ extracted" refers to the \% of the total isotope present in the acetone extract of feces which was present in the ether extract used for chromatographic analysis.

${ }^{\dagger}$ Not determined.

(system I). The first, running between 3-ketocholanic acid and cholanic acids, was easily saponified by weak hydrolysis, yielding isolithocholic acid. The second component, Compound B, ran slightly more slowly than cholanic acid, and its methyl ester ran slightly more slowly than methyl cholanate on thin-layer chromatography (system II). It could not be acetylated, and was not reduced by sodium borohydride, indicating the absence of hydroxyl or ketone groups. The left part of Figure 5 shows the rechromatography of Fraction B after hydrolysis. The lithocholic acid resulting from hydrolysis of the first component appears in the front. The middle part of Figure 5 shows Compound B separating from added cholanic acid on chromiatography with phase system G1. After catalytic reduction, ${ }^{8}$ however (Figure 5 , right part), the isotope runs together with the added cholanic acid. The identity of the reduction product of Compound $B$ and cholanic acid was confirmed by recrystallization to constant specific activity with unlabeled cholanic acid. The position of the double bond(s) in Compound B has not been established. 


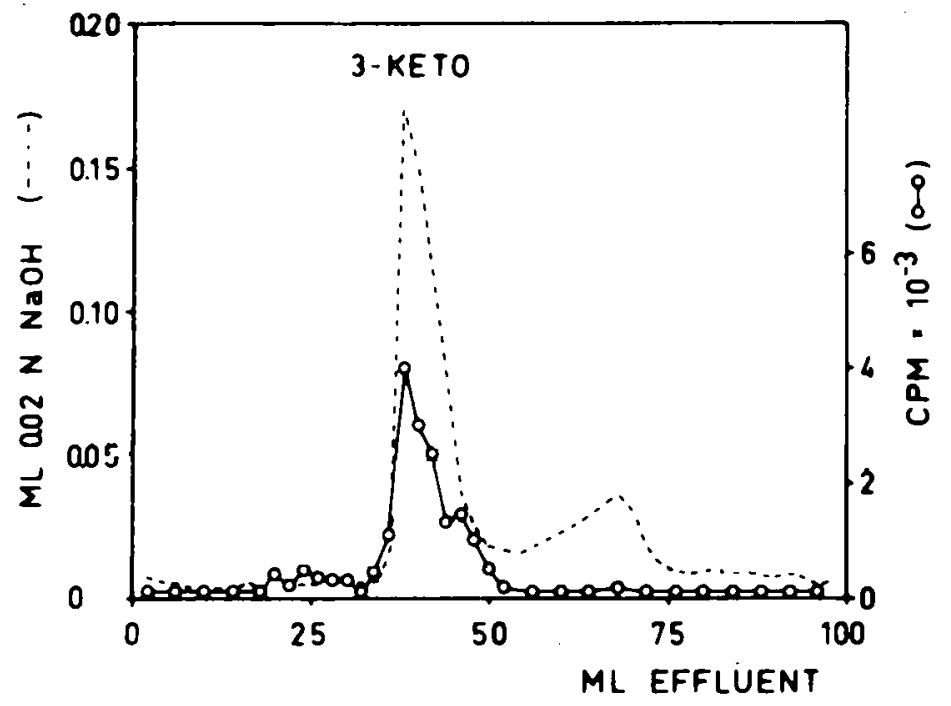

Figure 4. Isolation of labeled 3-ketocholanic acid from feces. Subject A.L., acetone-alcohol eluate from chromatography of hydrolyzed Fraction A with phase system F2, chromatographed with phase system F3. The titration peak is due to added reference: 3 -ketocholanic acid.

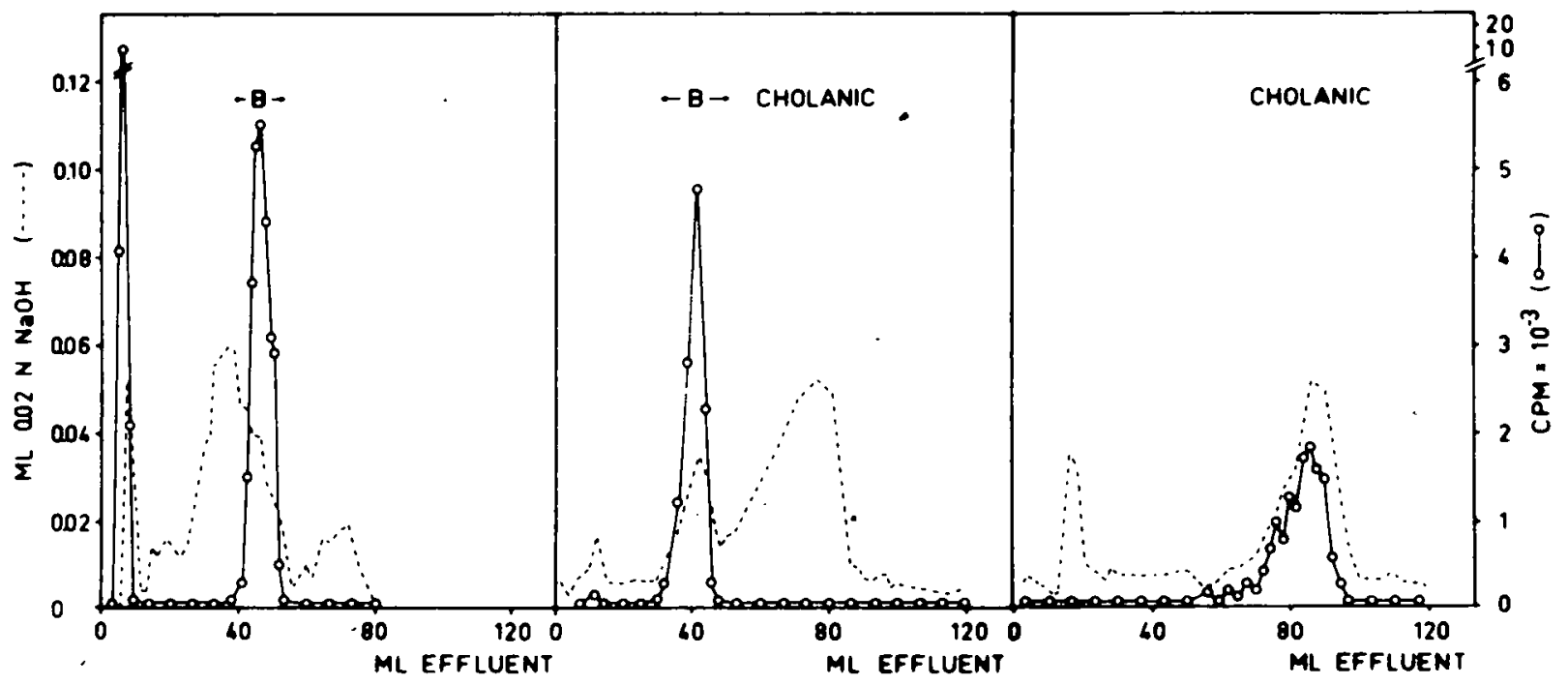

Figure 5. Chromatography of fraction $B$ with added cholanic acid, before and after reduction. Phase system G1. Left part - Fraction B after hydrolysis. Center part Peak B shown in the left part re-chromatographed wilh added cholanic acid. Right part - Re-chromatography of the fractions shown in the center part after reduction with $\mathrm{H}_{2}-\mathrm{PtO}_{2}$.

Chromatographic Fraction C. After elution of Fractions A and B with phase system G1, the compounds remaining in the stationary phase could be eluted with acetone-alcohol and isolated as a broad peak, Fraction C, with phase system H.D. The peak was not homogeneous, as at least two major compounds can be separated on thin-layer chromatography (system I). Weak hydrolysis yielded only isolithocholic acid and traces of glycoisolithocholic acid. 
Table 3 summarizes the results obtained from quantitative analysis, as described above, of the two fecal samples from patient A.E., and one from patient A.L. In addition to the nuclear alterations described above, it can be seen that 65 to 85 per cent of the isotope is present in saponifiable derivatives. These derivatives are not artifacts of the extraction and chromatographic procedures, as no similar products were formed when labeled lithocholic and isolithocholic acids were added to normal feces and isolated in a similar manner. The nature of the derivatives is not known, but they contain acidic groups which can be methylated.

\section{B. Labeled Compounds Present in Hydrolyzed Bile}

The usual hydrolytic procedures, i.e., $1 \mathrm{~N} \mathrm{NaOH}$ for 6 hours at $110^{\circ} \mathrm{C}^{24}$ or $4.5 \mathrm{~N} \mathrm{NaOH}$ for 6 hours at $130^{\circ} \mathrm{C},{ }^{25}$ were found to give varyingly incomplete hydrolysis of lithocholic acid metabolites. Therefore the present method, which always gave complete hydrolysis, was adopted for these investigations.

In the previous section it was shown that following oral administration of lithocholic acid$24-C^{14}$, the major labeled bile acids present in feces are lithocholic acid, isolithocholic acid, 3-ketocholanic acid, and Compound $B$. In the present study, all of these except 3-ketocholanic acid were also found in hydrolyzed bile. Figure 6 (left part) shows the results obtained from the

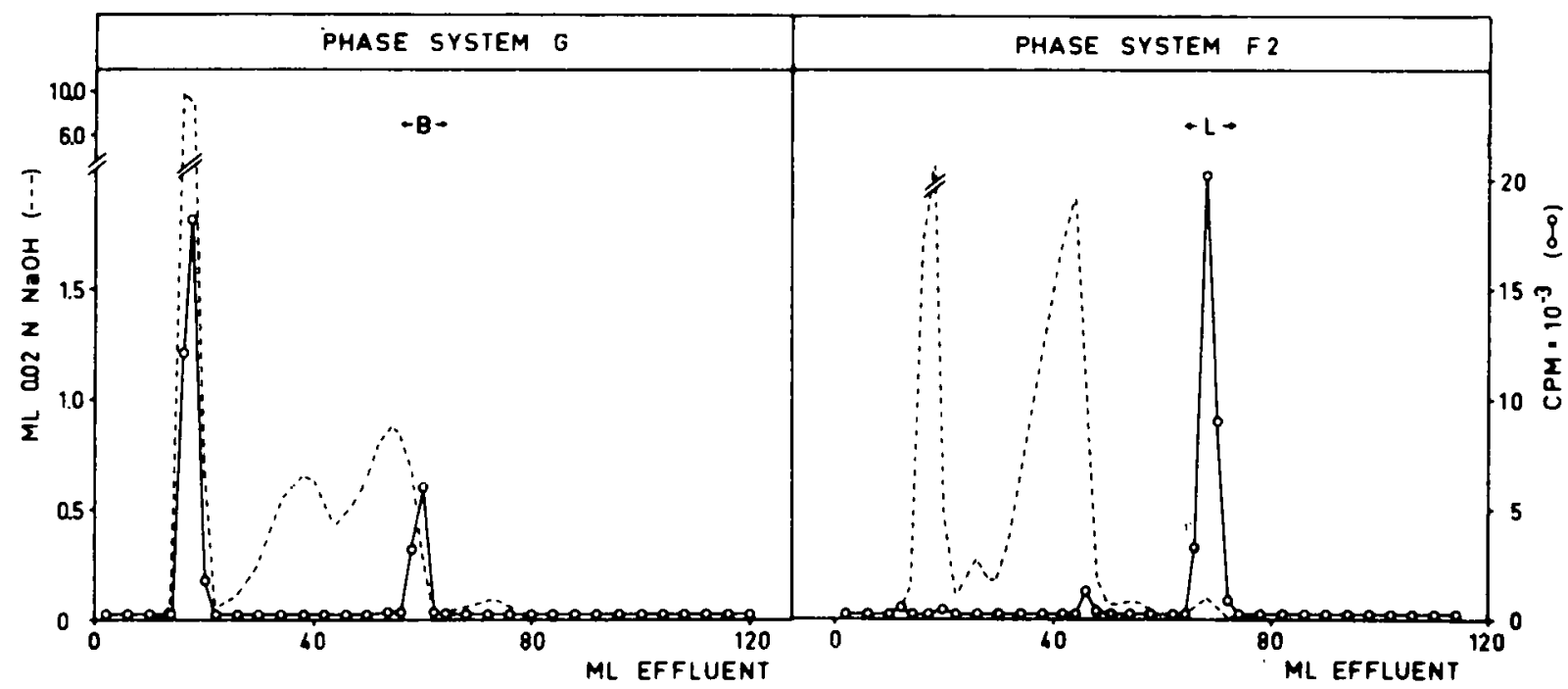

Figure 6. Chromatographic separation of labeled metabolites of lithocholic acid in hydrolyzed bile. Left part - chromatography of $2 \mathrm{ml}$ hydrolyzed bile from patient A.E. with phase system G. Right part - re-chromatography of the front peak shown in the left part with phase system F2.

chromatography of hydrolyzed bile from patient A.E. with phase system G: Labeled compounds are eluted with the front and at 55 to $65 \mathrm{ml}$ effluent. The titration peaks appearing before the latter isotope peak are fatty acids. The isotope in peak $B$ has the same mobility as Compound $B$ from feces on thin-layer chromatography, and the two compounds are presumably the same.

The front peak shown in the left part of Figure 6 was rechromatographed with phase system F2, as shown in the right part. The titration curve shows the cholic acid peak with the front, the dihydroxy-acid peak at 30 to $.50 \mathrm{ml}$, and a small 3 -monohydroxycholanic acid peak at 70 to $80 \mathrm{ml}$. 
Practically all of the radioactivity was found in the 3-monohydroxycholanic acid fraction, thus excluding any significant hydroxylation of the bile acid nucleus. After thin-layer chromatography (system I), 44 per cent of the isotope in the 3-monohydroxycholanic fraction was seen to be present as lithocholic acid and 56 per cent as isolithocholic acid. After methylation, the two labeled isomers were separated by adsorption chromatography on alumina, and shown to run together with reference samples of the methylated compounds on thin-layer chromatography (systems I and II). Direct thin-layer chromatography of ether extracts of hydrolyzed bile also showed that in all three patients most of the isotope was distributed between lithocholic acid, isolithocholic acid, and Compound B. However, bile from patients A.D. and M.K. showed a lower ratio of isoIithocholic acid/lithocholle acta lian blle from patient A.E.

3 -ketocholanic acid could not be demonstrated in any of the bile samples. To determine whether it could have been destroyed during hydrolysis, the effect of several hydrolytic procedures on labeled methyl-3-ketocholanic acid was investigated using thin-layer chromatography. Refluxing in $1 \mathrm{~N}$ methanolic $\mathrm{NaOH}$ for 2 hours hydrolyzed the ester without destruction of the bile acid nucleus. However, stronger hydrolytic procedures $\left(5 \mathrm{~N} \mathrm{NaOH}\right.$ for 6 hours at $130^{\circ} \mathrm{C}, 5$ $\mathrm{N} \mathrm{NaOH}$ for 24 hours at $135^{\circ} \mathrm{C}$, and $5 \mathrm{~N} \mathrm{NaOH}$ for 48 hours at $135^{\circ} \mathrm{C}$ ), resulted in progressive destruction of the 3-ketocholanic acid and the progressive appearance of spots with the mobility of lithocholic and isolithocholic acids, as well as small amounts of other more and less polar decomposition products. When the hydrolysate $\left(5 \mathrm{~N} \mathrm{NaOH}, 48\right.$ hours, $\left.135^{\circ} \mathrm{C}\right)$ was chromatographed with phase system F2, confirmatory results were obtained. About 10 per cent of the isotope appeared in the front peak, about 35 per cent was eluted together with added lithocholic acid, 50 per cent remained in the eluate, and the rest was scattered between the front and lithocholic acid peaks.

The effect of the hydrolytic procedure on labeled lithocholic acid, isolithocholic acid, and Compound B (isolated from feces) was also investigated. Lithocholic acid and Compound B were not affected, but small amounts of isolithocholic acid were apparently transformed into 3-ketucholanic acid and lithocholic acid, as judged by their mobility on thin-layer chromatography.

Conjugated metabolites of lithocholic acid-24- $\mathrm{C}^{14}$. Conjugated metabolites of lithocholic acid-24-C ${ }^{14}$ were investigated by thin-layer, paper, and column chromatography. In addition to the expected taurine and glycine conjugates of lithocholic acid, two and probably three other conjugates were observed. These were most clearly defined by thin-layer chromatography, as shown in Figure 7. A methanol extract of bile, obtained 20 hours after administration of isotope to patient M.K. was chromatographed with system III and the isotope quantitated by autoradiography. Less than half of the isotope was found in the bands corresponding to taurolithocholic and glycolithocholic acids. Approximately half of the total isotope was found in Compound $\mathrm{I}(6.6 \mathrm{~cm}$ from the origin), running more slowly than taurolithocholic acid $(7.5 \mathrm{~cm})$. These two compounds could be separated still farther with system IV, but with this system Compound II remained at the origin. Compound II, comprising 10 to 15 per cent of the isotope, was found at $2.3 \mathrm{~cm}$, running more slowly than taurocholic acid. The final 2 to 3 per cent of the isotope occurred as a very faint band $10 \mathrm{~cm}$ from the origin and was termed Compound III, although it may contain several compounds. It can also be seen in Figure 7 that no free lithocholic acid was detected. Entirely comparable results were obtained using bile from patient A.D., and the distribution of isotope in the various fractions from these two patients is shown in Table 3. Bile from patient A.E. showed roughly the same distribution, but because of the relatively low activity of the bile from this pa- 


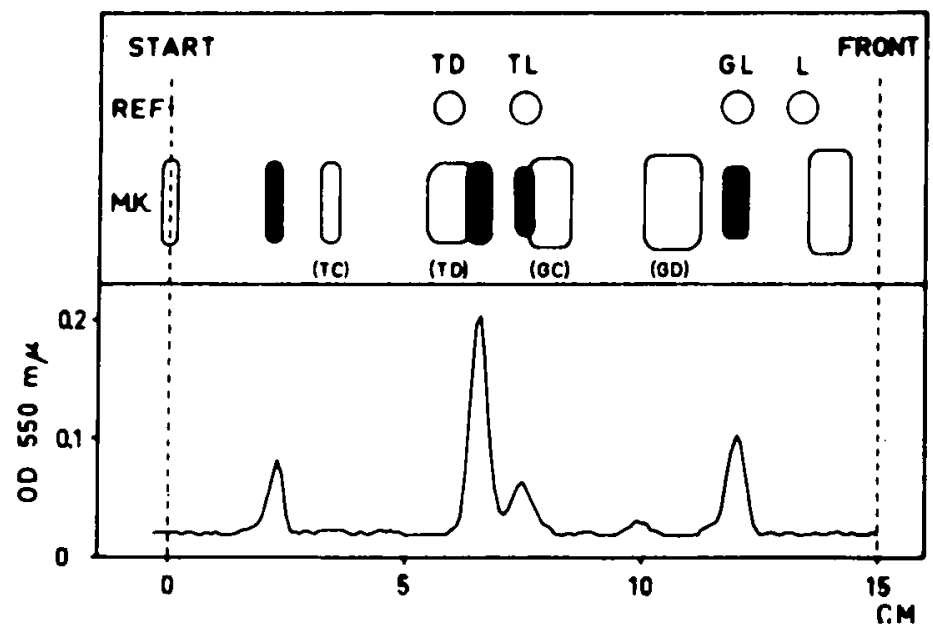

Figure 7. Thin-layer chromatographic separation of conjugated derivatives of lithocholic acid-24- $\mathrm{C}^{14}$ in bile. System III. Methanol extract of $2.5 \mu 1$ bile from patient M.K. Reference substances: taurodeoxycholic acid (TD), taurolithocholic acid (TL), glycolithocholic acid (GL), and lithocholic acid (L). Open figures represent spots detected by spraying with 10 per cent phosphomolybdic acid in ethanol. The major bands corresponding to the taurine and glycine conjugates of cholic and deoxycholic acid in bile are indicated by the letters in parentheses. The cross-hatching represents spots detected by autoradiography, and a densiometric recording of the autoradiograph is shown in the lower part of the figure.

tient, obtained 72 hours after administration of the isotope, accurate quantitation was not possible and the figures have been omitted.

Paper chromatography of bile gave similar results. While there was incomplete separation of Compound I and taurolithocholic acid, the four major peaks were clearly discernible, and quantitation by this method agreed closely with quantitation by thin-layer chromatography and autoradiography. Attempts were made to separate the conjugates with column chromatography.

Table 4

DISTRIBUTION OF ISOTOPE IN METHANOL EXTRACTS OF

WHOLE BILE AS DETERMINED BY THIN-LAYER CHROMATOGRAPHY (SYSTEM III)

\begin{tabular}{l|c|c}
\hline & M.K. & A.D. \\
\hline Compound I & 47 & 51 \\
Compound II & 12 & 9 \\
Compound III & 3 & 2 \\
Taurolithocholic acid & 14 & 16 \\
Glycolithocholic acid & $\underline{24}$ & $\underline{22}$ \\
& 100 & 100 \\
\hline
\end{tabular}


Glycolithocholic acid could be separated from the other conjugates with phase system F2, using an acidified methanol extract of bile, as shown in Figure 8. In this instance, inactive glycolithocholic and lithocholic acids were added for comparison. No radioactivity was detected in the lithocholic acid fraction, and the isotope in the glycolithocholic acid peak ran as a single spot at the correct position for glycolithocholic acid on thin-layer chromatography with system III.

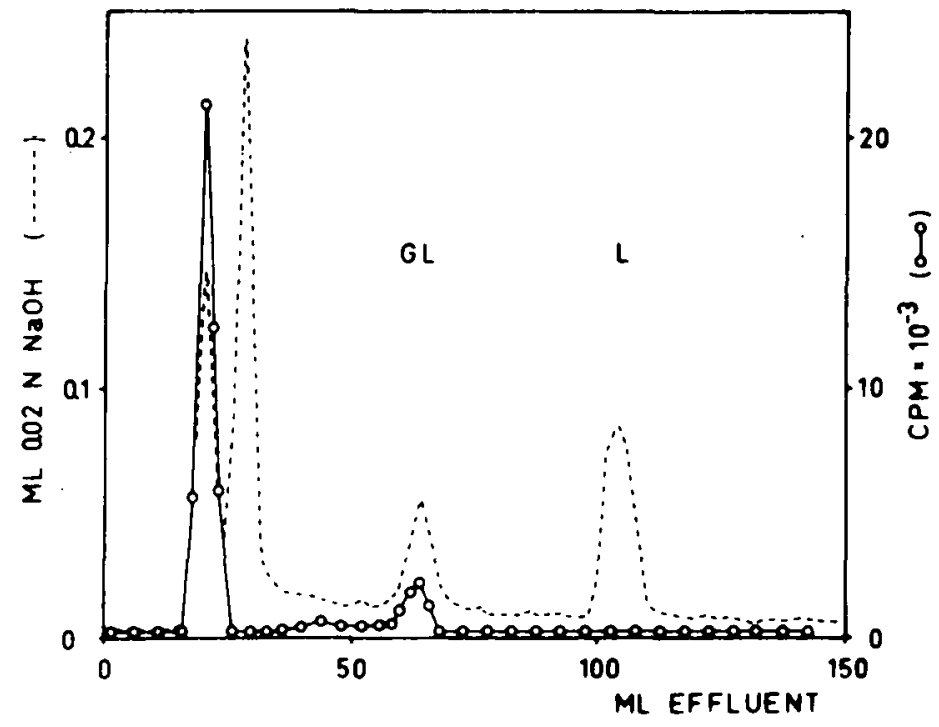

Figure 8. Chromatographic separation of labeled glycolithocholic acid from bile with phase system F2. Acidified methanol extract of $0.25 \mathrm{ml}$ of bile from patient A.D. Reference substances: glycolithocholic and lithocholic acids.

The remaining polar conjugates (I, II, III, and taurolithocholic acid) ran together in the front peak with phase system F2. Several phase systems have been tried for separation of these compounds on columns, but so far no satisfactory method has been found. Attempts to separate them with a butanol-water system gave irregular results, including retention of the isotope in the column, incomplete separation and loss of titratable acidity. One possible explanation for these effects was afforded when the isotope in the front peak following chromatography with phase system F2 was analyzed by thin-layer chromatography before and after butanol extraction. The isotope in the butanol extract had entirely different chromatographic characteristics, indicating the formation of transformation products. Butanol extraction of other bile acids has also given difficulty, notably resulting in the loss of titratable acidity.

\section{Physical State of the Lithocholic Acid Metabolites During the Enterohepatic Circulation}

The physical state of the metabolites in bile was investigated by paper electrophoresis and gel filtration. Representative results obtained by paper electrophoresis of gallbladder bile are shown in Figure 9. All of the labeled compounds, together with most of the bilirubin, were present in one band, traveling ahead of albumin. A methanol extract of the bile made up to its original concentration in water showed that the labeled products retained the same electrophoretic mobility as the native complex in bile, which was quite different from that of tracer doses of labeled tauro- and glycolithocholic acids. 

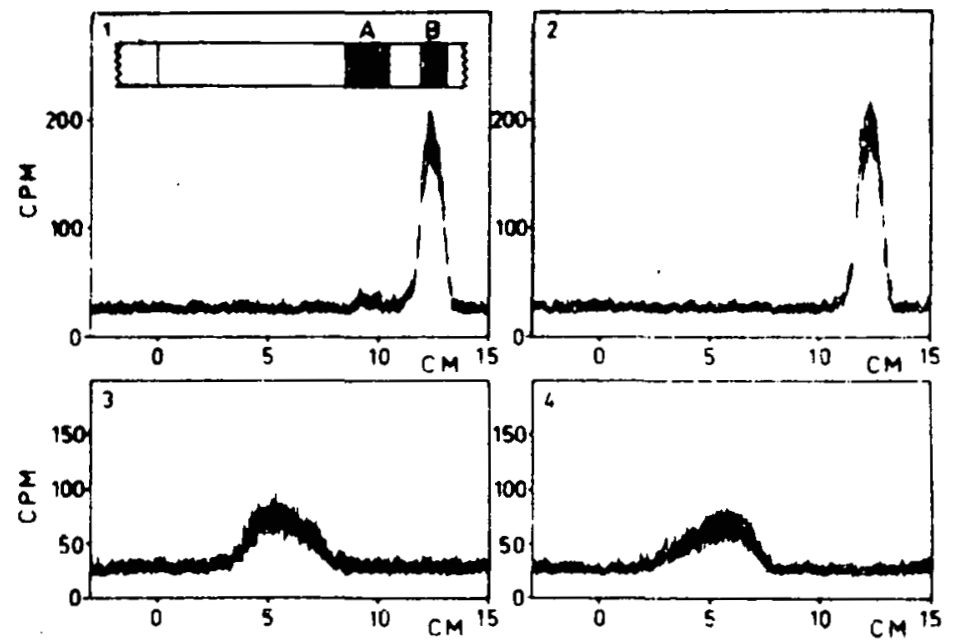

Figure 9. Paper electrophoresis of gallbladder bile. 1: Whole gallbladder bile, patient M.K. A: - albumin, revealed by protein staining; B: - bilirubin. 2: Methanol extract of 1. 3: Trace amounts of taurolithocholate-24- $\mathrm{C}^{14}$. 4: Trace amounts of glycolithocholate-24-C 14 .

Gel filtration of bile from the three patients on columns of Sephadex G-25 showed that most of the labeled compounds were isolated in a single peak after the macro-molecular fraction, which contained the protein, cholesterol and phospholipids. A representative gel filtration experiment is shown in Figure 10.

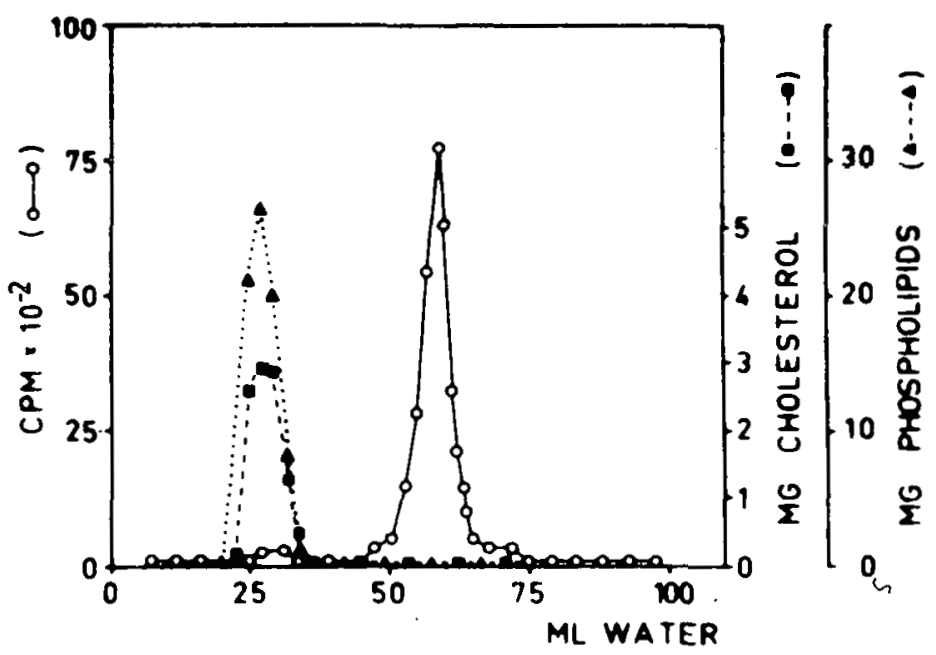

Figure 10. Gel filtration of gallbladder bile. Patient A.D.

The metabolites in feces were investigated by dialysis. Fecal saline homogenates (1 part feces to 2 parts saline) were dialyzed with shaking against 10 volumes of phosphate buffer, $\mathrm{pH}$ 7.4 , at $0^{\circ} \mathrm{C}$. After 12 hours the buffer was changed, and the process repeated 6 times. The residue was then centrifuged for 1 hour at $25,000 \mathrm{xg}$, yielding a sediment and a clear supernatant. 
As shown in Table 5, only 2.1 to 2.5 per cent of the labeled metabolites of lithocholic acid-24$\mathrm{C}^{14}$ were dialyzable. Practically all of the remaining non-dialyzable compounds were present in the sediment after centrifugation.

Table 5

PHYSICAL STATE OF LITHOCHOLIC ACID-24- $\mathrm{C}^{14}$ METABOLITES IN FECES

\begin{tabular}{c|c|c|c|c}
\hline & & \multicolumn{3}{|c}{$\begin{array}{c}\text { Percentage distribution of recovered } \\
\text { labeled compounds }\end{array}$} \\
\cline { 3 - 5 } Subject & $\begin{array}{c}\text { Sampling period } \\
\text { (Hours after adminis- } \\
\text { tration of lithocholic } \\
\text { acid-24- (14) }\end{array}$ & $\begin{array}{c}\text { Combined } \\
\text { dialysates }\end{array}$ & $\begin{array}{c}\text { Homogenate after dialysis and centri- } \\
\text { fugation for 1 hour at 25,000 x }\end{array}$ \\
\cline { 3 - 5 } & 24 to 48 & 2.1 & 1.5 & $\begin{array}{c}\text { Chloroform- methanol } \\
\text { extract of sediment }\end{array}$ \\
\hline A.L. & 48 to 72 & 2.5 & 0.6 & 96.4 \\
A.L. & & & & 96.9 \\
\hline
\end{tabular}

\section{DISCUSSION}

Lithocholic acid is apparently formed as a result of microbial dehydroxylation of chenodeoxycholic acid in the intestine. Small amounts of labeled lithocholic acid have been isolated from human bile following the oral administration of chenodeoxycholic acid-24- $\mathrm{C}^{14}, 24$ and the ability of human intestinal microorganisms to dehydroxylate chenodeoxycholic acid to lithocholic acid in vitro has been demonstrated. ${ }^{26}$ In addition, lithocholic acid disappears from human bile when the enterohepatic circulation is interrupted. ${ }^{25}$ However there is little evidence concerning its further metabolism in man. While the rat liver can hydroxylate lithocholic acid with the formation of a number of compounds, 27,28 Carey was able to find only small amounts ( 2 to 3 per cent) of more hydrophilic metabolites after the intravenous administration of lithocholic acid-24- $\mathrm{C}^{14}$ to patients with bile fistulae. ${ }^{25}$ However, larger amounts of these or other transformation products might occur in patients with an intact enterohepatic circulation. Intestinal microorganisms are capable of metabolizing lithocholic acid, and its in vitro transformation to 3 -ketocholanic and isolithocholic acids has been reported. ${ }^{29}$ The latter compound has been isolated from human feces, ${ }^{5}$ and Danielsson and associates have demonstrated its formation in vivo from chenodeoxycholic acid in humans. ${ }^{21}$ In the present investigation, the extensive transformation of lithocholic acid to isolithocholic acid in the human is reported, together with the isolation from feces and identification of 3-ketocholanic acid, the presumed intermediate. In addition, it was found that the transformation to isolithocholic acid was associated, to a large extent, with the formation of saponifiable derivatives. The relative importance of isomerization for the esterification process is indicated by the fact that almost all of the isolithocholic acid in feces was found in the saponifiable fractions, whereas almost all of the lithocholic acid occurred as the free bile acid.

The removal of the $\mathrm{C} 7$ hydroxyl group from chenodeoxycholic and cholic acids is an important microbial reaction, and Samuelsson has shown that the first step in this process is an oxidative removal of water, giving a $\Delta-6$.cholenic acid which is later reduced. ${ }^{30}$ In the present study, the formation of cholanic acid from lithocholic acid could not be demonstrated, but an un- 
substituted, unsaturated bile acid (Compound B) was observed which could result from an analogous oxidative removal of the C3 hydroxyl group without subsequent reduction. The introduction of a double bond in $r$ ing $A$ of other bile acids by microorganisms has been described. ${ }^{31}$

With extensive metabolism of lithocholic acid prior to its excretion in the feces, it is possible that its metabolites might be reabsorbed and excreted in the bile. Of these, isolithocholic acid and Compound $\mathrm{B}$ were found in samples of hydrolyzed bile. The inability to demonstrate 3-ketocholanic acid could be explained by either 1) its failure to be reabsorbed, 2) its reduction by the liver, or 3 ) its destruction during the hydrolytic procedure. We were also unable to demonstrate any significant amount of lithocholic acid hydroxylation products, which should have been easily separable by the technique used, either in bile or feces. Figure 11 summarizes the presumed intestinal transformations of lithocholic acid and its metabolites prior to their excretion in the feces. The percentage distribution of recovered isotope gives a rough idea of the relative quantitative importance of the different reactions with respect to the metabolism of orally administered lithocholic acid.

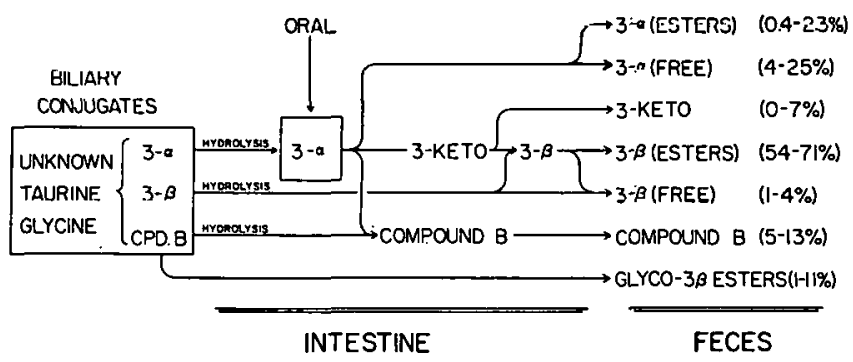

Figure 11. Metabolism of lithocholic acid-24- $\mathrm{C}^{14}$. A proposed scheme for the intestinal metabolism of orally administered lithocholic acid-24-C14, together with the metabolites present in bile and feces. $3 \alpha=$ lithocholic acid, $3 \beta=$ isolithocholic acid, 3 -keto $=3$-ketocholanic acid, glyco-3 $\beta=$ glycoisolithocholic acid.

In human bile, the main bile acids, i.e., cholic, deoxycholic and chenodeoxycholic acids, occur conjugated with either taurine or glycine. These conjugates are hydrolyzed in the intestine, so that only small amounts of the conjugates are found in feces. ${ }^{32}$ In the present investigation, taurine and glycine conjugates of lithocholic acid-24-C $\mathrm{C}^{14}$ were observed in bile, but most of the isotope occurred in at least two additional more polar conjugates. These conjugates would not have been detected without isotopic methods, as they occur chromatographically in areas usually associated with the di- and trihydroxy bile acid conjugates. No free bile acid metabolites of lithocholic acid-24- $\mathrm{C}^{14}$ were found in bile, but hydrolysis apparently took place in the intestine, as only small amounts of conjugated labeled bile acids were isolated from the feces. However, since some of the isotope in feces was not extracted with ether from an acidified water solution, the possibility exists that small amounts of the more polar conjugates could have been lost in this fraction, which was not chromatographically analyzed. The nature of these conjugates is unknown, and elucidation of their structure will require appropriate methods for their extraction and preparative isolation. It should be noted that abnormal bile acid conjugates in guinea pigs treated with bacterial polysaccharides have been described recently. ${ }^{33}$ These conjugates, which apparently contain ornithine, rather than taurine or glycine, are less polar than taurine 
conjugates and more polar than glycine conjugates.

Whatever the chemical nature of the conjugates, in the present investigations the labeled compounds in bile were shown to share certain physical properties, and to behave similarly on electrophoresis and gel filtration. Verschure has used paper electrophoresis to study gallbladder bile, and has demonstrated a "bililipoprotein" complex which traveled ahead of albumin, and which, from staining reactions, was thought to contain bile acids, cholesterol, phospholipids, bilirubin and protein. ${ }^{23}$ Labeled metabolites of cholic and chenodeoxycholic acid have recently been shown to travel in this complex. ${ }^{34}$ In the present electrophoretic studies, all of the metabolites of lithocholic acid were found to travel together in a complex with a similar mobility, running faster than albumin and reference taurolithocholic and glycolithocholic acids. Protcin does not seem to be an essential part of the complex, as the isotope in methanol extracts of bile had this same mobility. The complex can be broken by gel filtration, whereby all of the labeled metabolites are separated from the macro-molecular fraction, which contains protein and other water insoluble substances in bile, such as cholesterol and phospholipids.

The lithocholic acid metabolites thus enter the intestine in the form of a water soluble complex. In the small intestine, different physical conditions prevail and the formation of association colloids, containing bile acids and fatty acids, appears to be essential for the solubilization and absorption of water insoluble lipids such as cholesterol. ${ }^{35}$ In all probability it is this kind of physical environment that permits the absorption of orally administered lithocholic acid. From analyses of bile and feces, however, it appears that lithocholic acid formed in vivo is not, comparatively, well absorbed. Lithocholic and deoxycholic acids are formed by C-7 dehydroxylation of chenodeoxycholic and cholic acids respectively, and while the 3 -monohydroxycholanic and 3,12-dihydroxycholanic acid fractions in feces are roughly equivalent, the 3-monohydroxycholanic fraction in bile is considerably smaller than the 3,12-dihydroxycholanic fraction. This decrease in the biliary monohydroxy fraction appears to be too great to be explained by the relatively small amount of lithocholic acid that is dehydroxylated to the cholenic acid derivative, and seems to represent a real difference in absorption of these mono- and dihydroxy bile acids.

Physical factors may be of importance in this difference, since lithocholic acid and its conjugates are, in contrast to cholic, deoxycholic, chenodeoxycholic acids and their conjugates, relatively insoluble in aqueous solutions, and the formation of saponifiable derivatives undoubtedly decreases their solubility still further. Lithocholic acid and its derivatives are probably formed distal to the site of maximal bile acid and micellar absorption, and the physical state of the intestinal contents in the region of their formation could in part determine the extent of their solubilization and absorption. In any case, whether by virtue of the chemical transformations they undergo or as a result of alterations in the character of the intestinal contents, the water soluble melabolites of lithocholic acid in bile appear in the feces as water insoluble, non-dialyzable compounds. Clearly, more information on the site and mechanism of absorption of these metabolites is necessary for an understanding of their enterohepatic circulation.

While physical factors are undoubtedly of significance in determining the absorption and ultimate disposition of these compounds, the chemical transformations described in this report, clearly have physiological significance since the resulting metabolites probably differ quantitatively and qualitatively in their toxic properties. It is possible that the ability of lithocholic acid to produce cirrhosis of the liver in animals is related to the production of a metabolite rather than to the specific cytotoxic properties of lithocholic acid itself. Conversely, metabolites 
such as isolithocholic acid are probably much less toxic than lithocholic acid, since $3 \beta$-hydroxy steroids are in general less hemolytic than $3 \alpha$-hydroxy steroids. ${ }^{36}$ In fact, recent observations indicate that the $3 \beta$ isomer is much less pyrogenic than lithocholic acid, ${ }^{37}$ a situation in keeping with the structure-activity relationship of neutral steroid pyrogens. ${ }^{38}$ Finally, the unidentified conjugating substances described here may modify the toxic properties of lithocholic acid, as is the case with taurine conjugated lithocholic acid. ${ }^{1}$ Thus a better understanding of the biological properties of these various metabolites is necessary for a full evaluation of the toxic potential of lithocholic acid.

\section{ACKNOWLEDGMENT}

We wish to thank Dr. H. Danielsson for valuahle help in the course of these investigations.

\section{LITERATURF, CITEU}

1. Palmer, R. H., P. B. Glickman, and A. Kappas. J. Clin. Invest., 41;1573, 1962.

2. Holsti, P. Nature, 186:250, 1960.

3. Stolk, A. Experientia, 16:507, 1960.

4. Wootton, I. D. P., and H. S. Wiggins. Biochem. J., 55:292, 1953.

5. Heftman, E., E. Weiss, H. K. Miller, and E. Mosettig. Arch. Biochem. and Biophys., 84: $324,1959$.

6. Bergström, S., M. Rottenberg, and J. Voltz. Acta chem. scandinav., 7:481, 1953.

7. Jones, A. S., M. Webb, and F. Smith. J. chem. Soc. (London), 3:2164, 1949.

8. Reindel, F., and K. Niederlander. Ber. deut. chem. Ges. (Ber.), 68:1243, 1935.

9. Bergström, S., and A. Norman. Acta chem. scandinav., 7:1126, 1953.

10. Norman, A. Arkiv Kemi, 8:331, 1955.

11. Eneroth, P., K. Hellström, and J. Sjövall. 1963. (To be published.)

12. Sjövall, J. Acta physiol. scandinav., 29:232, 1953.

13. Norman, A. Acta chem. scandinav., 7:1413, 1953.

14. Bergström, S., H. Danielsson, and $\AA$. Göransson. Acta chem. scandinav., 13, 776, 1959.

15. Danielsson, H. Biochim. et biophys. acta, 27:401, 1958.

16. Sjövall, J. Clin. Chim. acta, 4:652, 1959.

17. Eneroth, P. J. Lip. Res., 4:11, 1963.

18. Gänshirt, H., F. W. Koss, and K. Morianz. Arzneimittel-Forsch., 10:943, 1960.

19. Hofmann, A. F. J. Lip. Res., 3:127, 1962.

20. Hofmann, A. F. J. Lip. Res., 3:391, 1962.

21. Danielsson, H., P. Eneroth, K. Hellström, S. Linstedt, and J. Sjövall. J. Biol. Chem., 238: $2299,1963$.

22. Raderecht, H. J., and S. Binnewies. Clin. Chim. acta, 7:875, 1962. 
23. Verschure, J. C. M., and F. M. C. Hoefsmit. Clin. Chim. acta, 1:38, 1956.

24. Hellström, K, and J. Sjövall. Acta physiol. scandinav., 51:218, 1961.

25. Carey, J. B., Jr., and G. Williams. J. Clin. Invest., 42:450, 1963.

26. Norman, A., and M. S. Shorb. Proc. Soc. Exptl. Biol. and Med., 110:552, 1962.

27. Bergström, S., J. Sjövall, and J. Voltz. Acta physiol. scandinav., 30:22, 1953.

28. Perry, G., and E. A. Doisy, Jr. Fed. Proc., 18:301, 1959.

29. Hayaishi, O., Y. Sato, W. B. Jakoby, and E. F. Stohlman. Arch. Biochem., 56:554, 1955.

30. Samuelsson, B. J. Biol. Chem., 235:361, 1960.

31. Hayakawa, S., T. Fujii, W. Saburi, and T: Eguchi. Nature, 179:537, 1957.

32. Norman, A. Faecal excretion products of cholic acid in man. (To be published.)

33. Peric-Golia, L., and R. S. Jones. Proc. Soc. Exptl. Biol. and Med., 110:327, 1962.

34. Norman, A. Nord. Med., 1963. (In press.)

35. Hofmann, A. F., and B. Borgström. Fed. Proc., 21:43, 1962.

36. Berliner, F., and R. Schoenheimer. J. Biol. Chem., 124:525, 1938.

37. Palmer, R. H. Unpublished observations.

38. Palmer, R. H., and A. Kappas. Med. Clin. N. Amer., 47:101, 1963. 


\section{BIOLOGIC PROPERTIES OF POLYNUCLEOTIDES. II. THE ANTICOAGULANT} PROPERTIES OF POLYNUCLEÓTIDES ${ }^{*}$

By

S. Yachnin ${ }^{\dagger}$

Recent evidence suggests that transformation of mammalian cells may be effected by exogenous nucleic acids. ${ }^{1-5}$ Thus the experimental or therapeutic administration of large amounts of nucleic acids to humans may be envisaged. Since little is known of the biological properties of nucleic acids, apart from their role in directing protein synthesis and cell replication, a systematic investigation of such properties has been undertaken. Our previous studies have dealt with the potential antigenicity of nucleic acids, ${ }^{6}$ their interaction with serum albumin, ${ }^{7-9}$ and their anticomplementary properties. ${ }^{10}$ The synthetic ribopolynucleotides, as well as naturally occurring nucleic acids, have been examined, since the former offer an opportunity to observe the effects of variations in base composition and secondary structure on the biologic properties of these macromolecules.

The anticoagulant properties of heparin are thought to derive largely from the strong negative charge of its many sulphate groups. Polynucleotides, by virtue of their phosphate groups, are also strong polyanions. Attention was therefore turned to the effects of polynucleotides upon the coagulation mechanism. The results demonstrate that certain polynucleotides do indeed possess anticoagulant properties; although the evidence indicates that it is not the phosphate groups per se which are responsible for these properties, but rather that such properties are dependent upon base composition and secondary structure.

\section{MATERIALS AND METHODS}

\section{Polynucleotides}

Preparation of the synthetic polyribonucleotides and some of their physical properties have already been described in detail; the isolation of the naturally occurring RNAs has also been presented. ${ }^{10}$ Synthesis of poly $G^{\ddagger}$ was accomplished by means of RNA polymerase ${ }^{\S}$ using a poly $\mathrm{C}$ template as described by Fox, Robinson, Haselkorn, and Weiss. ${ }^{11}$ Highly polymerized calf thymus DNA was obtained from Sigma Chemical Company, St. Louis, Missouri. Micrococcus

\footnotetext{
*A preliminary report of this work has been published in J. Clin. Invest., 42:996, 1963. The present report is taken from a paper appearing in Blood, 24:553, 1964. The work was supported in part by funds from the Joseph and Helen Regenstein Foundation.

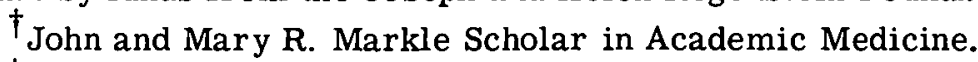

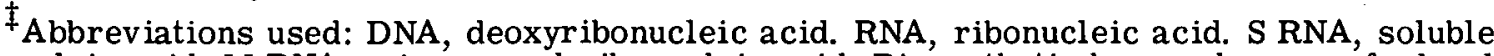
ribonucleic acid. M RNA, microsomal ribonucleic acid. Biosynthetic homopolymers of adenylic, guanylic, uridylic, cytidylic, and inosinic acids, poly A; poly G; poly U; poly C; and poly I, respectively. Copolymer of inosinic and uridylic acids, poly IU. Copolymer of guanylic and uridylic acids, poly GU. 5'-monophosphates of guanosine, uridine, inosine, adenosine or cytidine, GMP; UMP; INP; AMP; or CMP.

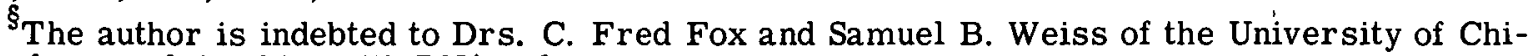
cago, for supplying him with RNA polymerase.
} 
lysodeikticus DNA and Tetrahymena pyriformis ${ }^{*}$ DNA were prepared as described by Marmur. ${ }^{12}$ Heat denaturation of DNA was accomplished by heating a DNA solution in boiling water for 10 minutes, followed by rapid cooling on ice. Apurinic acid was prepared from calf thymus DNA and M. lysodeikticus DNA by the method of Tamm, Hodes, and Chargaff. ${ }^{13}$ Polynucleotides were dissolved in $0.02 \mathrm{M}$ tris, $0.145 \mathrm{M} \mathrm{NaCl} \mathrm{pH} 7.4$ (TBS) at a concentration of $4 \mu \mathrm{mol} \mathrm{P}$ polynucleotide/ $\mathrm{ml}$ and were stored at $-20 \mathrm{C}$. The polynucleotides used are listed in Table 1. Phosphorus determinations were by the method of Fiske and SubbaRow. ${ }^{14}$

T'able 1

BASE COMPOSITION OF POLYNUCLEOTIDES

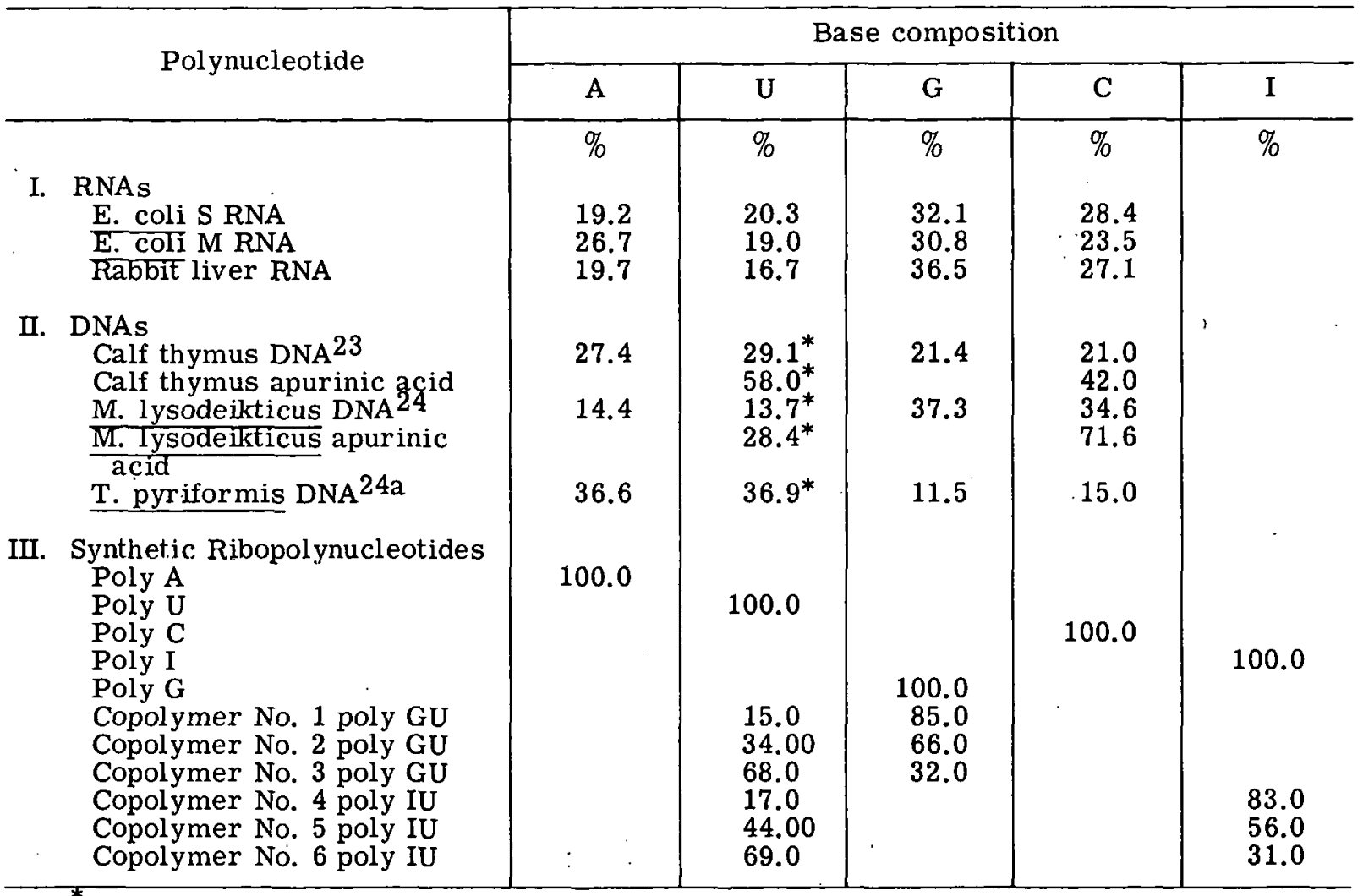

Thymine.

\section{Coagulation Reagents}

Blood was obtained from healthy donors or from hospital patients without hematologic disease, using a double syringe technique. Nine parts blood were mixed with one part $0.1 \mathrm{M}$ sodium oxalate or $0.1 \mathrm{M}$ sodium citrate; whenever necessary siliconized glassware was used (i.e., preparation of washed platelet suspensions). $\mathrm{BaSO}_{4}$ absorbed plasma was prepared from oxalate plasma; the Quick one-stage prothrombin time of this reagent was always greater than 3 minutes. Serum was prepared from blood allowed to clot for 4 hours at $37 \mathrm{C}$. Washed platelets were prepared by differential centrifugation of citrate plasma, and were suspended in:TBS at

* T. pyriformis DNA was a gift of Dr. Irving Goldberg of the University of Chicago. 
a concentration of 150,000 to $250,000 / \mathrm{mm}^{3}$ Where feasible reagents were used which had been frozen in small aliquots and stored at $-20 \mathrm{C}$. The following commercial preparations were also employed: human fibrinogen, 85 per cent coagulable protein (Merck Sharp and Dohme, Rahway, New Jersey); bovine fibrinogen, 90 per cent coagulable protein (Pentex, Inc., Kankakee, Ilinois); Russel Viper Venom (RVV) ("Stypven," Wellcome Research Laboratories, Beckenham, England); extrinsic thromboplastin ("Simplastin" Warner Cilcott, Morris Plains, New Jersey); Heparin (Testagar, Detroit, Michigan, 9.5 per cent S); protamine sulphate (Sigma Chemical Company, St. Louis, Missouri).

\section{Coagulation Tests}

The procedures used in assessing anticoagulant activity were adapted from those of Biggs and Macfarlane. ${ }^{15}$ All tests were done in a water bath at $37^{\circ} \pm 0.1$ and were performed at least in duplicate. Only the average values of two or more determinations are reported.

a. Silicune recalcification time of plasma. This test was performed in siliconized glassware, utilizing platelet rich plasma. Test system: $0.1 \mathrm{ml}$ plasma, $0.1 \mathrm{ml}$ TBS or polynucleotide solution, and $0.1 \mathrm{ml} 0.025 \mathrm{M} \mathrm{CaCl}_{2}$.

b. Quick one-stage prothrombin time. Test system: $0.1 \mathrm{ml}$ plasma $+0.1 \mathrm{ml}$ TBS or polynucleotide solution, $+0.2 \mathrm{ml}$ Simplastin (the latter contains the equivalent of $0.1 \mathrm{ml} 0.025 \mathrm{M}$ $\mathrm{CaCl}_{2}$ ).

c. Fibrinogen-fibrin conversion by thrombin. Test system: $0.4 \mathrm{ml}$ human fibrinogen ( $4 \mathrm{mg} / \mathrm{ml}$ in TBS), $0.1 \mathrm{TBS}$ or polynucleotide solution $+0.1 \mathrm{ml}$ thrombin solution $(20 \mathrm{units} / \mathrm{ml})$.

d. Plasma thrombin time. Test system: $0.2 \mathrm{ml}$ plasma $+0.1 \mathrm{ml}$ TBS or polynucleotide solution $+0.1 \mathrm{ml}$ thrombin (8 units $/ \mathrm{ml}$ ).

e. One-stage prothrombin time of plasma using RVV. One part RVV solution was mixed with an equal volume of $0.020 \mathrm{M} \mathrm{CaCl}_{2}$. Test system: $0.1 \mathrm{ml}$ plasma, $0.1 \mathrm{ml}$ TBS or polynucleotide solution, and $0.2 \mathrm{ml} \mathrm{RVV- \textrm {Ca } ^ { + + }}$ solution.

f. Thromboplastin generation test (TGT). The incubation mixture consisted of $0.2 \mathrm{ml}$ each $\mathrm{BaSO}_{4}$ absorbed plasma (diluted 1:5 with TBS), serum (diluted 1:10 with TBS), platelet suspension, TBS or polynucleotide solution, and $\mathrm{CaCl}_{2}$ solution. The substrate plasma contained 0.1 $\mathrm{ml}$ plasma $+0.1 \mathrm{ml}$ TBS or polynucleotide solution $(1 / 5$ the concentration used in the incubation mixture). At appropriate times $0.1 \mathrm{ml} 0.025 \mathrm{M} \mathrm{CaCl}_{2}$ and $0.1 \mathrm{ml}$ incubation mixture were added to an aliquot of substrate plasma and the clotting time recorded.

g. Two-stage prothrombin test (thrombin generation). The incubation mixture contained $0.3 \mathrm{ml}$ plasma, $0.3 \mathrm{ml}$ polynucleotide solution or TBS, and $0.6 \mathrm{ml}$ of a $1: 3$ dilution of Simplastin (diluted in a solution of equal parts TBS and $0.025 \mathrm{M} \mathrm{CaCl}_{2}$ ). The substrate fibrinogen solution consisted of $0.3 \mathrm{ml}$ bovine fibrinogen $(2.5 \mathrm{mg} / \mathrm{ml})+0.1 \mathrm{ml}$ TBS or $0.1 \mathrm{ml}$ of a $1: 4$ dilution of the polynucleotide solution used in the incubation mixture. At appropriate times a $0.1 \mathrm{ml}$ aliquot from the incubation mixture was added to an aliquot of substrate fibrinogen and the clotting time recorded. The clotting times were converted to units of thrombin as described by Biggs and Macfarlane. ${ }^{15}$

Calculation of the final $\left[\mathrm{Ca}^{++}\right]$in a given test system was as outlined by Nilsson and Wenkert $^{16}$ based on the stoichiometry between the amount of oxalate or citrate used as anticoagulant, and the amount of $\mathrm{Ca}^{++}$added. $\mathrm{CaCl}_{2}$ solutions ranging in concentration from 0.040 to 0.010 M were used. 
Plasma Recalcification Time (Silicone)

Poly $I$ is the only polynucleotide studied ${ }^{*}$ which significantly affects the recalcification time of plasma (Table 2). Four-tenths $\mu \mathrm{mol} P$ poly I lengthens the recalcification time to slightly more than 3 times the control value. Compared with heparin on an S:P molar ratio, poly I has $1 / 20$ the anticoagulant potency.

Table 2

THE EFFECT OF VARIOUS POLYNUCLEOTIDES UPON THE SILICONE RECALCIFICATION TIME OF PLASMA $(0.1 \mathrm{ml}$ PLATELET RICH PLASMA + $0.1 \mathrm{mI}$ SALINE OR POLYNUCLEOTIDE SOLUTION + $0.1 \mathrm{ml} 0.025 \mathrm{M} \mathrm{CaCl}_{2}$ )

\begin{tabular}{|c|c|c|}
\hline Test material & Amount added & Clotting time \\
\hline $\begin{array}{l}\text { Poly C } \\
\text { Poly U } \\
\text { Poly A } \\
\text { Calf thymus DNA } \\
\text { M. lysodeikticus native DNA } \\
\text { Rabbit liver RNA } \\
\text { E. coli S RNA } \\
\text { E. coli M RNA }\end{array}$ & $\begin{array}{ll}0.4 & \mu \mathrm{mol} \mathrm{P} \\
0.4 & \mu \mathrm{mol} \mathrm{P} \\
0.4 & \mu \mathrm{mol} \mathrm{P} \\
0.4 & \mu \mathrm{mol} \mathrm{P} \\
0.4 & \mu \mathrm{mol} \mathrm{P} \\
0.4 & \mu \mathrm{mol} \mathrm{P} \\
0.4 & \mu \mathrm{mol} \mathrm{P} \\
0.4 & \mu \mathrm{mol} \mathrm{P}\end{array}$ & $\begin{array}{l}3,45^{\prime \prime} \\
5,30^{\prime \prime} \\
5 ; \\
3 ! \\
4,45^{\prime \prime} \\
4,15^{\prime \prime} \\
5^{\prime} \\
5\end{array}$ \\
\hline $\begin{array}{l}\text { Poly I } \\
\text { Poly I } \\
\text { Poly I } \\
\text { Poly I }\end{array}$ & $\begin{array}{ll}0.05 & \mu \mathrm{mol} \mathrm{P} \\
0.1 & \mu \mathrm{mol} \mathrm{P} \\
0.2 & \mu \mathrm{mol} \mathrm{P} \\
0.4 & \mu \mathrm{mol} \mathrm{P}\end{array}$ & $\begin{array}{l}6^{\prime} 15^{\prime \prime} \\
9^{\prime} \\
11^{\prime} \\
14^{\prime} 15^{\prime \prime}\end{array}$ \\
\hline Oxalate & $0.4 \mu \mathrm{mol}$ & $5^{\prime} 15^{\prime \prime}$ \\
\hline
\end{tabular}

\section{Quick One-Stage Prothrombin Time}

Four-tenths $\mu$ mol P poly I lengthens the Quick time of plasma to 3 times the control value. Its anticoagulant potency is again $1 / 20$ that of heparin (Table 3 ).

\section{One-Stage Prothrombin Time Using RVV}

Four-tenths $\mu \mathrm{mol} P$ poly I delays the clotting time to approximately 3 times the control values. Poly $U$ has a slight inhibitory effect. No other polynucleotides tested have any effect (Table 4).

\section{Fibrinogen-Fibrin Conversion by Thombin}

Poly I has no effect with either purified fibrinogen or plasma as substrate. In the fibrinogen system poly $\mathrm{A}$ and poly $\mathrm{U}$ are slightly inhibitory and their effect is equal to or greater than an equivalent amount of heparin. However, in contrast to heparin, which shows an enormous increase in potency in the plasma system due to the presence of heparin co-factor, ${ }^{17}$. the inhibi-

\footnotetext{
${ }^{*}$ Poly G, poly GU, and poly IU were studied only in the TGT.
} 
Table 3

ONE-STAGE PROTHROMBIN TIME. THE EFFECT OF VARIOUS POLYNUCLEOTIDES ON THE QUICK ONE-STAGE PROTHROMBIN TIME. $(0.1 \mathrm{ml}$ PLASMA $+0.1 \mathrm{ml}$ SALINE OR POLYNUCLEOTIDE + $0.2 \mathrm{ml}$ "SIMPLASTIN")

\begin{tabular}{l|cc|c}
\hline \multicolumn{1}{c|}{ Test material } & Amount added & Clotting time \\
\hline & & & Seconds \\
Saline control & & & 14.5 \\
Poly A & 0.4 & $\mu \mathrm{mol} \mathrm{P}$ & 15.5 \\
Poly U & 0.4 & $\mu \mathrm{mol} \mathrm{P}$ & 13.8 \\
Poly C & 0.4 & $\mu \mathrm{mol} \mathrm{P}$ & 14.5 \\
Rabbit liver RNA & 0.4 & $\mu \mathrm{mol} P$ & 14.8 \\
Calf thymus DNA & 0.4 & $\mu \mathrm{mol} \mathrm{P}$ & 15.5 \\
Calf thymus apurinic acid & 0.4 & $\mu \mathrm{mol} \mathrm{P}$ & 15.4 \\
Poly I & 0.025 & $\mu \mathrm{mol} \mathrm{P}$ & 17.5 \\
Poly I & 0.1 & $\mu \mathrm{mol} \mathrm{P}$ & 26 \\
Poly I & 0.2 & $\mu \mathrm{mol} \mathrm{P}$ & 31.5 \\
Poly I & 0.4 & $\mu \mathrm{mol} \mathrm{P}$ & 41.5 \\
Oxalate & 0.4 & $\mu \mathrm{mol} \mathrm{P}$ & 14 \\
\hline
\end{tabular}

Table 4

THE EFFECT OF VARIOUS POLYNUCLEOTIDES ON THE RVV CLOTTING TIME OF PLASMA

\begin{tabular}{l|c}
\hline $\begin{array}{c}\text { Material } \\
(0.4 \mu \mathrm{mol} \text { P of each })\end{array}$ & Clotting time \\
\hline I. Saline control & Seconds \\
& 23.3 \\
Poly A & 24.5 \\
Poly C & 23.2 \\
Poly U & 31.8 \\
Poly I & 72.2 \\
II. Saline control & 19.8 \\
E. coli S RNA & 20.2 \\
E. coli M RNA & 20.6 \\
Rabbit liver RNA & 19.8 \\
Calf thymus DNA & 19.8 \\
M. lysodeikticus DNA & 22.3 \\
Calf thymus apurinic acid & 20.2 \\
Na Oxalate & 21.2 \\
\hline
\end{tabular}


tory effects of poly $\mathrm{A}$ and poly $\mathrm{U}$ on thrombin activity diminish in plasma (Table 5).

\section{Effect of $\mathrm{Ca}^{++}$Concentration}

Poly I, like other synthetic and naturally occurring polynucleotides, is known to bind alkaline earth cations such as $\mathrm{Ca}^{++}$and $\mathrm{Mg}^{++}$. Under certain conditions this binding is stoichiometric between the phosphate groups of the polymer and the cation on an equimolar basis. ${ }^{18}$ Since oxalate ion in equivalent concentrations has no effect on the coagulation tests described, it seems unlikely that the anticoagulant properties of poly I can be explained on the basis of $\mathrm{Ca}^{++}$ binding. On the other hand, increases in $\left[\mathrm{Ca}^{++}\right]$in the test mixture per se reduce the anticoagulant effects of poly $\mathrm{I}^{*}{ }^{*}$ llie same effect is noted if $\mathrm{Mg}^{++}$is added to the test system in addition to $\mathrm{Ca}^{++}$(Table 6). Further investigation reveals that the solubility of poly $\mathrm{I}$ is critically dependent upon $\left[\mathrm{Ca}^{++}\right]$, falling off rapidly at $\left[\mathrm{Ca}^{++}\right]>3 \mu \mathrm{mol} / \mathrm{ml}$ (Figure 1). $\mathrm{Mg}^{++}$also diminishes poly 1 solubility. These observations led to the use of more dilute $\mathrm{Ca}^{++}$solutions for recalcification of reagents in subsequent experiments. Precipitation of poly I can be avoided by using lower concentrations of $\mathrm{Ca}^{++}$without altering the control results. This principle is further illustrated in the next section.

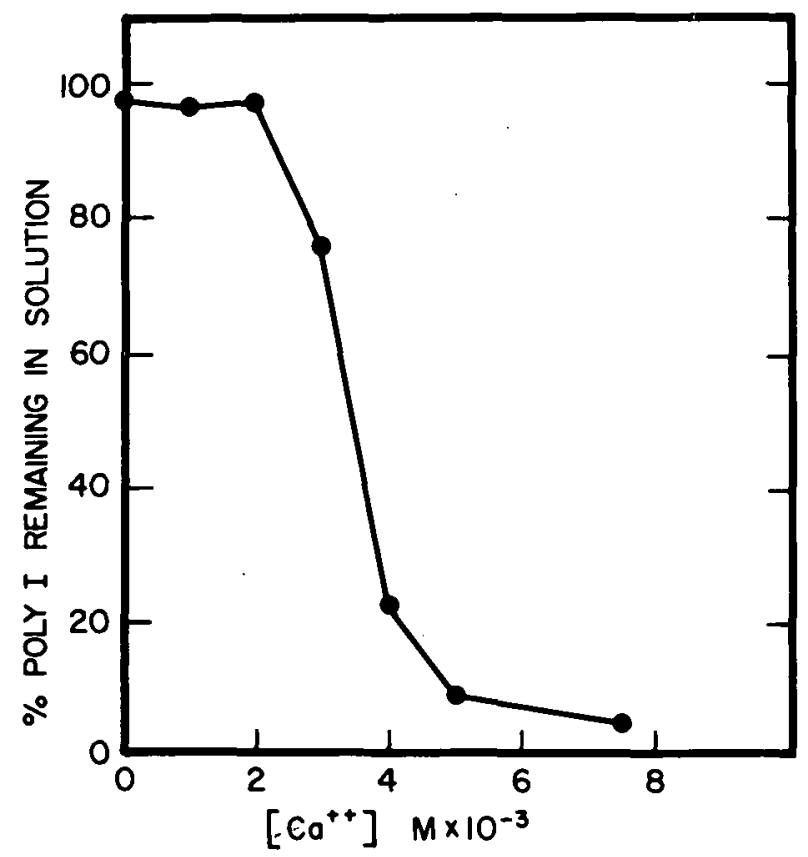

Figure 1. Solubility of poly I in varying $\left[\mathrm{Ca}^{++}\right] \cdot 0.16 \mu \mathrm{mol}$ $P$ poly $I$ in $0.1 \mathrm{ml}$ TBS was added to $5 \mathrm{ml}$ of TBS containing various $\left[\mathrm{Ca}^{++}\right]$and allowed to stand at room temperature for 3 hours. Solubility of poly I was calculated from residual supernatant O.D. at $249 \mathrm{~m} \mu$ after centrifugation at $14000 \mathrm{~g}$ for 30 minutes. poly I. 19

${ }^{*}\left[\mathrm{Ca}^{++}\right]>3 \mu \mathrm{mol} / \mathrm{ml}$ also diminishes or destroys the anticomplementary properties of 
Table 5

THE EFFECT OF VARIOUS POLYNUCLEOTIDES ON FIBRINOGEN-FIBRIN CONVERSION BY THROMBIN

\begin{tabular}{|c|c|c|c|c|c|}
\hline \multicolumn{3}{|c|}{ A. Purified fibrinogen substrate } & \multicolumn{3}{|c|}{ B. Plasma substrate } \\
\hline \multicolumn{3}{|c|}{$\begin{aligned} \text { Procedure: } & 0.4 \mathrm{ml} \text { fibrinogen } \\
& 0.1 \mathrm{ml} \text { saline or polynucleotide } \\
& 0.1 \mathrm{ml} \text { thrombin }(20 \mathrm{u} / \mathrm{ml})\end{aligned}$} & \multicolumn{3}{|c|}{$\begin{array}{ll}\text { Procedure: } & 0.2 \mathrm{ml} \text { plasma } \\
& 0.1 \mathrm{ml} \text { saline or polynucleotide } \\
& 0.1 \mathrm{ml} \text { thrombin }(8 \mathrm{u} / \mathrm{ml})\end{array}$} \\
\hline Test material & Amount added & Clotting time & Test material & A mount added & Clotting time \\
\hline & & Seconds & & & Seconds \\
\hline Saline control & & 15.7 & Saline control & & 16.1 \\
\hline Poly A & $0.2 \mu \mathrm{mol} \mathrm{P}$ & 32 & Poly A & $0.4 \mu \mathrm{mol} \mathrm{P}$ & 26 \\
\hline Poly U & $0.2 \mu \mathrm{mol} \mathrm{P}$ & 24.5 & Poly U & $0.4 \mu \mathrm{mol} \mathrm{P}$ & 16.5 \\
\hline Poly C & $0.2 \mu \mathrm{mol} \mathrm{P}$ & 20 & Poly C & $0.4 \mu \mathrm{mol} \mathrm{P}$ & 16 \\
\hline Poly I & $0.2 \mu \mathrm{mol} \mathrm{P}$ & 15 & Poly I & $0.4 \mu \mathrm{mol} \mathrm{P}$ & 17.5 \\
\hline Rabbit liver RNA & $0.2 \mu \mathrm{mol} \mathrm{P}$ & 18 & Rabbit liver RNA & $0.4 \mu \mathrm{mol} \mathrm{P}$ & 18 \\
\hline Calf thymus DNA & $0.2 \mu \mathrm{mol} \mathrm{P}$ & 16.5 & Calf thymus DNA & $0.4 \mu \mathrm{mol} \mathrm{P}$ & 18.5 \\
\hline Heparin & $0.2 \mu \mathrm{mol} \mathrm{S}$ & 24.5 & Heparin & $\begin{array}{l}(0.06 \mu \mathrm{g}) 0.0002 \mu \mathrm{mol} \mathrm{S} \\
(0.075 \mu \mathrm{g}) 0.00025 \mu \mathrm{mol} \mathrm{S} \\
(0.15 \mu \mathrm{g}) 0.0005 \mu \mathrm{mol} \mathrm{S}\end{array}$ & $\begin{array}{r}22 \\
115 \\
429\end{array}$ \\
\hline
\end{tabular}


Table 6

THE EFFECT OF INCREASING $\left[\mathrm{Ca}^{++}\right]$(A) OR $\left[\mathrm{Mg}^{++}\right]$(B) ON THE ANTICOAGULANT PROPERTIES OF POLY I

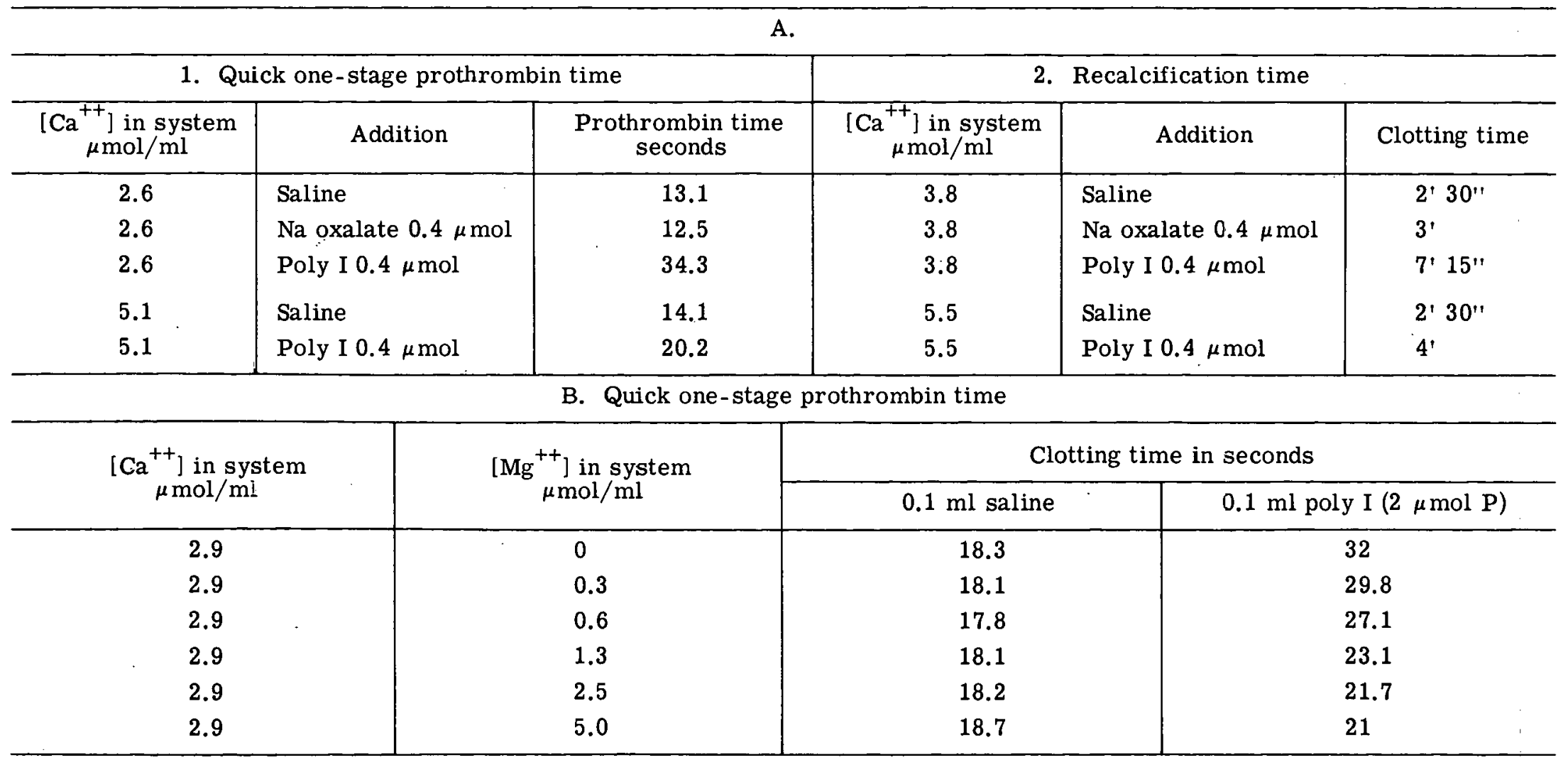


Only poly I and poly G show any capacity to inhibit thromboplastin generation (Figures 2 and 6). Poly G possesses only $1 / 4$ the anticoagulant potency of poly I. Figure 3 shows the effects of varying $\mathrm{Ca}^{++}$concentrations on the inhibition of thromboplastin generation by poly $\mathrm{I}$.

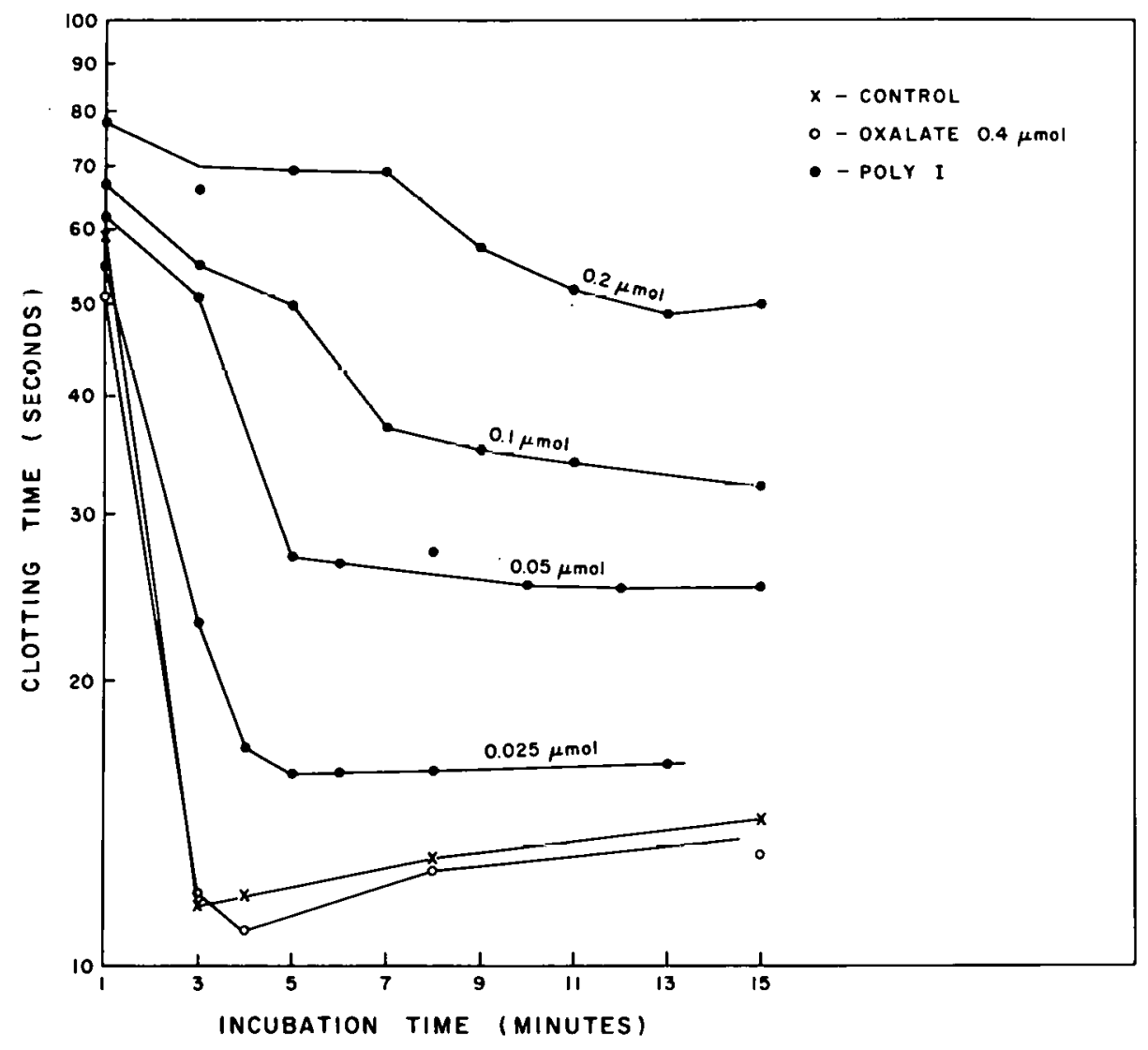

Figure 2. The effect of varying amounts of poly I on the thromboplastin generation test. The incubation mixture was recalcified with $0.0075 \mathrm{M} \mathrm{Ca}^{++}$, yielding a final $\left[\mathrm{Ca}^{++}\right]$of $1.0 \times 10^{-3} \mathrm{M}$. The saline control and polynucleotide controls were identical.

At a final $\left[\mathrm{Ca}^{++}\right]$of approximately $4.5 \mu \mathrm{mol} / \mathrm{ml}$ in the incubation mixture, poly $\mathrm{I}$ has only $1 / 4$ the anticoagulant effect it possesses at the lower $\left[\mathrm{Ca}^{++}\right]$, a figure in keeping with the solubility data shown earlier. The other homopolymers are inactive in amounts up to $0.8 \mu \mathrm{mol} P$; the fol-

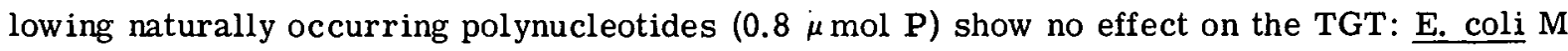
RNA, E. coli S RNA, rabbit liver RNA, all 3 DNAs, both native and heat denatured, and the apurinic acids. In no instance did the polynucleotide control differ from the saline control TGT.

Poly I is known to form hydrogen bonded helical structures with poly $\mathrm{A}$ or poly $\mathrm{C}$. ${ }^{18 \mathrm{a}}$ The former, in the presence of excess poly $I$, is triple stranded $(2 I+A)$ whereas the latter is double stranded $(I+C)$. The experiment shown in Figure 4 was designed to see whether poly I incorporated into such helical structures is capable of exerting an inhibitory effect on the TGT. It can be seen that both poly $\mathrm{A}$ and poly $\mathrm{C}$ are capable of abolishing the anticoagulant properties of 


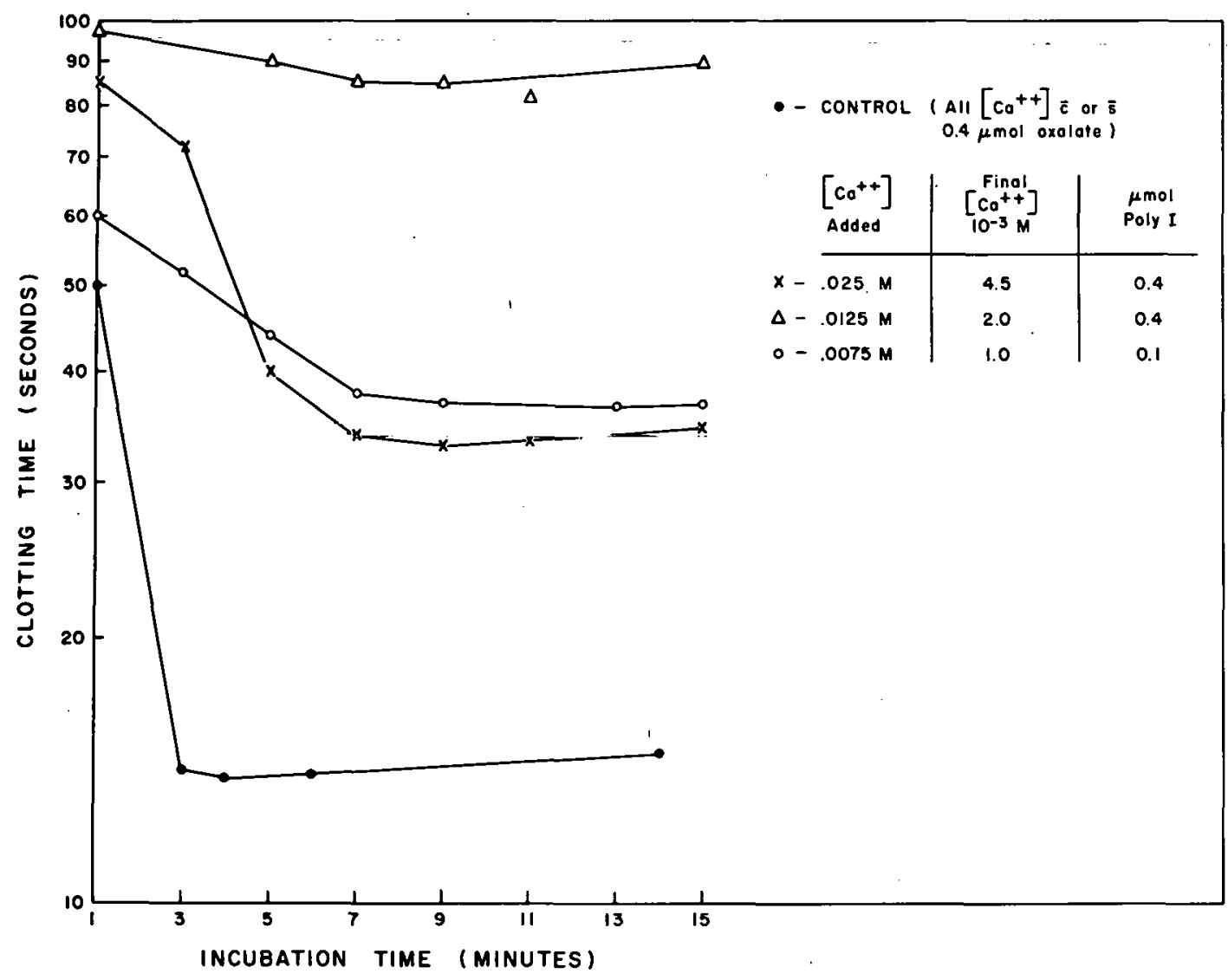

Figure 3. The effect of varying $\left[\mathrm{Ca}^{++}\right]$on the inhibition of thromboplastin generation by poly I. At a final $\left[\mathrm{Ca}^{++}\right]$of $1 \times 10^{-3} \mathrm{M}$ poly $I$ is 4 times as effective an inhibitor as it is at a final $\left[\mathrm{Ca}^{++}\right]$of $4.5 \times 10^{-3} \mathrm{M}$.

poly I, and the effectiveness of this abolition is stoichiometrically consistent with the nature of the helices formed. Poly U, which is incapable of helix formation with poly $\mathrm{I}$, is without effect.

Protamine is capable of reversing the anticoagulant properties of heparin, presumably by electrostatic interaction between molecules of opposite charge. Similarly it can interact with polynucleotides. Protamine also abolishes the anti-thromboplastin generation properties of poly I (Figure 5).

The effect of IU and GU copolymers on the TGT is shown in Figure 6. Only those copolymers with G or I contents of 60 per cent or greater are capable of inhibiting thromboplastin generation, and their potency is much less than equivalent amounts of poly I. Paradoxically, despite the fact that poly $I$ is a more potent anticoagulant than poly $G$, the GU copolymers havc greater inhibitory effects on thromboplastin generation than the IU copolymers of similar base composition.

\section{Two-Stage Prothrombin Test (Thrombin Generation)}

Poly $\mathrm{I}$ is the only homoribopolynucleotide capable of inhibiting the generation of thrombin (Figure 7); when incorporated into a hydrogen bonded helical structure with poly A or poly C this inhibitory effect is abolished. Rabbit liver RNA and calf thymus apurinic acid are without 


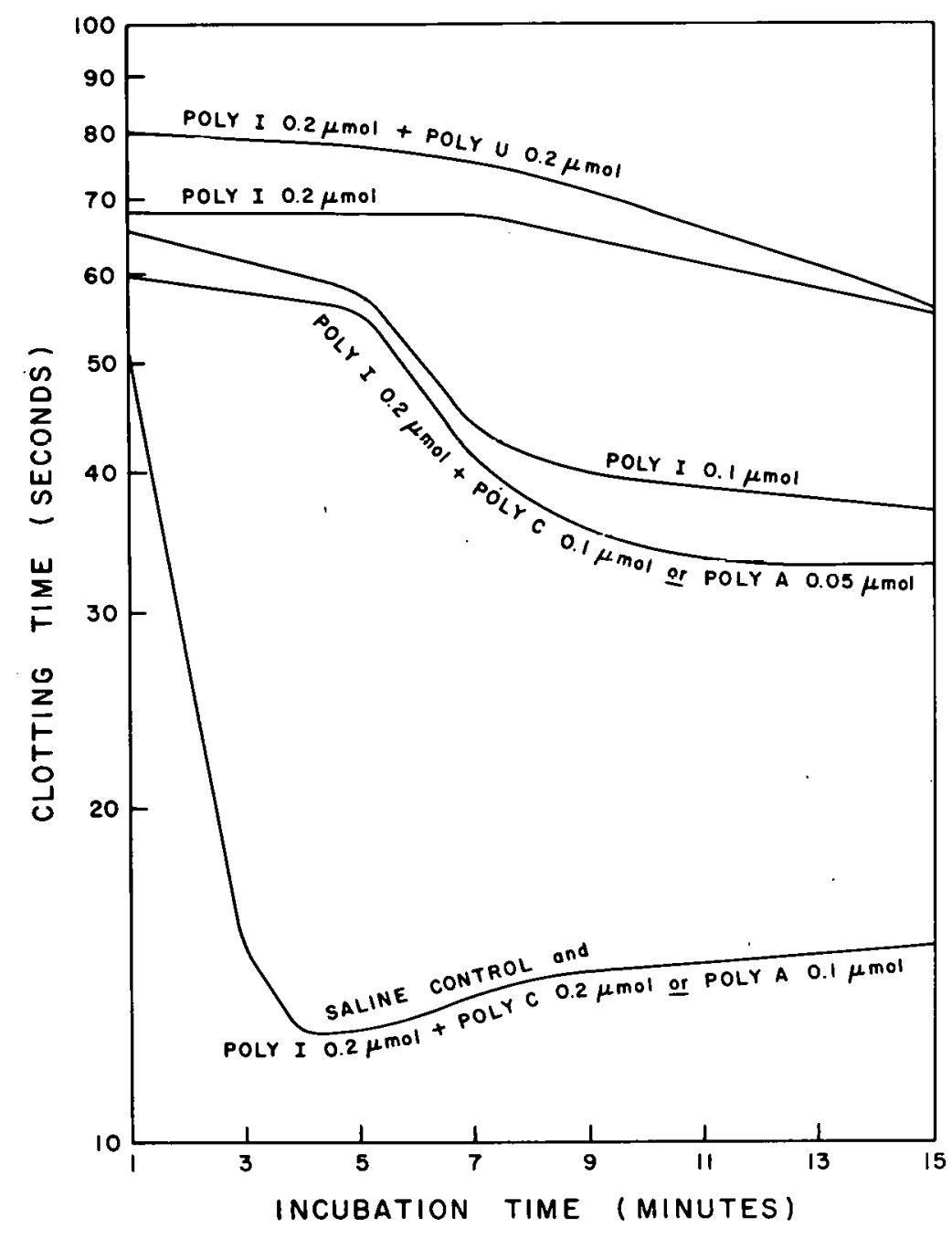

Figure 4. The effect of poly $\mathrm{A}$ and poly $\mathrm{C}$ on the inhibition of thromboplastin generation by poly $I$. The indicated amounts of polynucleotide were premixed in a total volume of $0.2 \mathrm{ml}$. Two-tenths $\mathrm{ml} 0.0075 \mathrm{M} \mathrm{Ca}^{++}$was used to recalcify the incubation mixture (final $\left[\mathrm{Ca}^{++}\right] 1 \times 10^{-3} \mathrm{M}$ ).

effect. The effects of DNA are difficult to assess for technical reasons since its presence in the incubation mixture results in the formation of an extremely viscous clot which makes removal of aliquots almost impossible.

Effect of Mononucleotides

IMP, UMP, AMP, GMP, and CMP, either alone or in combination, are devoid of effect in any of the coagulation systems when used in amounts equivalent to the most concentrated polynucleotide preparations tested.

\section{DISCUSSION}

Poly I, a very potent anticomplementary substance, also possesses anticoagulant properties. As an anticomplementary substance poly I is approximately 300 times more potent than 


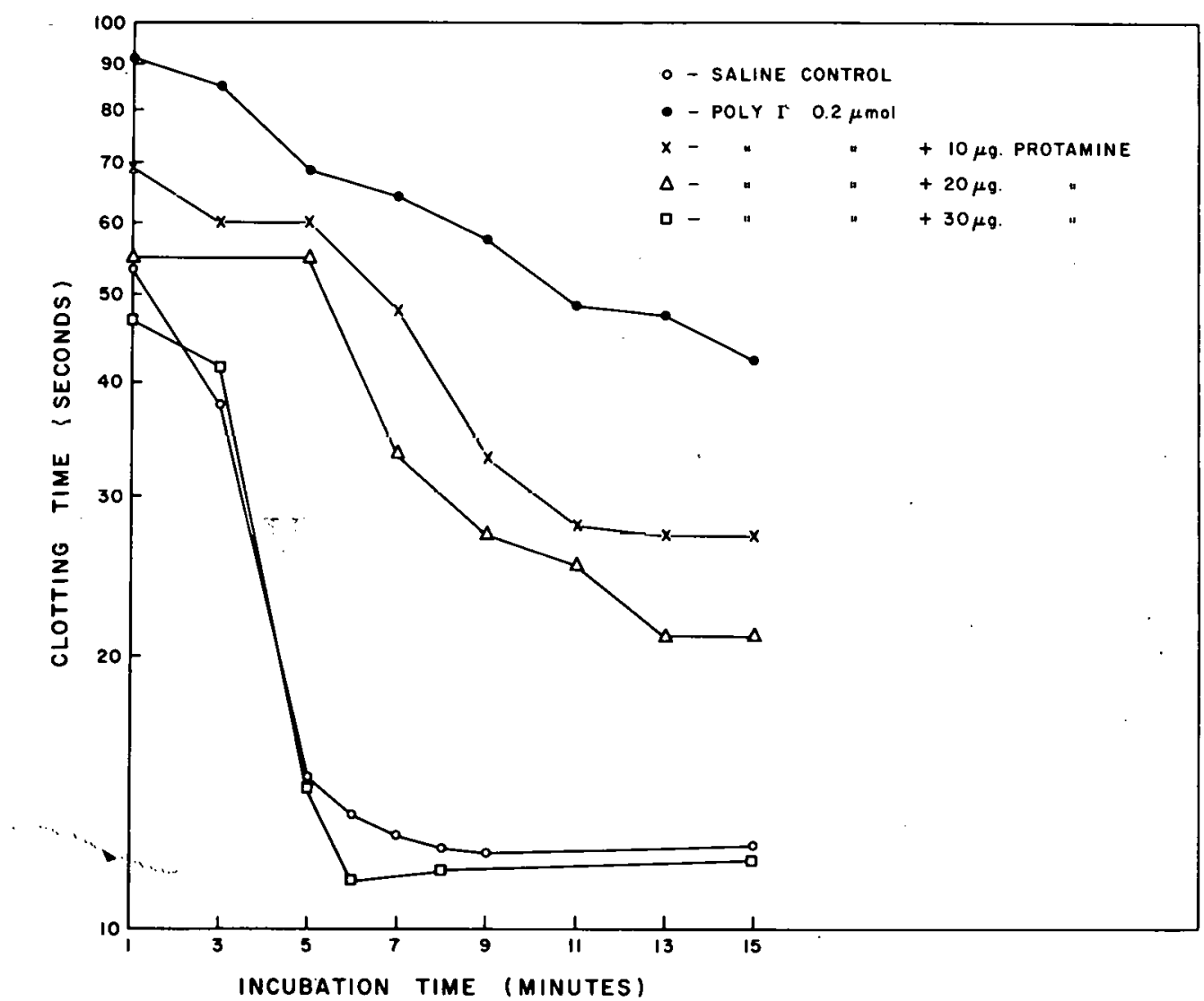

Figure 5. The effect of protamine sulphate on the inhibition of thromboplastin generation by poly I. The procedure followed was similar to that described in Figure 4.

heparin; ${ }^{10}$ heparin, on the other hand, is 20 to 50 times ${ }^{*}$ more potent an anticoagulant. Although $\left[\mathrm{Ca}^{++}\right]$plays a critical role in demonstrating the anticoagulant properties of poly I due to its ef-, fects on the solubility of the homopolymer, the anticoagulant properties of poly I are not explainable on the basis of $\mathrm{Ca}^{++}$binding. First, it is known that other polynucleotides lacking anticoagulant properties have similar chelating potential, and second, oxalate ion in equivalent or greater concentration has no inhibitory effect on the in vitro tests. Similarly, the anticoagulant properties of poly I and poly G, in contrast to the other homopolymers, cannot be explained on the basis of differences in secondary structure (single versus multistrand) or molecular size. ${ }^{10}$ The interaction of poly I and poly G with coagulation factors must depend primarily upon a structural feature of the polymer bestowed by the constituent base. In a manner analogous to the effects of polynucleotides on the complement system, ${ }^{10}$ we may conclude that the anticoagulant properties of polynucleotides depend in part upon the presence of a polymerized purine ring possessing an $\mathrm{OH}$ at the 6 position. Involvement of the $\mathrm{OH}$ group of poly $\mathrm{I}$ in hydrogen bond formation in the helical structures formed with poly $\mathrm{A}$ and poly $\mathrm{C}$ stoichiometrically abolishes anticoagulant activity. Under the conditions of these experiments poly $\mathrm{G}$ has an ordered multistranded

*The latter figure is based on the relative effectiveness of heparin in inhibiting thromboplastin generation. 

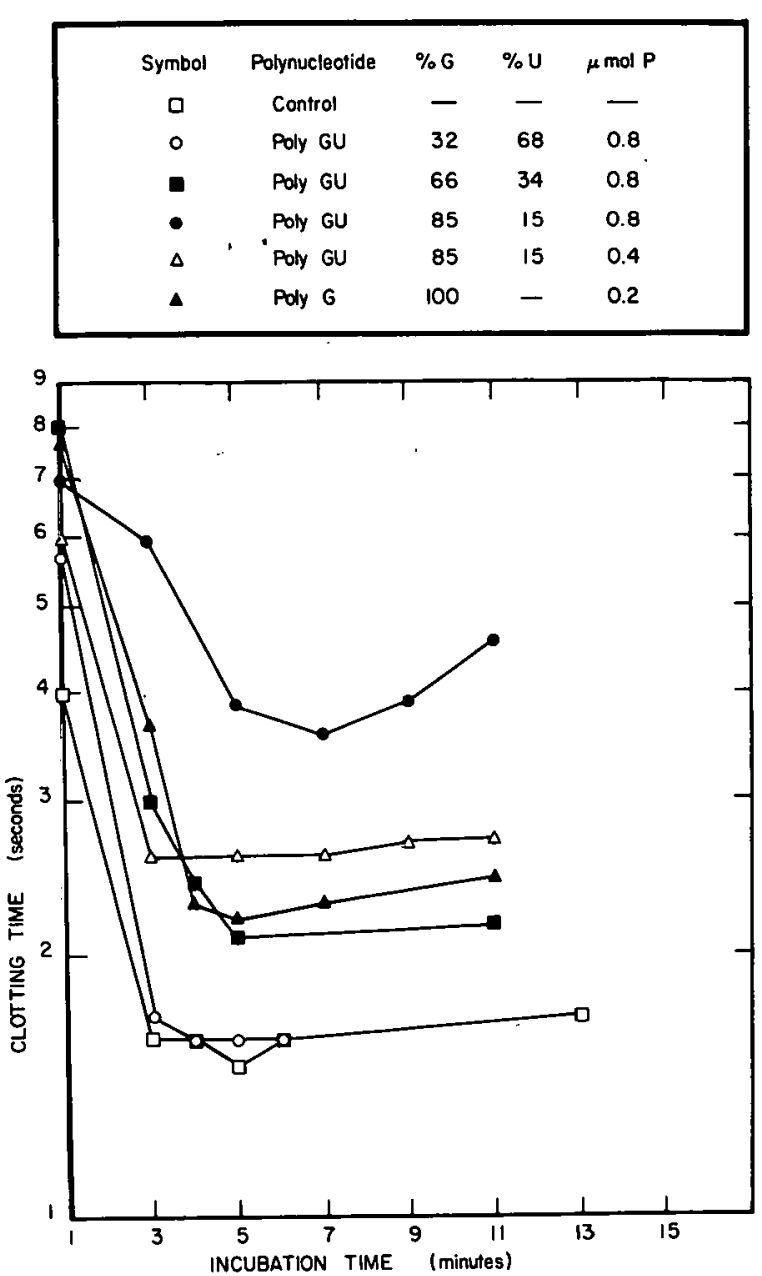

A

\begin{tabular}{|ccccc|}
\hline Symbol & Polynucleotide & $\because \%$ I & $\%$ U & $\mu$ mol P \\
0 & Control & - & - & - \\
$-\cdots$ & Poly IU & 31 & 69 & 0.8 \\
$\cdots--$ & Poly IU & 56 & 44 & 0.8 \\
$\square$ & Poly IU & 83 & 17 & 0.8 \\
0 & Poly I & 100 & - & 0.2 \\
$\Delta--\Delta$ & Poly I & 100 & - & 0.1 \\
$\square$ & Poly I & 100 & - & 0.05 \\
\hline
\end{tabular}

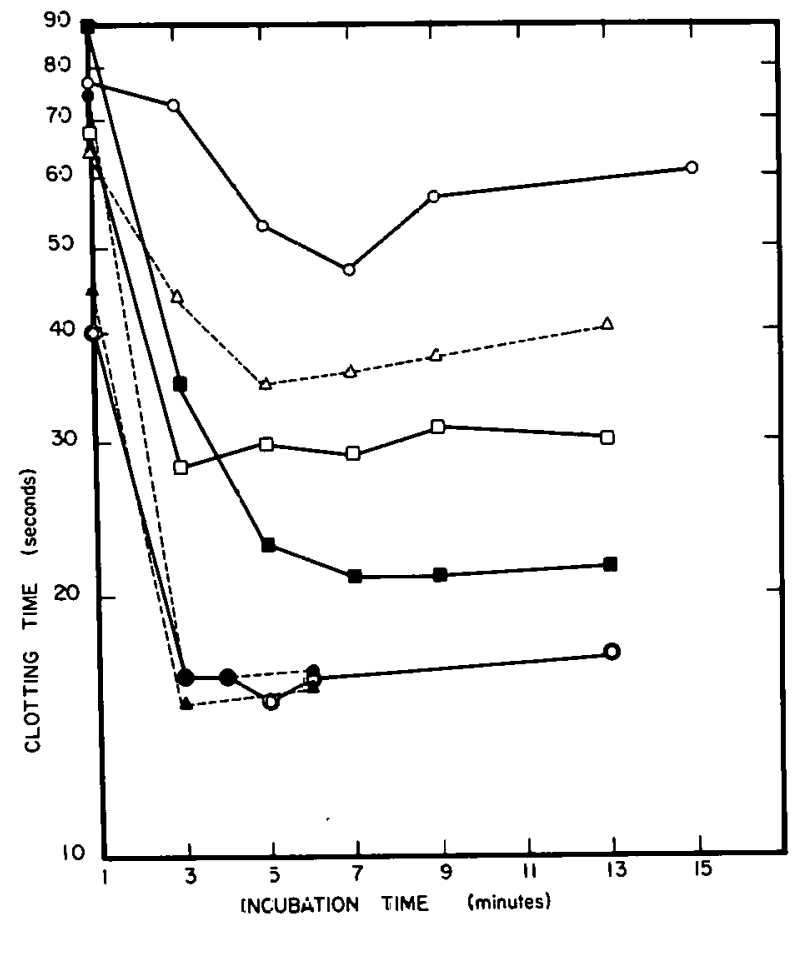

B

Figure 6. Comparison of the effects of poly GU and poly G (A) and of poly IU and poly I (B) on thromboplastin generation. Both sets of determinations were done using the same batch of coagulation reagents during a single experimental session. 
secondary structure ${ }^{20}$ while poly I does not; ${ }^{21}$ this may explain in part why poly G is a weaker inhibitor of thromboplastin generation than poly $I$.

The data presented in Figure 6 reveal that the anticoagulant activity of polymerized I residues falls off steeply when another base (U) is introduced into the copolymers. Thus, on the basis of I content, poly IU ( 83 per cent I, 17 per cent U) possesses only $1 / 26$ the anticoagulant activity of poly $\mathrm{I}$. The most reasonable explanation for this phenomenon is that the anticoagulant properties of polymerized I residues depend upon their occurrence in an extended sequence uninterrupted by another base. A statistical estimate of this critical chain length reveals that approximately 30 I residues are necessary for maximum anticoagulant effect, a figure close to that obtained for the critical chain length governing the anticomplementary properties of poly I. ${ }^{10}$

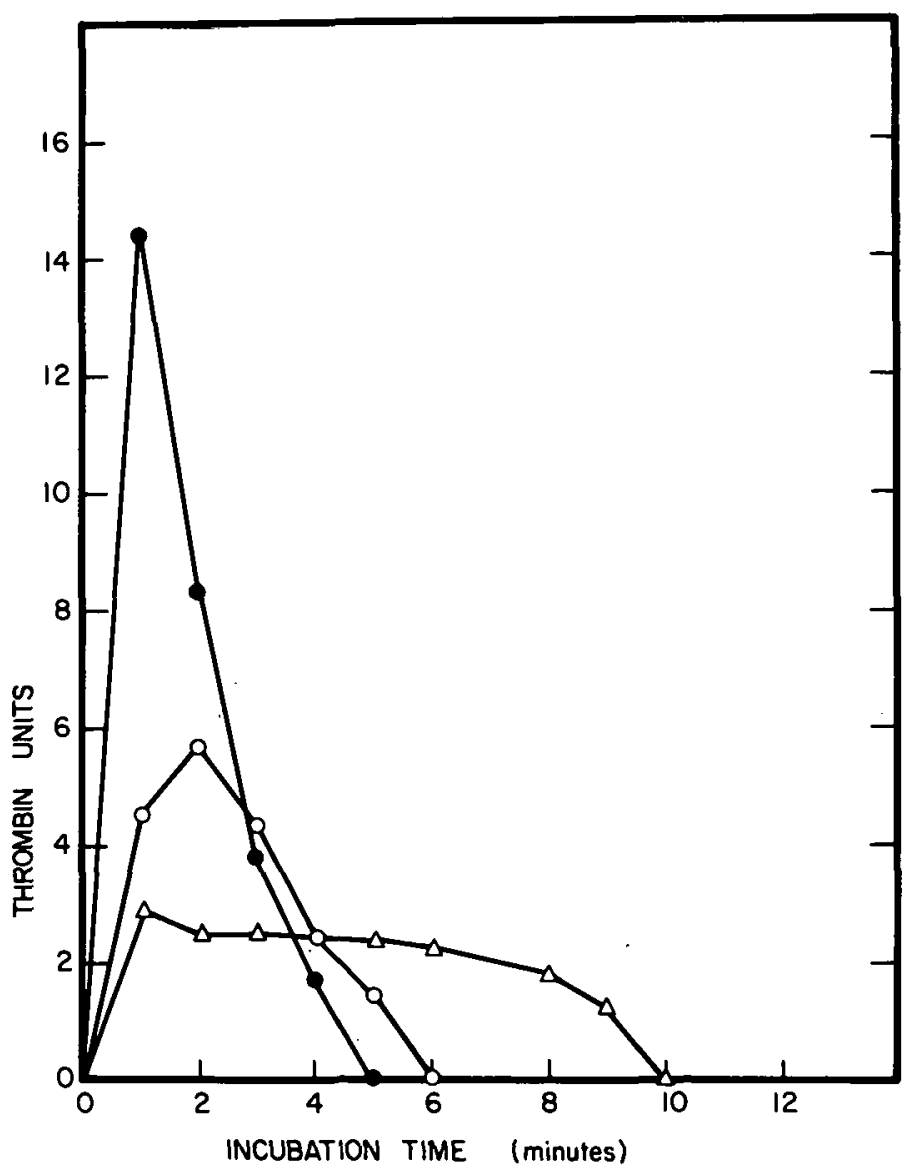

Figure 7. The effect of poly I on the two-stage prothrombin test. The saline and polynucleotide control curves were similar. $\multimap$, control; $\Delta \longrightarrow \Delta, 0.2 \mu \mathrm{mol}$ P poly I; $\multimap 0.15$ $\mu$ mol $\mathrm{P}$ poly $\mathrm{I}$.

Strict application of this chain length hypothesis to the $G$ containing series of synthetic polynucleotides would lead one to expect that poly $\mathrm{G}$ would be more potent an anticoagulant than poly. I, since the GU copolymers are more potent than the IU copolymers of similar base ratio. Although the secondary structure of poly $G$ may explain why poly $G$ is actually less potent than poly I, the fact that the anticoagulant effect of poly GU diminishes as its G content falls suggests 
that a similar principle determines the anticoagulant effect of polymerized G residues. In addition, one would not expect to find any anticoagulant activity in naturally occurring nucleic acids, where the G content ranges between 30 and 40 per cent.

Little can be said of the exact mechanism by which poly I functions as an anticoagulant in terms of the recognized coagulation factors, but certain distinctions can be made between it and heparin. Heparin is an extremely potent antithrombin when the plasma cofactor is present, whereas poly I has little or no antithrombin activity. The pattern of inhibition of thrombin generation by poly I (delay in rate of thrombin formation) differs from that of heparin, whose effect is due largely to an increased rate of thrombin neutralization. $15 \mathrm{a}$

These studies demonstrate that selected polynucleotides possess anticoagulant properties. The requirement for an extended base sequence of $\mathrm{G}$ or I residues resembles closely the situation found in the inhibition of complement by polynucleotides, ${ }^{10}$ and in a more general fashion is analogous to the antigenic determinants in DNA which react with DNA antibodies in lupus sera, where an extended sequence of thymine base residues plays a critical role. ${ }^{22}$

\section{LITERA'I'URE CITED}

1. Weisberger, A. S. Proc. Nat. Acad. Sc. (U.S.), 48:68, 1962.

2. Kraus, L. M. Nature, London, 192:1055, 1961.

3. Niu, M. C., C. C. Cordova, and L. C. Niu. Proc. Nat. Acad. Sc. (U.S.), 47:1689, 1961.

4. Fishman, M., and F. L. Adler. J. Exptl. Med., 117:595, 1963.

5. Mannick, J. A., and R. H. Egdahl. Ann. Surg., 156:356, 1962.

6. Yachnin, S. Nature, London, 195:1319, 1962.

7. Yachnin, S. Biochim. et Biophys. Acta, 72:572, 1963.

8. Yachnin, S. Biochim. et Biophys. Acta, 72:578, 1963.

9. Yachnin, S. J. Immunol., 91:528, 1963.

10. Yachnin, S. J. Clin. Invest., 42:1947, 1963.

11. Fox, C. F., W. S. Robinson, R. Haselkorn, and S. B. Weiss. J. Biol. Chem., 239:186, 1964.

12. Marmur, J. J. Mol. Biol:, 3:208, 1961.

13. Tamm, C., M. E. Hodes, and E. Chargaff. J. Biol. Chem., 195:49, 1952.

14. Fiske, C. H., and Y. SubbaRow. J. Biol. Chem., 66:375, 1925.

15. Biggs, R., and R. G. Macfarlane. Human Blood Coagulation and Its Disorders. Philadelphia, F. A. Davis Co., 1962 , pp. 369-421; (a) pp. 165-69.

16. Nilsson, I. M., and A. Wenckert. Acta med. Scandinav. Suppl. 22, 297, 1954.

17. Astrup, T., and S. Darling. Acta physiol. Scandinav., 5:13, 1943.

18. Steiner, R. F., and R. R. Beers. Polynucleotides; Natural and Synthetic Nucleic Acids. Amsterdam, Elsevier Publishing Co., 1961, p. 300; (a) p. 225.

19. Yachnin, S. Unpublished observations.

20. Fresco, J. R., and J. Nassoulie. J. Am. Chem. Soc., 85:1352, 1963. 
21. Haselkorn, R. The conformation properties of synthetic polynucleotides in solution. Ph.D. Thesis, Harvard University, 1959.

22. Stollar, D., L. Levine, H. I. Lehrer, and H. Van Vanukis. Proc. Nat. Acad. Sc. (U.S.), 48:874, 1962.

23. Chargaff, E., and J. N. Davidson, eds. The Nucleic Acids, Vol. 1, New York, Academic Press, 1955, p. 354.

24. Chargaff, E., and J. N. Davidson, eds. The Nucleic Acids, Vol. 3, New York, Academic Press, 1960, p. 170; (a) p. 175. 
BIOLOGIC PROPERTIES OF POLYNUCLEOTIDES. III. THE ANTICOMPLEMENTARY PROPERTIES OF POLYRIBOGUANYLIC ACID*

By

\author{
S. Yachnin ${ }^{\dagger}$
}

We.have previously reported that polyinosinic acid (poly I) ${ }^{\ddagger}$ possesses potent anticomplementary (Anti- $\mathrm{C}^{\prime}$ ) properties, which are not found in other homoribopolynucleotides (poly A, C and $U$ ) and naturally occurring nucleic acids. Synthetic poly IU and poly GU containing $>80$ per cent $\mathrm{G}$ or I were also found to possess Anti-C' properties, the $\mathrm{GU}$ copolymer being approximately $5 \mathrm{x}$ as potent as an IU copolymer of similar base ratio. ${ }^{1}$ This report describes the Anti$C^{\prime}$ potency of poly G synthesized by means of RNA polymerase according to the method of Fox, Robinson, Haselkorn and Weiss. ${ }^{2}$ The synthesis was carried out in $0.1 \mathrm{M}$ tris, pH 7.4 at $37^{\circ}$ for $2 \mathrm{hr}$, using a reaction mixture of $50 \mathrm{ml}$ contâining $1 \times 10^{-3} \mathrm{M}$ GTP, $4 \times 10^{-3} \mathrm{M} \mathrm{MnCl}_{2}, 120$ $\mu \mathrm{g} / \mathrm{ml}$ poly $\mathrm{C}$, and 3420 units RNA polymerase. ${ }^{\Im}$ The reaction was stopped with E'V'A, and the solution treated twice with 90 per cent phenol. Following extensive dialysis to remove nonpolymerized GTP, the product was digested with $4 \mathrm{mg}$ RNAse at $63^{\circ} \mathrm{C}$ for $5 \mathrm{hr}$, re-extracted with phenol and dialyzed extensively against $0.15 \mathrm{M} \mathrm{NaCl}, 0.01 \mathrm{M}$ tris $\mathrm{pH}$ 7.4. The final product (9 $\mu \mathrm{mol} \mathrm{P}$ ) yielded an absorption spectrum (Figure 1 ) identical to those previously described for poly $\mathrm{G},{ }^{2,3}$ had a molar absorbancy (P) of 10.1 at $260 \mathrm{~m} \mu$ and an $\mathrm{S}$ value of 3.2 . It was stored at $-20^{\circ}$ at a concentration of $0.2 \mu \mathrm{mol} \mathrm{P} / \mathrm{ml}$.

The Anti-C' potency of poly $\mathrm{G}$ was determined as previously. ${ }^{1}$ Guinea pig serum was used as a source of $C^{\prime}$. From the data shown in-Figure 2 it can be seen that $0.054 \mu$ mol P poly $G$ is required to inhibit $1 \mathrm{C}^{\prime} \mathrm{H}_{50}$. Table 1 summarizes the data on the relative Anti- $\mathrm{C}^{\prime}$ potency of poly I, poly G, poly IU and poly GU.

In explaining the marked drop in Anti-C' potency of polymerized I residues in the 83 per cent $I 17$ per icent $U$ copolymer, the hypothesis was presented that such Anti- $C^{\prime}$ properties depended upon the uninterrupted sequence of I residues within a polymer molecule. An estimate of the critical chain length (k) for I by statistical methods yielded a $k$ of 43 I residues for maximal Anti-C' activity. ${ }^{1}$ Utilizing the relative Anti-C' potency of poly $\mathrm{GU}$ and poly $\mathrm{G}$ in a similar statistical analysis, one obtains a $k$ of 17 polymerized $G$ residues for maximal Anti-C' potency.

The validity of such an analysis in the case of G-containing polymers depends upon the assumption that no other factors (e.g., secondary structure) operate in determining Anti-C' potency. It has previously been shown that poly I (which under the conditions of $\mathrm{pH}$ and ionic strength used in these experiments. is single stranded), ${ }^{4}$ loses its Anti-C' properties when combined in hydrogen bonded helical structures with poly $\mathrm{A}$ or poly $\mathrm{C} .{ }^{1}$ The fact that poly G itself,

\footnotetext{
*This report is taken from a paper appearing in J. Immunol., 93:155, 1964. The work was supported in part by funds from the Helen and Joseph Regenstein Foundation.

$\dagger_{\text {John }}$ and Mary R. Markle Scholar, in Academic Medicine

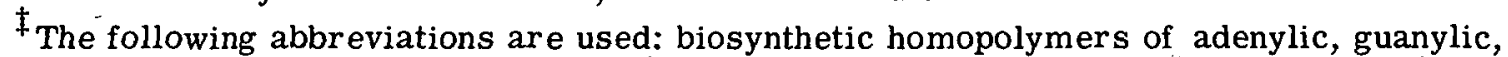
uridylic, cytidylic and inosinic acid: poly A, poly $\mathrm{G}$, poly $\mathrm{U}$, poly $\mathrm{C}$ and poly I respectively; copolymer of inosinic and uridylic acids: poly IU; copolymer of guanylic and uridylic acids: poly GU; GTP: guanosine triphosphate.

${ }^{\S}$ Kindly supplied by Drs. C. F. Fox and S. B. Weiss, University of Chicago.
} 


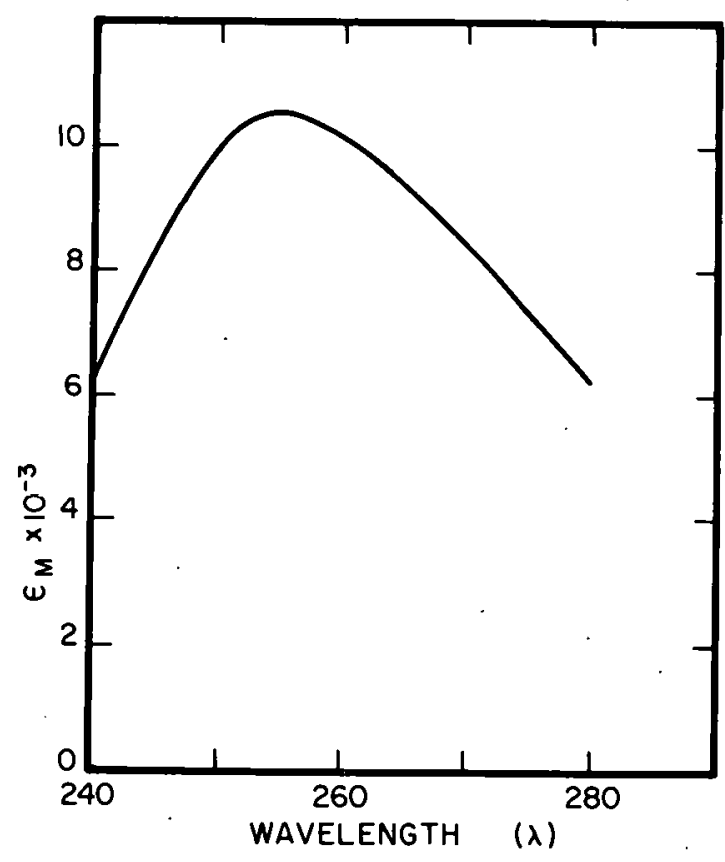

Figure 1. Near-ultraviolet absorption spectrum of poly $\mathrm{G}$ in $0.15 \mathrm{M}$ $\mathrm{NaCl}, 0.01 \cdot \mathrm{M}$ tris, pH 7.4.

Table 1

THE ANTI-C' POTENCY OF I AND G POLYMERS

\begin{tabular}{|c|c|c|c|c|c|}
\hline \multirow{2}{*}{ Polymer } & \multicolumn{3}{|c|}{$\begin{array}{c}\text { Base composition } \\
(\%)\end{array}$} & \multirow{2}{*}{$\begin{array}{l}\mu \mathrm{mol} P \text { needed to } \\
\text { inhibit } 1 \mathrm{C}^{\prime} \mathrm{H}_{50}\end{array}$} & \multirow{2}{*}{$\begin{array}{c}\text { Anti-C' potency compared } \\
\text { with poly I (based on } \\
\% \text { I or G content) }\end{array}$} \\
\hline & I & G & $\mathrm{U}$ & & \\
\hline Poly I & 100 & & & $0.0076^{a}$ & 1 \\
\hline Poly IU & 83 & & 17 & $1.23^{\mathrm{a}}$ & $1 / 134$ \\
\hline Poly G & & 100 & & 0.054 & $1 / 7$ \\
\hline Poly GU & & 85 & 15 & $0.25^{\mathrm{a}}$ & $1 / 27$ \\
\hline
\end{tabular}

${ }_{\text {Reference (1). }}$

under these conditions, exists in solution as a multistranded helix, ${ }^{3}$ may explain the paradox which these data present, namely, that whereas poly GU is $5 x$ more potent an Anti- $C^{\prime}$ agent than poly IU of similar base composition(and presumably of similar uninter rupted sequences of $I$ and G residues), poly $G$ is only $1 / 7$ as potent as poly $\mathrm{I}$. To obtain single stranded poly $\mathrm{G}$ by the usual methods it would be necessary to use such extremes of heat or $\mathrm{pH}$ as would themselves. inhibit complement activity; other methods of obtaining single stranded poly $\mathrm{G}$, which would not by themselves result in Anti-C' effects, are being sought in order to test the presumption that poly $G$ devoid of secondary structure would be at least as potent, if not more potent, an Anti-C' agent than poly $\mathrm{I}$. 


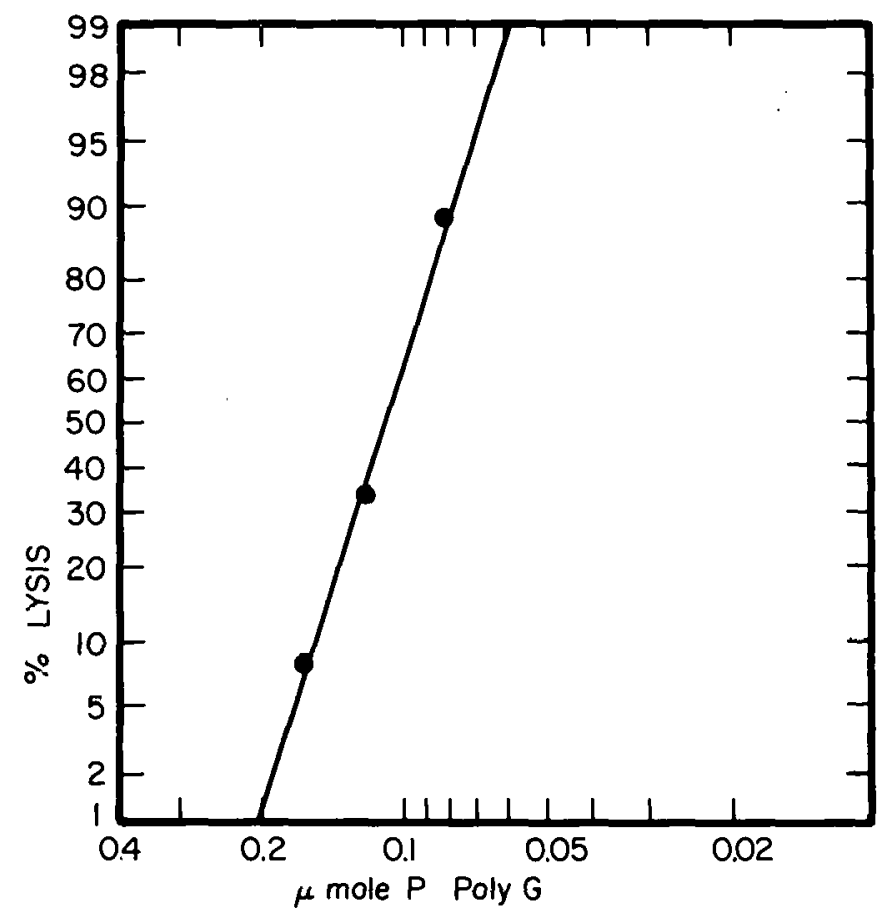
Figure 2. Titration of the inhibition of $\mathrm{C}^{\prime}$ by
poly G. Each test consisted of $1 \mathrm{ml}\left(5 \times 10^{8} \%\right.$ $\mathrm{ml}$ ) sensitized sheep cells, $3 \mathrm{C}^{\prime} \mathrm{H} 50$, the indicated amount of poly $\mathrm{G}$, and barbital-buffered saline (pH 7.4) with optimal. $\left[\mathrm{Ca}^{++}\right]$and $\left[\mathrm{Mg}^{++}\right]$to a total volume of $7.5 \mathrm{ml} .0 .108$ $\mu \mathrm{mol} P$ poly $\mathrm{G}$ yields 50 per cent lysis. $0.054 \mu \mathrm{mol} P$ poly $\mathrm{G}$ inhibits $1 \mathrm{C}^{\prime} \mathrm{H} 50$.

\section{LITERATURE CITED}

1. Yachnin, S. J. Clin. Invest., 42:1947, 1963.

2. Fox, C. F., W. S. Robinson, R. Haselkorn, and S. B. Weiss. J. Biol. Chem., 239:186, 1964.

3. Fresco, J. R., and J. Massoulie. J. Am. Chem. Soc., 85:1352, 1963.

4. Haselkorn, R. Ph.D. thesis, Harvard University, 1959. 


\title{
BIOLOGIC PROPERTIES OF POLYNUCLEOTIDES, IV. STUDIES ON THE MECHANISM OF COMPLEMENT INHIBITION BY POLYINOSINIC ACID TOGETHER WITH OBSERVATIONS ON THE IN VIVO EFFECT OF POLYINOSINIC ACID ON COMPLEMENT ACTIVITY*
}

By

\author{
S. Yachnin ${ }^{\dagger}$ and D. Rosenblum
}

In recent reports from this laboratory certain synthetic homoribopolynucleotides have been found to possess Anti- $\mathrm{C}^{\prime}$ activity. ${ }^{1,2}$ Of these, poly I is the most potent. Attempts to define the mechanism of action of poly $I$ by use of the $R$ reagents suggested that $C^{\prime} 1$ might be most vulnerable to inactivation by poly $\mathrm{I}^{1}$ and therefore experiments utilizing the kinetic analysis methods of Mayer and others were designed. ${ }^{3}$ The results indicate that poly I does in fact selectively inhibit $C^{\prime} 1$. In contrast to other potent $C^{\prime} 1$ inhibitors such as $\mathrm{DFP}^{4}$ and the $\mathrm{C}^{\prime} 1$ esterase serum inhibitor, ${ }^{5}$ poly I has no effect on $C^{\prime} 1$ esterase activity. In addition, poly $I$ has been found to be an effective in vivo inhibitor of $\mathrm{C}^{\prime}$ activity when administered to Wistar rats.

\section{MATERIALS AND METHODS}

Polyinosinic Acid. The synthesis of this material was as previously described. ${ }^{1}$

Guinea Pig Serum. Guinea pig blood obtained by cardiac puncture was allowed to clot for 4 hours at room temperature. The serum was then separated and stored in aliquots at $-40^{\circ} \mathrm{C}$.

Salts of EDTA. ${ }^{\$} \mathrm{Na}_{2} \mathrm{H}_{2}$ EDTA was prepared in a stock solution of $0.15 \mathrm{M}$ and titrated to $\mathrm{pH} 7.4$ (at this $\mathrm{pH}$ it is largely in the form $\mathrm{Na}_{3}$ HEDTA). $\mathrm{Na}_{2} \mathrm{Mg}$ EDTA solutions were prepared in an identical manner.

Buffer Diluents. Barbital buffered saline (BBS), pH 7.4, containing $1.5 \times 10^{-4} \mathrm{M} \mathrm{Ca}^{++}$and $5 \times 10^{-4} \mathrm{M} \mathrm{Mg}^{++}$was employed as a diluent in most experiments. BBS-Na ${ }_{3}$ HEDTA buffer con- : tained $7.5 \times 10^{-3} \mathrm{M} \mathrm{Na}_{3}$ HEDTA; BBS-Na $2 \mathrm{Mg}$ EDTA buffer contained $15 \times 10^{-3} \mathrm{M} \mathrm{Na}_{2} \mathrm{MgEDTA}$. BBS containing $1 \times 10^{3} \mathrm{M} \mathrm{Ca}^{++}$only was used in the preparation of $\mathrm{C}^{\prime} \mathrm{y}$.

\section{Preparation of EA}

The procedure for sensitizing sheep red cells has been described previously. ${ }^{1}$ The usual concentration of EA was $5 \times 10^{8}$ per $\mathrm{ml}$; for more concentrated preparations, the cells were spun

\footnotetext{
This report is taken from a paper that appeared in J. Clin. Invest., 43:1175, 1964. The work was supported in part by funds from the Joseph and Helen Regenstein Foundation.

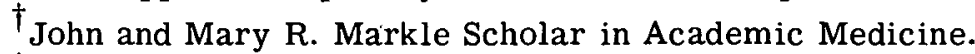

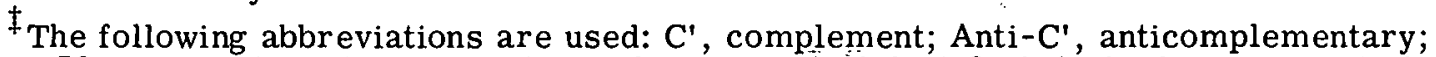
$\mathrm{C}^{\prime} \mathrm{H}_{50}, 50$ per cent hemolytic unit of complement; $\mathrm{C}^{\prime} 1, \mathrm{C}^{\prime} 2, \mathrm{C}^{\prime} 3, \mathrm{C}^{\prime} 4$, the first, second, third, or fourth component of complement; R1, R2, R3, R4, serum lacking the designated component of complement; EA, sensitized sheep erythrocytes; EAC' ..., per sensitized erythrocytes bearing complement components as designated by numerical subscript; $E^{*}$, red cells irreversibly damaged by the action of complement; DFP, diisopropylfluophosphate; poly I, polyinosinic acid; EDTA, ethylenediaminetetraacetate; ALTEE, N-acetyl-L-tyrosine ethyl ester.

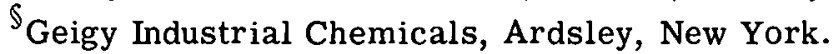


down and resuspended in a smaller volume. In experiments with RI it was necessary to sensitize the red cells in $\mathrm{Na}_{3}$ HEDTA-BBS, and subsequently wash them 3 times, once in $\mathrm{Na}_{3} \mathrm{HEDTA}-\mathrm{BBS}$ and twice in BBS, in order to avoid attachment of the $C^{\prime} 1$ present in commercial glycerinated hemolysin. ${ }^{6}$ Failure to do this resulted in high blank lysis of EA in Rl.

\section{Preparation of Guinea Pig C' Reagents}

$\mathrm{R}$ reagents were prepared from freshly drawn guinea pig serum as outlined in Mayer's text. ${ }^{7}$ The R3, prepared by incubating guinea pig serum with $13.0 \mathrm{mg}$ zymosan ${ }^{*}$ per $\mathrm{ml}$ at $37^{\circ}$ for 90 minutes, proved to be an excellent reagent for the preparation of $\mathrm{EAC}_{1,4,2}^{\prime} \mathrm{C}^{\prime} \mathrm{x}$ (guinea pig serum depleted of $\mathrm{Ca}^{++}$and $\mathrm{Mg}^{++}$by IRC 50 resin treatment) and $\mathrm{C}^{\prime} \mathrm{y}$ (a reagent containing only $\mathrm{C}^{\prime} 2$ and $\mathrm{C}^{\prime} 3$ ) were prepared as described by Levine and Mayer. ${ }^{8}$

Preparation of Complexes Between $\mathrm{C}^{\prime}$ and EA (Persensitized Cells)

General considerations. Although recent work indicates that $C^{\prime} 1$ and $C^{\prime} 3$ are complex factors each consisting of at least 3 separate components, ${ }^{9,10}$ the basic concepts regarding the sequence of action of $\mathrm{C}^{\prime}$ components in the lysis of EA remain unchanged. ${ }^{7 \mathrm{a}}$ In the presence of $\mathrm{Ca}^{\prime \prime \prime}$, EA reacts with $\mathrm{C}^{\prime} 1$ to form $\mathrm{EAC}^{\prime}{ }_{1}$; at the same time the esterase associated with $\mathrm{C}^{\prime} 1$ is activated. $\mathrm{C}^{\prime} 1$ esterase interacts with $\mathrm{C}^{\prime} 4$ to yield $\mathrm{EAC}_{1,4}$, which, in the presence of $\mathrm{Mg}^{++}$, reacts with $C^{\prime} 2$ to form $E A C^{\prime}{ }_{1,4,2}$. This step also requires the presence of $C^{\prime} 1$ and $C^{\prime} 1$ esterase activity, but $\mathrm{C}^{\prime} 1$ is not required for the subsequent stages of immune red cell lysis. $\mathrm{EAC}^{\prime}{ }_{1,4,2}$ even in the absence of divalent cations, then reacts with $\mathrm{C}^{\prime} 3$ to form $\mathrm{EAC}_{1,4,2,3}$ or $\mathrm{E}^{*}$. $\mathrm{E}^{*}$, an irreversibly damaged cell, loses its hemoglobin and becomes a ghost. This sequence of events is schematically outlined in Table 1.

Table 1

THE SEQUENCE OF EVENTS OCCURRING DURING IMMUNE HEMOLYSIS

\begin{tabular}{ll}
$\mathrm{EA}+\mathrm{C}^{\prime} 1 \mathrm{q}+\mathrm{C}^{\prime} 1 \mathrm{r}+\mathrm{C}^{\prime} 1 \mathrm{~s} \longrightarrow \mathrm{Ca}^{++}$ & $\mathrm{EAC}_{1}^{\prime}$ \\
$\mathrm{EAC}_{1}^{\prime}+\mathrm{C}^{\prime} 4 \longrightarrow \mathrm{Mg}^{++}$ & $\mathrm{EAC}_{1,4}^{\prime}$ \\
$\mathrm{EAC}_{1,4}^{\prime}{ }_{1,4} \mathrm{C}^{\prime} 2 \longrightarrow \mathrm{EAC}^{\prime}{ }_{1,4,2}$ \\
$\mathrm{EAC}_{1,4,2}^{\prime}+\mathrm{C}^{\prime} 3 \mathrm{a}+\mathrm{C}^{\prime} 3 \mathrm{~b}+\mathrm{C}^{\prime} 3 \mathrm{c} \longrightarrow \mathrm{E}^{*}$ \\
$\mathrm{E}^{*} \longrightarrow$ ghost + hemoglobin \\
\hline
\end{tabular}

EAC' $_{1,4,2}$. This intermediate complex was prepared by mixing together $10 \mathrm{ml}$ EA $\left(5 \times 10^{8}\right.$ per $\mathrm{ml}$ and $0.5 \mathrm{ml} \mathrm{R} 3$ at $1^{\circ} \mathrm{C}$ for 30 minutes. The cells were then washed 3 times with cold BBS and resuspended at a concentration of $5 \times 10^{8}$ per $\mathrm{ml}$ in cold $\mathrm{Na}_{3}$ HEDTA BBS. Since $\mathrm{C}^{\prime} 2$ activity decays rapidly at higher temperatures, ${ }^{11}$ it is imperative to keep these cells at $1^{\circ} \mathrm{C}$ prior to use.

The activity of this complex can be measured by lysis in guinea pig serum diluted in $\mathrm{Na}_{3}$ HEDTA BBS which chelates $\mathrm{Ca}^{++}$and $\mathrm{Mg}^{++}$, thereby blocking the action of $\mathrm{C}^{\prime} 1, \mathrm{C}^{\prime} 4$, and $\mathrm{C}^{\prime} 2$, but permitting the reaction of $C^{\prime} 3$. Conversely these cells can be used to quantify the $C^{\prime} 3$ activity

* Lot no. 2 F 1581 Standard Brands, New York, New York. 
of a given reagent.

$\mathrm{EAC}_{1,4}$. This persensitized cell was prepared by inactivating the $\mathrm{C}^{\prime} 2$ activity of $\mathrm{EAC}_{1,4,2}$ in $\mathrm{B} \overline{\mathrm{BS}}$ at $37^{\circ}$ for 90 minutes. ${ }^{12}$ The activity of this complex can be measured by lysis in guinea pig serum diluted in $\mathrm{Na}_{2} \mathrm{Mg}$ EDTA-BBS. $\mathrm{Na}_{2} \mathrm{Mg}$ EDTA chelates $\mathrm{Ca}^{++}$but not $\mathrm{Mg}^{++}$, thereby blocking the action of $C^{\prime} 1$, but permitting $C^{\prime} 2$ and $C^{\prime} 3$ to function. These cells can be used to quantify the combined $C^{\prime} 2$ and $C^{\prime} 3$ activity of a given reagent. In certain experiments $E^{\prime} A C^{\prime}{ }_{1,4}$ were prepared from $C^{\prime} x^{8},{ }^{8}$ or from $C^{\prime} y$ (diluted in BBS).

EAC' $_{4}$. This persensitized red cell was prepared by eluting $C^{\prime} 1$ from EAC' $1,4^{\cdot}{ }^{12}$ The elu-

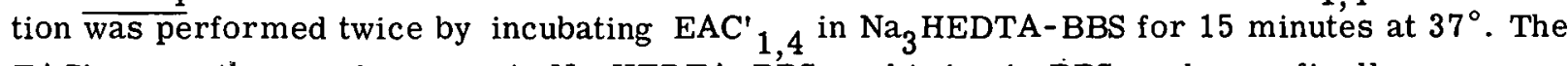
$\mathrm{EAC}_{4}{ }_{4}$ were then washed once in $\mathrm{Na}_{3} \mathrm{HEDTA}-\mathrm{BBE}$, and twice in BBS, and were finally resuspended in the latter reagent. This complex, which will not lyse in $\mathrm{Na}_{2} \mathrm{Mg}$ EDTA guinea pig serum, will lyse in $\mathrm{R} 4$.

EAC $_{1}{ }_{1}$. This inter mediate complex was formed by the reaction of EA (sensitized in $\mathrm{Na}_{3}$ HEDTA-BBS, washed and resuspended in BBS) with $\mathrm{R} 4 .{ }^{13}$ Ten $\mathrm{ml}$ EA (5 x $10^{8}$ per $\mathrm{ml}$ ) were allowed to react with $1 \mathrm{ml} \mathrm{R} 4$ at $1^{\circ}$ for 10 minutes. They were then washed 3 times in the cold and resuspended in BBS. The activity of these cells was quantified by measuring the extents of their hemolysis in $\mathrm{R} 1$. EAC' ${ }_{1}$ will also lyse in guinea pig serum diluted in $\mathrm{Na}_{2} \mathrm{Mg}$ EDTA-BBS.

The Effect of Poly I on the Formation and Lysis of Persensitized Cells

Three general problems were investigated: a) will poly I prevent the formation of a given persensitized cell? b) will a given persensitized cell lose its activity if it is subsequently exposed to poly $I$ ? and $\underline{c}$ ) will poly $I$, if added to the $C^{\prime}$ reagent used to test the lytic capacity of a persensitized cell, act to inhibit such lysis?

In all instances care was taken to use an excess of poly I calculated in terms of the number of $\mathrm{C}^{\prime} \mathrm{H}_{50}$ present in an equivalent amount of whole guinea pig serum. ${ }^{1}$ The details of each experiment will be presented subsequently. The lytic experiments involving persensitized red cells were all carried out at $32^{\circ} \mathrm{C}$ for 60 minutes.

\section{C'1 Esterase}

Human $C^{\prime} 1$ esterase prepared from a crude $C^{\prime} 1$ fraction $^{15}$ was further purified by means of DEAE and TEAE cellulose chromatography; ${ }^{16}$ the latter preparation contained 233 esterase units per ml. Highly purified $C^{\prime} 1$ esterase serum inhibitor was prepared by the method of .Pensky. ${ }^{17}$ Estimation of $C^{\prime} 1$ esterase activity was done by microformol titration using ALTEE as a substrate. 18,19

\section{Density Gradient Ultracentrifugation}

Since aggregated gamma globulin is known to possess Anti-C' properties, ${ }^{20}$ mixtures of purified $7 \mathrm{~S}$ gamma globulin ${ }^{*}$ and poly I were subjected to ultracentrifugation in a sucrosc density gradient in order to determine whether poly I, a) formed a complex with gamma globulin, or $\underline{b}$ ) caused its aggregation. The procedure has been described earlier. ${ }^{21}$

The Effects of Poly I on C' Activity In Vivo

Groups of 6 male Wistar rats weighing between 150 and $300 \mathrm{~g}$ were injected with varying amounts of poly I dissolved in Tris buffered saline, $\mathrm{pH} 7.4$; the animals were then bled $(0.5$ to

* Cohn Fraction II, Cutter Laboratories, Berkeley, California. 
$0.8 \mathrm{ml}$ ) in serial fashion by cardiac puncture, the sera were separated within an hour, and were pooled for each time period. A control group of 6 animals was injected with an equal volume of Tris buffered saline and they were bled in an identical fashion. All pooled serum samples, including a preinjection pooled sample for both experimental and control groups, were then assayed for $\mathrm{C}^{\prime}$ activity by the technique of Mayer. ${ }^{\prime \mathrm{b}}$ All assays were carried out in $\mathrm{BBS}$ free of $\mathrm{Ca}^{++}$and $\mathrm{Mg}^{++}$, since the presence of divalent cations lowers the $\mathrm{C}^{\prime}$ titer of Wistar rat serum by a significant amount. ${ }^{22} \mathrm{C}^{\prime}$ assays were carried out within 2 hours of bleeding, and the sera were kept on ice during the intervening time. Wistar rat serum $\mathrm{C}^{\prime}$ activity was found to be labile to prolonged standing and to freezing and thawing. Preliminary in vitro studies showed that poly I was a potent inhibitor of rat serum $C^{\prime}$ activity.

\section{EXPERIMENTAL AND RESULTS}

\section{The Effect of Poly I on Formation and Lysis of Persensitized Cells}

$\mathrm{EAC}_{1,4,2}$. To study the effect of poly I on $\mathrm{EAC}_{1,4,2}$ formation, $2 \mu \mathrm{mol} \mathrm{P}$ poly I was added per $10 \mathrm{ml} \mathrm{EA}$ and $0.5 \mathrm{ml} \mathrm{R} 3$. A $10 \mathrm{ml}$ aliquot (in BBS) of washed $\mathrm{EAC}_{1,4,2}$ formed in the absence of poly I was subsequently exposed to $2 \mu \mathrm{mol} P$ poly I for 30 minutes at $1^{3} \mathrm{C}$, washed 3 times and resuspended in $\mathrm{Na}_{3}$ HEDTA-BBS. One $\mathrm{ml}$ samples $\left(5 \times 10^{8}\right.$ cells per $\mathrm{ml}$ ) of these two cell suspensions were added to $6.5 \mathrm{ml}$ serial dilutions of guinea pig $\mathrm{C}^{\prime}$ in $\mathrm{Na}_{3}$ HEDTA-BBS and incubated at $32^{\circ}$ for 60 minutes. Control $\mathrm{EAC}^{\prime}{ }_{1,4,2}$ cells were also added to similar $\mathrm{C}^{\prime}$ dilutions. A fourth test series utilizing control $\mathrm{EAC}_{1,4,2}^{\prime}$ cells was set up in identical $\mathrm{C}^{\prime}$ dilutions containing $1 \mu \mathrm{mol}$ P poly I per test.

Results of experiments performed on two separate occasions were identical. One of these experiments is graphically presented in Figure 1. Fxposure of $\mathrm{EAC}_{1,4,2}$ to poly I does not affect

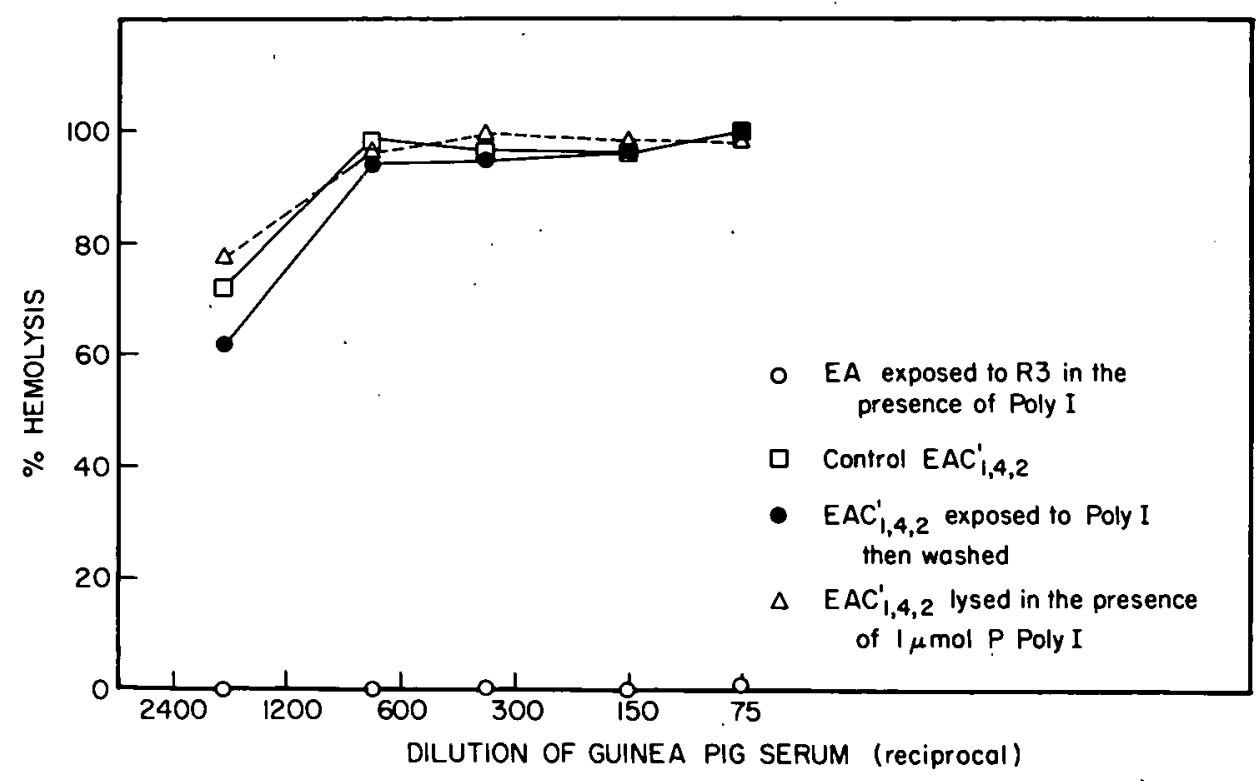

Figure 1. The Effect of Polyinosinic Acid on the Formation and Lysis of EAC' $1,4,2 \cdot 5 \times 10^{8}$ persensitized sheep red cells were subjected to lysis in $7.5 \mathrm{ml}$ of varying dilutions of guinea pig serum diluted in BBS containing $7.5 \times 10^{-3} \mathrm{M}$ Na3HEDTA. 
their susceptibility to hemolysis, nor does the presence of poly $\mathrm{I}$ in the diluted guinea pig $\mathrm{C}^{\prime}$ ef fect $C^{\prime} 3$ activity. The poly $I$ that is present during the exposure of EA to R3 completely inhibits the formation of $\mathrm{EAC}_{1,4,2}$. The failure to form functional $\mathrm{EAC}_{1,4,2}$ might be attributed to acceleration of the decay reaction of $\mathrm{EAC}_{1,4,2}^{\prime}$ to $\mathrm{EAC}_{1,4}$. Accordingly the effect of poly $\mathrm{I}$ on the rate of decay of $\mathrm{EAC}^{\prime}{ }_{1,4,2}$ at $37^{\circ}$ was studied. The results (Figure 2) indicate that poly I has no effect on the temperature dependent rate of decay of $\mathrm{EAC}_{1,4,2}$ to $\mathrm{EAC}_{1,4}$.

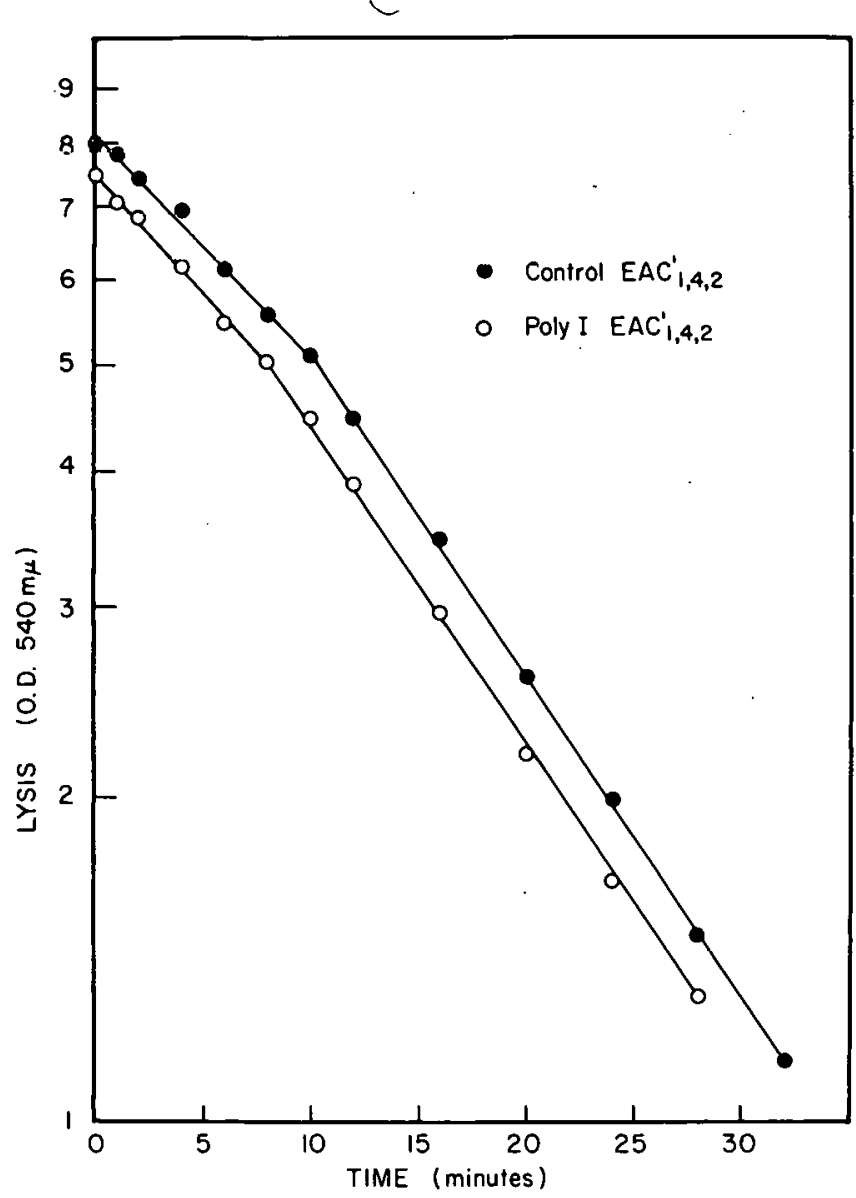

Figure 2. The Effect of Polyinosinic Acid on the Decay of $\mathrm{EAC}^{\prime} 1,4,2 \rightarrow \mathrm{EAC}^{\prime} 1,4$ at $37^{\circ} \mathrm{C}$. Two aliquots $(18 \mathrm{ml})$ EAC' $1,4,2$, one containing $4 \mu \mathrm{mol} \mathrm{P}$ poly $\mathrm{I}$, were placed in a $37^{\circ}$ waterbath. When they reached $37^{\circ}$ (0 time), one $\mathrm{ml}$ aliquots were removed at the designated intervals and added to $4 \mathrm{ml}$ of a 1:160 dilution of guinea pig serum in Na3HEDTA BBS. Lysis was performed at $32^{\circ} \mathrm{C}$ for 60 minutes.

$\mathrm{EAC}_{1,4}$. To study the effect of poly I on $\mathrm{EAC}_{1,4}$ formation, $2 \mu \mathrm{mol} \mathrm{P}$ poly I was added per 10 mIEA during the exposure to $\mathrm{R} 3$ at $1^{\circ} \mathrm{C}$. The control $\mathrm{EAC}_{1,4}$ cells were split into 2 portions, one of which was incubated for another 30 minutes at $37^{\circ}$ in BBS while the other was incubated

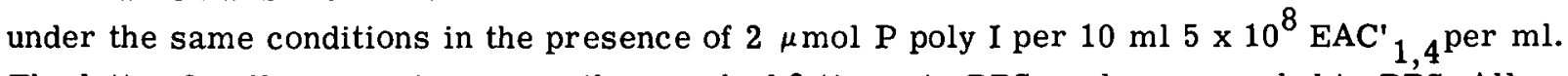
The latter 2 cell suspensions were then washed 3 times in BBS, and resuspended in BBS. All three cell suspensions were then subjected to hemolysis in serial dilutions of guinea pig serum in $\mathrm{Na}_{2} \mathrm{Mg}$ EDTA BBS as described for $\mathrm{EAC}_{1,4,2}$ EAC' $_{1,4}$ not previously exposed to poly I were 
tested for lysis in identical dilutions of guinea pig $\mathrm{C}^{\prime}$ to which $1 \mu \mathrm{mol} \mathrm{P}$ poly I per tube had been added.

Figure 3 illustrates the results obtained in one of three such comparable experiments. Poly I

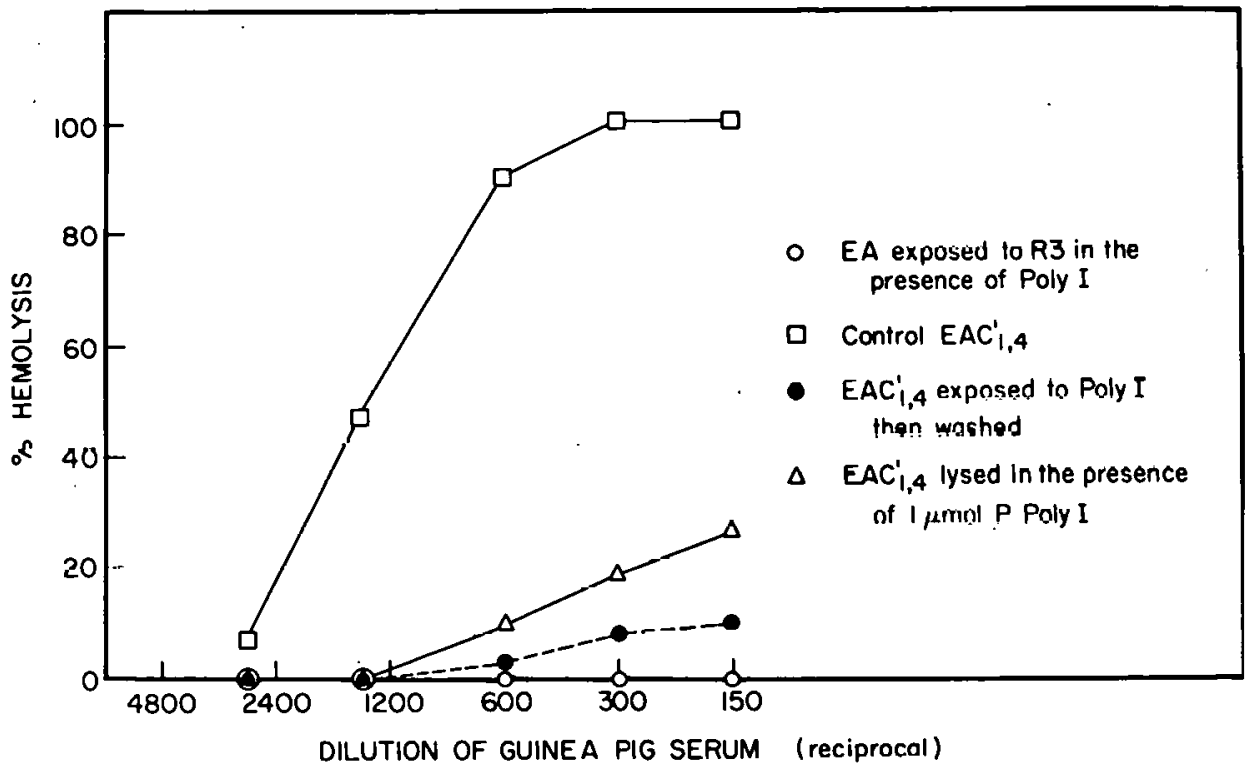

Figure 3. The Effect of Polyinosinic Acid on the Formation and Lysis of EAC'1,4. Conditions and technique as in Figure 1. Lysis was carried out in varying dilutions of guinea pig serum in BBS containing $15 \times 10^{-3} \mathrm{M}$ Na2 $\mathrm{Mg}$ EDTA.

completely inhibits the formation of $\mathrm{EAC}_{1,4}$. Exposure of $E A C^{\prime}{ }_{1,4}$ to poly I followed by wash ing, greatly inhibits subsequent lysis of $\mathrm{EAC}_{1,4}$ in $\mathrm{Na}_{2} \mathrm{Mg}$ EDTA guinea pig serum; lysis of EAC' $_{1,4}$ is inhibited almost to the same extent by the presence of poly I during the actual lytic step. Similar experiments performed twice with $\mathrm{EAC}_{1,4}^{\prime}$ formed with $\mathrm{C}^{\prime} \mathrm{x}$ and tested for lytic capacity in $\mathrm{C}^{\prime} \mathrm{y}$ yielded identical results.

$\mathrm{EAC}_{4}{ }_{4}$. During the preceding experiments on $\mathrm{EAC}_{1,4}$ we found that poly I prevented the formation of cells having $\mathrm{EAC}_{4}$ activity since EA treated with R3 in the presence of poly I failed to lyse in R4. Accordingly, the experiments were limited to the effect of poly I on $\mathrm{EAC}_{4}$ formed in the absence of poly $I$.

EAC $_{4}$ were exposed to $2 \mu$ mol P poly I (per $10 \mathrm{ml}$ cell suspension) for 15 minutes at $37^{\circ}$ and were then washed 3 times. These cells were subjected to lysis in a total volume of $7.5 \mathrm{ml}$ of varying dilutions of $\mathrm{R} 4$ in BBS. Control $\mathrm{EAC}_{4}{ }_{4}$ cells were similarly tested; in addition, $\mathrm{EAC}_{4}$ cells were subjected to lysis in identical R4 dilutions containing $1 \mu \mathrm{mol} \mathrm{P}$ poly I.

Exposure of $\mathrm{EAC}_{4}$ cells to poly I followed by washing did not affect their subsequent lysis in R4. The presence of poly I during the lytic phase, however, did inhibit EAC' ${ }_{4}$ lysis (Figure 4). EAC' $_{1}$. Ten $\mathrm{ml}\left(5 \times 10^{8}\right.$ per $\left.\mathrm{ml}\right) \mathrm{EA}$ sensitized in $\mathrm{Na}_{3}$ EDTA-BBS were exposed to $1 \mathrm{ml} \mathrm{R} 4$ at $1^{\circ} \mathrm{C}$ for 10 minutes, both with and without $4 \mu \mathrm{mol} P$ poly I. After washing 3 times, a $10 \mathrm{ml}$ aliquot of $\mathrm{EAC}^{\prime}{ }_{1}$ formed in the absence of poly I was exposed to $4 \mu \mathrm{mol} \mathbf{P}$ poly I for 30 minutes at $1^{\circ} \mathrm{C}$, and the cells were again washed. The lytic tests were similar to those previously described, but the test reagent consisted of varying dilutions of R1 in BBS. 


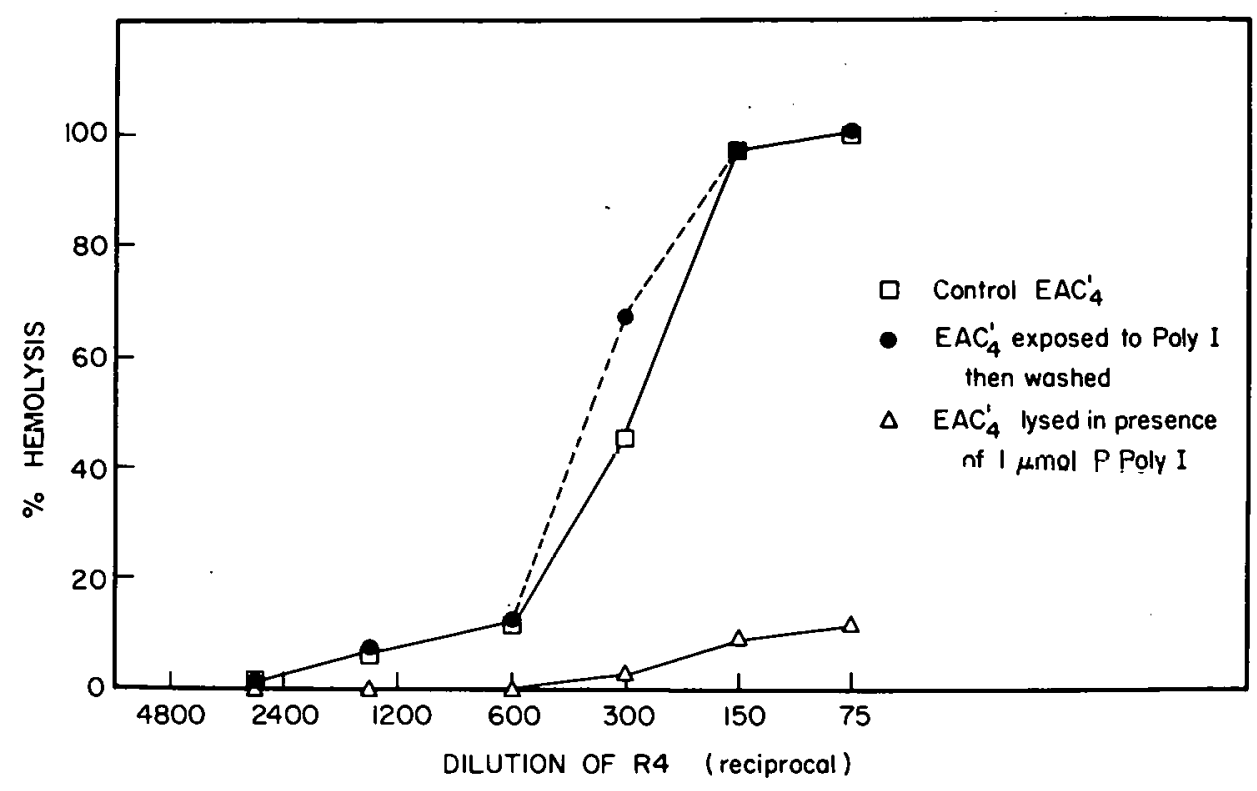

Figure 4. The Effect of Poly I on the Lysis of EAC' 4 in Varying Dilutions of R4. (5 $\times 10^{8} \mathrm{EAC}^{\prime} 4$; total volume per test $7.5 \mathrm{ml}$ ).

Poly I prevents the formation of $\mathrm{EAC}_{1}$. Control EAC' $_{1}$ cells exposed to poly I and subsequently washed, or subjected to lysis in R1 in the presence of $1 \mu \mathrm{mol} \mathrm{P}$ poly I, were almost completely inhibited (Figure 5).

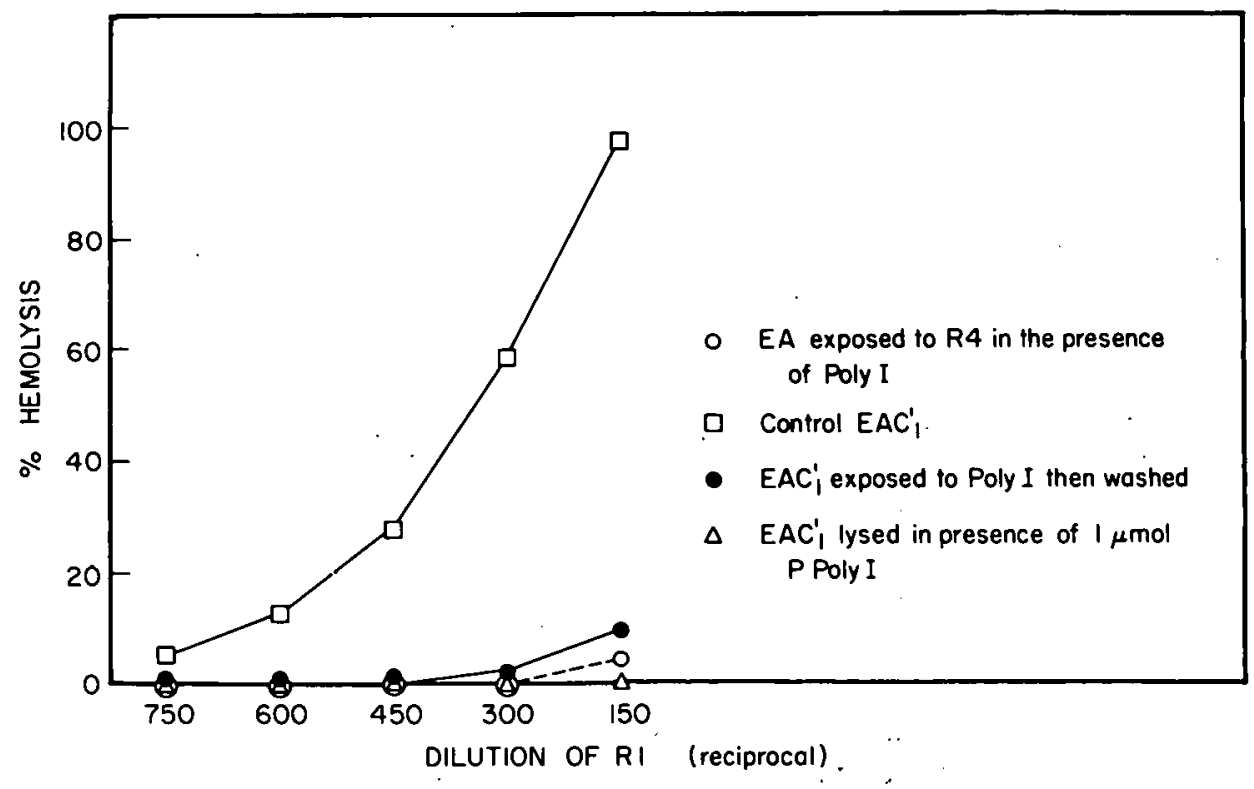

Figure 5. The Effect of Poly I on the Formation and Lysis of $\mathrm{EAC}^{\prime} 1.5 \times 10^{8}$ cells and $7.5 \mathrm{ml}$ of varying dilutions of R1 were used for each test. 


\section{Studies on $C^{\prime} 1$ Esterase and $C^{\prime} 1$ Esterase Serum Inhibitor}

Tables 2 and 3 show that poly $I$ is not capable of inhibiting $C^{\prime} 1$ esterase activity, nor can it prevent the inhibition of $C^{\prime} 1$ esterase by $C^{\prime} 1$ esterase serum inhibitor.

Table 2

THE EFFECT OF POLY I ON C'1 ESTERASE ${ }^{a}$ ACTIVITY

\begin{tabular}{c|c|c|c|c|c}
\hline & Sample & $\begin{array}{c}\text { Poly I } \\
\text { present }\end{array}$ & $\begin{array}{c}\text { C'1 esterase } \\
\text { activity }\end{array}$ & Average & Inhibition \\
\hline & & $\mu$ mol & $\mathrm{U}$ & & $\%$ \\
$\mathrm{~A}^{\mathrm{b}}$ & & 23.2 & & \\
& $1^{\prime}$ & & 22.4 & \\
& 2 & 1 & 24.7 & & \\
$2^{\prime}$ & 1 & 23.2 & 24.0 & 0 \\
3 & 5 & 23.5 & 23.3 & 0 \\
$\mathrm{~B}^{\mathrm{c}}$ & 5 & 23.0 & & \\
& $3^{\prime}$ & & 23.7 & 23.1 & \\
& 1 & & 22.5 & & \\
$1^{\prime}$ & 2 & 25.5 & 25.5 & 0 \\
$2^{\prime}$ & 1 & 25.5 & & \\
& 3 & 5 & 22.0 & 22.3 & 3.5 \\
\hline
\end{tabular}

${ }^{a}$ The $C^{\prime} 1$ esterase used in this experiment was a highly purified preparation containing 233 units per ml (undiluted).

${ }^{b}$ Poly I and substrate added together to enzyme at 0 time.

${ }^{c}$ Poly I and enzyme preincubated together at $37^{\circ}$ for 30 minutes prior to addition of substrate.

Table 3

THE EFFECT OF POLY I ON THE INHIBITION OF C'1 ESTERASE ${ }^{a}$ ACTIVITY BY C'1 ESTERASE SERUM INHIBITOR ${ }^{b}$

\begin{tabular}{c|c|c|c|c}
\hline $\begin{array}{c}\text { Sample } \\
\text { no. }\end{array}$ & $\begin{array}{c}\mathrm{C}^{\prime} 1 \text { esterase } \\
\text { serum inhibitor }\end{array}$ & $\begin{array}{c}\text { Poly I } \\
\text { present }\end{array}$ & $\begin{array}{c}\text { C'1 esterase } \\
\text { activity }\end{array}$ & $\begin{array}{c}\text { Inhibition of } \\
\text { esterase activity }\end{array}$ \\
\hline & & $\mu \mathrm{mol}$ & $\mathrm{U}$ & $\%$ \\
1 & + & 0 & 0.9 & 96 \\
$2^{\mathrm{c}}$ & + & 1 & 0 & 100 \\
3 & & 0 & 20.4 & 0.5 \\
4 & & 1 & 20.3 & \\
\hline
\end{tabular}

${ }^{\mathrm{a}} \mathrm{C}^{\prime} 1$ esterase was a crude preparation containing $40 \mathrm{U}$ per $\mathrm{ml}$.

${ }^{b} C^{\prime} 1$ esterase serum inhibitor was a highly purified preparation containing $110 \mathrm{U}$ per ml. $0.14 \mathrm{ml}$ of a 1:10 dilution of this material was used wherever noted.

${ }^{c}$ Poly I and C' 1 esterase serum inhibitor were preincubated for $30 \mathrm{~min}$ utes at $37^{\circ}$ prior to addition of $\mathrm{C}^{\prime} 1$ esterase and substrate. 


\section{Density Gradient Ultracentrifugation of Polyinosinic Acid and Human $7 \mathrm{~S}$ Gamma Globulin}

When the sedimentation pattern of a mixture of poly I and $7 \mathrm{~S}$ gamma globulin in a sucrose density gradient is compared with the pattern for each substance analyzed separately under the same condition, no gross evidence for interaction between the two, or of aggregation of one by the other, can be seen (Figure 6).

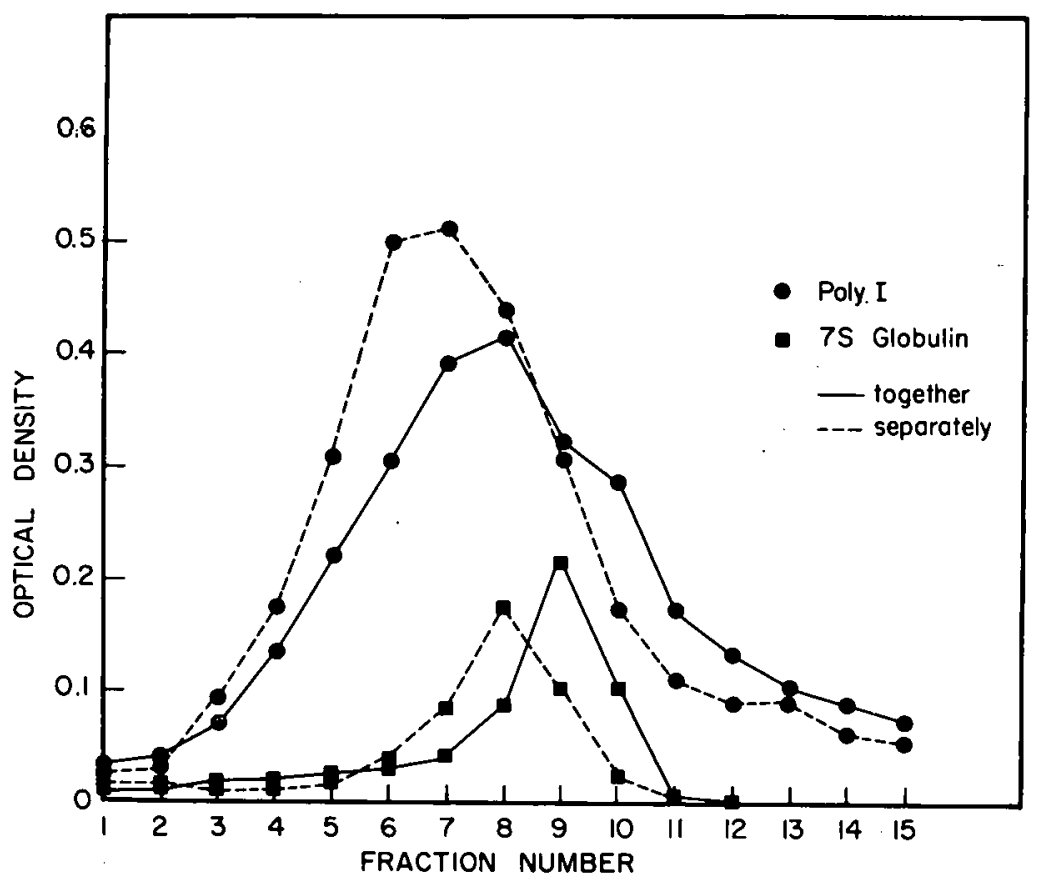

Figure 6. Three $10-40 \%$ sucrose density gradients were prepared using Tris buffered saline (pH 7.4) as solvent. Solutions of $7 \mathrm{~S}$ gamma globulin $(3 \mathrm{mg}$ per $\mathrm{ml})$, poly I $(2 \mu \mathrm{mol} \mathrm{P}$ per $\mathrm{ml}$ ) and a mixture of $7 \mathrm{~S}$ globulin and poly I (same concentrations) were prepared. $0.2 \mathrm{ml}$ of each solution was layered over one of the gradients, and all three were spun simultaneously for 16 hours, $4^{\circ} \mathrm{C}, 38,000 \mathrm{rpm}$, in the SW-39 head of a Spinco Model L ultracentrifuge. Following termination of the run, fractions were collected dropwise from the bottom of the tube $(1=$ bottom, $15=$ top $)$ and were analyzed for polynucleotide (O.D. $249 \mathrm{~m} \mu$ ) and protein (Folin, O.D. 660).

- - poly I, - 7 S globulin; - - - spun separately, - spun as mixture.

\section{Effect of Foly I on $C^{\prime}$ Activity In Vivo}

When administered by iv injection to Wistar rats in doses of $10 \mu \mathrm{mol} \mathrm{P}$, poly I consistently caused a precipitous decline in $C^{\prime}$ activity; after 2 hours $C^{\prime}$ activity had returned to $>50$ per cent of the preinjection level (Table 4, Figure 7). Five $\mu$ mol P poly I given intravenously to several groups of animals yielded results ranging from no effect (one group), to 50 per cent inhibition of $\mathrm{C}^{\prime}$ activity (2 groups) and on one occasion to 90 per cent inhibition of $\mathrm{C}^{\prime}$ activity at the 15 minute bleeding. Intraperitoneal doses as high as $15 \mu \mathrm{mol} \mathrm{P}$ poly I failed to cause a consistent significant fall in $C^{\prime}$ titer, although partial (50 per cent) inhibition was occasionally seen. 
Table 4

THE IN VIVO EFFECT OF POLY I ON THE COMPLEMENT TITER OF WISTAR RATS

\begin{tabular}{|c|c|c|c|c|c|c|c|c|c|c|c|c|c|c|c|c|c|}
\hline \multirow{3}{*}{$\underset{\text { group }}{\text { Animal }}$} & \multirow{3}{*}{ Titer } & \multirow{2}{*}{\multicolumn{4}{|c|}{ Preinjection }} & \multicolumn{12}{|c|}{ Time - postinjeztion } \\
\hline & & & & & & \multicolumn{4}{|c|}{15 minutes } & \multicolumn{4}{|c|}{1 hour } & \multicolumn{4}{|c|}{2 hours } \\
\hline & & $\begin{array}{l}\text { OD } \\
540\end{array}$ & $\begin{array}{c}\text { OD } 540 \\
- \text { blankb }\end{array}$ & Lysis ${ }^{c}$ & $C^{\prime} \mathrm{H}_{50}$ & $\begin{array}{l}O D \\
540\end{array}$ & $\begin{array}{l}\text { OD } 540 \\
\text { - blank }\end{array}$ & Lysis & $\mathrm{C}^{\prime} \mathrm{H}_{50}$ & $\begin{array}{l}\text { OD } \\
540\end{array}$ & $\begin{array}{l}\text { OD } 540 \\
\text { - blank }\end{array}$ & Lysis & $\mathrm{C}^{\prime} \mathrm{H}_{50}$ & $\begin{array}{l}\text { OD } \\
540\end{array}$ & $\begin{array}{l}\text { OD } 540 \\
\text { - blank }\end{array}$ & Lysis & $\mathrm{C}^{\prime} \mathrm{H}_{50}$ \\
\hline \multirow{4}{*}{$\begin{array}{l}\text { Control } \\
1 \text { ml Tris } \\
\text { saline iv }\end{array}$} & & & & $\%$ & \multirow{6}{*}{36} & & & $\%$ & \multirow{6}{*}{28} & & & $\%$ & \multirow{6}{*}{28.7} & $\because$ & & $\%$ & \multirow{6}{*}{26.2} \\
\hline & $1: 2$ & 0.710 & 0.685 & 100 & & 0.710 & 0.685 & 100 & & 0.702 & 0.677 & 100 & & 0.690 & 0.665 & 99 & \\
\hline & $1: 5$ & 0.652 & 0.627 & 93 & & 0.655 & 0.630 & 93 & & 0.635 & 0.610 & 90 & & 0.625 & 0.600 & 89 & \\
\hline & $1: 10$ & 0.640 & 0.615 & 91 & & 0.640 & 0.615 & 91 & & 0.600 & 0.575 & 85 & & 0.600 & 0.575 & 85 & \\
\hline \multirow{7}{*}{$\begin{array}{l}\text { Experi- } \\
\text { mental } \\
10 \mu \mathrm{mol} P \\
\text { poly I iv }\end{array}$} & $1: 20$ & 0.580 & 0.555 & 82 & & 0.525 & 0.500 & 74 & & 0.532 & 0.507 & 75 & & 0.500 & 0.475 & 70 & \\
\hline & $1: 40$ & 0.315 & 0.290 & 43 & & 0.187 & 0.162 & 24 & & 0.200 & 0.175 & 26 & & 0.164 & 0.139 & 21 & \\
\hline & $1: 2$ & 0.690 & 0.665 & 99 & \multirow{5}{*}{30} & 0.132 & 0.107 & 16 & \multirow{5}{*}{1.4} & 0.495 & 0.470 & 70 & \multirow{5}{*}{3.4} & 0.690 & 0.665 & 99 & \multirow{5}{*}{17.2} \\
\hline & $1: 5$ & 0.655 & 0.630 & 93 & & 0.066 & 0.041 & 6 & & 0.263 & 0.238 & 35 & & 0.640 & 0.615 & 91 & \\
\hline & $1: 10$ & 0.640 & 0.615 & 91 & & 0.038 & 0.013 & 2 & & 0.070 & 0.045 & 7 & & 0.550 & 0.525 & 78 & \\
\hline & $1: 20$ & 0.565 & 0.540 & 80 & & 0.028 & 0.003 & 0 & & 0.041 & 0.016 & 2 & & 0.305 & 0.280 & 41 & \\
\hline & $1: 40$ & 0.205 & 0.180 & 27 & & 0.020 & & 0 & & 0.023 & & 0 & & 0.011 & 0.049 & 7 & \\
\hline
\end{tabular}

${ }_{6}^{a} 6$ animals in each group. Ave wt $191 \mathrm{~g}$.

$\mathrm{b}_{\text {Blank } \pm 0.025 \text {. }}$

$\mathrm{c}_{100 \% \text { lysis }}=$ OD 0.675 . 


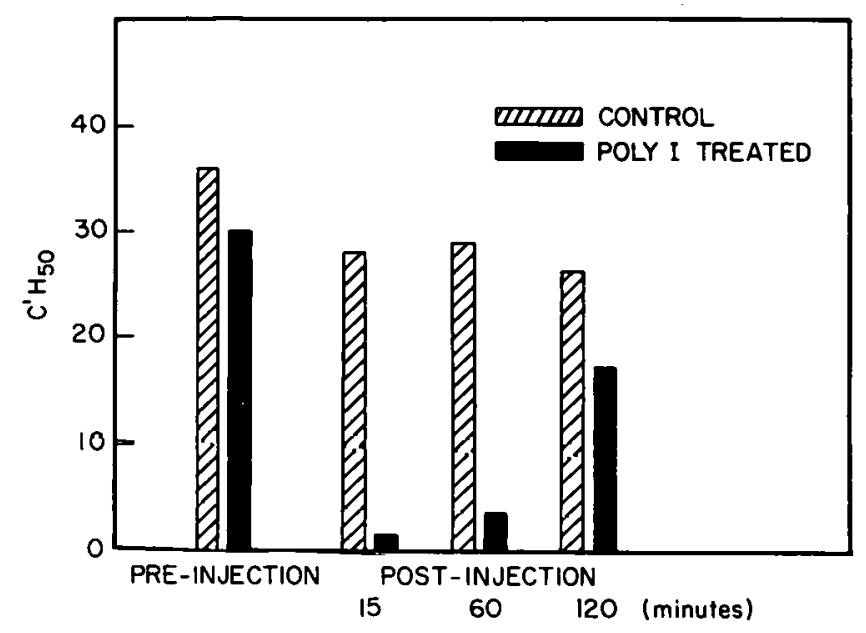

Figure 7. The Effect of Intravenously Administered Polyinosinic Acid on the Complement Levels of Wistar Rats.

A graphic representation of the data in Table 4.

The poly I injections did not seem to affect the animals adversely; detailed pharmacologic studies, however, were not carried out.

\section{DISCUSSION}

Examined within the framework of our present understanding of the $C^{\prime}$ system, these studies suggest that poly I has a specific inhibitory action on $C^{\prime} 1$. The experiments with $\mathrm{EAC}^{\prime}{ }_{1,4,2}$ clearly indicate that poly $I$ has no inhibitory effect on $C^{\prime} 3$ activity. The fact that $\mathrm{EAC}^{\prime}{ }_{1,4,2} \mathrm{ex}^{-}$ posed to poly $I$, and subsequently washed, retained full hemolytic susceptibility to $C^{\prime} 3$ indicates that poly I cannot inactivate cell-bound $\mathrm{C}^{\prime} 2$ or $\mathrm{C}^{\prime} 4$. Even if it were inactivating cell-bound $\mathrm{C}^{\prime} 1$ activity, this should not affect the susceptibility of these cells to lysis in $\mathrm{C}^{\prime} 3$, since Becker has shown that $\mathrm{EAC}_{4,2}$ retain full lytic capacity in a $\mathrm{C}^{\prime} 3$ reagent, despite the absence of $\mathrm{C}^{\prime} 1 .^{23}$ The inhibition of lysis of EAC' 1,4 by poly I present during the actual lytic phase might imply an inhibitory effect on $\mathrm{C}^{\prime} 2$, but the fact that the same inhibition is obtained by pre-exposure of EAC' $_{1,4}$ to poly I, suggests that in fact a cell-bound activity is affected. Since $\mathrm{EAC}_{4}$ exposed to poly I are not inhibited from subsequent lysis in R4, and since active cell-bound $C^{\prime} 1$ is necessary for the attachment of $\mathrm{C}^{\prime} 2$ to $\mathrm{EAC}_{1,4},{ }^{5,23}$ the experiments with $E A C^{\prime}{ }_{1,4}$ point to $\mathrm{C}^{\prime} 1$ as the most likely site of poly I inhibition. The experiments with $\mathrm{EAC}_{4}{ }_{4}$ are consistent with this hypothesis, since, while cell-bound $C^{\prime} 4$ activity is not affected by poly $I$, the presence of the latter in $\mathrm{R} 4$ effectively inhibits $\mathrm{EAC}_{4}{ }_{4}$ lysis. In contrast to $\mathrm{EAC}^{\prime}{ }_{4}$, and in a manner analogous to $\mathrm{EAC}_{1,4}, \mathrm{EAC}_{1}$ are effectively inhibited, both by pre-exposure to poly $\mathrm{I}$, and by its presence during the lytic test in R1. Since the attachment of $C^{\prime} 1$ to EA constitutes the first step in the activity of the $\mathrm{C}^{\prime}$ system, it is not surprising that poly $\mathrm{I}$, if indeed it is an inhibitor of $\mathrm{C}^{\prime} 1$, can prevent the formation of $\mathrm{EAC}_{1}$, as well as of all the subsequent intermediate complexes of guinea pig $C^{\prime}$ and EA. The inhibitory effect of poly $\mathrm{I}$ on the various persensitized red cells is analogous in every respect to the effect of $C^{\prime} 1$ esterase serum inhibitor on similar sensitized sheep red cell - $\mathrm{C}^{\prime}$ intermediate complexes. ${ }^{5}$ 
While poly I can thus be considered as a potent inhibitor of $\mathrm{C}^{\prime} 1{ }^{*}$ in a manner analogous to $C^{\prime} 1$ esterase serum inhibitor or DFP, it differs notably from these two $C^{\prime} 1$ inhibitors in having no inhibitory effect on $C^{\prime} 1$ esterase activity. The recent success of Lepow and his associates in fractionating $C^{\prime} 1$ activity into three subcomponents, of which $C^{\prime} 1$ (pro) esterase is only one, ${ }^{9}$ offers the option, currently being investigated, that poly I may interact specifically with one of the other two subcomponents in its inhibition of $C^{\prime} 1$.

Aggregated $7 \mathrm{~S}$ gamma globulin is a potent inhibitor of $\mathrm{C}^{\prime}$ activity, and has been shown by Marcus $^{25}$ to be an inhibitor of $C^{\prime} 1$. It was considered possible, therefore, that poly I might be Anti-C' through the mediation of an aggregation of, or interaction with, $7 \mathrm{~S}$ gamma globulin. While the sucrose density gradient ultracentrifugation experiments do not suggest any gross interaction such as that previously noted between polyribonucleotides and bovine serum albumin, ${ }^{21}$ the presence of a small amount of aggregate material cannot be definitely excluded by this technique. On the other hand, the inactivation of cell-bound $C^{\prime} 1$ activity on thoroughly washed persensitized red cells, where free $7 \mathrm{~S}$ gamma globulin is presumably lacking, makes the possibility that the Anti- $\mathrm{C}^{\prime}$ activity of poly I depends on the mediation of $7 \mathrm{~S}$ gamma globulin seem quite rcmote.

The experiments utilizing Wistar rats demonstrate that poly I can also serve as an efficient decomplementing agent in vivo without any overt toxic effects to the animals. The amount needed to affect $\mathrm{C}^{\prime}$ titers in vivo is somewhat larger than the theoretical amount calculated on the basis of in vitro data, and the duration of $\mathrm{C}^{\prime}$ activity inhibition in vivo is shorter than for other decomplementing agents such as aggregated gamma globulin. ${ }^{26}$ Nevertheless, its efficacy as an Anti$\mathrm{C}^{\prime}$ agent in vivo sustains the speculation that poly I may serve to protect against cellular injury in situations where $C^{\prime}$ participation in immune reactions is involved.

\section{ACKNOWLEDGMENT}

The experiments concerning $C^{\prime} 1$ esterase and $C^{\prime} 1$ esterase serum inhibitor were performed by one of the authors (D.R.) in the laboratory of Dr. Irwin H. Lepow, Western Reserve University. The authors are most grateful to Dr. Lepow for his hospitality, and for his generous advice and helpful criticism.

\section{LITERATURE CITED}

1. Yachnin, S. J. Clin. Invest., 42:1947, 1963.

2. Yachnin, S. J. Immunol., 93:155, 1964.

3. Mayer, M. M. Progr. Allergy, 5:215, 1958.

4. Becker, E. L. J. Immunol., 77:462, 1956.

5. Lepow, I. H., and M. A. Leon. Immunology, 5:222, 1962.

6. DeLooze, L. L., A. Ransby, and M. A. Leon. Proc. Soc. Exptl. Biol. (N.Y.) 109:393, 1962.

7. Kabat, E. A., and M. M. Mayer. Experimental Immunochemistry. Springfield, Ill., Charles C. Thomas, 1961 , p. 162 , (a) p. 186, (b) p. 149 .

8. Levine, L., and M. M. Mayer. J. Immunol., 73:426, 1954.

${ }^{*}$ Exposure of $\mathrm{EAC}^{\prime} 1$ to as little as $8 \times 10^{-4} \mu \mathrm{mol} \mathrm{P}$ poly I per ml will result in 90 per cent inhibition of lytic susceptibility. 24 
9. Lepow, I. H., G. B. Naff, E. W. Todd, J. Pensky, and C. F. Hinz, Jr. J. Exptl. Med., $117: 983,1963$.

10. Taylor, A. B., and M. A. Leon. Fed. Proc., 20:19, 1961.

11. Mayer, M. M., L. Levine, H. J. Rapp, and A. A. Marucci. J. Immunol., 73:443, 1954.

12. Leon, M. A. J. Immunol., 76:428, 1956.

13. Becker, E. L. J. Immunol., 82:43, 1959.

14. Klein, P. G. J. Exptl. Med., 111:77, 1960.

15. Lepow, I. H., O. D. Ratnoff, F. S. Rosen, and L. Pillemer. Proc. Soc. Exptl. Biol. (N.Y.), 92:32, 1956.

16. Haines, A. L., and I. H. Lepow. Fed. Proc., 21:17, 1962.

17. Pensky, J. Fed. Proc., 19:76, 1960.

18. Ratnoff, O. D., and I. H. Lepow. J. Exptl. Med., 106:327, 1957.

19. Levy, L. R., and I. H. Lepow. Proc. Soc. Exptl. Biol. (N.Y.), 101:608, 1959.

20. Christian, C. L. J. Immunol., 84:112, 1960.

21. Yachnin, S. Biochim. Biophys. Acta (Amst.), 72:578, 1963.

22. Osler, A. G., M. M. Hawrisiak, Z. Ovary, M. Siqueira, and O. G. Bier. J. Exptl. Med., 106:811, 1957 .

23. Becker, E. L. J. Immunol., 84:299, 1960.

24. Yachnin, S., I. H. Lepow, and D. Rosenblum. Unṕublished observations.

25. Marcus, D. M. J. Immunol., 84:273, 1960.

26. Christian, C. L. J. Immunol., 84:117, 1960. 


\title{
THE SYNTHESIS OF 4',5'-DIIODO-4-AMINOELUORESCEIN IODINE-131*
}

\author{
By \\ J. Verbiscar ${ }^{\dagger}$
}

Coons' method ${ }^{1}$ for labeling antibody proteins with fluorescein isocyanate has become a frequently used tool in immunology. Since the original paper appeared in 1942 several comprehensive reviews ${ }^{2-4}$ and over 300 papers have appeared. We were interested in making a similar reagent that would be adaptable to quantitative studies, and the present work was undertaken in order to prepare a fluorescein derivative that would couple with an antibody protein in the nor mal manner, and be radioactive as well as fluorescent.

Nitro- and aminofluoresceins I and II were synthesized according to the standard method. ${ }^{\$ 5,6}$ No attempt was made to determine the structure of these isomers until Borek ${ }^{7}$ carried $^{2}$ out an infrared spectral study of the nitrofluoresceins and structurally related compounds. Borek concluded that the structure of intrafluorescein I was 5-nitrofluorescein and that the II isomer was 4-nitrofluorescein. The ultraviolet spectra (Table 1) are consistent with these designations. However, the nomenclature ${ }^{8}$ used here is preferred over that used previousiy. ${ }^{7}$

The cold title compound was obtained quite readily by creating a solution of 4-aminofluorescein in $1 \mathrm{~N}$ hydruchloric acid with two equivalents of iodine monochloride. The immediate orange precipitate of $4^{\prime}, 5^{\prime}$-diiodo-4-aminofluorescein gave a reasonably acceptable elementary analysis and was used in subsequent iodide-131 exchange reactions. The radioactive $4^{\prime}, 5^{\prime}$-diiodo4-aminofluorescein could then be converted to the corresponding isocyanate as needed, and coupled with an antibody protein without isolation of the isocyanate.

A less satisfactory method was originally used in the preparation of this compound. In this series of reactions 4-nitrofluorescein was iodinated with iodine monochloride in acetic acid. $\$$ The crude 4', $5^{\prime}$-diiodo-4-nitrofluorescein was purified through the easily crystallized diacetate. Deacetylation followed by catalytic hydrogenation resulted in a $4^{\prime}, 5^{\prime}$-diiodo-4-aminofluorescein which analyzed low in iodine. Under identical reduction conditions the iodines of $4^{\prime}, 5^{\prime}$-diiodofluorescein ${ }^{14}$ were not affected.

The preference toward $4^{\prime}, 5^{\prime}$-substitution in fluorescein has been demonstrated effectively by previous workers. ${ }^{11-14}$ In order to show that iodination with iodine monochloride in acidic media occurs in the $4^{\prime}, 5^{\prime}$-positions, fluorescein was treated with this reagent. Thin layer chro-

* This report is

$\dagger$ Present address: Institute of Drug Design, 770 South Arroyo Parkway, Pasadena, California.

${ }_{\text {It }}$ It was found here that 4-nitrofluorescein diacetate exists in two crystaline forms. When crystallized from benzene the product had m.p. 194-196 ${ }^{\circ}$, and from ethanol m.p. 215-217 ${ }^{\circ}$ Either form was readily converted to the other. The infrared spectra of these two forms were only slightly (in $\mathrm{KBr}$ ) different in the fingerprint region.

${ }^{\$}$ Boyack, et al. ${ }^{9}$ treated fluorescein with iodine monochloride generated in situ from dichloramine $T$ and potassium iodide-131 in acetic acid. No structural evidence was given for the positions of the iodines.

${ }^{9}$ Roe, et al. ${ }^{10}$ repeated the work of Boyack, et al. ${ }^{9}$ but found that some chlorination as well as tri- and tetrachalogenation had occurred. 
<smiles>O=C(O)c1cc([N+](=O)[O-])ccc1-c1c2ccc(=O)cc-2oc2cc(O)ccc12</smiles>

4-Nitrofluoresceln

$4^{\prime}, 5^{\prime}$-1)iiodo-4-nitroflunrescein<smiles>Nc1ccc(-c2c3ccc(=O)cc-3c3ccc(O)cc3oc2=O)c(C(=O)O)c1</smiles><smiles>Nc1ccc(-c2oc3c(I)c(O)ccc3c3c(I)c(=O)ccc2-3)c(C(=O)O)c1</smiles>

4-Aminofluorescein

$4^{\prime}, 5^{\prime}$-Diiodo-4-aminofluorescein

Table 1

ULTRAVIOLET ABSORPTION SPECTRA ${ }^{a}$

\begin{tabular}{|c|c|c|}
\hline & $\lambda \mathrm{m} \mu$ & E mäx \\
\hline fluorescein ${ }^{b}$ & 223 & 60,300 \\
\hline 5 -nitrofluorescein (I) & 222 & 68,200 \\
\hline 4-nitrofluorescein (II) & 225 & $58 ; 300$ \\
\hline 5 -aminofluorescein & 222 & 60,000 \\
\hline 4-aminofluorescein & $\begin{array}{l}222 \\
285\end{array}$ & $\begin{array}{l}68,200 \\
20,600\end{array}$ \\
\hline 5 -nitrofluorescein diacetate & 219 & 70,000 \\
\hline 4-nilrof luorescein diacetate & 218 & 65,500 \\
\hline $4^{\prime}, 5^{\prime}$-diiodo-4-aminofluorescein & $\begin{array}{l}205 \\
229 \\
290\end{array}$ & $\begin{array}{l}42 ; 800 \\
47,000 \\
22,300\end{array}$ \\
\hline $4^{\prime}, 5^{\prime}$-diiodo-4-nitrofluorescein diacetate & 204 & 67,500 \\
\hline $4^{\prime}, 5^{\prime}$-diiodofluorescein ${ }^{\mathrm{b}}$ & $\begin{array}{l}204 \\
230\end{array}$ & $\begin{array}{l}52,000 \\
40,300\end{array}$ \\
\hline
\end{tabular}

${ }^{a}$ Taken in ethyl alcohol from 200-400 millimicron on a Beckman Model DK-1 recording spectrophotometer.

$\mathrm{b}_{\text {Eastman Kodak grade. }}$ 
matography showed the main product to be identical with $4^{\prime}, 5^{\prime}$-diiodofluorescein obtained from a commercial source* but several minor spots indicated impurities. ${ }^{10}$

The exchange reactions of sodium iodide-131 with $4^{\prime}, 5^{\prime}$-diiodo-4-aminofluorescein were accomplished in high radioactive yield by mixing the materials in acetic acid overnight (Table 2). Warming was necessary to effect solution.

Table 2

IODIDE-131 EXCHANGE REACTIONS

\begin{tabular}{|c|c|c|}
\hline & 1 & 2 \\
\hline $4^{\prime}, 5^{\prime}$-diiodo-4-aminofluorescein & $60 \mathrm{mg}$ & $61 \mathrm{mg}$ \\
\hline Acetic acid solvent & $2.0 \mathrm{ml}$ & $2.0 \mathrm{ml}$ \\
\hline Sodium iodide- 131 aqueous ${ }^{\mathrm{d}}$ & $0.40 \mathrm{ml}$ & $0.40 \mathrm{ml}$ \\
\hline Initial activity ${ }^{\mathrm{b}}$ & $4.36 \mathrm{mc}$ & $6.02 \mathrm{mc}$ \\
\hline Reaction conditions & $8.5 \mathrm{hr}$ at $95-102^{\circ}$ & $19 \mathrm{hr}$ at $78-94^{\circ}$ \\
\hline Decay time $\mathrm{e}^{\mathrm{c}}$ & $46 \mathrm{hr}$ & $29 \mathrm{hr}$ \\
\hline Activity of product ${ }^{d}$ & $37 \mu \mathrm{c} / \mathrm{mg}$ & $88 \mu \mathrm{c} / \mathrm{mg}$ \\
\hline Per cent exchange & $60 \%$ & $99 \%$ \\
\hline
\end{tabular}

${ }^{\mathrm{a}}$ Carrier free.

${ }^{b}$ Activity at start of exchange reaction.

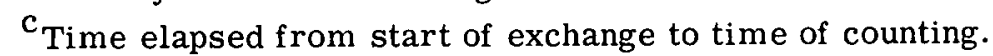

$\mathrm{d}_{\text {Measured activity at time of counting }}$

The mechanism of the exchange reaction with iodide-131 is uncertain. It has been reported 15 that iodine atoms and not iodide ions exchange into thyroxine and that only the iodides adjacent to the phenolic function exchange. It is possible that under our exchange conditions iodide ion was oxidized to iodine to catalyze the exchange with organic iodide adjacent to the phenolic function. However, it is also known ${ }^{16-18}$ that halogenated quinones readily undergo nucleophilic displacement of their halogens. The organic iodide in our fluorescein has the character of an atom ortho to a quinoid as well as phenolic function, and the possibility of nucleophilic displacement by iodide-131 ion should not be dismissed.

\section{EXPERIMENTAL ${ }^{\dagger}$}

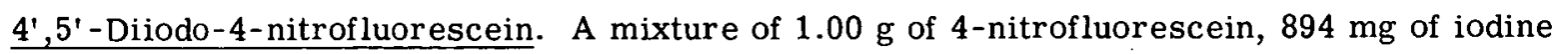
monochloride and $25 \mathrm{ml}$ of glacial acetic acid was stirred for $5 \mathrm{hr}$. The original suspension of 4nitrofluorescein gradually dissolved and a new orange solid precipitated. After standing overnight, $200 \mathrm{ml}$ of water was added and the precipitate became red. It was filtered, redissolved in cold 1 $\underline{\mathrm{N}}$ sodium hydroxide, reprecipitated with acetic acid, collected, washed with water and dried. The crude red $4^{\prime}, 5^{\prime}$-diiodo-4-nitrofluorescein, $1.56 \mathrm{~g}$, had a m.p. $228-240^{\circ} \mathrm{dec}$. This crude product was purified somewhat through its diacetate.

* The author would like to thank C. Kuimjiam of Distillation Products Industries for his comments on the iodination reactions and for a generous sample of $4^{\prime}, 5^{\prime}$-diiodofluorescein.

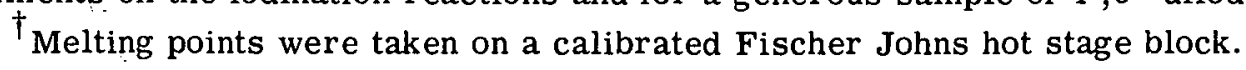


Acetylation. The crude $4^{\prime}, 5^{\prime}$-diiodo-4-nitrofluorescein was refluxed with sodium acetate in acetic anhydride for an hr. Working up the product with recrystallization from acetic anhydride gave $4^{\prime}, 5^{\prime}$-diiodo-4-nitrofluorescein diacetate as fine crystals with a slight yellow tinge, m.p. $296-298^{\circ}$.

Analysis. Calculated for $\mathrm{C}_{24} \mathrm{H}_{13} \mathrm{NO}_{9} \mathrm{I}_{2}$ : C, 40.41 per cent; $\mathrm{H}, 1.84$ per cent; I, 35.59 per cent. Found: C, 40.43 per cent; H, 1.96 per cent; I, 35.55 per cent.

Deacetylation. A suspension of the above diacetate in a saturated solution of sodium hydroxide in 90 per cent ethanol was stirred and warmed gently until all dissolved. Dilution with water, and acidification with glacial acetic acid, gave a purified 4',5'-diodo-4-nitrofluorescein monohydrate, m.p. $262-264^{\circ} \mathrm{dec}$. On drying in a vacuum at $110^{\circ}$ this solid lost weight equivalent to an equimolar portion of water. On exposure to air the weight again gradually increased.

Analysis. Calculated for $\mathrm{C}_{20} \mathrm{H}_{9} \mathrm{NO}_{7} \mathrm{I}_{2} \cdot \mathrm{H}_{20}: \mathrm{C}, 37.11$ per cent; $\mathrm{H}, 1.71$ per cent; $\mathrm{I}, 39.24$ per cent. Found: C, 37.0 per cent; H, 1.38 per cent; I, 39.55 per cent.

4',5'-Diiodo-4-aminofluorescein. (a) Iodination of 4-aminofluorescein in hydrochloric acid. A warm solution of $470 \mathrm{mg}$ of iodine monochloride in $10 \mathrm{ml}$ of $1 \underline{\mathrm{N}}$ hydrochloric acid was added to a warm stirred solution of $501 \mathrm{mg}$ of 4 -aminofluorescein in $60 \mathrm{ml}$ of $0.7 \mathrm{~N}$ hydrochloric acid. A solid precipitated immediately. The mixture was heated nearly to boiling, cooled and the solid was collected, washed well with water and dried. The bright orange $4^{\prime}, 5^{\prime}$-diiodo-4-aminofluorescein, $860 \mathrm{mg}$ (99 per cent), m.p. $213-218^{\circ} \mathrm{dec}$, gave a reasonable elemental analysis and was used in the exchange reactions.

Analysis. Calculated for $\mathrm{C}_{20} \mathrm{H}_{11} \mathrm{NO}_{5} \mathrm{I}_{2}: \mathrm{C}, 40.09$ per cent; $\mathrm{H}, 1.85$ per cent; I, 42.36 per cent. Found: C, 40.78 per cent; H, 2.03 per cent; I, 42.60 per cent.

(b) Hydrogenation of $4^{\prime}, 5^{\prime}$-Diiodo-4-nitrofluorescein. The hydrogenation of $286 \mathrm{mg}$ of purified 4', $5^{\prime}$-diiodo-4-nitrofluorescein was carried out in $10 \mathrm{ml}$ of ethanol at room temperature for $1 \mathrm{hr}$ using hydrogen at 53 p.s.i. and about $2 \mathrm{~g}$ of Raney nickel catalyst. The catalyst was filtered, and the ethanol solution was reduced in volume by gentle heating in a stream of nitrogen. The addition of $100 \mathrm{ml}$ of water produced an unfilterable suspension which was extracted into ether. Evaporation gave $156 \mathrm{mg}$ of a crude bright orange $4^{\prime}, 5^{\prime}$-diiodo-4-aminof luorescein, m.p. $205-210^{\circ}$ dec. which analyzed low in iodine. Under identical conditions the iodines of $4^{\prime}, 5^{\prime}$-diiodofluorescein were not affected.

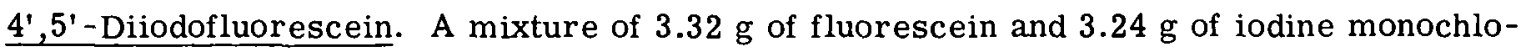
ride in $25 \mathrm{ml}$ of glacial acetic acid was warmed to $115^{\circ}$ for $1 \mathrm{~min}$, cooled, and stirred for $8 \mathrm{hr}$ at room temperature. The solid was collected and washed successively with $10 \mathrm{ml}$ of acetic acid and $100 \mathrm{ml}$ of water. It was then suspended in acetone, collected, and dried giving $3.54 \mathrm{~g}$ of crude orange $4^{\prime}, 5^{\prime}$-diiodofluorescein as a powder, m.p. 220-235 . An Eastman Kodak grade material had a m.p. 247-250 ${ }^{\circ}$ dec. Thin layer chromatography on Merck Silica Gel G using methanol showed these compounds to be identical except for several minor spots in our product, which may be the chloride or other polyhalogenated material. ${ }^{13}$ No purification of this product was attempted.

Exchange reactions with iodine-131. The 4',5'-diodo-4-aminofluorescein was suspended in acetic acid in a centrifuge tube. Aqueous sodium iodide- 131 was added and the mixture was stirred and heated to about $100^{\circ}$ using a silicone bath. At this temperature nearly all of the solid dissolved. After the reaction time indicated in Table 2, the mixture was cooled, diluted with wa- 
ter and centrifuged. The solid was washed three times with water and then dried and stored in a vacuum desiccator. There was no change in the melting point.

\section{ACKNOWLEDGMENT}

The problem was suggested by Dr. Robert J. Hasterlik to whom the author is grateful for his encouragement. The author would also like to thank Mr. Robert Hart for the spectral studies, Mr. William Saschek of the University of Chicago Microanalytical Laboratory for the elemental analyses, and $\mathrm{Mr}$. Leon Gortler for synthesizing the 4- and 5-nitrofluorescein diacetates. The generous and helpful comments, as well as the general assistance of Dr. Weldon Brown of the Argonne National Laboratories are also appreciated.

\section{LITERATURE CITED}

1. Coons, A. H., H. J. Creech, R. N. Jones, and E. Berliner. J. Immunol., 45:158, 1942.

2. Coons, A. H. In International Review of Cytology, Vol. 5, G. H. Bourne, ed., New York Academic Press, Inc., 1255, pp. 1-23.

3. Beutner, E. H. Bact. Rev., 25:49, 1961.

4. Coons, A. H. J. Immunol., 87:499, 1961 .

5. Coons, A. H., and M. H. Kaplan. J. Exptl. Med., 91:1, 1950.

6. Bogert, R. T., and R. G. Wright. J. Am. Chem. Soc., 27:1310, 1905.

7. Borek, F. J. Org. Chem., 26:1292, 1961.

8. The Ring Index, RR15935, Reinhold Publishing Company, New York, 1961.

9. Boyack, G., G. E. Moore, and D. F. Clausen. Nucleonics, 3:62, 1948.

10. Roe, A., R. L. Hayes, and H. D. Bruner. J. Am. Chem. Soc., 73:4483, 1951.

11. Sandin, R. B., and R. L. Orvis. J. Org. Chem., 23:1235, 1958.

12. Orndorf, W. R., and A. J. Hemmer. J. Am. Chem. Soc., 49:1272, 1927.

13. Phillips, M. A. J. Chem. Soc., 724, 1932.

14. Sandin, R. B., A. Gillies, and S. C. Lynn. J. Am. Chem. Soc., 61:2919, 1939.

15. Gleason, G. I. J. Biol. Chem., 213:837, 1955.

16. Buu-Hoi, Ng. Ph., R. Royer, and M. Hubert-Habart. Rec. trav. chim., 73:188, 1954.

17. Berlin, A. Ya., and A. N. Makarova. Zhur. obschchei. Khim., 30:1380, and 1582, 1960. CA $55: 499$ and $1500,1961$.

18. Hancock, J. W., C. E. Morrell, and D. Rhum. Tetrahedron Letkis, 987, 1962. 


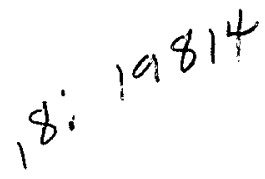

THE USE O

$$
\begin{aligned}
& \text { C 5-4-64 } \\
& \text { CONF-4.53-1; } \\
& \text { LIVER AND BRAIN SCANNING* }
\end{aligned}
$$

By

P. V. Harper, K. A. Lathrop, R. J. McCardle, and G. Andros: ${ }^{\dagger}$

The objective in any clinical tracer study is to obtain as much useful information as possible consistent with reasonabie radialion dooago to the patient, and without undue cost or inconvenience. In order to achieve the greatest possible effectiveness a number of factors must be considered, among them the characteristics of the particular radioactive tracer material chosen. The physical parameters of technetium-99m appear even on casual perusal to be so favorable from this point of view that an extended study of its chemical and biological characteristics was undertaken to explore its possibilities as an agent for clinical use.

Technetium-99m decays ${ }^{1}$ with a 6 -hour physical half-life emitting a clean $0.140 \mathrm{MeV}$ gamma ray and dissipating only $0.014 \mathrm{MeV} /$ disintegration as low energy beta-like radiation (conversion electrons, Auger electrons, and soft fluorescent photons). Thus the effective half-life is very short, and the energy deposited in the tissues is very small compared to most particleemitting radionuclides: Even the gamma ray dose rate constant is very low $(0.61 \mathrm{r} / \mathrm{mc}$ hour at $1 \mathrm{~cm}$ ). It thus would appear feasible to administer substantial millicurie quantities to an individual without intolerable radiation dosage.

The $140 \mathrm{KeV}$ gamma may be scanned with conventional equipment, but specially designed detectors provide further substantial advantages. Optimally designed collimators will increase counting efficiency by at least a factor of two over collimators of equal resolution designed for $\mathrm{I}^{131}$, and since 6 millimeters of lead give complete shielding, a shielded detector weighing 2 or 3 kilograms is quite feasible. ${ }^{2}$ A $1 \mathrm{~cm}$ thick NaI crystal gives maximal counting efficiency and resolution with low background, and the compactness and lightness of the shield and collimator facilitate the use of multiple detector heads (Figure 1). In addition, the energy of the gamma is not so low as to make the use of camera type detectors unthinkable.

The 6-hour half-life of $\mathrm{Tc}^{99 \mathrm{~m}}$ that would ordinarily preclude its use poses no problem because this isotope is available as the daughter of 2.8 day molybdenum-99, one of the most abundant of the fission products. This latter material is available at reasonable cost adsorbed on an alumina column from which the daughter technetium $-99 \mathrm{~m}$ may be eluted with dilute $(0.1 \mathrm{~N})$ hydrochloric acid as needed. ${ }^{3}$

The technetium-99m decays to technetium-99 which in turn decays to stable ruthenium-99. Since the $\mathrm{Tc}^{99}$ has a half-life of $2.1 \times 10^{5}$ years there is no significant residual radioactivity from the decay of $\mathrm{Tc}^{99 \mathrm{~m}}$. One mc of $\mathrm{Tc}^{99 \mathrm{~m}}$ decays to $3 \times 10^{-6} \mu \mathrm{c}$ of $\mathrm{Tc}^{99}$, and $1 \mathrm{mc}$ of $\mathrm{Mo} 9$ decays to $3 \times 10^{-5} \mu \mathrm{c}$ of $\mathrm{Tc}^{99}$.

The chemical form of $\mathrm{Tc}^{99 \mathrm{~m}}$ as it is eluted from the generator is that of the stable pertech-

\footnotetext{
*This paper was presented at the IAEA Symposium on Medical Radioisotope Scanning in Athens, Greece, April 1964. It will appear in the Proceedings of the Symposium.

${ }^{\dagger}$ Present address: Laboratory of Physiology, National Cancer Institute, National Institutes of Health, Bethesda 14, Maryland, U.S.A.
} 
netate ion. In strong acid solution this forms the volatile pertechnic acid. The eluate contains traces of other fission products in submicrocurie amounts, consisting largely of $\mathrm{I}^{131}, \mathrm{Ru}^{103}$ and $\mathrm{Ru}^{106}$. The ruthenium may be removed easily by extraction of the $\mathrm{TcO}_{4}{ }^{-}$from $5 \mathrm{~N} \mathrm{NaOH}$ into methyl ethyl ketone ${ }^{4}$. The ketone then is removed by evaporation and the pertechnetate may be made up to any desired specific activity in sterile solution.

Pertechnetate is reduced by ascorbic acid in $2.5 \mathrm{~N} \mathrm{HCl}$. In the presence of $\mathrm{Fe}^{+++}$, which acts as a redox buffer, the technetium is reduced to the +5 state ${ }^{5}$ in which it is very reactive. It forms a fat-soluble thiocyanate and makes firm complexes with simple organic compounds such as glycine as well as with proteins. In acid pertechnetate solution $(1 \mathrm{~N} \mathrm{HCl})$ on the addition of $\mathrm{H}_{2} \mathrm{~S}$ the technetium activity is precipitated along with elemental sulfur, possibly as the sulfide $\mathrm{Tc}_{2} \mathrm{~S}_{7}$. In the presence of a protective colloid such as 1 per cent gelatin, this remains as a sulfur colloid. 6

Biological studies have been carried out on a number of these compounds of $\mathrm{Tc}^{99 \mathrm{~m}}$ and will be reported in detail elsewhere. To summarize these results: pertechnetate belongs to a group of ions $\left(\mathrm{TeO}_{4}{ }^{-}, \mathrm{ReO}_{4}{ }^{-}, \mathrm{ClO}_{4}{ }^{-}, \mathrm{BO}_{3} \mathrm{~F}^{-}, \mathrm{I}^{-}, \mathrm{At}^{-}\right)$which have a symmetrical spherical or tetrahedral configuration and which are handled in a similar manner in the organism. ${ }^{7}$ The resemblance of $\mathrm{TcO}_{4}{ }^{-}$to $\mathrm{I}^{-}$is particularly close. As judged by the thyroid/serum ratios and by the salivary/ serum and gastric juice/serum ratios, ${ }^{8}$ pertechnetate is trapped in the stomach, salivary glands and thyroid to nearly the same degree as iodide. Excretion is largely by way of the urine during the first day, although here the resemblance to iodide becomes less marked since increasingly more of the pertechnetate appears in the stools, 10 to 15 per cent being excreted by this route on the $3 \mathrm{rd}$ day. The overall average excretion in 10 subjects was 50 per cent in 1.8 days. Pertechnetate thus appears to be somewhat labile chemically in the body. Sorensen and Archambault ${ }^{9}$ have shown that $\mathrm{Tc}^{99 \mathrm{~m}}$ formed from Mo ${ }^{99}$ that has been taken up by the liver remains in the liver, further suggesting that technetium can exist in the body in forms other than pertechnetate, since injected pertechnetate is not localized in the liver.

The blood disappearance curve ${ }^{9}$ shows a rapid component with a half time of 10 minutes, and a second component of approximately equal magnitude with a half-life of about 6 hours. These same components have been observed in gastrectomized-nephrectomized dogs, and in animals pre-treated with $\mathrm{ClO}_{4}{ }^{-}$(which abolishes localization) and the curves are quite similar to those for iodide in subjects with blocked thyroids. This would indicate that $\mathrm{TcO}_{4}{ }^{-}$is distributed initially in the extracellular space, as is iodide.

Up to 2 per cent of the injected dose of pertechnetate is localized in the thyroid gland in experimental animals (mice) and in euthyroid humans at 30 to 60 minutes after injection. In uptake measurements in human thyroids the high neck background makes it necessary either to measure the change in count rate after administration of perchlorate, which displaces the $\mathrm{TcO}_{4}{ }^{-}$ from the gland, or to quantitate the dot scan by scanning an injection standard and subtracting the background count measured on an appropriate adjacent area of the neck. The use of the thigh background count is not practical. Agreement between these methods is excellent and the $\mathrm{TcO}_{4}{ }^{-}$trapping thus measured is practically the same as the trapping of iodide in the propylthiouracil blocked thyroid. Administration of thyroid hormone decreases this uptake to zero. Administration of thyroid stimulating hormone does not increase the uptake above normal. In hyperthyroid individuals the localization is increased to between 6 and 30 per cent of the injected dose, and in both Basedow's disease and Plummer's disease the increased trapping of $\mathrm{TcO}_{4}{ }^{-}$by the 
thyroid is clearly independent of TSH.

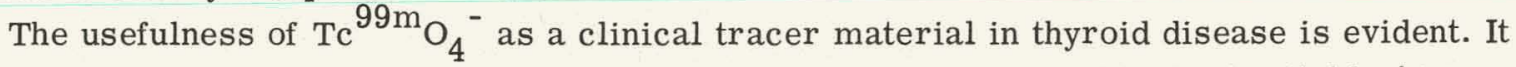
allows observation of the ion trapping mechanism without perturbing the gland with blocking or discharging agents, and scans of comparable and sometimes of superior quality to those obtained with radioiodine are obtainable 30 minutes after intravenous administration of $1 \mathrm{mc}$ of $\mathrm{TcO}_{4}{ }^{-}$, the radiation dosage to the thyroid gland being about 100 millirads, i.e., about $1 / 1000$ of that produced by the usual scanning dose of $\mathrm{I}^{131}$ (Figures 2 and 3 ).

Since it has been shown that materials distributed in the extracellular space may be used

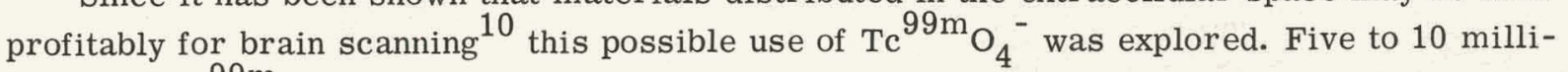

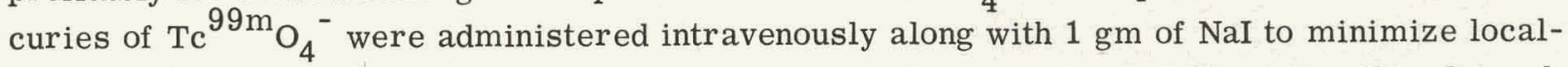
ization in the thyroid. Brain scans of excellent quality demonstrating midline as well as lateral lesions were obtained in 10 to 15 minutes. The localization appears to be almost immediate and has been followed for as long as 3 hours. Experience with 100 patients indicates diagnostic accuracy comparable to that of other scanning agents (Figures 4, 5, and 6).

Localization of $\mathrm{Tc}^{99 \mathrm{~m}}$ in the liver as the thiocyanate was achieved by injecting this material dissolved in a commercial fat emulsion prepared for intravenous use (Lipomul). The thiocyanate was prepared as described above, extracted into butyl acetate from the acid solution, the butyl acetate removed by evaporation, and the thiocyanate taken up in the fat emulsion under sterile conditions. Residual technetium activity was removed from the aqueous phase by anion exchange resin (IR-4B). This material disappears from the blood with a half time of 40 to 60 minutes and reaches optimal scanning concentration in the liver in 4 to 6 hours, with 50 per cent of the injected dose in the organ. The uptake is apparently parenchymal, being greatly reduced in liver disease. Good uptake was obtained in one case of primary hepatoma (Figures 7 and 8).

$\mathrm{Tc}^{99 \mathrm{~m}}$ bound to colloidal sulfur has been used to produce liver and spleen scans. This material disappears from the blood stream with a half-life of 2 to 5 minutes, and in experimental animals (mice and dogs) 70 to 90 per cent of the injected material is recoverable in the liver, and about 5 per cent in the spleen. With 5 millicuries of this material, scans are obtainable with count rates of 20,000 to 50,000 per minute using collimators designed for thyroid scanning. Under these circumstances, with fine resolution and good statistics, some difficulties arise from the motion of the liver and spleen with respiration. Great improvement is obtained by temporary paralysis of the appropriate phrenic nerve with local anesthetic (Figures 9-12).

The complex of pentavalent technetium with glycine is rapidly excreted in the urine following intravenous administration. Over 90 per cent of the radioactivity may be recovered in the urine after one hour in the mouse, and 60 per cent after 3 hours in human subjects. Renal scans are possible with this material (Figure 13).

In summary, $\mathrm{Tc}^{99 \mathrm{~m}}$ has ideal physical characteristics for a variety of tracer studies in patients, and has versatile chemical characteristics, not yet fully explored, that make it a satisfactory agent for thyroid, liver, brain, and kidney scanning, studies of ion trapping by the thyroid, and possibly other uses. It is of especial interest for use in children where radiation dosage is much more critical than in adults. 


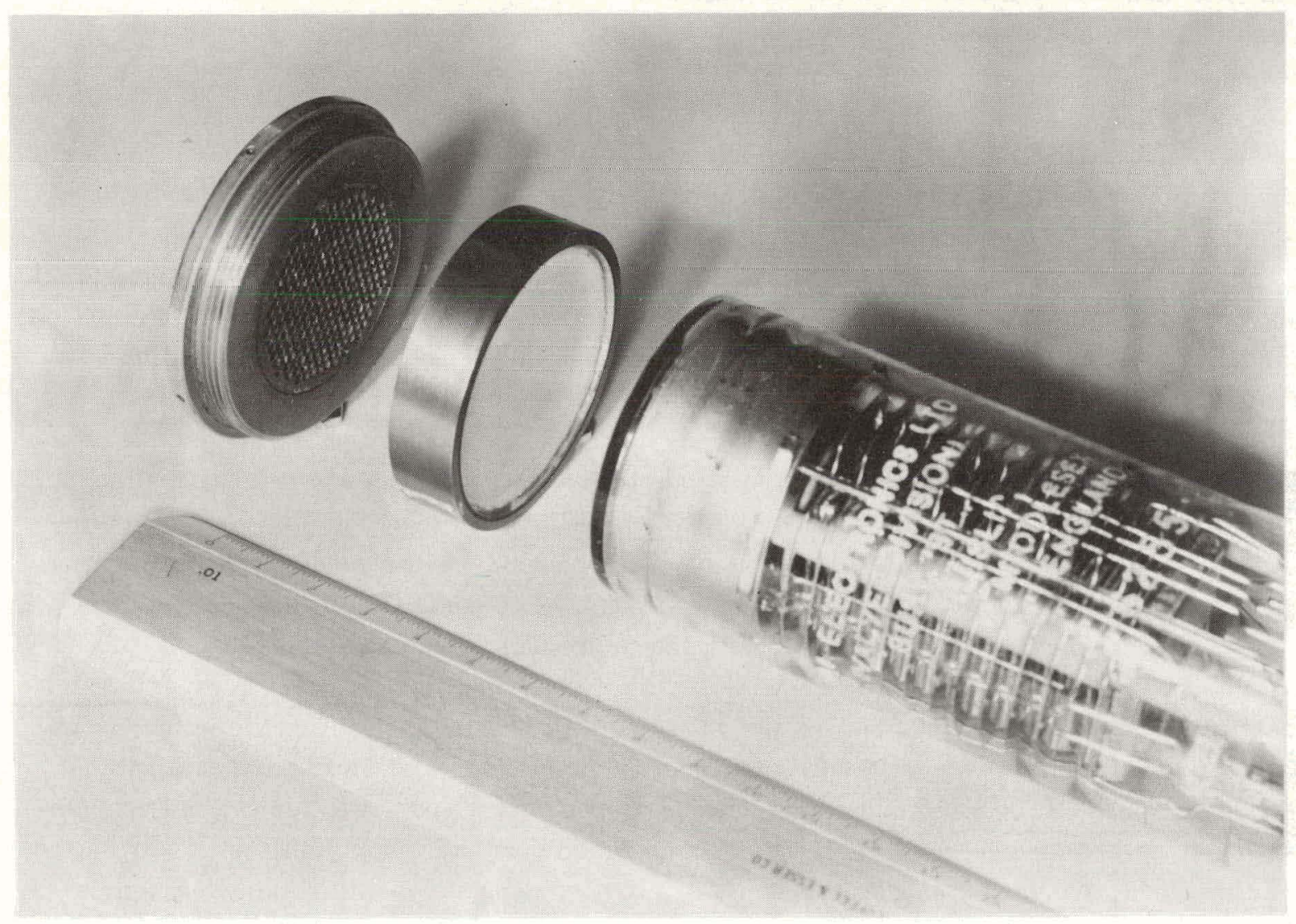

Figure 1. Exploded view of low energy collimator-detector. Lead collimator has 253 holes, $6.25 \mathrm{~cm}$ focal length, $1.59 \mathrm{~cm}$ diameter of view at focus. Efficiency $4.12 \times 10^{-3}$ counts/disintegration/ $\mathrm{cm}^{2}$. Septum thickness at front $0.019 \mathrm{~cm}$. NaI crystal 2" x $1 / 2$ " with $0.025 \mathrm{~cm}$ beryllium jacket. This detector collimator is satisfactory in the range 27 to $140 \mathrm{KeV}$. At the latter energy $6.3 \mathrm{~mm}$ of lead gives complete lateral shielding. 


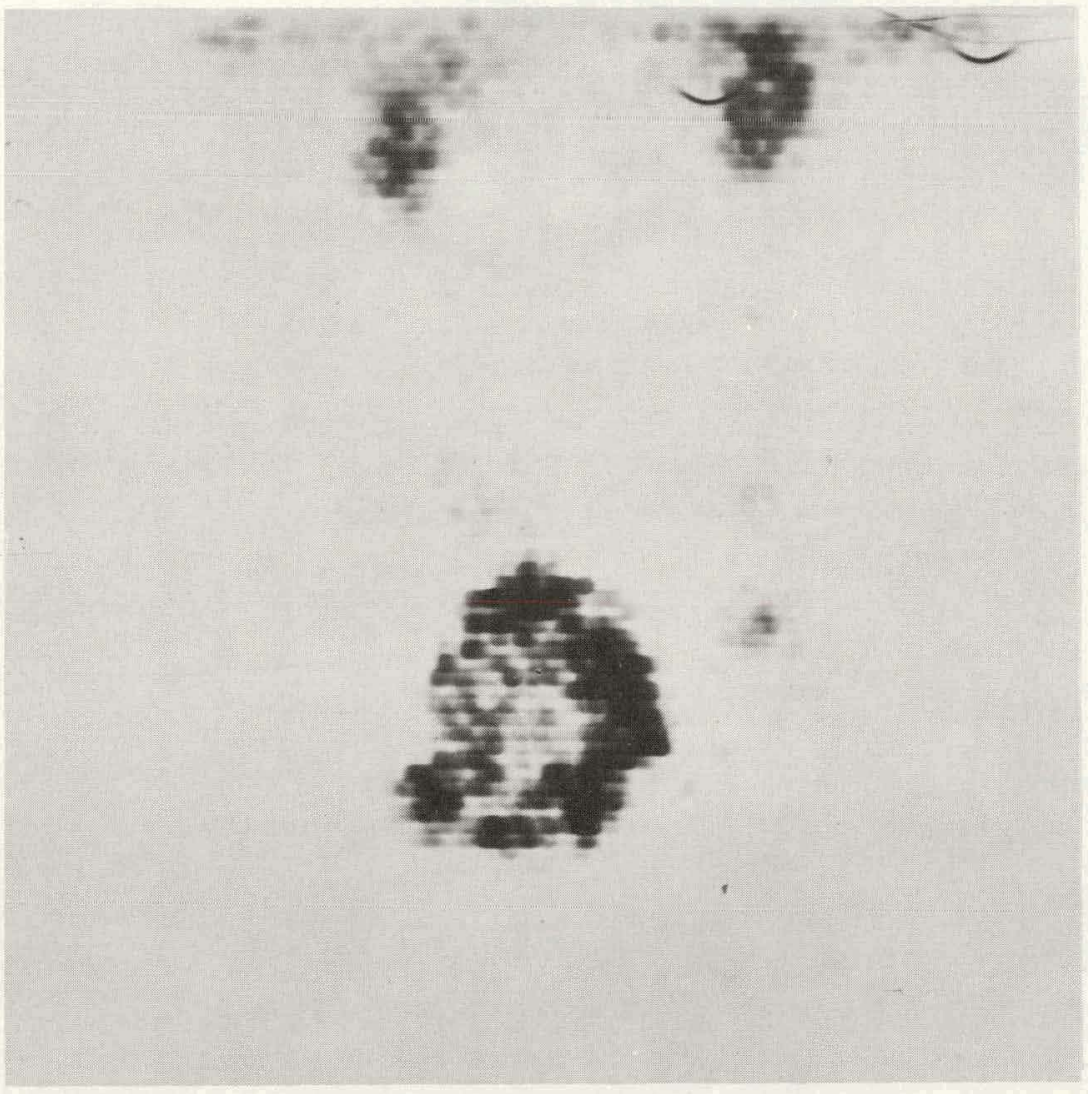

Figure 2. Thyroid scan 30 minutes following intravenous administration of $1 \mathrm{mc}$ of $\mathrm{Tc}^{99 \mathrm{~m}}$ as $\mathrm{TcO}_{4}^{-}$. Note the markedly increased trapping of $\mathrm{TcO}_{4}{ }^{-}$in a cystic hyperactive nodule and suppression of uptake in the remainder of the gland. Salivary glands are well visualized. 
a

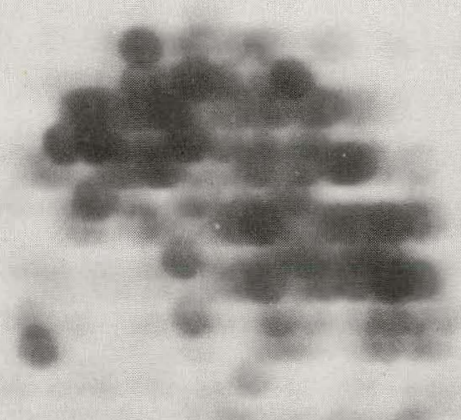

b

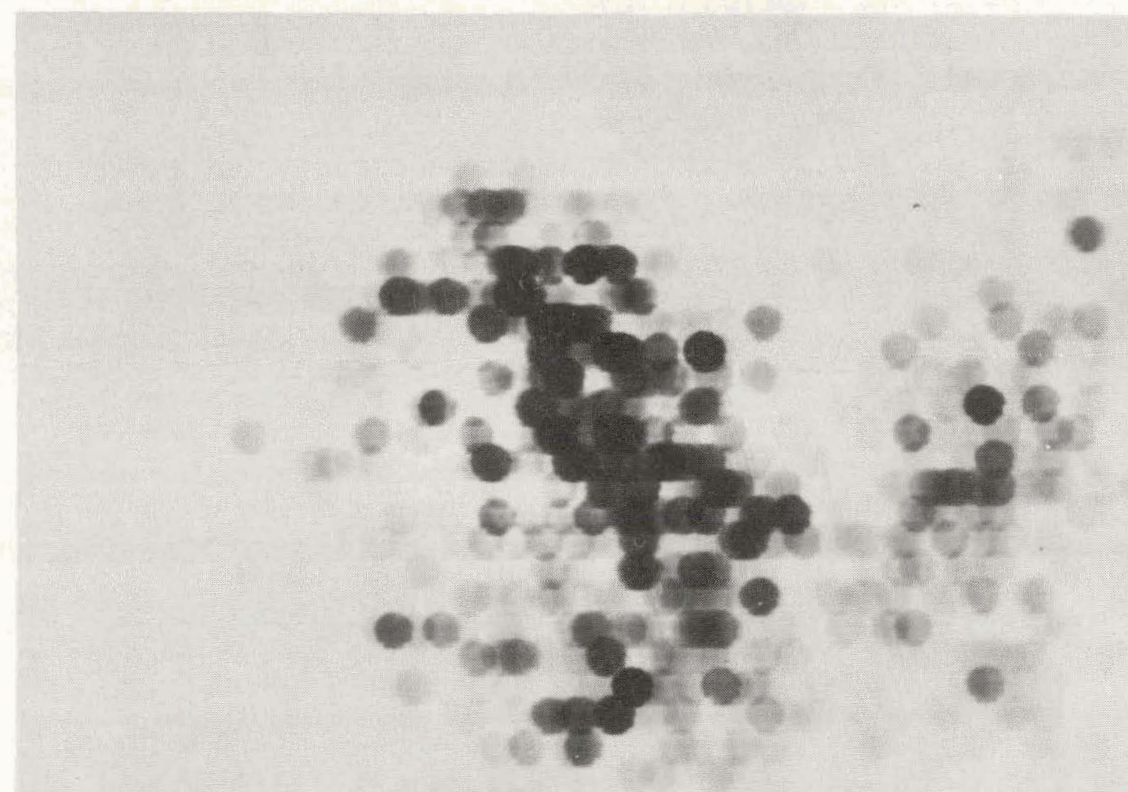

Figure 3. (a) $\mathrm{TcO}_{4}^{-}$scan of thyroid similar to Figure 2. (b) $\mathrm{I}^{131}$ scan of same patient. The radiation dosage to the gland with $1 \mathrm{mc}$ of $\mathrm{Tc}^{9} 9 \mathrm{mO}_{4}{ }^{-}$is about $100 \mathrm{~m} \mathrm{rad}$ or $1 / 1000$ of the dose from $50 \mu \mathrm{c}$ of $\mathrm{I}^{131}$. 


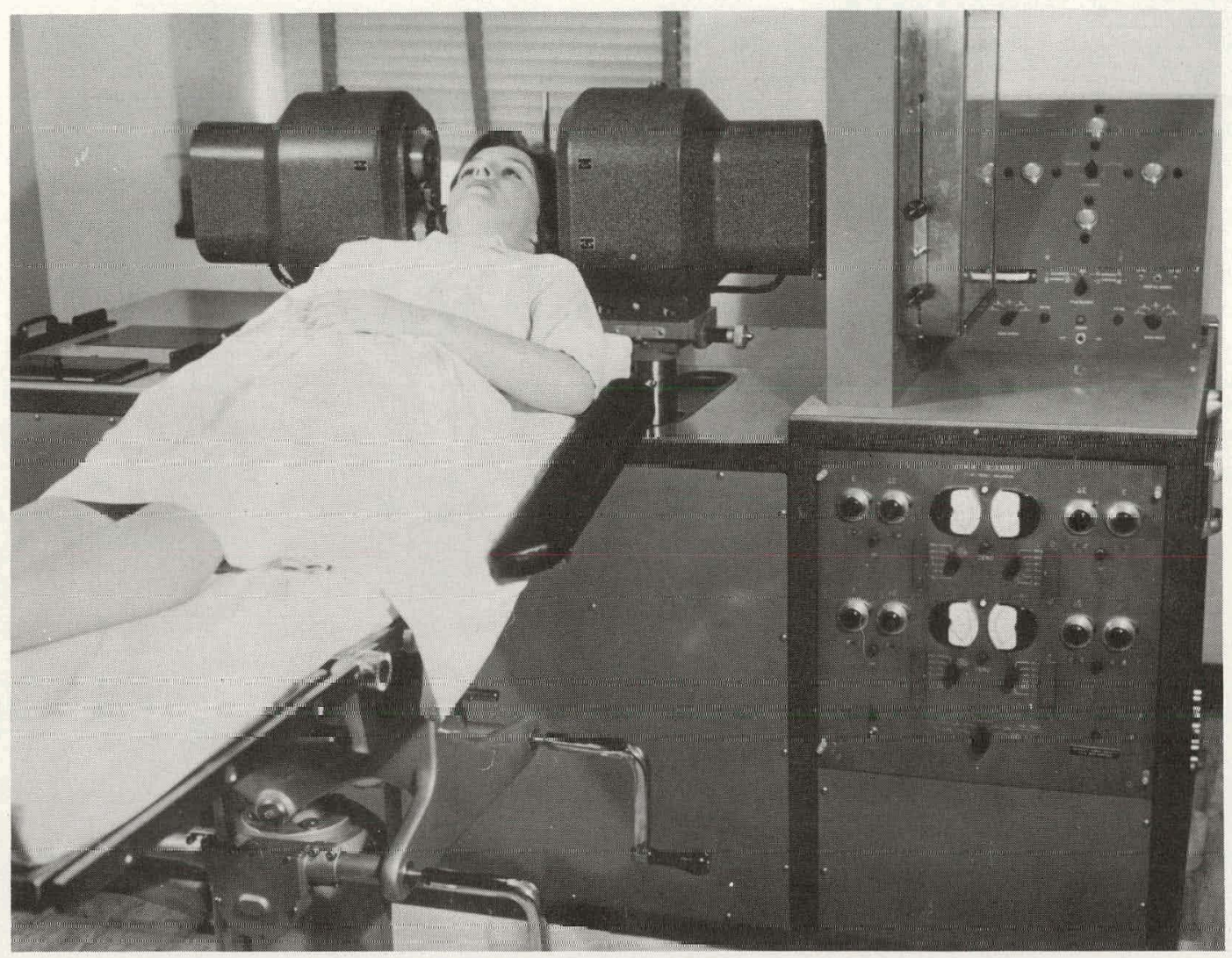

Figure 4. Argonne Cancer Research Hospital brain scanner. To shorten the scanning time, two detectors are used simultaneously on each side of the head. Optimal collimators, contour limitation, and rapid scanning $(2.5 \mathrm{~cm} / \mu \mathrm{c})$ with small index $(1.6 \mathrm{~mm})$ give a smoother picture with little line structure in minimal time. Photo readout with diffused spots with Gaussian density profile reduce statistical structure. 

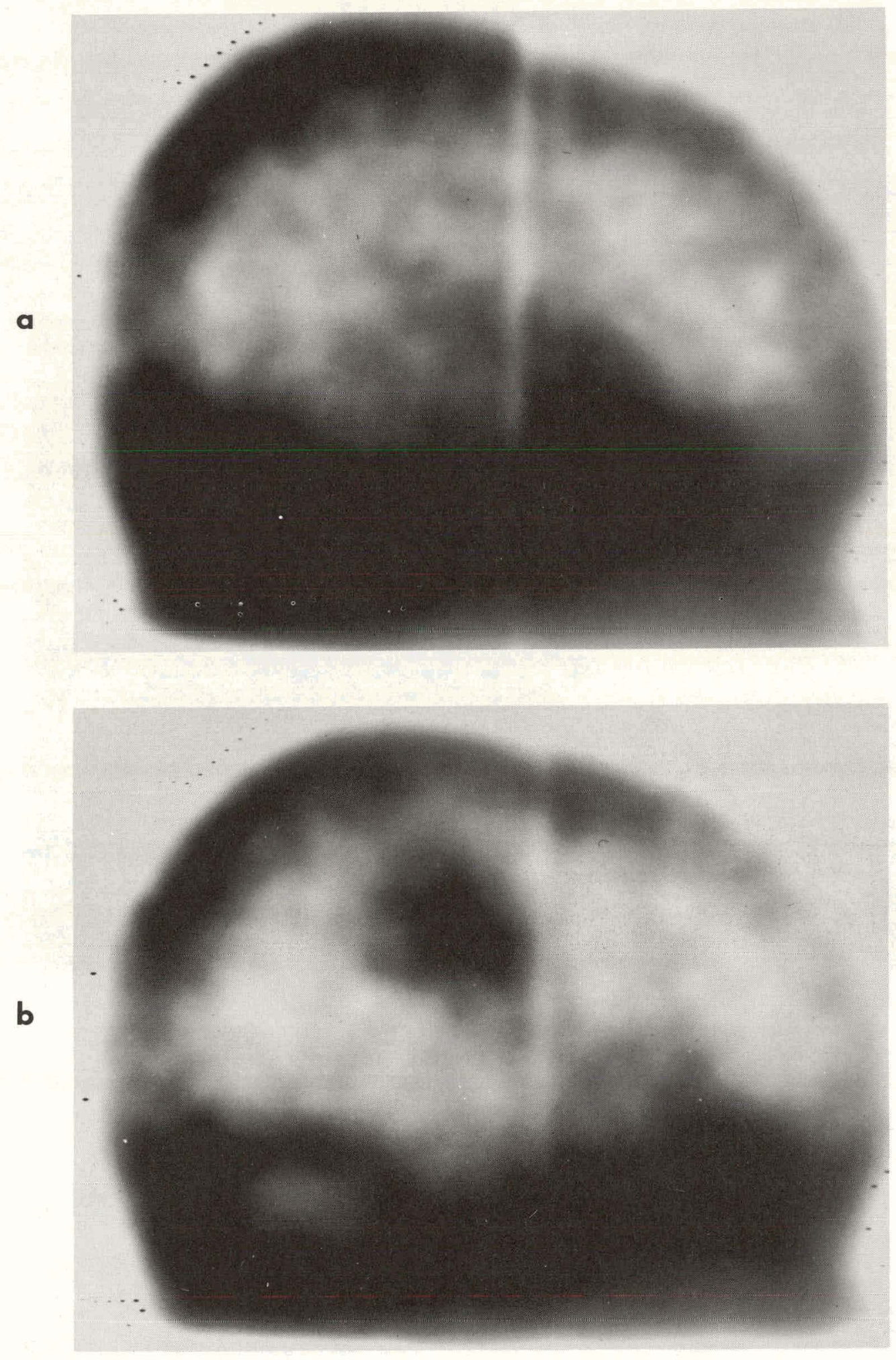

Figure 5. ( $a$ and $b)$ Right and left lateral scans of patient with superficial glioma. Note that tumor is faintly visible from opposite side of head. Duration of scan 15 minutes; started immediately following intravenous injection of $5 \mathrm{mc}^{\text {of }} \mathrm{TcO}_{4}{ }^{-}$in $1 \mathrm{gm}$ of NaI solution. Total body radiation dosage approximately $60 \mathrm{~m}$ rad. 

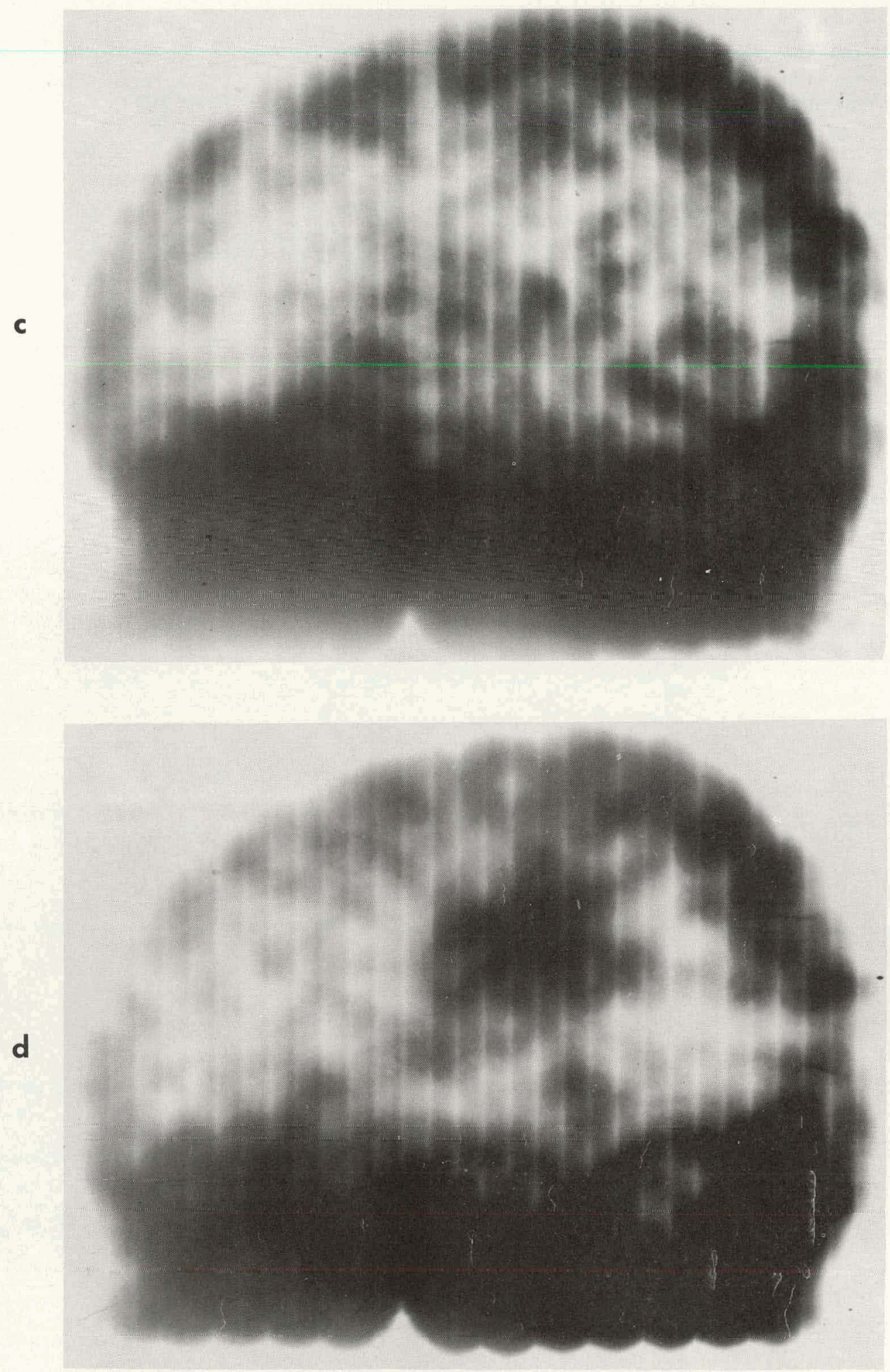

Figure 5. (c and d) Same patient, scanned using $6.3 \mathrm{~mm}$ index. Duration of scan 90 seconds; started 17 minutes following injection. 

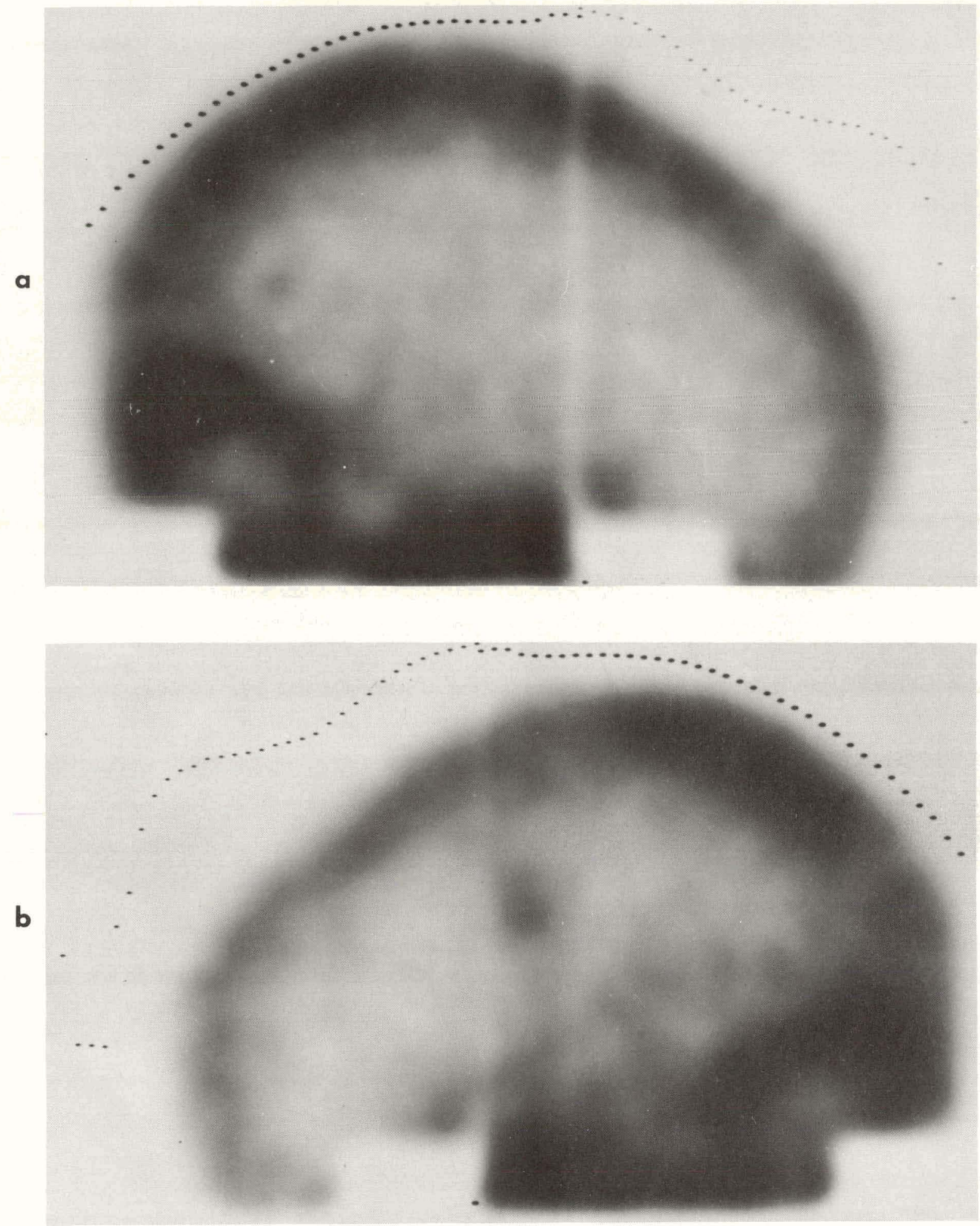

Figure 6. (a) Left lateral; (b) right lateral scans of patient with oligodendroglioma. Duration of scans 7 to 8 minutes, time for entire examination 45 minutes. Five mc $\mathrm{TcO}_{4}{ }^{-}$injected intravenously with $1 \mathrm{gm}$ of NaI to reduce thyroid and gastric localization. 

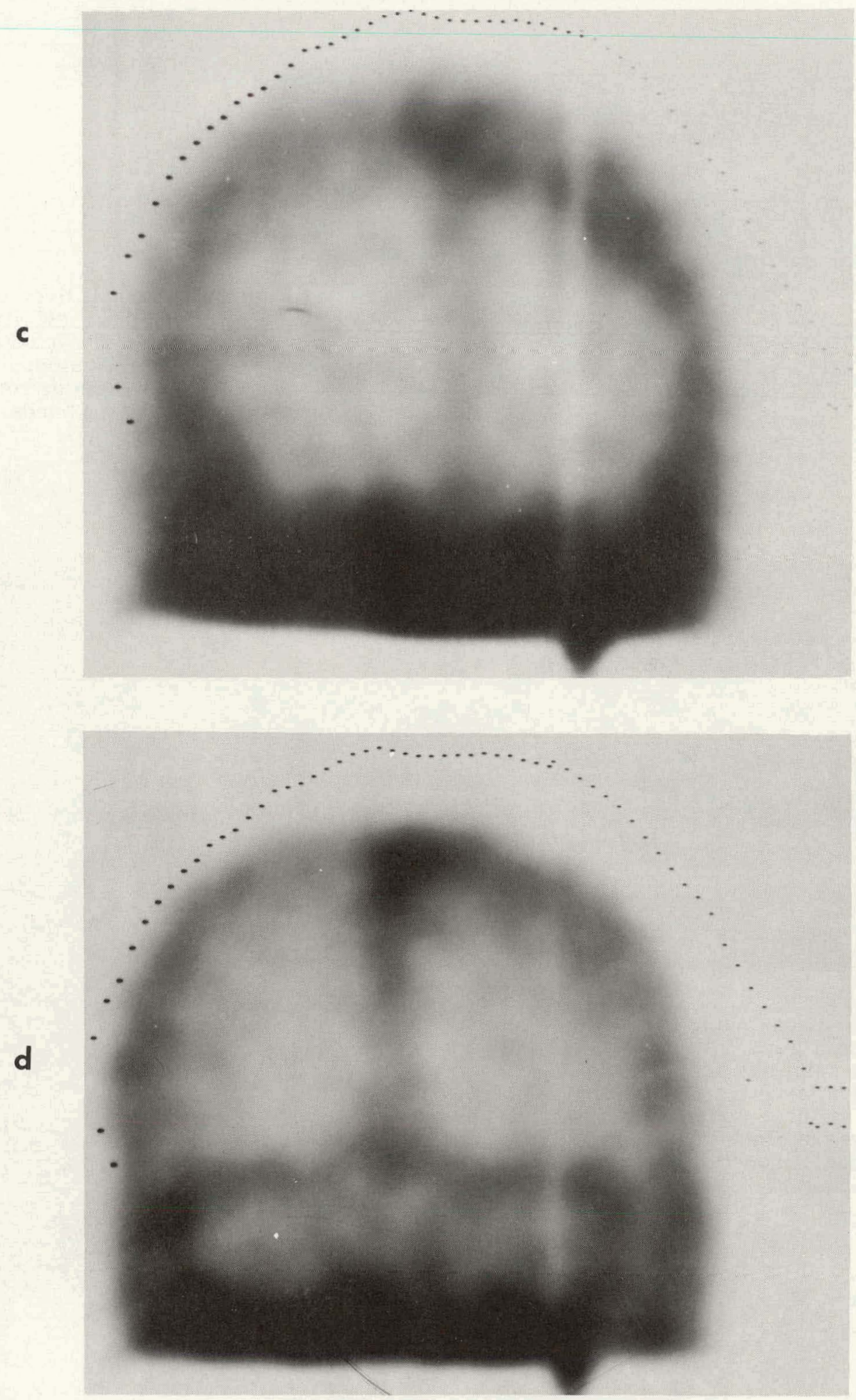

Figure 6. (c) Anterior; (d) posterior scans of patient with oligodendroglioma. Duration of scans 7 to 8 minutes, time for entire examination 45 minutes. Five mc $\mathrm{TcO}_{4}{ }^{-}$injected intravenously with $1 \mathrm{gm}$ of $\mathrm{NaI}$ to reduce thyroid and gastric localization. 


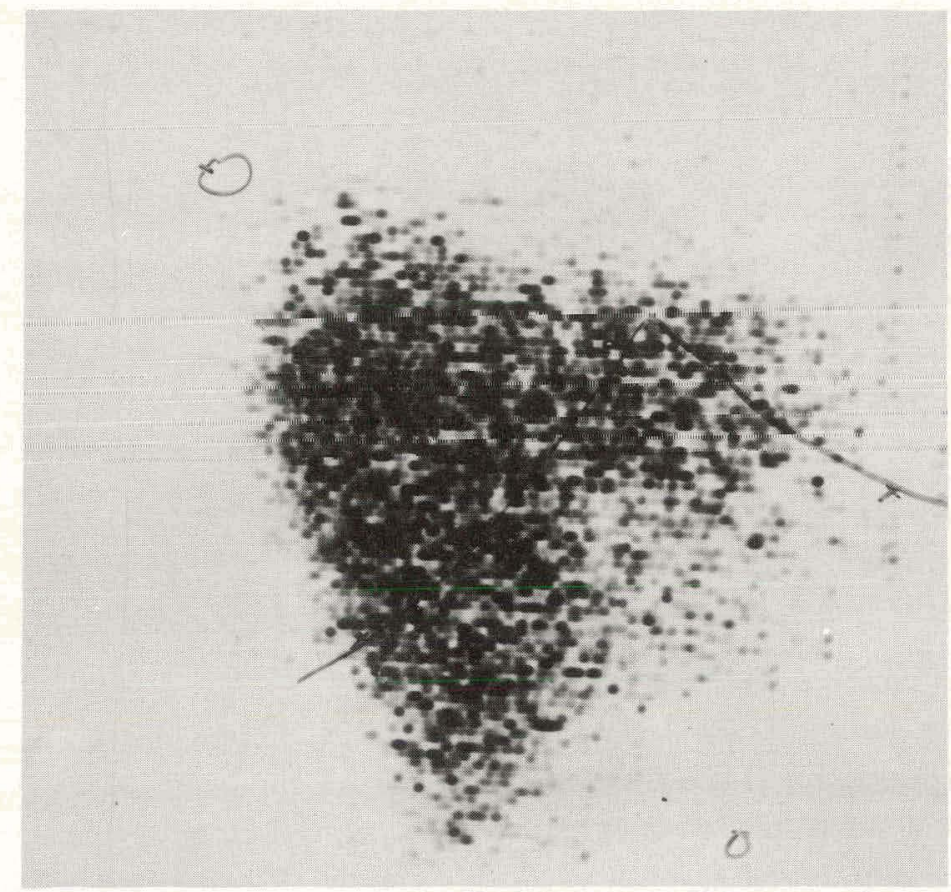

Figure 7. Normal liver scan using $1 \mathrm{me}$ of $\mathrm{Tc} 99 \mathrm{~m}(\mathrm{SCN})_{5}$ in fal emulsion. Scan started 5 hour's after injcction. Equipment: Picker Magnascanner with thyroid collimator. Note sharp borders of organ.

Figure 8. Liver scan using same technique as in Figure 7 , in patient with severe hepatic damage following prolonged obstructive jaundice. Note greatly reduced uptake, continued presence of circulatory activity in cardiac silhouette, as well as some degradation of Tc $(\mathrm{SCN})_{5}$ back to $\mathrm{TcO}_{4}^{-}$with gastric localization.

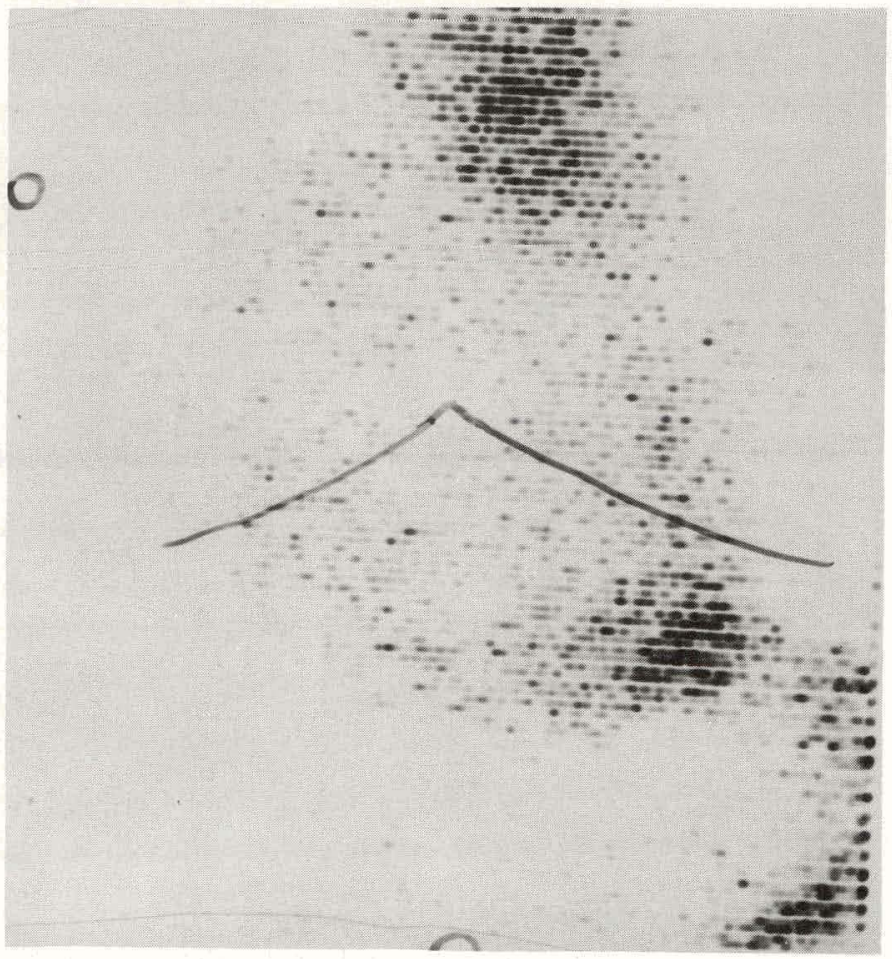




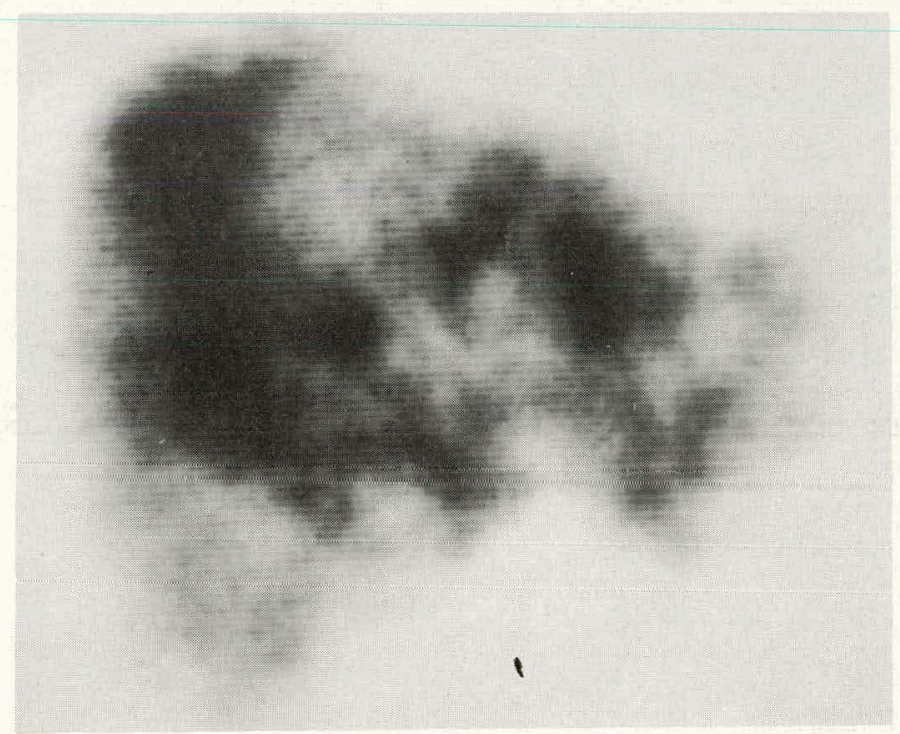

Figure 9. Metastatic carcinoma of the colon in liver demonstrated with $\mathrm{Tc}_{2} \mathrm{~S} 7$ in sulfur emulsion. Scan performed 5 minutes after intravenous injection of $2 \mathrm{mc}$ of $\mathrm{Tc} 99 \mathrm{~m}$. Probe (Figure 1) used with read-out similar to brain scanner. Serrated appearance of superior margin of organ is due to respiratory motion.

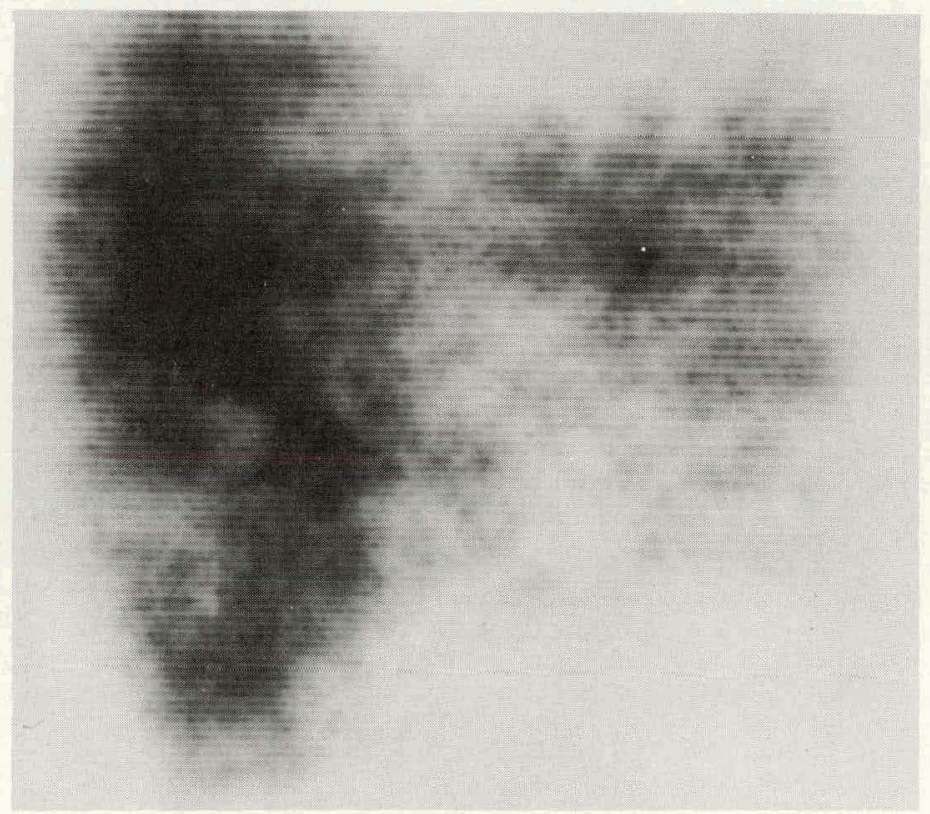

Figure 10. Liver scan showing metastases from carcinoma of breast. Technique same as in Figure 9. Maximum count rates $40,000 \mathrm{c} / \mathrm{min}$. The right phrenic nerve was blocked to prevent motion; however, the motion artifact of the left lobe is evident. 


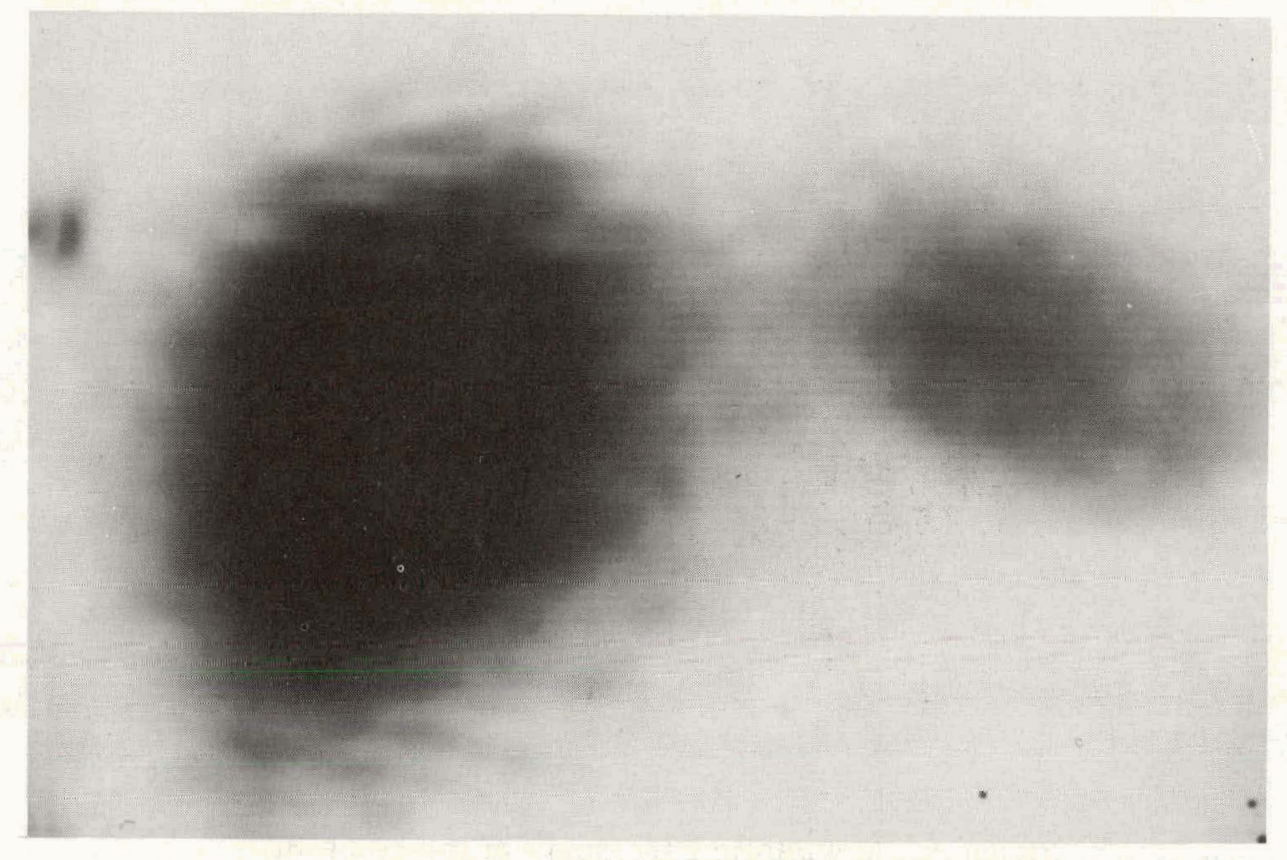

Figure 11. Posterior scan of liver and spleen using the $\mathrm{Tc}^{99 \mathrm{~m}}$ sulfur colloid. The left phrenic nerve has been blocked. Note motion artifacts in liver scan.

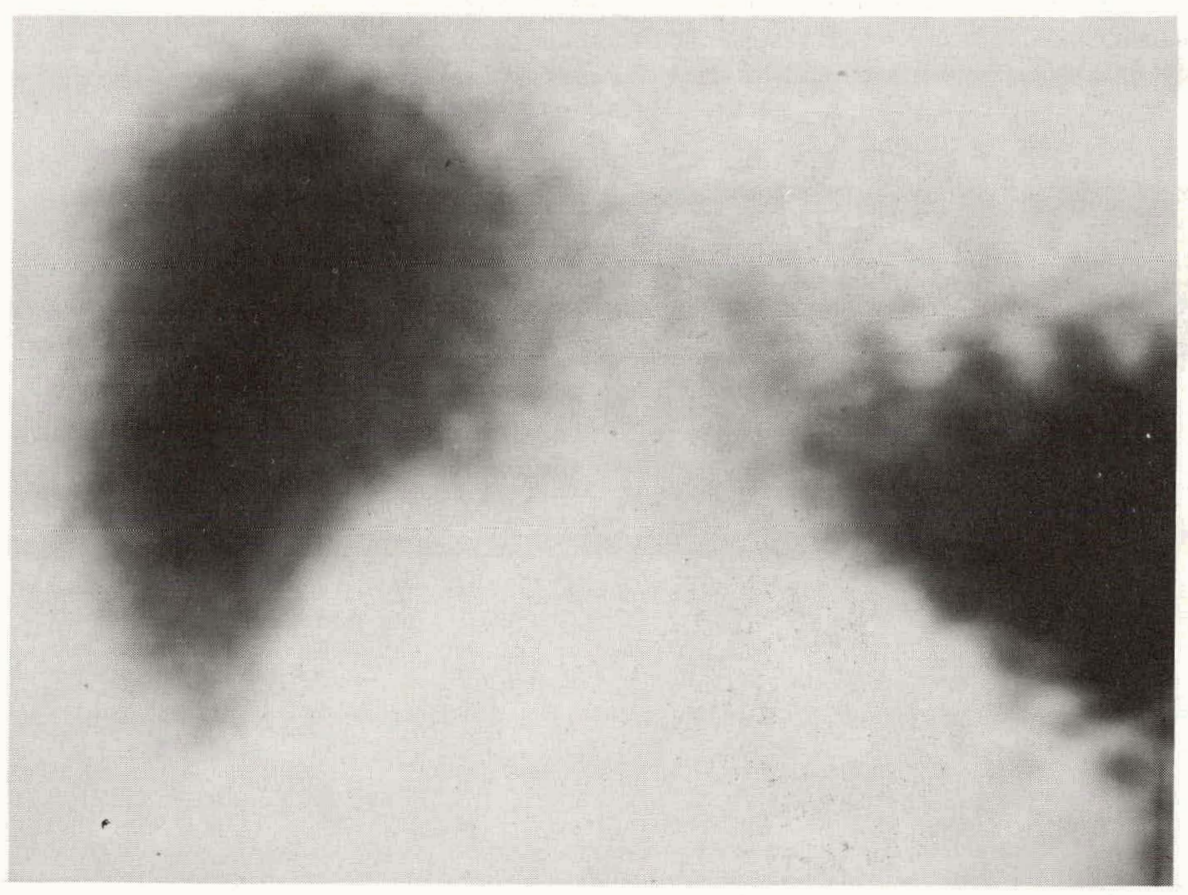

Figure 12. Similar to Figure 11 but with right phrenic nerve paralyzed. Again note the motion artifact in the spleen scan. 


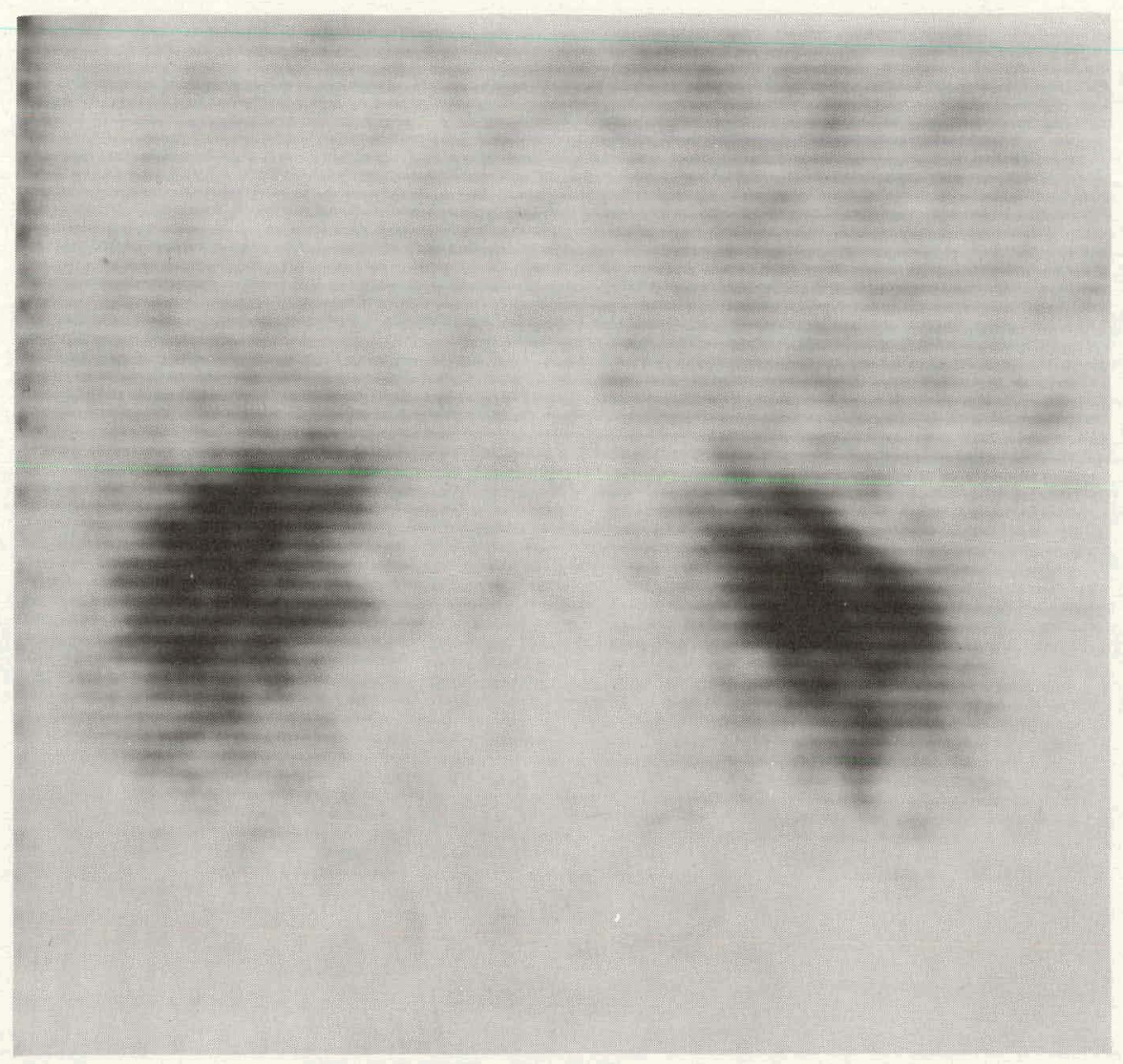

Figure 13. Renal scan started immediately after intravenous injection of $2 \mathrm{mc} \mathrm{Tc}^{99 \mathrm{~m}}$-glycine preparation showing kidney contours. Duration of scan - 20 minutes.

\section{LITERATURE CITED}

1. Strominger, D., J. M. Hollander, and G. T. Seaborg. Revs. Modern Phys., 30:673, 1958.

2. Harper, P. V., R. Beck, D. Charleston, and K. A. Lathrop. Nucleonics, 22:50, 1964.

3. Tucker, W. D., M. W. Greene, A. J. Weiss, and A. Murrenhoff. Brookhaven National Laboratory Report No. 3746, 1958.

4. Gerlit, J. B. In Proceedings of the First International Conference on the Peaceful Uses of Atomic Energy 7. Geneva United Nations Publication, 1956, p. 145.

5. Howard, O. H., and C. W. Weber. Anal. Chem., 34:530, 1962.

6. Stang, L. G., and P. Richards. Nucleonics, 22:46, 1964.

7. Wolff, J., and J. R. Maurey. Biochem. biophys. Acta, 69:58, 1963.

8. Harper, P. V., G. Andros, and K. Lathrop. Argonne Cancer Research Hospital Semiannual Report to the Atomic Energy Commission, 18:76, 1962.

9. Sorensen, L. B., and M. Archambualt. J. Lab. Clin. Med., 62:330, 1963.

10. Anger, H. O., and A. Gottschalk. J. Nucl. Med., 4:326, 1963. 


\section{COLLIMATORS FOR RADIOISOTOPE SCANNING SYSTEMS*}

By

\section{R. N. Beck}

The successful use of scanning systems in diagnostic procedures depends upon the preferential uptake of the administered isotope in certain tissues, and the detailed mapping of the distribution of radioactivity by means of a collimated gamma ray detector (see Figure 1). These procedures become useful clinical tests only if the radiation dosage to the patient is low, the time required is short, the statistical reliability is high, and the spatial resolution of the distribution of radioactivity is good. These factors are determined by the sensitivity and field of view of the collimated detector. Making use of equations derived elsewher $\mathrm{e}^{1}$ for collimator response to distributed sources, this paper deals with the design of single and multichannel collimators, such as those shown in Figures 1 and 2.

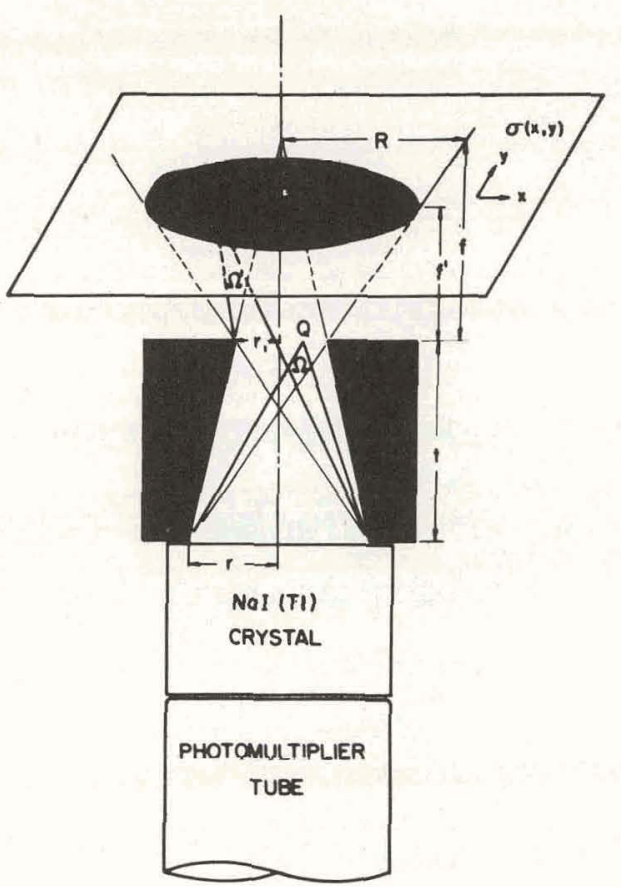

Figure 1. Scintillation detector with a single hole collimator which defines a circular field of view with radius $\mathrm{R}^{\prime}$ at distance $\mathbf{f}^{\prime}$. The response to a uniform sheet distribution, $\sigma\left(\frac{y^{\prime} \mathrm{s} \text { emitted }}{\mathrm{cm}^{2}-\mathrm{sec}}\right)$, is independent of the distance $\mathrm{f}^{\prime}$ to the sheet.

* This paper was presented at the IAEA Symposium on Medical Radioisotope Scanning in Athens, Greece, April 1964. It will appear in the Proceedings of the Symposium. 


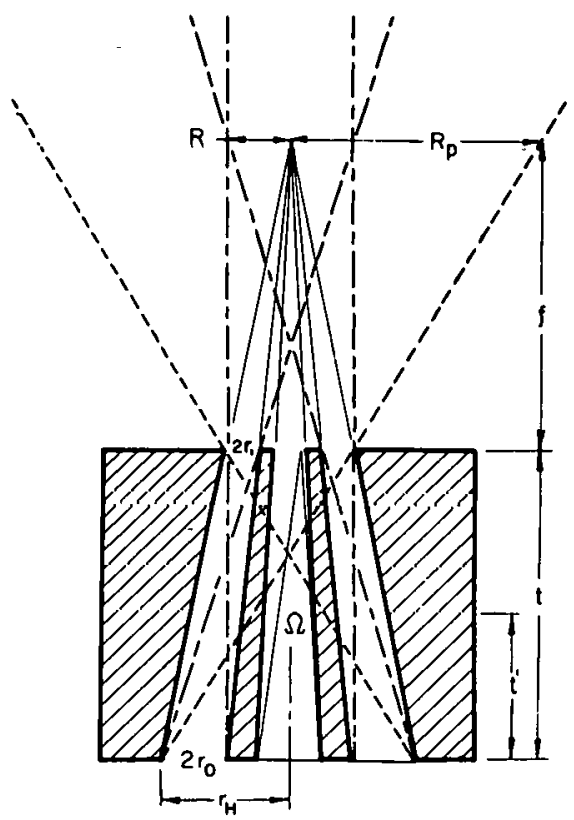

Figure 2. Focused collimator cross section. Gamma rays arising anywhere within the fields of view of the small holes may enter the collimator properly or "geometrically." In addition, gammas arising within the region defined by $R_{p}$ may enter the detector by penetrating the collimator septa which must be made thick enough to limit the penetration to a negligible fraction of the geometrical response.

\section{Detector Response}

The total response of a scintillation detector is the sum of responses to gammas which have entered the collimator a) properly (geometrical efficiency), b) after being scattered in the source or collimator, and c) by penetrating the collimator septa or surrounding shielding. The total response can be written as:

$$
\mathrm{C}\left(\frac{\text { counts }}{\mathrm{sec}}\right)=\mathrm{E}_{\mathrm{T}} \eta \sigma=\mathrm{E}(1+\mathrm{P}+\mathrm{S}) \eta \sigma
$$

where $\mathrm{E}_{\mathrm{T}}\left(\mathrm{cm}^{2}\right)=$ the total collimator efficiency.

$\mathrm{E}\left(\mathrm{cm}^{2}\right)$

$\mathbf{P}$

$$
\mathbf{S}
$$

$\eta$
$=$ the geometrical efficiency for distributed sources.

$=$ penetration fraction, or the penetration efficiency relative to the geometrical efficiency.

$=$ scatter fraction

= photopeak crystal efficiency. $\sigma\left(\frac{y^{\prime} \mathrm{s} \text { emitted }}{\mathrm{sec}-\mathrm{cm}^{2}}\right)=\begin{aligned} & \text { source strength, or the concentration of activity on a uniform sheet } \\ & \text { distribution. }\end{aligned}$

"If the actual source is a uniform volume distribution having concentration $\rho\left(\frac{y^{\prime} \mathrm{s} \text { emitted }}{\mathrm{sec}-\mathrm{cm}^{3}}\right)$, thickness $\mathrm{H}$ and attenuation coefficient $\mu$, then the same response to unattenuated gammas would 
In any particular application $\sigma$ is limited by the radiation dosage that can be permitted, and the response is determined by the detector efficiency (or sensitivity), $E_{T} \eta=(1+P+S) \eta$. To maximize sensitivity, the scintillation crystal should be large enough for $\eta$ to be near 1; larger crystals simply increase the background count rate and require heavy shields. The total collimator efficiency, $\mathrm{E}_{\mathrm{T}}$, cannot be simply maximized, because the penetration and scatter components of response (EP and ES) degrade the spatial resolution. The aim of collimator design is then to maximize the geometrical efficiency, $E$, for a given set of conditions, while keeping $P+S$ small compared to 1 .

The scatter fraction is the sum of two components due to scattering events which take place in the source and in the collimator. The source scatter fraction has been discussed elsewhere, ${ }^{1}$ and is not relevant to collimator design. Mather ${ }^{2}$ has shown that the collimator scatter fraction is a monotonic increasing function of gamma energy and is less than 0.07 for energies below 1

$\mathrm{MeV}$ for a collimator with $\frac{\mathrm{t}}{\mathrm{r}}=32$. This fraction is considered negligible and the problem of collimator design is reduced to a consideration of the geometrical and penetration responses.

\section{Collimator Design}

Since no single design procedure is appropriate for the entire range of gamma energies, the problem is considered in three parts.

1) Below approximately $0.150 \mathrm{MeV}$, few gammas can penetrate the thinnest lead septa that can be conveniently cast. Here the design procedure maximizes geometrical response for specified focal length, radius of view, septum thickness and crystal diameter (or "shape factor," to be introduced later).

2) In the energy range from approximately 0.150 to $1 \mathrm{MeV}$ the response to gammas which penetrate the collimator septa is not negligible and must be controlled. In this case, geometrical response is maximized for specified gamma energy, collimator material, focal length, radius of view, penetration fraction and crystal diameter (or shape factor).

3) Above approximately $1 \mathrm{MeV}$ it is not always possible to design a multichannel collimator having an acceptably low penetration fraction. In this case, a single hole having a taper that maximizes geometrical response is used.

\section{Specification of Parameters}

In all cases, the design procedure requires the specification of a certain radius of view, $\mathrm{R}^{\prime}$, at a certain distance, $\mathrm{f}^{\prime}$, from the collimator face, where $\mathrm{f}^{\prime}$ may not be equal to $\mathrm{f}$, the "focal" distance (see Figure 1). The choice of $\mathrm{R}^{\prime}$ may be based on any one of several considerations.

1) First, we may have in mind the smallest tumor that we hope to detect, and a range of depths at which it might exist. For example, we may wish to design a collimator for detecting brain lesions that are at least $2 \mathrm{~cm}$ in diameter and that might exist anywhere between the surface of the brain and the midline. Newell ${ }^{3}$ has concluded that any choice of $2 \mathrm{R}^{\prime}$ between 0.9 and 2 times the tumor diameter is within 20 per cent of optimum. Here, "optimum" is determined by a statistical criterion based on the time required to detect the tumor. If, in addition to detec-

be observed if this source were replaced an "equivalent" sheet distribution $\sigma=\rho\left(\frac{1-\mathrm{e}^{-\mu \mathrm{H}}}{\mu}\right)$. Similar expressions apply when the volume distribution has a concentration which varies with depth. 
tion time, some significance is attached to the sharpness with which the tumor is outlined (this is important if the tumor is to be detected by a visual inspection of the scan picture), then the optimum diameter of view is probably closer to the small end of the range specified by Newell. Thus, a choice of $2 R^{\prime}$ equal to the tumor diameter should not be far from optimum.

2) An alternative, but similar, basis for choosing $R^{\prime}$ is as follows: A suitable detector figure of merit, $Q$, is maximized by some value of $R^{\prime}$ for detecting structures of a specified size. The procedure for finding this $R^{\prime}$ is facilitated by expressing $Q$ in terms of the "modulation transfer function," $M$, which can be conveniently measured as a function of $R^{\prime}$. The quantities $Q$ and $M$ are discussed in the section on testing collimators.

3) Finally, for a given source concentration $\sigma$, in an area $A$, to be scanned in time $T$, the value of $R^{\prime}$ can be computed which maximizes the "information content," $I$, in the scan picture." Single Hole Collimators

In the case of single hole collimators (which may be the only possibility for relatively high energy gammas), Mather ${ }^{2}$ has shown that the effective radius of view is larger than $R^{\prime}$ due to edge penetration. If a slab equal in thickness to one mean free path length in lead were removed from each face of the collimator, then the $R^{\prime}$ would equal the effective radius of view with edge penetration.

With the choice of $R^{\prime}$ determined by this and the above considerations, and $f^{\prime}$ set approximately equal to the deepest structure that we wish to detect, it remains only to maximize the geometrical efficiency, which can be expressed in a very general form, applicable to straight and tapered holes.

$$
E=\frac{\pi r^{2}}{4 t^{2}}\left(\frac{t R^{\prime}-f^{\prime} r}{f^{\prime}+t}\right)^{2}
$$

The simplest collimator is a single straight hole, for which equation (1) can be put in the form

$$
E=\frac{\pi r^{2}}{16 f^{\prime}}\left(R^{\prime}-r\right)^{2}
$$

For specified values of $R^{\prime}$ and $f^{\prime}, E$ is maximum when $2 r=R^{\prime}$ and $t=2 f^{\prime}$; thus,

$$
E_{\max }=\frac{\pi R^{\prime}}{256 f^{\prime 2}}
$$

The most efficient straight hole requires a crystal with diameter $D \geq 2 r=R^{\prime}$. For the same crystal diameter, $R^{\prime}$ and $f^{\prime}$, a tapered hole can be found (with $t=1.37 f^{\prime}$ ) which is 15 per cent more efficient. In general, for tapered holes with specified values of $R^{\prime}, f^{\prime}$ and $r$ (where $r$ is given its maximum convenient value) $E$ is maximum when $t=\frac{r f^{\prime}}{R^{\dagger}}\left(1+\sqrt{1+\frac{R^{\top}}{r}}\right)$. In this case $f^{\prime}$ is not equal to $f$ (see Figure 1).

For tapered holes with specified values of $R^{\prime}, f^{\prime}$, and $t$ (where $t$ is given its maximum convenient value), $E$ is maximum when $r=\frac{t R^{\prime}}{2 f^{\prime}}$. This relation implies that $f^{\prime}=f$ (and consequently $R^{\prime}=R$ ); thus $r=\frac{t R}{2 f}$ and equation (1) can be written

$$
E=\frac{\pi r^{4}}{4 t^{2}} \frac{\pi R^{4}}{\left(1+\frac{t}{f}\right)^{2}}=\frac{\pi f^{2}\left(\frac{R}{r}+2\right)^{2}}{16}
$$

Using this formulation, a tapered hole can be found which is 78 per cent more efficient than a 
straight hole having the same $R^{\prime}, f^{\prime}$ and $t$. However, the required crystal diameter is twice as large. Thus it is always possible to find a tapered hole that is more efficient than a straight hole for the same values of $R^{\prime}, f^{\prime}$ and $t$ or $r$.

For multichannel focused collimators, $\mathrm{f}^{\prime}=\mathrm{f}$ provides the most convenient taper; thus the relation $2 \mathrm{rf}=\mathrm{Rt}$ and equation (2) will be used in all focused collimator design.

\section{Focused Collimators for Low Energy Gamma Rays}

By using $\mathrm{N}$ holes tapered to a single point, the collimator efficiency given by equation (2) is multiplied by $\mathrm{N}$, without altering the radius of view $\mathrm{R}$ at the focal distance $\mathrm{f}$. Figure 2 shows in cross section the overlapping fields of view of three such tapered holes, which are part of a seven-hole hexagonal array. Gammas emitted at points outside the geometrical field of view but within the region denoted by $R_{p}$ may enter the scintillation crystal by penetrating the collimator septa. This degrades the spatial resolution. However, for gamma energies below approximately $150 \mathrm{keV}$, lead is sufficiently opaque that the probability of septum penetration is small even for quite thin septa.

In this case, the goal of collimator design is to maximize

$$
E=\frac{N \pi R^{4}}{16 f^{2}\left(\frac{R}{r}+2\right)^{2}}
$$

for specified $R, f$ and $s$, the thinnest septa which can be conveniently cast. Two special cases arc discussed.

Collimators for specified $\mathrm{R}, \mathrm{f}, \mathrm{s}$, and $\mathrm{D}$. If the collimator is to be designed for a given crystal, we begin by expressing $E$ in terms of $R, f, s$, and $D$, where $D$ is the diagonal of the hexagonal array of $\mathrm{N}$ round tapered holes, and is usually set equal to the crystal diameter. The septum thickness, $s$, is measured at the crystal face. If $n$ is the number of holes on a diagonal of the array, then

$$
D=2 r n+s(n-1)
$$

The total number of holes in the array is

$$
\mathrm{N}=\frac{3 \mathrm{n}^{2}+1}{4} \cong \frac{3 \mathrm{D}^{2}}{4(2 \mathrm{r}+\mathrm{s})^{2}}
$$

where $\mathrm{n}=1,3,5,7, \ldots \ldots \ldots$

give $\mathbf{N}=1,7,19,37, \ldots \ldots \ldots$

Under most circumstances, $D \gg s$ and $N \gg 1$.

In this case, the approximation for $\mathrm{N}$ in equation (4) is valid, and equation (2a) can be written

$$
E=\frac{3 \pi R^{4} D^{2}}{64 f^{2}\left(\frac{R}{r}+2\right)^{2}(2 r+s)^{2}}
$$

Solution for maximum E: For specified values of $R, f, s$, and $D$; $E$ is maximum when $2 r=\sqrt{R s}$. This relation can then be used to find the values of $t, N$, and $E_{\max }$.

$$
\begin{aligned}
& t=f \sqrt{\frac{S}{R}} \\
& N \cong \frac{3 D^{2}}{4(\sqrt{R s}+s)^{2}}
\end{aligned}
$$




$$
E_{\max }=\frac{3 \pi R^{4} D^{2}}{256 f^{2}(\sqrt{R}+\sqrt{s})^{4}}
$$

For example, if we specify $R=5 / 32^{\prime \prime}, \mathrm{f}=2.5^{\prime \prime}, \mathrm{s}=0.012^{\prime \prime}$ and $\mathrm{D}=1.75^{\prime \prime}$, then $\mathrm{E}$ is maximum when $2 \mathrm{r}=0.043^{\prime \prime}, \mathrm{t}=0.69^{\prime \prime}, \mathrm{N} \cong 750$ and $\mathrm{E}_{\max }=1.66 \times 10^{-4} \mathrm{in}^{2}=1.07 \times 10^{-3} \mathrm{~cm}^{2}$.

Solution for near maximum $\mathrm{E}$. The above example raises the serious practical problem of constructing collimators consisting of large numbers of small holes. Before undertaking the construction of such a collimator, it is advisable to determine how much less efficient are collimators with fewer holes (but the same R, f, s, D). For this purpose, if we substitute equations (3) and (4) in equation (2a), then we get

$$
E=\frac{\pi R^{4}}{256 f^{2}}\left[\frac{3 n^{2}+1}{\left(\frac{R n}{D-s(n-1)}+1\right)^{2}}\right]
$$

Then $\mathrm{E}$ can be computed for each value of $\mathrm{n}(1,3,5,7, \ldots)$, and the procedure terminated when $E$ is "close enough" to $E_{\max }$.

The collimator shown in Figures 3 and 4 (IX) was designed in this way for the values of $R$, $\mathrm{f}, \mathrm{s}$ and $\mathrm{D}$ specified in the above example. It consists of 253 holes (an incomplete 271-hole array) having base diameter $2 \mathrm{r}=0.085^{\prime \prime}, \mathrm{t}=1.36^{\prime \prime}$ and $\mathrm{E}=1 \times 10^{-3} \mathrm{~cm}^{2}$, which is very close to $E_{\max }=1.07 \times 10^{-3} \mathrm{~cm}^{2}$. The other collimators shown in Figure 4 were formed by cutting off the basic mold to double and quadruple the efficiency.

Collimators for specified $R, f, s$, and $K$. The above procedure is probably satisfactory

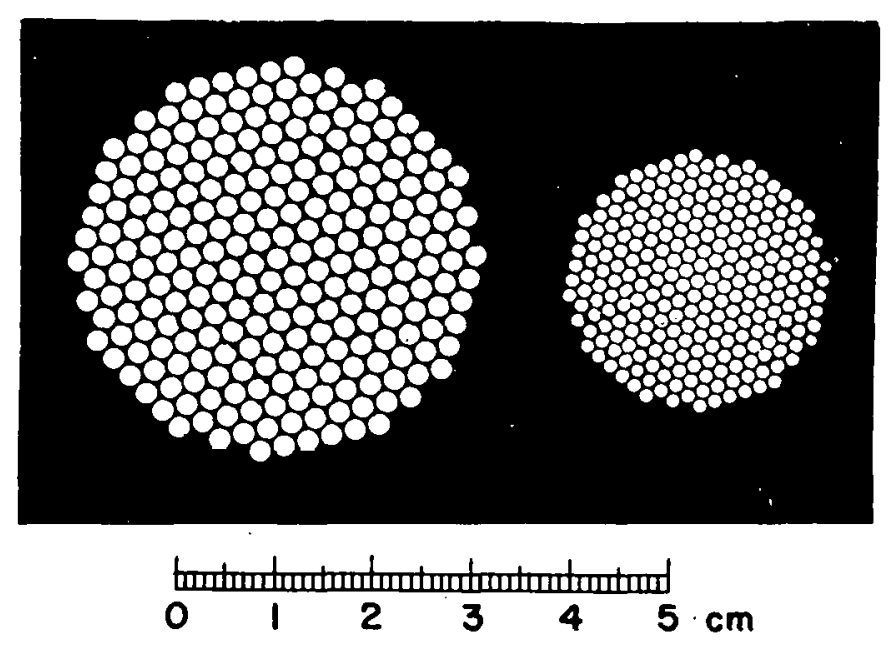

Figure 3. For low energy gammas, the penetration fraction is negligible and the septa are made as thin as possible to maximize the geometrical response. Here the septa are 0.012" at the large end and $0.008^{\prime \prime}$ at the small end of the collimator. 


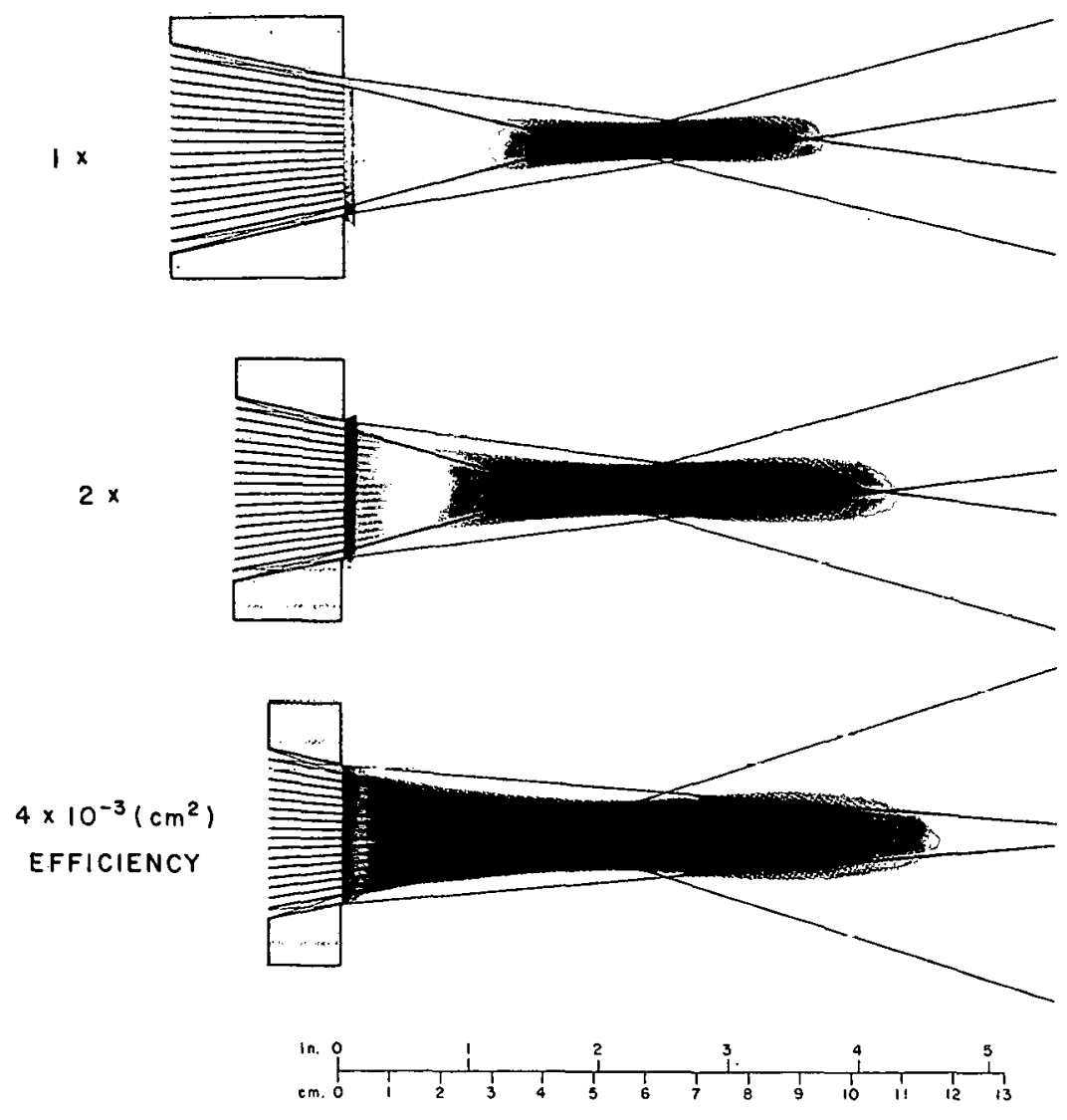

Figure 4. Response patterns for a set of collimators for low energy gammas having the hole layout shown in Figure 3. The center and lower collimators were formed by cutting down the original casting to double and quadruple the geometrical response to distributed sources, with some loss in resolution.

whenever the source is not very thick, when a small crystal is used, or when good resolution is required only near the focal distance. (This set has been used primarily for thyroid and liver scanning with $\mathrm{I}^{125}\left(\sim 30 \mathrm{keV}\right.$ and $\left.\mathrm{Tc}^{99 \mathrm{~m}}(140 \mathrm{keV})\right)$. However, for large crystals, this procedure leads to collimators having very "divergent" fields of view; that is, the width of the field of view increases rapidly with distance from the focal point. This can be described by a "shape factor," $\mathrm{K}$, which is defined by the equation

$$
\frac{3 \sqrt{3} D^{2}}{8}\left(\frac{R}{R+2 r}\right)^{2}=\pi R^{2} K
$$

which simply says that the cross sectional area of the field of view at the collimator face is $\mathrm{K}$ times the area of view at the focal distance. For $\mathrm{K}=1$, the field of view has a cross sectional area which is essentially constant from the collimator face to the focal distance. Beyond this point, the field of view diverges. Equation (10) can be solved for $\mathrm{D}^{2}$ which reduces equation (5) to 


$$
E=\frac{\pi^{2} R^{4} K}{8 \sqrt{3} f^{2}\left(\frac{s}{r}+2\right)^{2}}
$$

In this case, for specified $R, f, s$, and $K, E$ is maximum when $r$ is maximum. Using equations (3) and (10), $r$ can be expressed as

$$
\mathrm{r}=\frac{\mathrm{kR}-\mathrm{s}(\mathrm{n}-1)}{2(\mathrm{n}-\mathrm{k})}
$$

where

$$
\mathrm{k}=\sqrt{\frac{8 \pi \mathrm{K}}{3 \sqrt{3}}}=2.2 \sqrt{\mathrm{K}}
$$

It is clear from equation (12) that $r$ is maximum when $(n-k)$ takes on its minimum positive value.

This occurs for the smallest value of $n$ satisfying $n \geq 2.2 \sqrt{K}$, where $n=1,3,5, \ldots$.

It is interesting to note that, in this case, where $K$ is specified in place of $D$, the most efficient collimators consist of a small number of large holes and tend to be quite thick and to require large diameter crystals. In practical cases, it is usually necessary to sacrifice some efficiency by using larger values of $n$.

\section{Focused Collimators for the 0.150 to $1 \mathrm{MeV}$ Energy Range}

For gamma energies above approximately $150 \mathrm{keV}$, lead is not so opaque that septum penetration is negligible when $s$ is less than approximately $0.020^{\prime \prime}$. In order to limit the penetration response $(\mathrm{PE} \sigma)$ to some small fraction of the geometrical response $(\mathrm{E} \sigma)$, it is necessary to have an equation which estimates the penetration fraction $P$ in terms of the collimator parameters, $R$, $\mathrm{f}, \mathrm{D}, \lambda, \mathrm{N}$ and $\mathrm{r}$, where $\lambda$ is the attenuation coefficient of the collimator material (lead, gold, tungsten, etc.) for the particular gamma energy under consideration. For example, the septum thickness required to reduce the penetration fraction to 0.01 is not as great for $\mathrm{Hg}^{203}(279 \mathrm{keV})$ as it is for $\mathrm{I}^{131}(364 \mathrm{keV})$. Since some geometrical efficiency $(E)$ is wasted if the septa are unnecessarily thick, an equation which estimates $\mathrm{P}$ is needed to enable one to design collimators having a specified penetration fraction. This problem has been discussed elsewhere. ${ }^{1}$ Briefly,

$$
P=\frac{E_{H}-E}{E} M
$$

Where $\mathbf{M}$ is the mean probability of septum penetration for gammas emitted from a uniform sheet distribution $\sigma$ which is at least large enough to cover the region denoted by $R_{P}$ in Figure 2. Here $E_{H}$ is the geometrical efficiency of the large hexagonal hole which would be formed if all the septum material were removed (or were transparent to gamma rays). An estimate ${ }^{*}$.of $M$ which is probably adequate under most conditions 1 is

$$
M=e^{-\lambda t(1-r)}
$$

where $r$ is called the transmission ratio and is defined by

$$
t=\frac{8 \mathrm{~N} \pi \mathrm{r}^{2}}{3 \sqrt{3} \mathrm{D}^{2}}=\frac{\text { total base area of the } \mathrm{N} \text { small holes }}{\text { base area of the large hexagonal hole }}
$$

\footnotetext{
*It should be noted that this estimate of $M$ is insensitive to the distribution of path lengths through the septa. For a given transmission ratio $r$, an array of hexagonal holes provides fewer short paths through the septa than does an array of round holes; therefore, $M$ and $P$ are somewhat smaller for hexagonal holes than for round holes. For an alternative formulation, based on a path length distribution function, see Ref. 1.
} 
To complete the formulation, $E_{H}$ is estimated by the geometrical efficiency of a round tapered hole with the same base area. Here we make use of an expression for $\mathrm{E}$ which is slightly different from equation (2) and which has been derived elsewhere. ${ }^{1}$

$$
E=\frac{\pi r^{4}}{2\left(2 t^{2}+r^{2}\right)(1+t / f)^{2}}=\frac{\pi R^{4}}{2\left(8 f^{2}+R^{2}\right)\left(\frac{R}{r}+2\right)^{2}}
$$

This equation is more accurate than equation (2) when $r$ is not negligible compared to $t$, as in the case of $\mathrm{E}_{\mathrm{H}}$ for the large hexagonal hole. Here, the equivalent hole radius, $\mathrm{r}_{\mathrm{H}}$, is found by solving $\pi \mathrm{r}_{\mathrm{H}}{ }^{2}=\frac{3 \sqrt{3} \mathrm{D}^{2}}{8}$; the equivalent radius of view is $\mathrm{R}_{\mathrm{P}}=\sqrt{\frac{3 \sqrt{3}}{2 \pi}} \frac{\mathrm{fD}}{\mathrm{t}}$. Using these relations for $\mathrm{r}_{\mathrm{H}}$ and $R_{P}$ in equation (16) for $E_{H}$, and $N$ times equation (16) for the geometrical efficiency of the collimator, the penetration fraction can be expressed in terms of the collimator parameters.

$$
\mathrm{P}=\left[\frac{27 \mathrm{D}^{4}\left(1+\frac{\mathrm{R}^{2}}{8 \mathrm{f}^{2}}\right)}{64 \pi^{2} \mathrm{r}^{4} \mathrm{~N}\left(1+\frac{3 \sqrt{3} \mathrm{D}^{2} \mathrm{R}^{2}}{64 \pi \mathrm{r}^{2} \mathrm{f}^{2}}\right.}-1\right] \exp \left[-\frac{2 \mathrm{rf}}{\mathrm{R}} \lambda\left(1-\frac{8 \mathrm{~N} \pi \mathrm{r}^{2}}{3 \sqrt{3} \mathrm{D}^{2}}\right)\right]
$$

This equation is used in two procedures for collimator design.

Collimators for specified $R, f, P, \lambda$ and $D$. In this case, we wish to design a collimator with specified $R$ and $f$ for a particular gamma energy and collimator material which together determine $\lambda$, for a crystal having a diameter at least equal to $D$, and for $P$ equal to some small fraction, say 0.1 or 0.01 . It will become apparent later that the exact value specified for $P$ is not very critical. When these quantities are introduced into equation (17), only $\dot{N}$ and $r$ are undetermined. Then the problem is first to find those pairs of values of $N$ and $r$ which satisfy this equation, and then to find that pair which maximizes $\mathrm{E}$ as given in equation (2a). If we restrict the design to hexagonal arrays of holes, $\mathrm{N}$ can take on only discrete values: $7,19,37 \ldots$ This leaves only $r$ to be determined for each value of $N$. However, equation (17) is transcendental in $r$ and cannot be solved explicitly in closed form. The simplest procedure from this point is the graphical method illustrated in Figure 5, where a lead collimator is to be designed for $\mathrm{Hg}^{203}(279 \mathrm{keV})$ and having $D=2^{\prime \prime}, R=0.5^{\prime \prime}, f=4^{\prime \prime}$ and $P=0.1$. Here $P$ is plotted as a function of $r$ for several values of $N$. For $N=7,19,37$ and 61 , there exist values of $r$ which make $P=0.1$. For each set of values of $N$ and $r$ satisfying $P=0.1$ the geometrical efficiency, $E$, is computed. In this particular case, $\mathrm{E}$ is maximum when $\mathrm{N}=37$ and $\mathrm{r}=0.130^{\prime \prime}$. For this hole size, $\mathrm{t}=2.08^{\prime \prime}$. For values of $\mathrm{N}$ larger than 61 , there are no solutions for $P=0.1$. Had we specified $P=0.01$, it is apparent from Figure 5 that no solution exists when $\mathrm{N}$ is greater than 37 , although solutions do exist for $\mathrm{N}=7,19,37$. In this case, the most efficient collimator again has 37 holes; however, these holes are somewhat smaller $\left(r=0.120^{\prime \prime}\right)$ and the geometrical efficiency is reduced about 12 per cent. Thus, in this example, when $P$ was reduced by a factor of $10, E$ was reduced by approximately 0.12 . This suggests that little is lost in geometrical efficiency even when quite conservative values are specified for the penetration fraction. The practical value of this comes from the fact that we will probably never know the accuracy of estimates of $P$ such as equation (17) for all combination of 


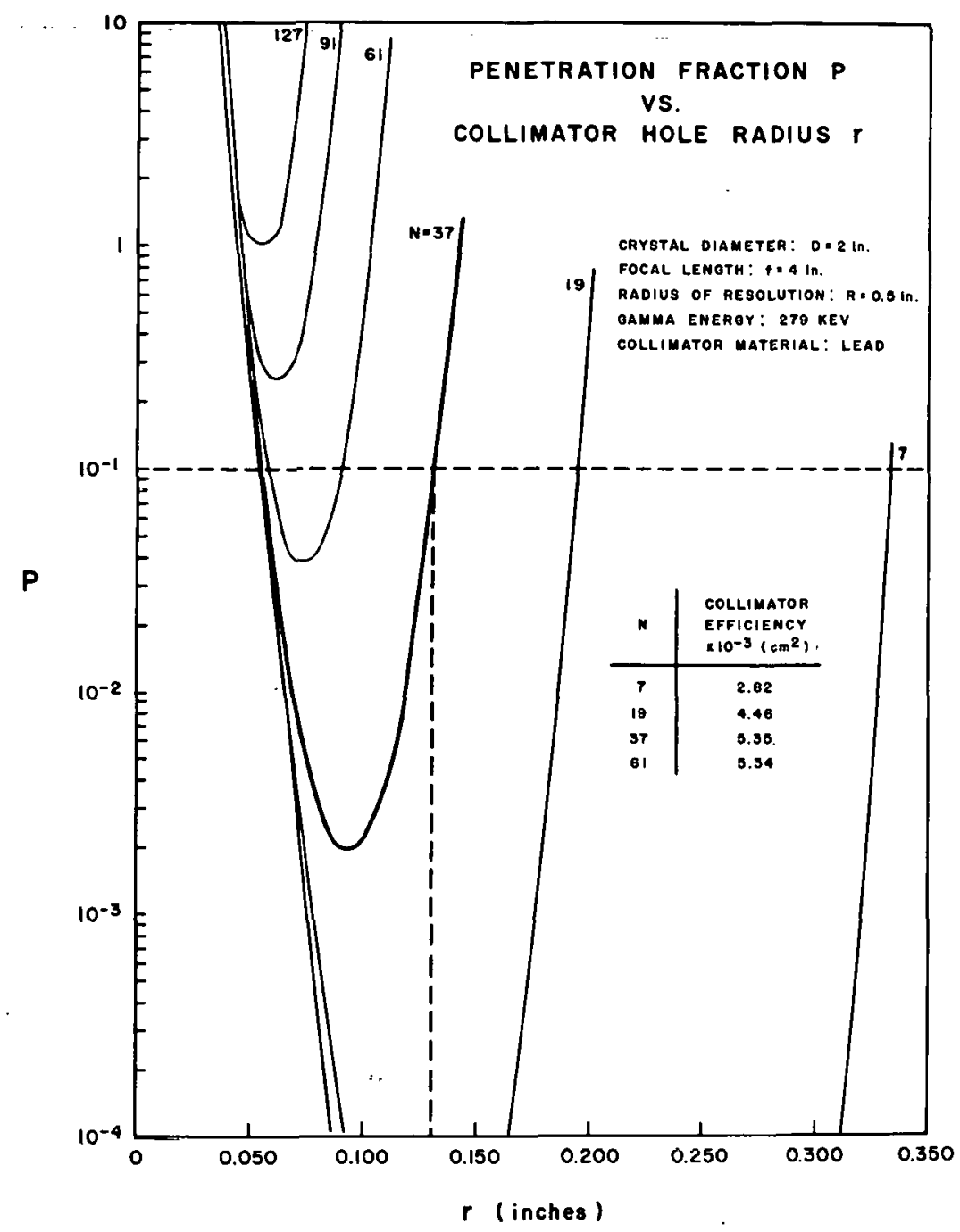

Figure 5. Example of the graphical method for finding the most efficient collimator satisfying the values specified for $R, f, P, D$ and $\lambda$. Here the "optimum" collimator has 37 holes with radius $\mathrm{r}=0.130^{\prime \prime}$.

$R, f, \lambda$, and $D$. even when each parameter has only a finite range. However, by specifying a quite small value for $P$, say 0.01 , little absolute accuracy is required of the equation estimating $P$, yet little loss in $\mathrm{E}$ is incurred.

It is of interest to note in Figure 5 that for $N=7,19,37$, and 61 , a second value of $r$ satisfying $P=0.1$ exists at approximately $r=0.050^{\prime \prime}$ for all $N^{\prime} s$. These solutions have no practical significance because in each case, $E$ is greater for the larger value of $r$. Solutions tend to exist for larger values of $N$ if $f, D, P$, or $\lambda$ is increased or $R$ is decreased. On the other hand, if $\lambda$ is small (as it is for high energy gammas), it may happen that no solution exists, even for $\mathrm{N}=7$. In that case, the single hole collimator is the only choice.

The effect of collimator material on E. While it is intuitively evident that more efficient collimators can be constructed from gold than from lead, for the same values of $R, f, P, D$ and gamma energy (since $\lambda$ is larger for gold than for lead), it is of interest to know how much $E$ 
can be increased, since the cost of gold collimators is substantial. This can be found by direct calculation or by plotting $E$ versus $\lambda$ for a set of lead collimators designed for different gamma energies; then the corresponding values of $E$ for gold collimators can be estimated by interpolation. In the example used to illustrate the interpolation procedure (see Figure 6) $\mathrm{D}=2 " \mathrm{f}=4^{\prime \prime}$, $P=0.01$. For $511 \mathrm{keV}$ photons, the gold collimators are about 50 per cent more efficient than their lead counterparts, for the three values of $\mathrm{R}$ considered. For $279 \mathrm{keV}\left(\mathrm{Hg}^{203}\right)$, the increase in $\mathrm{E}$ is only about 25 per cent, and continues to decrease with decreasing gamma energy. While the efficiency to be expected from gold collimators can be estimated in this way, the number and size of the holes can be found only by the design procedure outlined above.

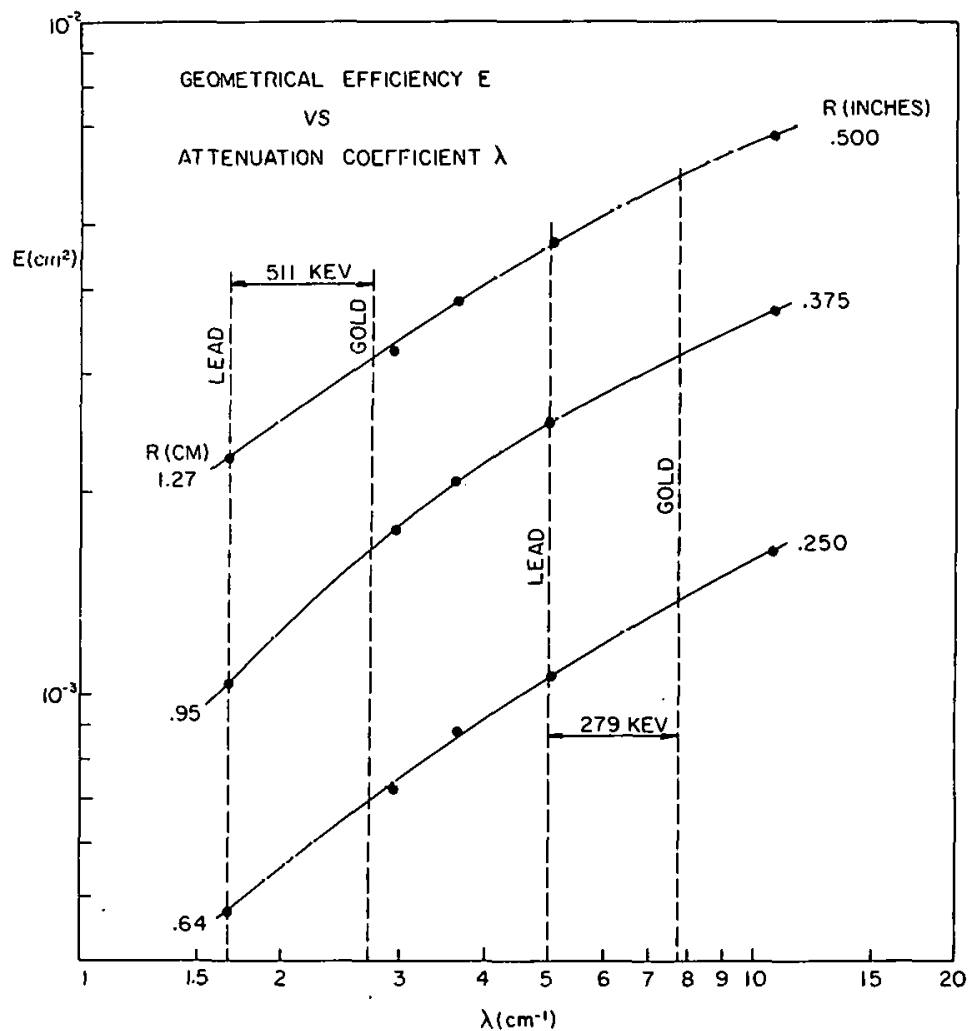

Figure 6. Comparison of geometrical efficiencies of lead and gold collimators designed for the same R, f, P, D and $\gamma$. At $511 \mathrm{keV}$, gold collimators are about 50 per cent more efficient than corresponding lead collimators. This advantage decreases with gamma energy and is about 25 per cent at $279 \mathrm{keV}$.

Collimators for specified $\mathrm{R}, \mathrm{f}, \mathrm{P}, \lambda$ and $\mathrm{K}$. The procedure in the preceding section is analogous to the low energy case discussed for collimators for specified R, f, s and D and, similarly, leads to collimators having "divergent" fields of view for large values of $D$, etc. An alternative procedure, analogous to that discussed for collimators for specified $R, f, s$ and $K$, makes use of the "shape factor" defined by equation (10), and is useful when the source is thick, etc. Clearly, equation $(10)$ can be solved for $D^{2}$ which can then be used to express $P$ as a function of $R, f, \lambda$, 
$\mathrm{K}, \mathrm{N}$ and $\mathrm{r}$. From this point, a design procedure that is virtually identical to that described in the preceding section can be used.

A slight, but interesting, variation on this procedure makes use of a simplified equation for P. In this case it is assumed that $\mathrm{E} \ll \mathrm{E}_{\mathrm{H}}$ (see equation (13)) and that equation (2) provides an adequate basis for estimating $\mathrm{E}_{\mathrm{H}}$. Then $\mathrm{P}$ can be put in the form

$$
\mathrm{P} \cong\left[\frac{27 \mathrm{D}^{4}}{64 \pi^{2} \mathrm{r}^{4} \mathrm{~N}}\right] \text { exp }\left[\frac{-2 \mathrm{rf} \lambda}{\mathrm{R}}\left(1-\frac{8 \mathrm{~N} \pi \mathrm{r}^{2}}{3 \sqrt{3} \mathrm{D}^{2}}\right]\right.
$$

Substituting for $\mathrm{D}^{2}$ from equation (10) and rearranging the terms, we get

$$
\mathrm{f} \lambda=\frac{\mathrm{R}}{2 \mathrm{r}}\left[\log _{\mathrm{e}} \frac{\left(\frac{\mathrm{R}}{\mathrm{r}}+2\right)^{4} \mathrm{~K}^{2}}{\mathrm{PN}}\right]\left[1-\frac{\mathrm{N}}{\left(\frac{\mathrm{R}}{\mathrm{r}}+2\right)^{2} \mathrm{~K}}\right]^{-1}
$$

A convenient design procedure which retains a degree of generality can be used if only $\mathrm{P}$ and $\mathrm{K}$ are specified at the outset. For example, we may wish to design a set of collimators having different values of $R, f$ and $\lambda$ but having the same values of $P$ and $K$. The procedure is illustrated in Figure 7 for $P=0.01$ and $K=1$; in this case, the area of view at the focal distance is equal to the area of the hexagonal array at the collimator face. In Figure $7 \mathrm{f} \lambda$ is plotted as a function of $\frac{R}{r}$ for several values of $N$ using equation (19) and as a function of $f$ for several gamma energies. In addition, $\frac{E}{\pi R^{4} / 16 f^{2}}=\frac{N}{\left(\frac{R}{r}+2\right)^{2}}=K r$ is plotted as a function of $\frac{R}{r}$. Suppose we wish to design a collimator for $\mathrm{Hg}^{203}(279 \mathrm{keV})$ having $\mathrm{f}=4^{\prime \prime}$ and $\mathrm{R}=0.5^{\prime \prime}$. Starting at $\underline{\mathrm{a}}$ in Figure 7 with $\mathrm{f}=4^{\prime \prime}$, $\mathrm{f} \lambda$ for $279 \mathrm{keV}$ is found to be 51 at $\underline{b}$. This value of $f \lambda$ occurs for $N=7$ and $N=19$ at $\underline{\mathrm{c}}$ and $\underline{\mathrm{d}}$. For $N=7, f \lambda=51$ when $\frac{R}{r}=\frac{2 f}{t}=0.71$; however, the seplum thickness is zero when $\frac{R}{r}=0.78$, and smaller values have no significance unless hexagonal holes are used. Even in that case, the 7hole collimator would be more than 11" thick and would require a crystal with a diameter at least 4.25". For $N=19, \mathrm{f} \lambda=51$ when $\frac{\mathrm{R}}{\mathrm{r}}=\frac{2 \mathrm{f}}{\mathrm{t}}=3$ (see $\underline{\mathrm{e}}$, Fig. 7). This implies that $\mathrm{r}=0.166^{\prime \prime}, \mathrm{t}=$ $2.66^{\prime \prime}$ and $\mathrm{D}=1.83^{\prime \prime}$. Also, for this value of $\frac{\mathrm{R}}{\mathrm{r}}, \mathrm{E}=\frac{\pi \mathrm{R}^{4}(0.75)}{16 \mathrm{f}^{2}}$ (see $\underline{\mathrm{f}}$, Fig. 7). The 7-hole collimator described above, with hexagonal holes, is more efficient, with $E=\frac{\pi R^{4}}{16 f^{2}}(0.95)$; however, the 19hole collimator shown in Figure $9 \mathrm{~b}$ is much easier to construct. This situation is analogous to to that described in the section on collimators for specified $R, f, S$ and $K$ where it was noted that when $\mathrm{K}$ is specified instead of $\mathrm{D}$, the most efficient collimator has the smallest number of holes satisfying the relevant equations. Again, practical considerations may dictate the construction of less efficient collimators having more holes. For larger values of $\mathrm{K}$, significant solutions may not exist for small values of $\mathrm{N}$; for example, for $\mathrm{K}=2$, no significant solutions exist for $\mathrm{N}=7$. In this case, the most efficient collimators tend to have 19 holes, while the 37 -hole collimators tend to have more practical dimensions of length and required crystal diameter.

\section{Construction of Focused Collimators}

The method of construction naturally depends upon the collimator material used and the shape of the individual channels. The casting technique described here is used for constructing 


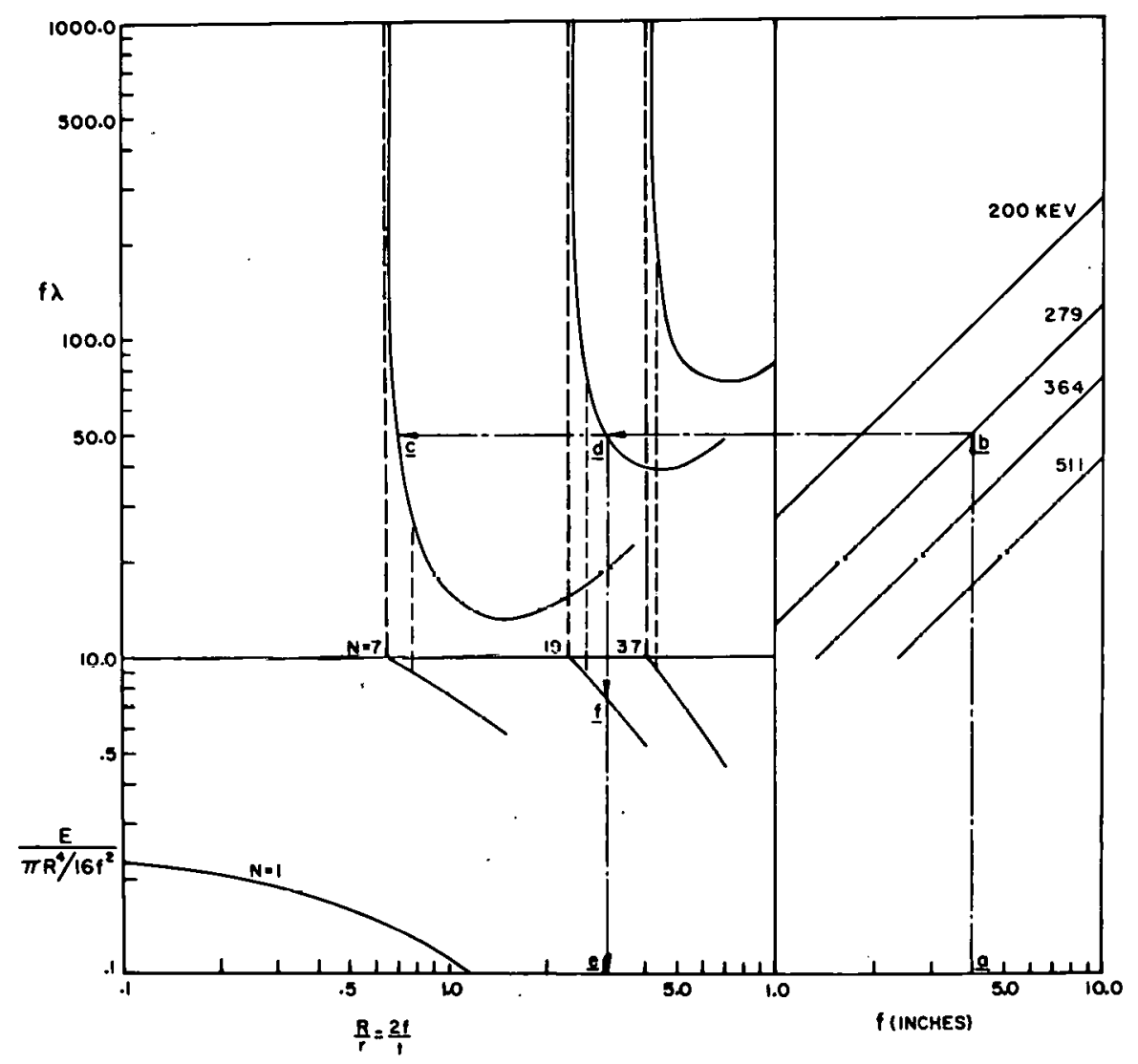

Figure 7. Graphical procedure for designing collimators having $P=0.01$ and "shape factor" $\mathrm{K}=1$. Letters a through $f$ indicate the design of the collimator shown in Figure $9 \mathrm{~b}$. See text.

lead collimators consisting of round tapered hules. The mold consists of round tapered steel rods held in place by upper and lower guide plates as shown in Figure 8 and surrounded by a thin stainless steel cylinder that serves as a protective jacket for the finished collimator. If the holes are few and fairly large, the rods can be tapered on a lathe; for many small holes, the tapered rods can be formed on a centerless grinder. Before assembling the mold, each rod is coated with a spray graphite lubricant (such as dgf 123, a product of Miracle Power Products Co.) which forms a thin protective film to prevent wetting of the steel rods by hot lead, and assures easy extraction of the rods from the completed casting. This is especially important if the septa are thin and fragile. The assembled mold is preheated in a furnace to about $500^{\circ} \mathrm{C}$, and the lead is heated to approximately $375^{\circ} \mathrm{C}$. Just before the casting is made, the surface layer of lead oxide is carefully removed to prevent its clogging the septa. For casting, a ladle large enough to fill the mold in a single pouring is used to prevent oxide interfaces. On cooling, lead shrinks appreciably and this tends to produce voids in the septa. These voids can be prevented by keeping the top of the casting melted with a torch as the lead solidifies from the bottom up, and adding more lead if necessary. The upper surface of the solidified casting (this fits against the crystal face) is not flat and must be "faced off." (Our practice is to design the mold so that the casting is somewhat thicker than the finished collimator is to be; this excess is then "faced off"). If the 


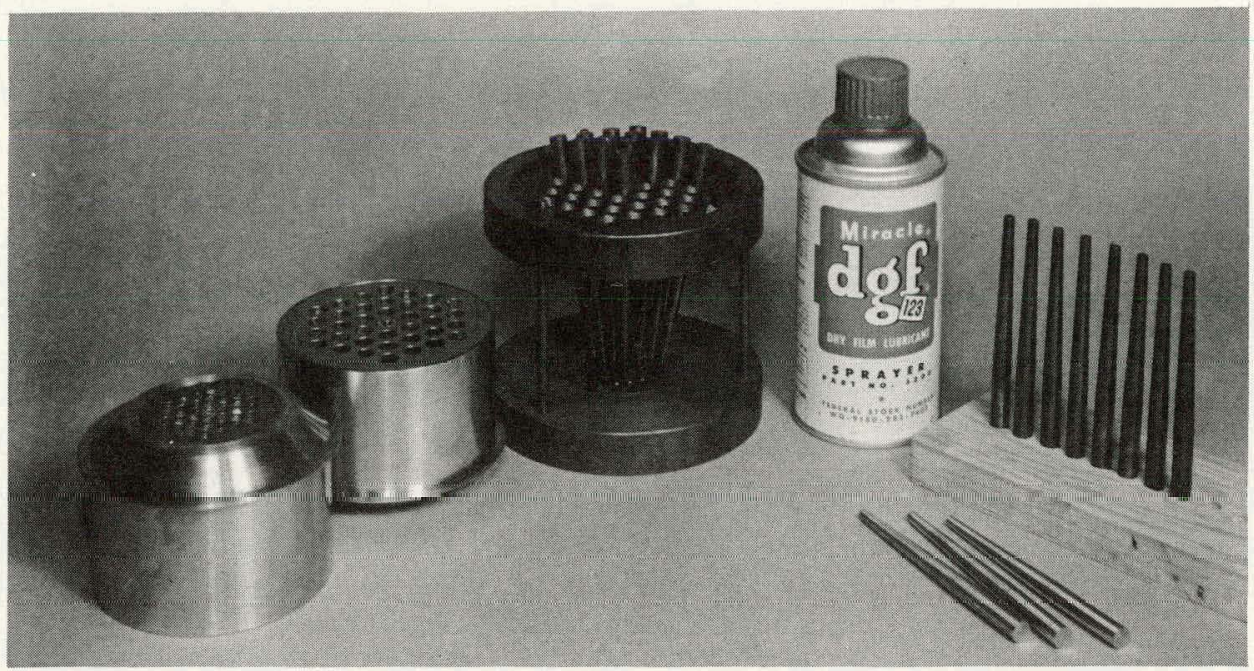

Figure 8. Center - Mold for casting lead collimators shown on the left. Stainless steel jacket was removed to show the lower guide plate for the tapered rods.

septa are fairly thick, this operation presents no problem; however, if the septum thickness is less than about $0.02 "$ ", special precautions must be taken. In this case, the collimator holes are filled with a molten mixture of approximately equal parts of graphite and sulfur, which has a melting point well below that of lead. On cooling, this forms a solid machinable mass which protects the fragile septa while the collimator is faced off in a lathe. The collimator holes are then opened by gradual heating in an oven until the sulfur-graphite mixture melts and runs off. The collimator is finally cleaned in an ultrasonic bath to remove any residual scale.

\section{Testing Collimators}

Tests for collimators can be divided, somewhat arbitrarily, into two categories: 1) those designed to determine the accuracy of equations for the theoretical response components; and 2) those designed to determine the "effectiveness" of the collimator for detecting nonuniformities in the source distribution.

The best known and most widely used test of collimator performance is the measurement of the response to a point source. These measurements are usually summarized in the form of isoresponse contour lines. Geometrical response can be determined by using a low energy point source, while penetration and scatter responses can be studied using sources of higher energy gammas. Measured responses have been compared with theoretical values by a number of writers. ${ }^{4,5}$

Analogous tests using uniform disc sources have been devised, and are in some ways more easily interpreted. Some of these tests are illustrated in Figure 9 for the "constant area" $(\mathrm{K}=1)$ collimator discussed in the section on collimators for specified $R, f, P, \lambda$ and $K$.

A detailed qualitative picture (see Figure $9 \mathrm{~b}$ ) of the point source response function can be produced by placing a uniform sheet distribution of $\mathrm{I}^{125}$ (27.4 keV x-rays) against the crystal side of the collimator and a sheet of film on the collimator axis in what is normally the source field. Photons passing "backwards" through the collimator expose the film. By reciprocity, this 

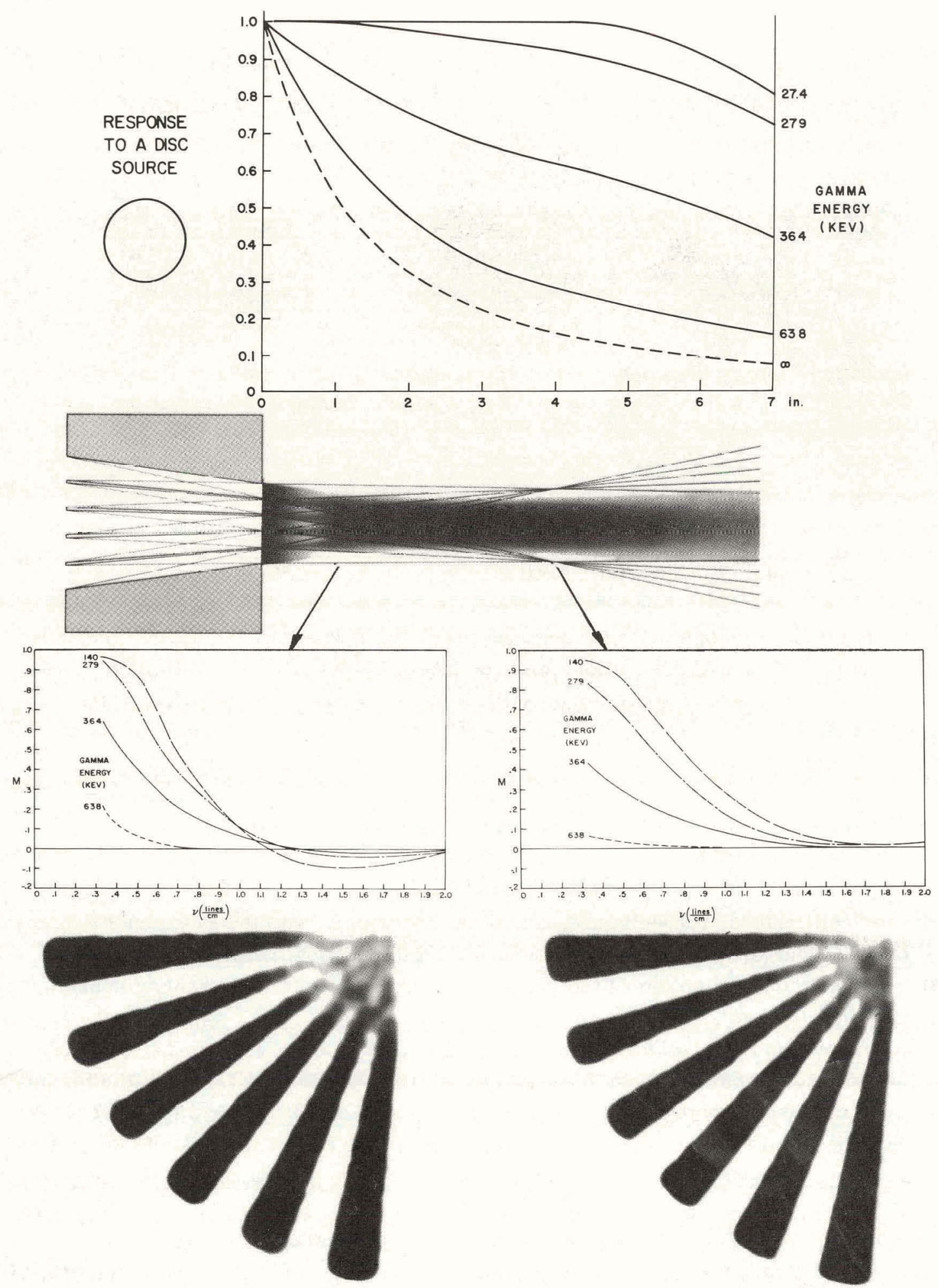

Figure 9. Four tests of a collimator for brain scanning with $\mathrm{Hg}^{203}(279 \mathrm{keV})$. Collimator was designed by the method illustrated in Figure 7. (a) Collimator response to disc sources just large enough to cover the field of view to the focal point. (b) Point source response pattern. (c) The modulation transfer function, $M$ at 1" and 4" from the collimator face. (d) Scans of radioactive sunburst pattern at 1" and 4". This test pattern was used to measure M. 
interchange of source and detector (film in this case) reproduces the geometrical response pattern provided that the film is not exposed by: a) scattered radiation, and b) photons which have penetrated the collimator septa. These conditions are approximately satisfied by $\mathrm{I}^{125}$.

Making use of the fact that the geometrical response to a uniform sheet distribution that covers the field of view is independent of the distance from the collimator, any decrease in response with distance is attributable to the effects of penetration or scatter. This is shown in Figure 9a, where response to a small disc source is plotted for several gamma energies. The effects of septum penetration and small angle scatter are not readily separated experimentally. Taking Mather's ${ }^{2}$ theoretical values of collimator scatter to be exact, the penetration response can be estimated. For example, on the basis of an 8 per cent decrease in count rate as the disc of $\mathrm{Hg}^{203}(279 \mathrm{keV})$ is moved to the focal distance, the combined penetration and scatter fractions can be estimated to be less than 10 per cent. For an omnidirectional source of this energy, the scatter fraction is approximately 3 per cent so that $\mathrm{P} \leq 7$ per cent experimentally. The theoretical value of $\mathrm{P}$ is approximately 1 per cent. In general, "order of magnitude" or better agreement with equation (17) has been observed.

An interesting exception has occurred in the case of the set of low energy collimators shown in Figure 4. Using a uniform disc of $\mathrm{I}^{125}$ covering the collimator face, the relative geometrical efficiencies of these collimators agree with theoretical values to within less than 2 per cent. However, for $\mathrm{Tc}^{99 \mathrm{~m}}(140 \mathrm{keV})$ the response of the thinnest collimator (with efficiency $4 \mathrm{x}$ $10^{-3} \mathrm{~cm}^{2}$ ) is about 30 per cent higher than would be expected. While the theoretical penetration fraction is highest for this collimator, at $140 \mathrm{keV} P$ is only 2.5 per cent. Differences in scatter from the septa for the three collimators are believed to be negligible at this energy. Thus, the accuracy of equation (17) for P appears to be somewhat less than "order of magnitude" in this case. It would appear that, when the septum thickness is much smaller than $\mathrm{t}(1-r)$, the estimate of $\mathrm{M}$ given in the section on construction of focused collimators may not be adequate. The estimate of $M$ based on a distribution of path lengths, referred to in the footnote to that section, leads to a penetration equation

$$
P=\frac{6 N}{\lambda^{3} t^{3}(2+\tau)(1-\tau)^{2 \tau 2}}
$$

It is interesting to note that for this equation, $\mathrm{P}$ is approximately 34 per cent for the above collimator, in close agreement with the observed 30 per cent excess over geometrical response. The general behavior of this alternative estimate of $\mathrm{P}$ has not been fully explored. Should it become important to estimate $\mathrm{P}$ more accurately, it may be necessary to develop several equations, each quite accurate in a limited energy range.

The problem of determining the "effectiveness" of a collimator for detecting lesions has two aspects. The choice of a suitable model or "phantom" and the choice of a suitable criterion for "effectiveness" are both somewhat arbitrary. The excellent work of different writers is sometimes difficult to compare because different models and criteria are used.

It appears that much of this work (both theoretical and experimental) could be discussed in terms of a concept which has been referred ${ }^{6}$ to as "sine wave response," "space frequency response," "modulation transfer function," "contrast transmission," etc. This function describes the detector response to objects of different sizes; more precisely, it describes the response to sinusoidal variations in the distribution of activity as a function of the space frequence expressed in lines/cm. This function can be determined approximately from the detector response to a 
"square wave" test pattern such as the Siemen's star ${ }^{*}$ in Figure 9d, consisting of alternate wedges of activity and no-activity. This pattern can be easily constructed from lucite sheets, and conveniently emptied and refilled with radioactive solutions through screw sealed access ports. In this case, the modulation transfer function, $M$ is defined by

$$
M=\frac{C_{t}-C_{o}}{C_{t}+C_{o}}
$$

where $C_{t}$ and $C_{O}$ are the maximum responses to source and no-source wedges respectively. $A$ plot of $M$ versus space frequency, $\nu$, (see Figure 9c) indicates the detector response to structures of decreasing size as $\nu$ increases. This function is quite sensitive to the shape of the point source response function, septum penetration, and scattered radiation, as indicated in Figure 9c (for penetration).

The "effectiveness" of a collimator for detecting lesions is dependent not only on this count rate "contrast" but also on the sensitivity; thus, a large change in count rate (or large $\mathrm{M}$ ) over a lesion does not assure its detection if the overall count rate is very low due to an inefficient collimator. These factors of sensitivity (as measured by $\mathrm{C}=\mathrm{E} \eta \sigma$ ) and contrast (as measured by $\mathrm{M}$, which serves as a generalization of collimator resolution) can be combined ${ }^{1}$ in a measure of effectiveness or figure of merit, $Q$, where

$$
\mathrm{Q}=\frac{\mathrm{C}_{\mathrm{O}}\left(\frac{\mathrm{C}_{\mathrm{t}}}{\mathrm{C}_{\mathrm{O}}}-1\right)^{2}}{4\left(\frac{\mathrm{C}_{\mathrm{t}}}{\mathrm{C}_{\mathrm{O}}}+1\right)}=\frac{\mathrm{C}_{\mathrm{O}} \mathrm{M}^{2}}{2(1-\mathrm{M})}=\frac{\mathrm{C}_{\mathrm{t}} \mathrm{M}^{2}}{2(1+\mathrm{M})}
$$

This quantity can be determined for any collimated detector and used as a criterion for comparing different systems. Clearly, the value of any such criterion (and others, equally plausible, can be formulated) must be determined by its usefulness in establishing improved scanning procedures.

\section{ACKNOWLEDGMENT}

The author is indebted to D. B. Charleston, P. V. Harper, M.D., and P. Eidelberg for many suggestions and constant assistance, and to J. J. Stupka, C. R. Brebach and B. W. Fromes for their complete cooperation in the construction of collimators and related equipment.

\section{LITERATURE CITED}

1. Beck, R. N. A Theory of Radioisotope Scanning Systems in These Proceedings, International Atomic Energy Agency Symposium on Medical Radioisotope Scanning, 1964.

2. Mather, R. L. Research and Development Technical Report USNRDL-TR-174 NS 081-001, 20 May 1957

3. Newell, R. R., W. Saunders, and E. Miller. Nucleonics, 10:36, 1952.

4. Myhill, J. Intern. J. Appl. Radiation Isotopes, 12:10, 1961.

\footnotetext{
${ }^{*}$ This test pattern is used in optics to measure $\mathrm{M}$ for lenses.
} 
5. Hefferlin, R. A., and W. E. Kreger. Research and Development Technical Report USNRDLTR-202 NS 081-001, 12 March 1958.

6. Perrin, F. H. J. Soc. Motion Picture Television Engrs., 69:March 151, April 239, 1960. 


\section{TECHNIQUES WHICH AID IN QUANTITATIVE INTERPRETATION OF SCAN DATA*}

By

D. B. Charleston, R. N. Beck, P. Eidelberg, and M. W. Schuh

As scanning systems have become more sophisticated and we more critical of artifacts, there has been a trend toward the increased use of auxillary equipment and techniques which aid in the interpretation of scan data.

Conventional scanning systems must be designed to avoid irrcgularities in mechanical function. Scanning speed and index step widths must be precise and consistent to avoid the introduction of modulation by speed variation and irregularities in line width structure. Studies of human perception indicate that contours which are discontinuous ${ }^{1}$ or imbedded in a system of parallel lines $^{2,3}$ tend to be concealed. In a fairly uniform scan picture (Figure 1) small gaps in mechani-

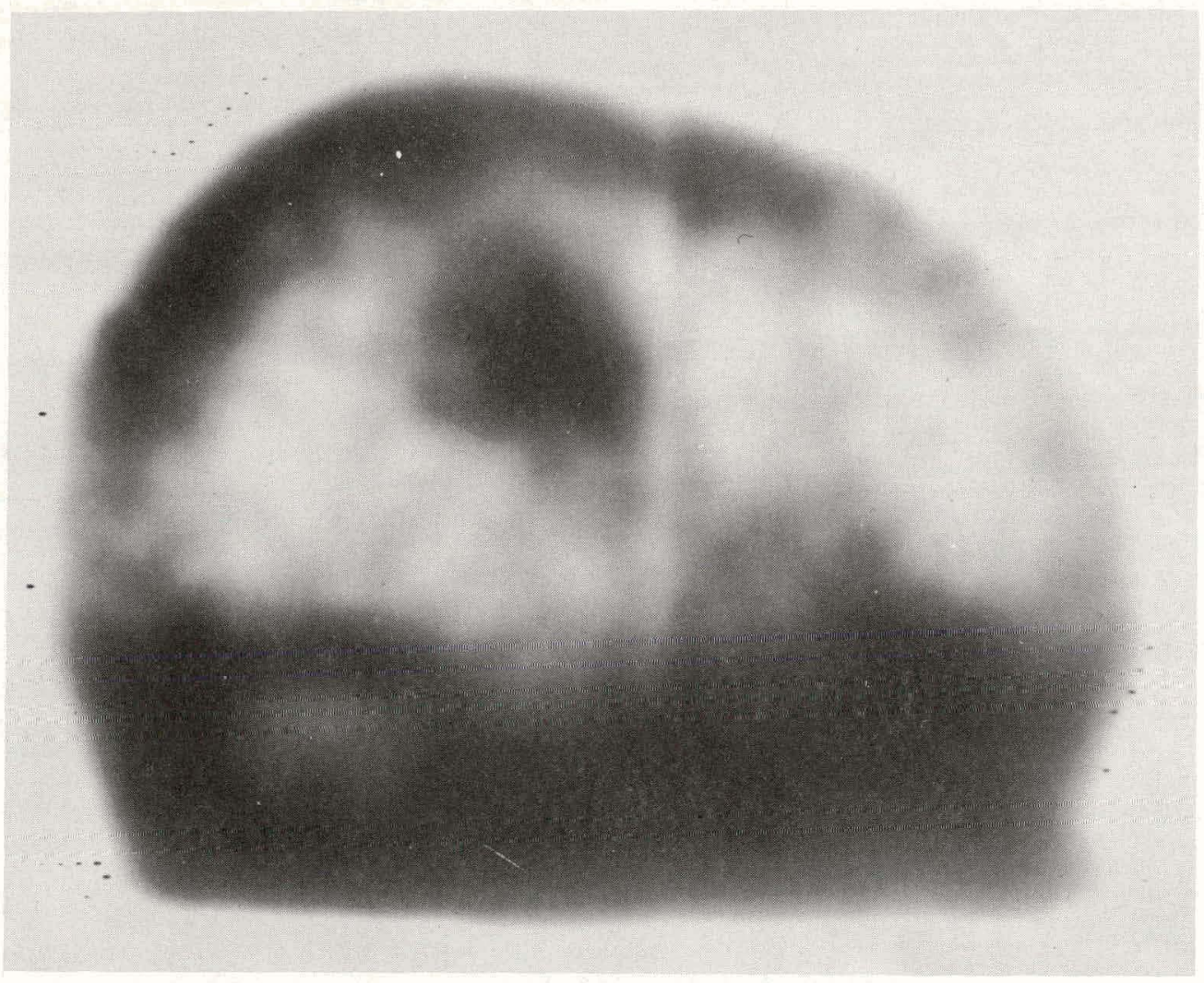

Figure 1. Reproduction of a scan readout film which demonstrates how obvious a small (0.008 inch) gap can be in an otherwise uniform and smooth display.

* This paper was presented at the IAEA Symposium on Medical Radioisotope Scanning in Athens, Greece, April 1964. It will appear in the Proceedings of the Symposium. 
cal operation can be most disturbing. For example, the line seen in the middle of the scan appears to be an omitted scan pass in our 0.0625 inch $(0.158 \mathrm{~cm})$ index step pattern. Actually it is a mechanical error which presents a gap of 0.008 inches $(0.02 \mathrm{~cm})$ between the two halves of the scan. It is most obvious to the eye and upsets the viewers' interpretation of the scan film. An overlap of the same magnitude is equally disturbing. Even with the elimination of machine-made irregularities, statistical deviations alone present the observer with enough confusion to warrant the use of aids for the interpretation of scan pictures. Some of the aids presented in this paper have been incorporated into the Argonne Cancer Research Hospital's brain scanning system, which has four scintillation detector channels (two on each side of the head) that operate simultancously.

The Argonne Cancer Research Hospital's brain scanning system produces two films simultaneously, each representing activity distributions for opposite sides of the head. The opposing pairs of detectors have direct mechanical linkage with the projector pairs which produce the Gaussian spots on separate films. It is possible to compare relative count levels on opposite sides of the head by film examination. An off-centerline "hot spot" or tumor will show a greater intensity on the film corresponding to the side nearest the tumor. A mid-line tumor will show equally well on both sides.

With relatively low energy isotopes, tumors on one side of the head are most likely to be seen by the detector on that side only: The opposing detector can sense very little because of attenuation through the greater path length in the head. It has been shown ${ }^{3}$ that the optimum energy for scanning a standard $16 \mathrm{~cm}$ head is approximately $100 \mathrm{keV}$, if scatter effects are neglected.

With use of higher energy gammas the off-center tumor may be seen by both detectors, and it becomes increasingly important to determine which side receives the greater number of counts so that tumor depth may be estimated.

The tumor position might be determined accurately by making both anterior-posterior and lateral scans of the head. In some cases however, the tumor may be evident in one view and hidden by normally active regions in line with the tumor in the other. In such cases additional data that aid in estimating the tumor position are most welcome.

The technique used to aid interpretation of scan data may be divided into two categories, digital (or numeric) and analogue.

\section{DIGITAL OR NUMERIC TECHNIQUES}

These techniques make use of the numbers of counts detected in small regions of the total area scanned.

When fast sweep speeds are employed, ratemeters and integrators are too slow to follow abrupt changes in count rate without spatial displacement or "scalloping," fast digital recording is therefore preferable to analog readout. A multichannel analyzer system was used as a digital data logging and readout device for feasibility studies. The digital recorder (in this case a multichannel analyzer) with a direct linear readout display is convenient for these measurements.

A multichannel analyzer used in the multi-scaling mode can be a useful aid for scan data interpretation. The technique is simple. Each single channel of a multichannel analyzer can be utilized to act as a separate scaler or count register for any predetermined interval of time, at the end of which the analyzer can be switched to the next higher channel or "scaler." The unit therefore can substitute for a number of scalers or counters. 
For use in scanning systems the multi-scalers can be employed to accumulate the total count for each scan sweep in a separate channel (every index step advances the multi-scaler to the next higher channel). This accumulated count-per-scan-line will hereafter be referred to as "count-per-index" to differentiate it from another method which uses the multi-scaler to accumulate counts within fixed increments of the distance along the sweep line. This approach will be referred to as the "count-per-increment" method.

The digital count-per-index data display is comparable to a linear scanner display obtained with a slit collimator, ratemeter and an analog readout. Both systems present a profile display along the axis of the region scanned.

The Argonne Cancer Research Hospital's small animal scanner system ${ }^{4}$ utilizes the countper-index technique to plot a profile of the distributed activity (Figure 2). The linear display feature of the multichannel analyzer is a direct quantitative aid to eye interpretation of the mouse scan photo readout below.

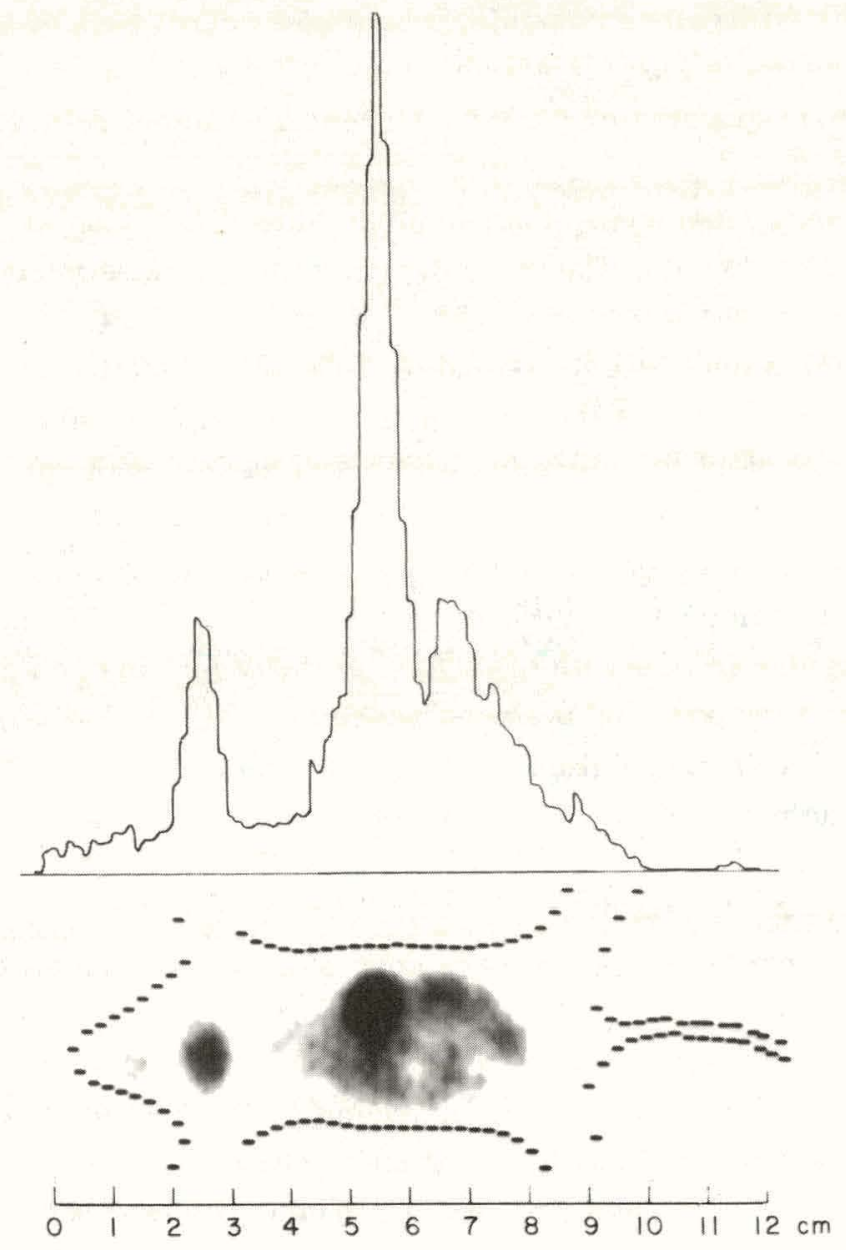

Figure 2. Upper - A profile graph of the activity distribution recorded on a multichannel analyzer. Lower - A scan picture presentation of the distribution of Tc $99 \mathrm{~m}$ in a mouse four hours after injection. Note the absence of gross line and spot structure. 
The scan in Figure 2 was produced by indexing horizontally with $1 / 24$ inch steps, and vertically with the scanning sweep motion. It is obvious that a profile display produced with the mouse rotated $90^{\circ}$ would be less helpful for interpretation of the scan picture. A combination of the two views might be of help, but a repeat scan would be necessary.

From the data accumulated in this way it is possible to determine quantitatively the total amount of activity in the animal (a sum of all counts accumulated, divided by the scan time over the animal), and the percentage of total activity in any region of the scan.

Scanning of large organs presents a much more complex problem to this method of quantitative interpretation of data. For large, usually rectangular scans of liver, pancreas, lungs, kidneys, thyroids or brain, the count-per-index system will accumulate information about activity within the entire rectangular scan region in such a way that it is impossible to separate regions of interest from regions of non-interest that are in the same line as the scan sweep.

A more useful technique for large area scans can be achieved by producing a profile display for each scan sweep.

Studies have been made using the Argonne Cancer Research Hospital's brain scanning system with multichannel analyzer in the multi-scaling mode, where each channel corresponds to the count accumulation in $1 / 4$ inch $(0.635 \mathrm{~cm})$ increments along each scan sweep.

A simple phantom study was undertaken to establish the feasibility of the count-per-increment method, using as phantom a 6 -inch diameter $(15.24 \mathrm{~cm})$ plastic container filled with a mercury solution containing $0.2 \mu \mathrm{c}$ per cc of $\mathrm{Hg}^{203}$.

Three "tumors" were positioned off center line in the container (Figure 3). These tumors were made up as 1 inch, $3 / 4$ inch and $1 / 2$ inch diameter spheres, each filled with $\mathrm{Hg}^{203}$ in a concentration 7 times that of the surrounding liquid to simulate a 7 to 1 uptake ratio.

Scans were made with $1 / 16(0.158 \mathrm{~cm})$ index steps, each scan sweep being broken up into $1 / 4$ inch sections which were recorded sequentially in separate channels of a multichannel analyzer.

Each scan sweep profile accumulation was stored on magnetic tape, and adjacent profiles were summed in blocks of 4 to construct a matrix layout of $1 / 4 \times 1 / 4$ inch squares over the scanned area (Figure 4). The readout film was analyzed by direct comparison with a number overlay on the film.

By photographing the count-per-increment digital readout in a slightly displaced sequence, an apparent three-dimensional display is produced (Figure 5) which can be compared directly with the readout photograph. Position information must be retained to interpret this count rate profile.

The curve $\mathrm{A}$ in Figure 5 is equivalent to the count-per-index accumulation display and represents the sum of all the curves on the left side of the picture. Curves B and C indicate positively that there is increased activity in two of the tumors. Display $\mathrm{D}$ is made by scanning off the tumor region and it outlines the container activity alone. The series of curves gives a better insight into the count distribution over an area of interest.

A model (Figure 6) was constructed using the digital information obtained from the phantom studies previously described. The numbers displayed in the matrix of Figure 4 were used to determine the scale length of the $1 / 4$ inch diameter rods. To make a model for each scan would be unreasonable, but the example does demonstrate the difficulty inherent in the detection of small tumors in a large volume of surrounding activity with any degree of statistical validity. 


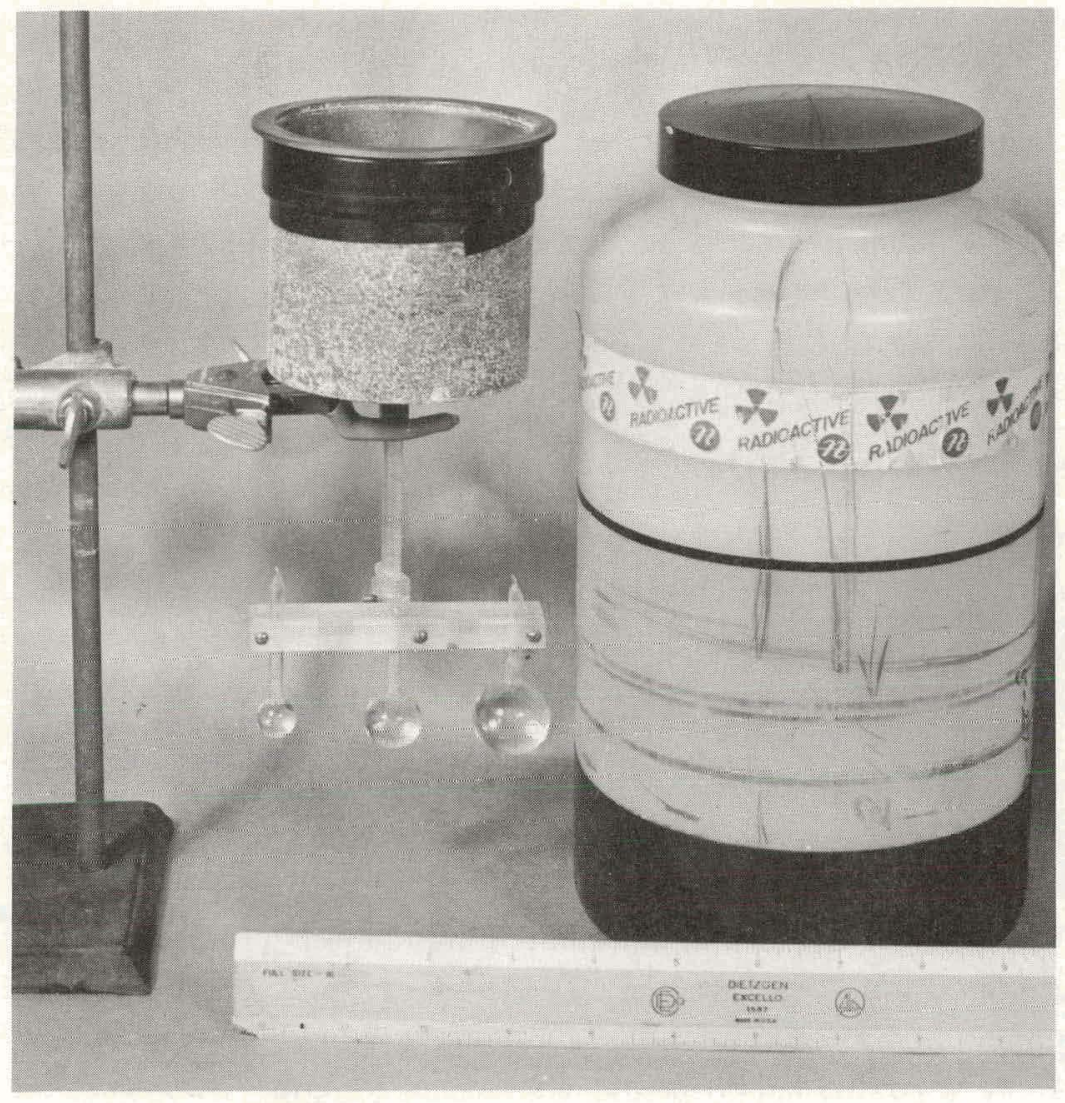

Figure 3. Photograph of the "head" phantom used to produce test films and data for both digital and analog data processing. The sealed glass vials represent the "tumors" which may be positioned anywhere within the container.

It can be seen from the model that the $1 / 2$ inch "tumor" (Figure $6 \mathrm{~A}$ ) would not have been verified from the scan photograph. There is a faint indication on the film, but statistically this would not justify a positive decision. The same scan made with contrast enhancement can produce a darker spot in this region, but is likely to produce a "false positive" spot in some other region due to statistical fluctuations.

Data accumulated and stored by the multi-scaling method can be presented by tape to a digital computer programmed to produce a series of matrices with numbers printed in each area cell similar to the small section shown in Figure 4 from which our model was constructed. A series of cell areas with varying sizes can be printed out by the computer, summing groups of smaller cells to make a coarse cell matrix. A two-dimensional matrix display of this type is difficult to interpret by itself, but is useful as an overlay on a film readout for direct comparison.

A 7094 computer was programmed to perform a variety of statistical measurements on such matrices of numbers, with the idea of comparing each cell with its neighbors (or groups of neighbors) to determine whether or not the measurements were significantly different. It might be expected that any tumor that was detectable by visual inspection could be found with at least equal reliability by a computer programmed to determine the statistical significance of the data. Al- 


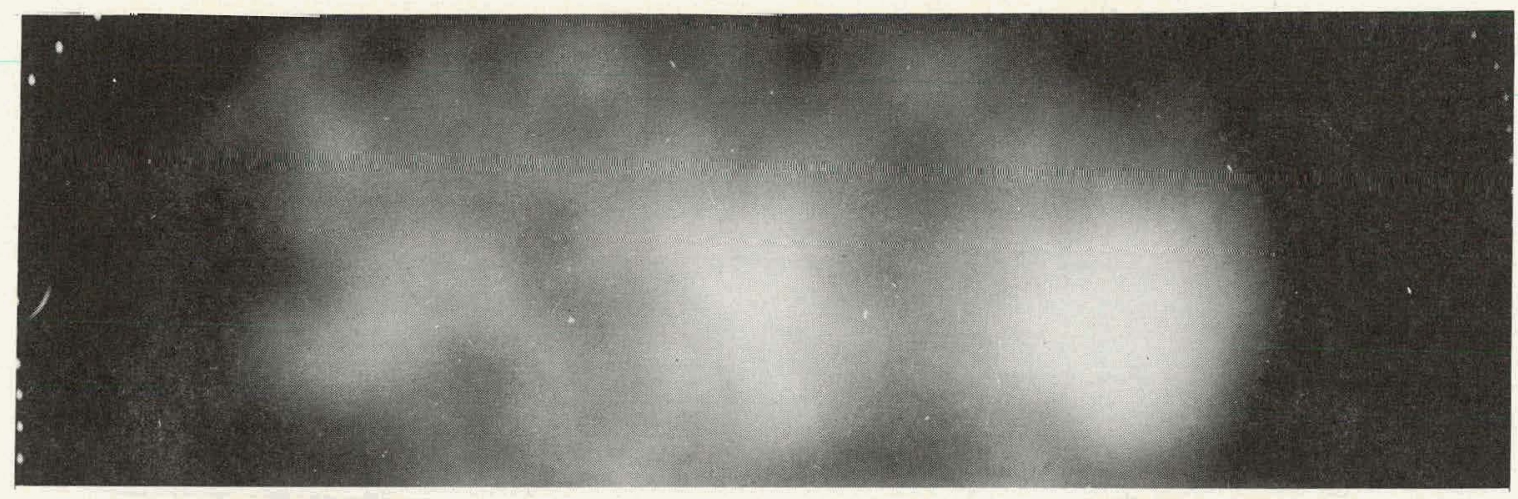

\begin{tabular}{|c|c|c|c|c|c|c|c|c|c|c|c|c|c|c|c|c|c|c|c|c|c|c|c|}
\hline 1 & 2 & 3 & 4 & 5 & 6 & 7 & 8 & 9 & 10 & 11 & 12 & 13 & 14 & 15 & 16 & 17 & 18 & $: 9$ & 20 & 21 & 22 & 23 & 24 \\
\hline 49 & 72 & 111 & 124 & 130 & 140 & 144 & 147 & 147 & 150 & 152 & 158 & 147 & 150 & 139 & 147 & 150 & 155 & 144 & 140 & 120 & 100 & 72 & 40 \\
\hline 46 & 86 & 125 & 126 & 132 & 145 & 137 & 150 & 140 & 156 & 159 & 175 & 139 & 154 & 140 & 151 & 149 & 149 & 130 & 158 & 121 & 108 & 80 & 35 \\
\hline 45 & 83 & 102 & 116 & 127 & 125 & 134 & 172 & 143 & 170 & 144 & 166 & 171 & 153 & 162 & 163 & 180 & 183 & 164 & 167 & 124 & 113 & 73 & 33 \\
\hline 47 & 75 & 110 & 129 & 120 & 140 & 157 & 147 & 156 & 163 & 167 & 193 & 167 & 170 & 129 & 164 & 195 & 214 & 204 & 152 & 134 & 108 & 76 & 41 \\
\hline 51 & 79 & 116 & 130 & 147 & 154 & 162 & 165 & 143 & 197 & 174 & 197 & 194 & 159 & 169 & 171 & 219 & 208 & 242 & 190 & 144 & 99 & 91 & 31 \\
\hline 52 & 89 & 111 & 133 & 133 & 158 & 130 & 156 & 145 & 170 & 167 & 162 & 145 & 152 & 169 & 157 & 178 & 207 & 190 & 168 & 128 & 115 & 79 & 41 \\
\hline 56 & 89 & 92 & 124 & 132 & 155 & 138 & 167 & 159 & 146 & 173 & 166 & 160 & 167 & 135 & 159 & 152 & 165 & 146 & 145 & 145 & 100 & 86 & 49 \\
\hline 46 & 80 & 109 & 121 & 135 & 141 & 143 & 145 & 157 & 135 & 147 & 153 & 152 & 154 & 163 & 115 & 159 & 159 & 154 & 124 & 110 & 98 & 68 & 24 \\
\hline
\end{tabular}

Figure 4. A photocopy of a film readout made from a phantom scan is shown over a matrix display of the actual counts accumulated per unit area during the scan.

though several (admittedly simple) programs were tried, they tended to reveal more problems than they solved. The statistical analysis may be formulated as follows. If No and Nt are the numbers of counts in adjacent cells, the question is whether or not these counts come from the same "population" or the same true mean count rate. Such counts are Poisson distributed and therefore have standard deviations of No and Nt respectively. The difference, (No - Nt) has a standard deviation of $\sqrt{\mathrm{No}+\mathrm{Nt}}$. To test the statistical significance of the difference we form the "null hypothesis" that the observed counts do in fact represent the same count rate. This hypothesis is rejected whenever the observed difference exceeds a certain "critical level" corresponding to a certain number of standard deviations. The standardized variable, $Z$, is defined by $Z=$

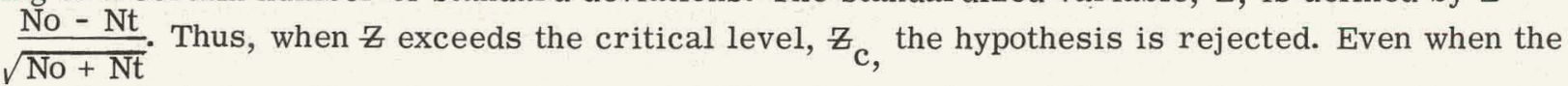
hypothesis is true, there is a certain probability of observing a difference that exceeds the critical level, and this probability depends on where $z_{c}$ is set. For $z_{c}=1$, the probability of deciding incorrectly that the count rates are different is about 32 per cent; for $z_{c}=2$, this probability drops to about 5 per cent. By making $z_{c}$ large, this kind of error ("false positive" or error of the 1st kind; also called a error) can be made arbitrarily small, resulting in an increased probability of deciding that there is no difference when one actually exists (this amounts to not finding tumors which exist, and is sometimes called an error of the 2nd kind or a $\beta$ error). One 


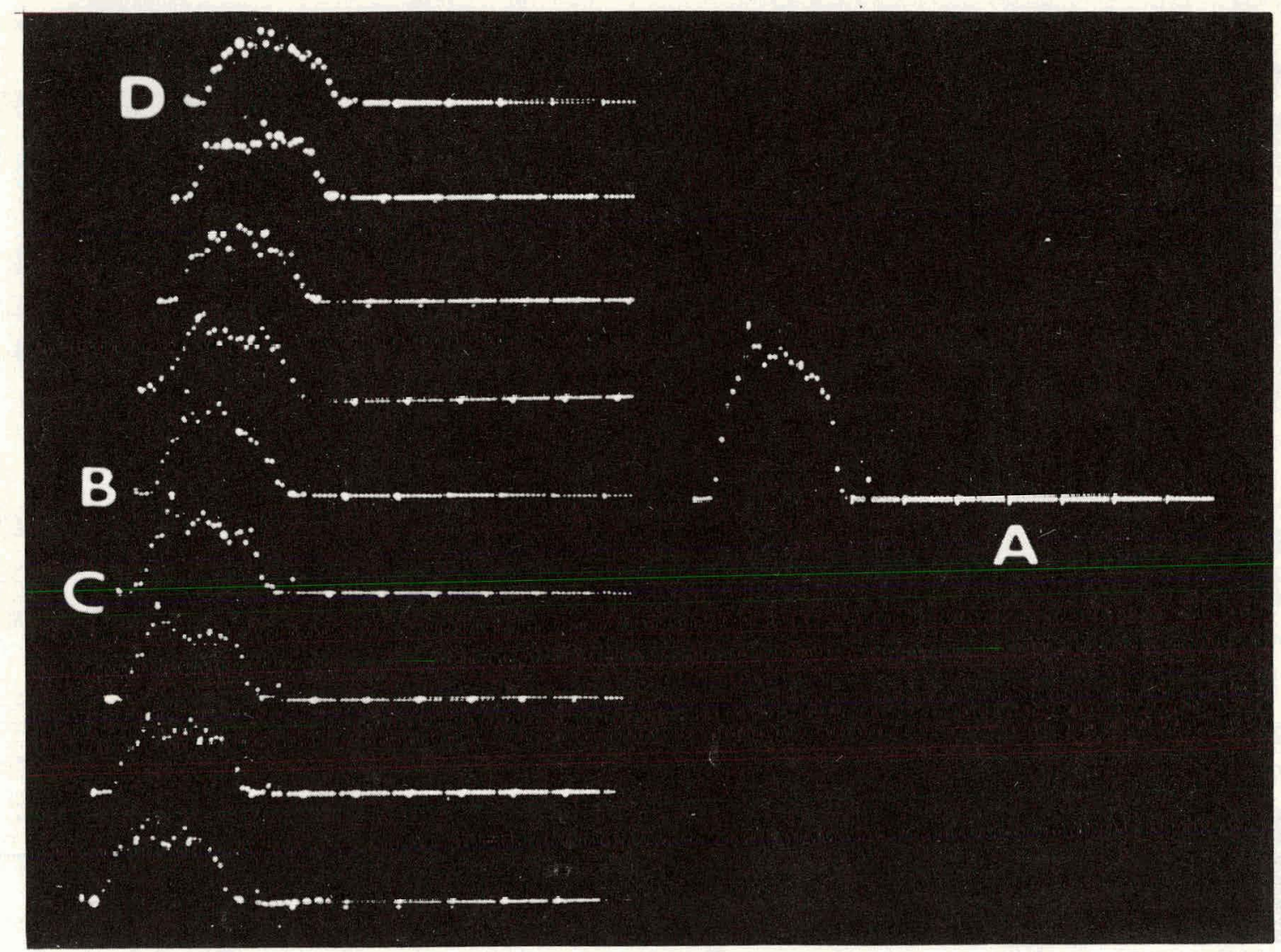

Figure 5. Reproduction of a polaroid photograph of displaced scan sweep count rate profiles. Nine "slices" are displayed on the left, and the sum of these profiles is shown at the right.

solution is to set the critical level, $z_{c}$, midway between zero and the observed standard variable; that is $z_{c}=\frac{Z}{2}$. This indicates the value that might be given $z_{c}$ to establish a test that would take into account both types of error.

Stored data from the matrix and film strip shown in Figure 4 demonstrate the digital computer techniques used in search for a method to aid in the evaluation of scan data.

In this simple example the smallest unit area "cell" was the $1 / 4$ inch square. The counts per unit cell varied from about 40 to 240 counts, with an average of approximately 120 counts. A tumor will present itself as a sum of counts over an area which is proportional to the cross-sectional area of the tumor. To determine the presence of a tumor from the stored data, the number $z_{c}$ as defined previously was calculated for any two given areas. The problem of defining the area which is to be compared to the unknown tumor area was approached in three different ways.

The computer was programmed to determine the $z_{c}$ between a unit cell area with each of its neighbor cells, with the average for any three neighbor cells, and with the average for the sum of its eight neighbor cells.

These three methods offered little in the way of a definite demonstration of tumor size or location when referred to the model of Figure 6. Other computer programs have been written to compare the unit cell with groups of adjoining cells. This study is still under way and the results will be presented in a subsequent paper. It could be argued that the cell and area sizes selected 


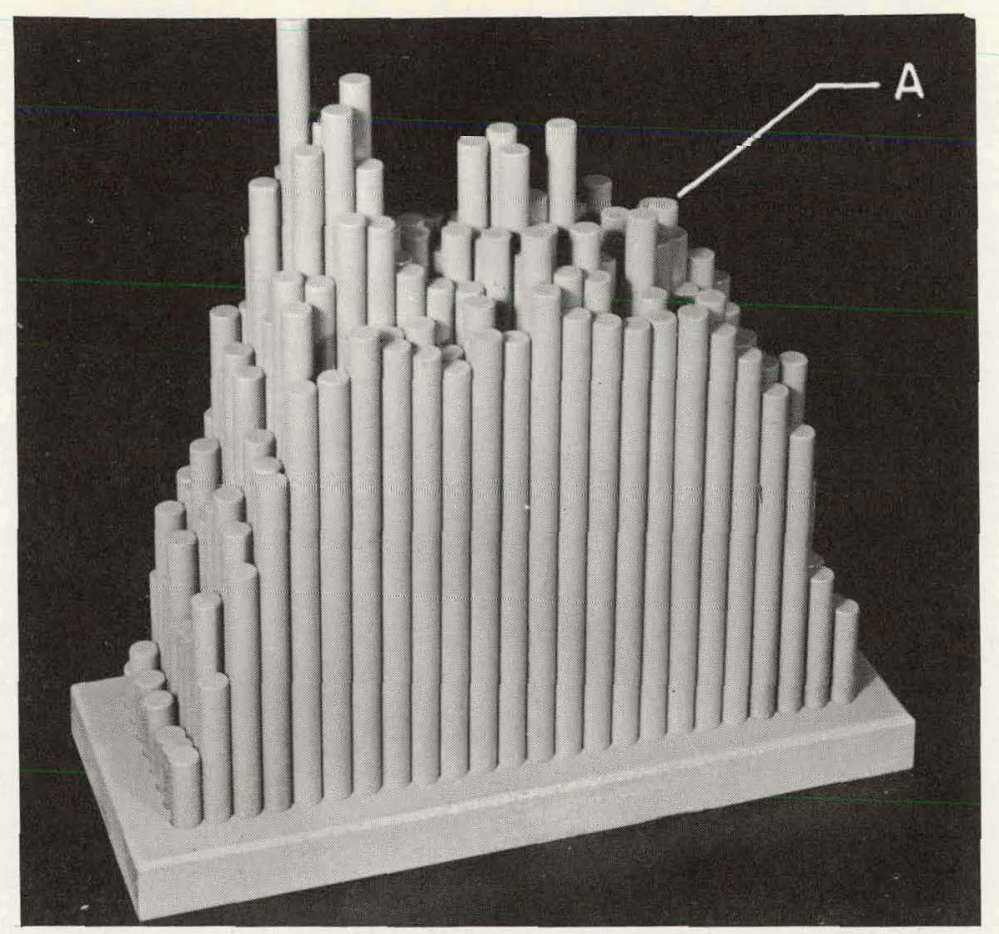

Figure 6. Photograph of a model constructed using the data accumulated from a brain phantom scan. The rod lengths were scaled to represent the numbers stored in the matrix of Figure 4.

for comparison were too small, but it would be almost impossible to define these areas without some pre-knowledge of the suspect region.

A fourth method, which used the information derived from the film readout was employed. The indicated tumor areas were compared with areas around the tumor that were equivalent in terms of their geometric form as well as size. These calculations were considered meaningful, and confirmed the opinion that a small tumor could not be verified with any degree of confidence.

A digital computer can be programmed to produce contour displays from stored scan data. Contour studies have been made of frequency distributions obtained from multi-parameter analyzers for fission fragment experiments. ${ }^{6}$ The basic studies differ, but the data display and reduction techniques are directly applicable to scanning data reduction.

Contour plots can be generated by computer from the digital numbers obtained per unit area from a scan matrix but these plots are sensitive to the pre-selected contour intervals. Peaks can be falsely indicated or omitted by selection of improper intervals. If many intervals are taken the observer is faced with a massive quantity of information, a wide range of contours, and great numbers of false peaks. It is more difficult to evaluate a series of contour plots produced by a computer than it is to analyze a film readout display directly by eye.

Although much has been done to improve digital computer analysis and readout presentation of virtual three-dimensional information, especially in the field of nuclear physics utilizing multi-parameter analyzers, the programs are highly sophisticated, the auxillary equipment is expensive and the machine time is considerable. 


\section{ANALOG TECHNIQUES AS AIDS FOR INTERPRETATION OF SCANNING DATA}

Film can be used as both a readout display and a storage medium for further data reduction. It is possible to operate on the information content of the film to obtain considerable aid to quantitative interpretation.

The logarithmic response of film permits it to accept several decades of exposure between the lower fog level and the upper saturation region. If each detected event produces a spot density just above the fog level of the film, it is possible to display one or one thousand spots in one place without reaching the saturation level. This rate exceeds the highest expected display rate in any one spot because the scanner is always moving.

Counts are stored on film as they are detected without the "cell size" position ambiguity inherent in direct digital data logging for computer use.

Provided no data manipulation such as enhancement control, background erase, integrating circuitry time lag, or mechanical modulation, enter intn producing the film 1 eaduul, it is possible to store and retrieve nearly all information from the film and to perform the data manipulation with simple inexpensive auxillary equipment. Contrast enhancement and background erase manipulations can be performed on the film readout after the scan is completed by the closed circuit television enhancement technique introduced by M. A. Bender in $1959,{ }^{7}$ or by direct photocopy of the original with different contrast film and/or varying exposures (Figure 7). The closed circuit television method has advantages in that it is simple to operate and the original film can be examined visually for direct comparison with the television picture.

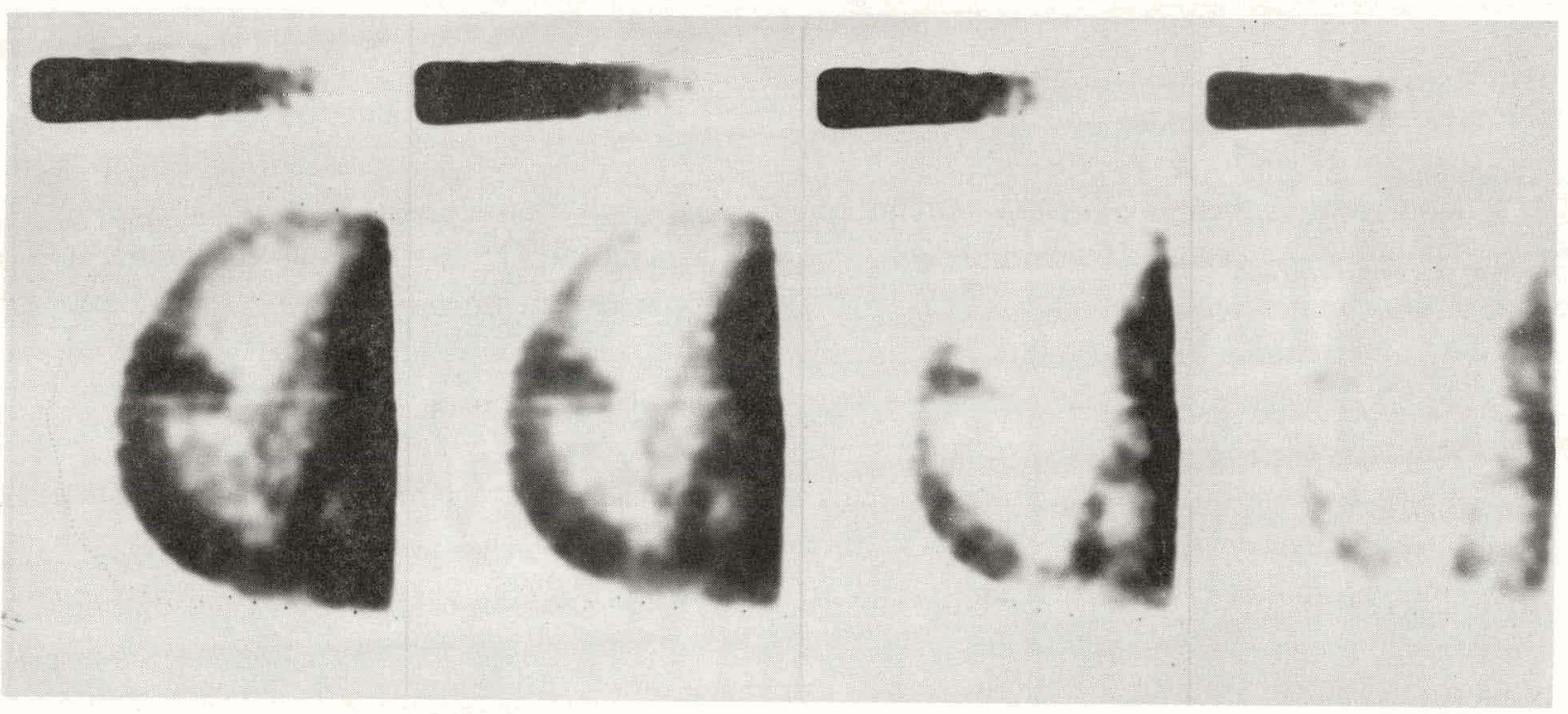

Figure 7. A series of photocopies which were made by varying the exposure time for printing. The same effect can be accomplished by use of closed circuit television enhancement.

The Argonne Cancer Research Hospital's brain scanner has an internal calibration system which produces a graduated step-wedge display of random pulses. This unit has been a valuable aid to quantitative analysis of scan film displays (Figures 8 and 9). 


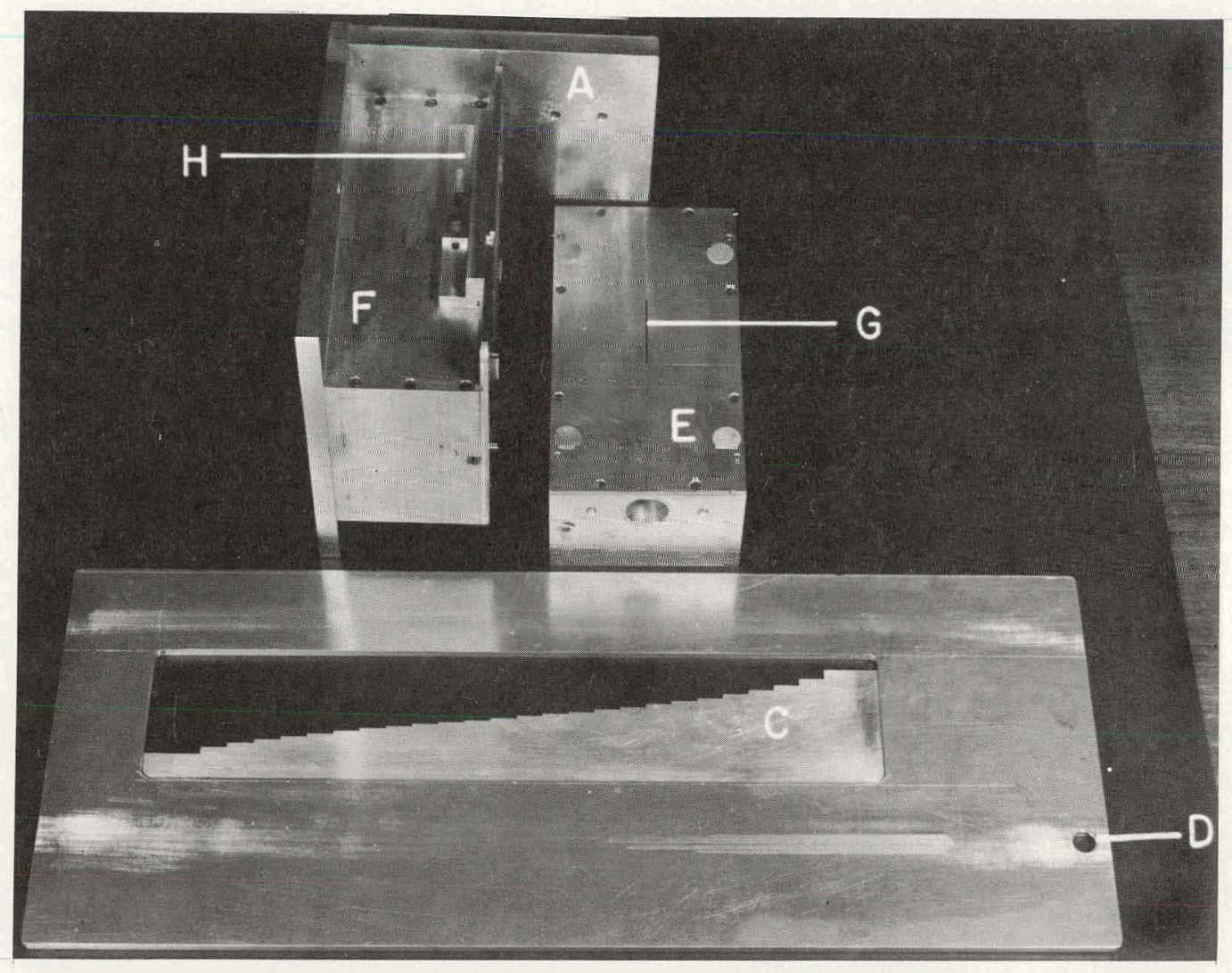

Figure 8. Photograph of component parts of the step-wedge calibration device which is permanently mounted to the brain scanner.

The basic components of the step-wedge calibrator are: a line source of $\beta$ activity (thallium-204), a low (0.76 MeV) energy $\beta$ with a fairly long half-life (3.6 years), a stepped windowlike shield (C) and a simple geiger counter detector system with a shield (E). The line source is sealed in a thin polyethylene tube which is inserted (B) into a shield consisting of an aluminum inner liner (to eliminate Bremsstrahlung radiation) and a lead outer shield ( $\mathrm{F}$ ). The source is held vertically in the same plane as the geiger tube center wire. Both the geiger tube and the line source have slit collimation $(G)$ to ensure good resolution of the step-wedge. The source collimation slit is made adjustable $(\mathrm{H})$ to correct for the beta source half-life.

The step-wedge $(C)$ is made of an aluminum-lead-aluminum laminate to prevent Bremsstrahlung radiation effects. The step-wedge window is designed to generate 20 per cent changes in count rate per step for 26 steps over the count rate range of 100 to $9500 \mathrm{cpm}$ as the window is drawn between the source and detector. The detector and sourcc shields are held in a frame (A) and mounted to a stationary part of the machine, and the step-wedge window is fastened at (D) to the moving scan mechanism so that it may be drawn back and forth between the source and detector. As the unit scans, a graduated line of exposure densities is projected on a section of the film by the same projector light system used for producing the actual scan picture. The width of this calibrated exposure wedge can be adjusted by changing the number of index steps used. 


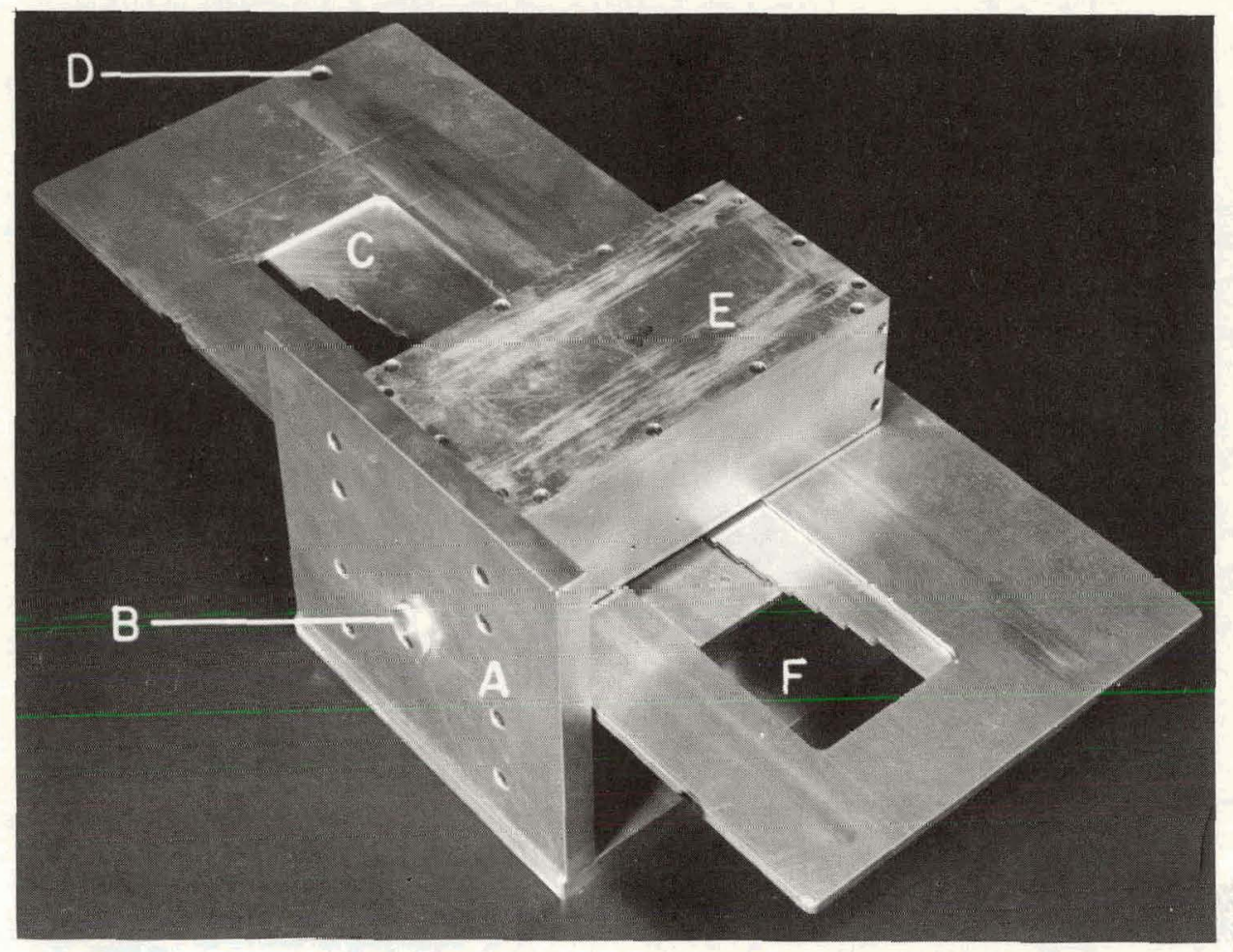

Figure 9. Assembled step-wedge random pulse calibrator.

A device of this type, constructed for use with the Argonne Cancer Research Hospital's brain scanning system, has been a valuable aid for film interpretation. Similar units will be incorporated into our other scanning systems.

Although the unaided eye can compare any region of a scan picture's exposure density to an equivalent exposure density on the calibration wedge, it is even more helpful if viewed by means of the closed circuit television technique. As the contrast and intensity controls are varied, regions of interest can be enhanced or erased, and equivalent regions on the calibration wedge will be enhanced or erased to the same degree. One can quickly evaluate the density of the darkest spot on the scan picture by erasing all but that region and comparing it directly against the remaining edge of the exposure wedge (Figure 7). Exposure densities of 20 per cent differences can be distinguished.

A densitometer or flying-spot-scanner can be used to plot film density contour lines (count rate contours) to aid the visual interpretation of films. Provided that the film exposure densities are continuous, useful flying-spot plots of contour lines can be made without gross line or spot structure. Small index steps, fast scanning, and projection of relatively large Gaussian spots on film, are combined to produce smooth film displays from the Argonne Cancer Research Hospital's brain scanner.

A comparison of contour plots made from films that contained identical statistical data but used different spot sizes is shown in Figure 10. The larger 1/2 Gaussian spots produce a smoother picture and smoother contour lines. One-quarter inch Gaussian spots produced the more ragged less informative contour plot. 
A typical brain scan isodensity plot is shown in Figure 11. The upper picture was produced by normalizing the upper level of the isodensity plotter to the most dense region on the film and
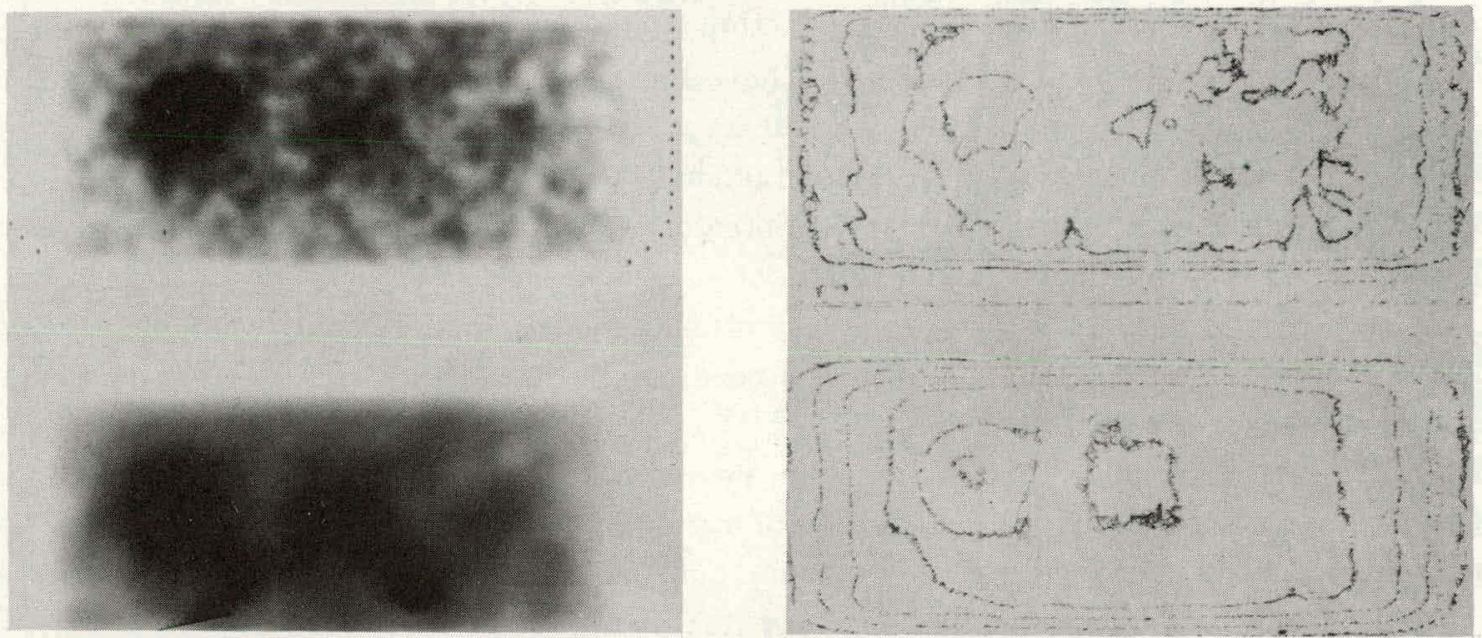

Figure 10. Photographs of isodensity contour plots made from the films on the left. The spot sizes used were 1/4 inch Gaussian for the upper pictures and 1/2 inch Gaussian for the lower pictures.

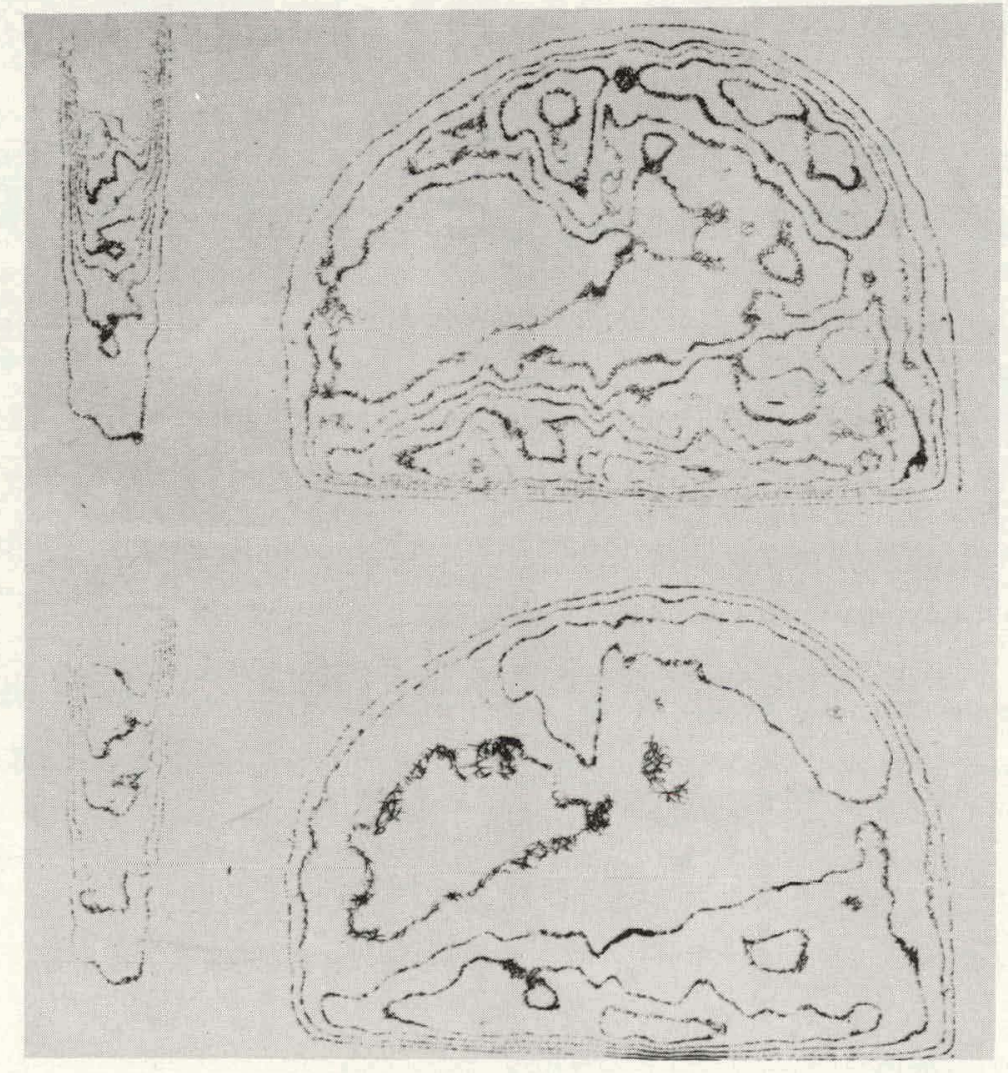

Figure 11. Upper - Photograph of a brain scan contour plot showing six contour intervals. Lower - The same scan showing only four contour intervals. In both cases the top line of the step-wedge on the left indicates the level of the most dense spot on the film. 
then plotting the 90 per cent, 80 per cent, 60 per cent, 40 per cent, 20 per cent and 10 per cent contour lines. The lower picture shows only the 90 per cent, 80 per cent, 50 per cent and 20 per cent lines. The full range of isodensity lines at 10 per cent intervals can be plotted simultaneously or singly at any density level selected. These lines can be compared with the calibration step-wedge by mapping each contour level separately and noting the corresponding line or the wedge. A flying spot scanner system would be faster and more versatile. A dual beam system is at present being devised which will combine the features of the closed circuit television readout and the isodensity plotter and will be used to compare count rate information contained in the two films (left and right sides of the head) produced simultaneously by the brain scanner. A simple analog system will be arranged to compute and read out the per cent differences in count rate between identical regions on the two films.

While the digital techniques offer accurate, undistorted (except for finite cell size), rccording of the scan data, the computer techniques for manipulating the data are quite complex. The analog techniques are less accurate, in the sense that the numerical data is lost, but appear presently to offer a wider range of simple convenient manipulative procedures.

\section{ACKNOWLEDGEMENTS}

The authors wish to thank Dr. L. O. Jacobson and Dr. Paul V. Harper for their continued interest and active support of these studies.

\section{LITERATURE CITED}

1. Titchner, E. B. A Textbook of Psychology, New York, Macmillan Co., 1911, p. 327.

2. Osgood, C. E. Method and Theory in Experimental Psychology, New York, Oxford Press, 1953 , p. 230.

3. Woodworth, R. S., and H. Schlosberg. Experimental Psychology, New York, Henry Holt, 1956 , p. 415.

4. Harper, P. V., R. N. Beck, D. Charleston, and K. A. Lathrop. Nucleonics, 22:50, 1964.

5. Beck, R. N., and D. Charleston. Intern. J. Appl. Radiation Isotopes, 15:101, 1964

6. Proceedings, Conference on the Utilization of Multiparameter Analyzers in Nuclear Physics, November 1962, Columbia University, New York. Office of Technical Services, Department of Commerce, Washington, D.C. CU(PNPL)-227, NYO-10595.

7. Bender, M. A., and M. Blau. In Medical Radioisotope Scanning STI/PUB/3. International Atomic Energy Agency, Vienna, 1959, p. 31. 


\section{STAFF PUBLICATIONS}

Beck, R. N., and D. B. Charleston. A small-animal scanning system. Intern. J. Appl. Radiation Isotopes, 15:101, 1964.

Chow, D. C., S. Rothman, A. L. Lorincz, F. Malkinson, and A. Sandburg. Reduction in rate of hair growth in mice as an lindlialor of expoouro to chronir lnw dosage ionizing radiation. (Abstract). Rad. Res., 22: No. 1, May 1964.

Dukes, P. P., F. Takaku, and E. Goldwasser. In vitro studies on the effect of erythropoietin on glucosamine-1-14C incorporation into rat bone marrow cells. Endocrinology, 74:960, 1964.

Gallien-Lartigue, O., and E. Goldwasser. Hemoglobin synthesis in marrow cell culture: the effect of rat plasma on rat cells. Science, 145:277, 1964.

Glickman, P. B., R. H. Palmer, and A. Kappas. Steroid fever and inflammation. Arch. Internal Med., 114:46, 1964.

Gurney, C. W., D. Hofstra, E. Simmons, and C. Newton. Quantitation of erythroid hypoplasia in mice following irradiation. (Abstract). Rad. Res., 22: No. 1, May 1964.

Gurney, C. W. Dynamics of the stem cell compartment. Reprinted from the proceedings of the IX Congress of the International Society of Hematology, Vo. III, held in Mexico City, September 1962 , p. 355.

Heinrikson, R. L., and E. Goldwasser. Studies on the biosynthesis of 5-ribosyluracil 5'-monophosphate in Tetrahymena pyriformis. J. Biol. Chem., 239:1177, 1964.

Lanzl, L. H., and J. H. Pingel. Radiation accidents and emergencies: Science, 143:1352.

Lanzl, L. H. Particle accelerators. In Atomic Medicine, fourth edition, ch. 27, Admiral C. F. Behrens, Ed., Baltimore, The Williams and Wilkins Co., 1964, p. 615.

LeRoy, G. V. Carbon-14 in clinical research. Science, 144:731, 1964.

Mendel, G. A., and R. J. Weiler. Observations on the gastrointestinal absorption of iron in experimental hypoplastic and iron-deficiency anemias. Reprinted from the proceedings of the IX Congress of the International Society of Hematology, Vol. III, held in Mexico City, September 1962 , p. 289.

Mendel, G. A. Iron metabolism and etiology of iron-storage diseases. J. Amer. Med. Assoc., $189: 45,1964$.

Mendel, G. A. Increased iron absorption during liver regeneration induced by partial hepatectomy. J. Amer. Med. Assoc., 189:369, 1964.

Newton, C. M., R. J. Hasterlik, M. Gazda, and D. Garigan. Computer correction for various absorptive effects in total-body counting. (Abstract). Rad. Res., 22: No. 1, May 1964.

Norman, A., and R. H. Palmer. Metabolites of lithocholic acid-24-C ${ }^{14}$ in human bile and feces. J. Lab. Clin. Med., 63:986, 1964.

Palmer, R. H. Haemolytic effects of steroids. Nature, 201:1134, 1964.

Rowley, J., S. Muldal, J. Lindsten, and C. W. Gilbert. $\mathrm{H}^{3}$-thymidine uptake by a ring X chromosome in a human female. Proc. Natl. Acad. Sci., 51:779, 1964.

Strandjord, N. M., and P. V. Harper, Jr. Fluoroscopic and polaroid control of hypophysis destruction. Postgrad. Med., 36:A-69, 1964. 
Takaku, F., P. P. Dukes, and E. Goldwasser. In vitro studies of cell types responsive to erythropoietin. Endocrinology, 74:968, 1964.

Weiss, S. B., and C. F. Fox. The effect of polyamines on the DNA-dependent synthesis of RNA. In Histone Biology and Chemistry, J. Bonner, Ed., San Francisco, Holden-Day, Inc., 1964, p. 298.

Weiss, S. B. Studies on the In vitro synthesis of RNA with Micrococcus lysodeikticus RNA polymerase. Reprinted from abstracts volume of the Sixth International Congress of Biochemistry, New York City, July-August, 1964.

Wissler, R. W. Effects of cytotoxic antibodies on tumour cells and their possible role in controlling metastases. Bull. Swiss Acad. Med. Sci., 20:122, 1964.

Yachnin, S. Biologic properties of polynucleotides. III. The anticomplementary properties of polyriboguanylic acid. J. Immunol., 93:155, 1964.

Yachnin, S. Studies on the interaction between bovine serum albumin and natural and synthetic polyribonucleotides. III. Immunologic studies on heated mixtures of polyribonucleotides and bovine serum albumin. J. Immunol., 91:528, 1963.

Yachnin, S., and D. Rosenblum. Biologic properties of polynucleotides. IV. Studies on the mechanism of complement inhtbition by polyinosinic acid together with observations on the In vivo effect of polyinosinic acid on complement activity. J. Clin. Invest., 43:1175, 1964.

Zak, R., M. Rabinowitz, B. Beller, and L. DeSalles. Ribosomal amino-acid incorporating system from heart muscle. (Abstract). Federation Proc., 23: No. 2, March-April, 1964. 